\title{
Pesticides in the Nation's Streams and Ground Water, 1992-2001
}

National Water-Quality Assessment Program
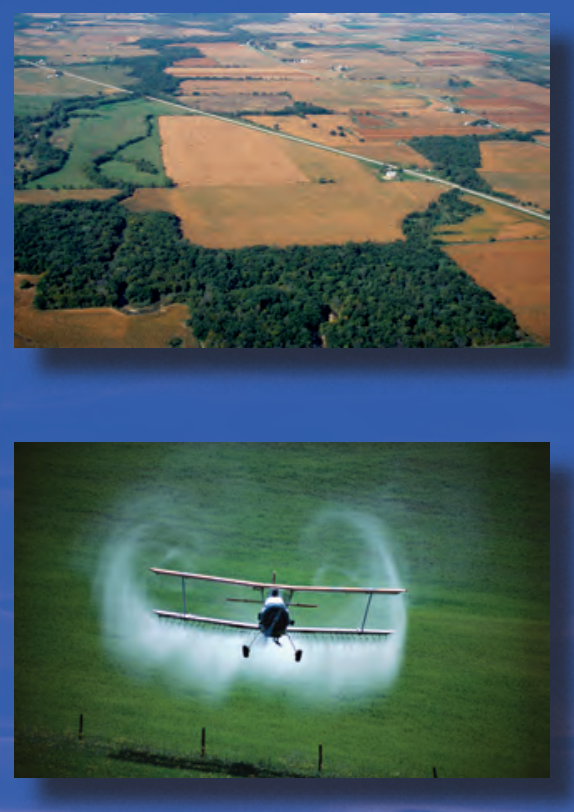

Circular 1291 
Front cover middle photograph (c) Corbis 


\section{The Quality of Our Nation's Waters Pesticides in the Nation's Streams and Ground Water, 1992-2001}

By Robert J. Gilliom, Jack E. Barbash, Charles G. Crawford, Pixie A. Hamilton, Jeffrey D. Martin, Naomi Nakagaki, Lisa H. Nowell, Jonathan C. Scott, Paul E. Stackelberg, Gail P. Thelin, and David M. Wolock

Circular 1291 


\title{
U.S. Department of the Interior DIRK KEMPTHORNE, Secretary \\ U.S. Geological Survey \\ P. Patrick Leahy, Acting Director
}

\author{
U.S. Geological Survey, Reston, Virginia: 2006 \\ Revised February 15, 2007
}

For product and ordering information:

World Wide Web: http://www.usgs.gov/pubprod

Telephone: 1-888-ASK-USGS

For more information on the USGS - the Federal source for science about the Earth, its natural and living resources, natural hazards, and the environment:

World Wide Web: http://www.usgs.gov

Telephone: 1-888-ASK-USGS

Any use of trade, product, or firm names is for descriptive purposes only and does not imply endorsement by the U.S. Government.

Although this report is in the public domain, permission must be secured from the individual copyright owners to reproduce any copyrighted materials contained within this report.

Suggested reference:

Gilliom and others, 2006, The Quality of Our Nation's Waters-Pesticides in the Nation's Streams and Ground Water, 1992-2001: U.S. Geological Survey Circular 1291,172 p.

\section{Library of Congress Cataloging-in-Publication Data}

Pesticides in the nation's streams and ground water, 1992-2001 : the quality of our nation's waters / by Robert J.

Gilliom ... [et al.].

p. cm. -- (Circular 1291)

Includes bibliographical references.

1. Water--Pollution--United States. 2. Agricultural pollution--United States. 3. Pesticides--Environmental aspects. 4. Water quality--United States. I. Gilliom, Robert J. II. U.S. Geological Survey circular ; 1291.

TD428.A37P47 2006

$363.738^{\prime} 49820973--d c 22$

2005037748

ISBN 1-411-30955-3 
“The Heinz Center depends heavily on NAWQA data to support our periodic report: 'The State of the Nation's Ecosystems.' NAWQA data provide the foundation for our description of chemical contamination -including pesticides and other compounds - both nationally and among different land uses, and for tracking how contaminant levels change over time. We appreciate NAWQA's strong commitment to making its information and data readily accessible to meet our organization's needs and to address the Nation's water-resource information needs."

Robin O'Malley, Senior Fellow and Program Director, The H. John Heinz III Center for Science, Economics and the Environment

“EPA has worked closely with the USGS NAWQA Program since it began in 1991, with the goal of advancing the scientific tools and data that are available to assess the potential risks posed by pesticides in surface water and ground water. Recently, EPA and USGS have collaborated in developing statistical models to predict concentrations of atrazine and other pesticides in streams around the country, including quantitative estimates of reliability. The models, developed by USGS from NAWQA data, increase EPA's capacity to estimate surface-water concentrations of pesticides. Model results are being used to identify locations where additional monitoring may be needed to evaluate the ecological condition of watersheds."

Elizabeth Behl, Chief of Environmental Risk Branch, Office of Pesticide Programs,

U.S. Environmental Protection Agency 


\section{National Water-Quality Assessment Program}

The U.S. Geological Survey (USGS) is committed to serving the Nation with accurate and timely scientific information that helps enhance and protect the overall quality of life, and facilitates effective management of water, biological, energy, and mineral resources (http://Www. usgs.gov/). Information on the quality of the Nation's water resources is of critical interest to the USGS because water quality is integrally linked to the long-term availability of water that is clean and safe for drinking and recreation and that is suitable for industry, irrigation, and habitat for fish and wildlife. Escalating population growth and increasing demands for multiple water uses make water availability, now measured in terms of quantity and quality, even more critical to the long-term sustainability of our communities and ecosystems.

The USGS implemented the National Water-Quality Assessment (NAWQA) Program (http://water. usgs.gov/nawqa/ to support national, regional, and local information needs and decisions related to water-quality management and policy. Shaped by and coordinated with ongoing efforts of other Federal, State, and local agencies, the NAWQA Program is designed to answer: What is the quality of our Nation's streams and ground water? How is the quality changing over time? How do natural features and human activities affect the quality of streams and ground water, and where are those effects most pronounced? By combining information on water chemistry, physical characteristics, stream habitat, and aquatic life, the NAWQA Program aims to provide science-based insights for current and emerging water issues and priorities. NAWQA results can contribute to informed decisions that result in practical and effective water-resource management and strategies that protect and restore water quality.

Since 1991, the NAWQA Program has implemented interdisciplinary assessments in 51 of the Nation's most important river basins and aquifers, referred to as Study Units, and the High Plains Regional Ground Water Study (see accompanying map and list of studies). Collectively, these areas account for more than 70 percent of total water use (excluding thermoelectric and hydropower) and more than 50 percent of the population's supply of drinking water. The areas are representative of the Nation's major hydrologic landscapes, priority ecological resources, and agricultural, urban, and natural sources of contamination.

Each assessment is guided by a nationally consistent study design and methods of sampling and analysis. The assessments thereby build local knowledge about water-quality issues and trends in a particular stream or aquifer while providing an understanding of how and why water quality varies regionally and nationally. The consistent, multi-scale approach helps to determine if certain types of water-quality issues are isolated or pervasive, and allows direct comparisons of how human activities and natural processes affect water quality and ecological health in the Nation's diverse geographic and environmental settings. Comprehensive assessments of pesticides, nutrients, volatile organic compounds, trace elements, and aquatic ecology are developed at the national scale through national data analysis and comparative analysis of the Study Unit findings.

The USGS places high value on the communication and dissemination of credible, timely, and relevant science so that the most recent and available knowledge about water resources can be applied in management and policy decisions. We hope this NAWQA publication will provide you the needed insights and information to meet your needs, and thereby foster increased awareness and involvement in the protection and restoration of our Nation's waters.

The NAWQA Program recognizes that a national assessment by a single program cannot address all water-resource issues of interest. External coordination at all levels is critical for a fully integrated understanding of watersheds and for cost-effective management, regulation, and conservation of our Nation's water resources. The Program, therefore, depends extensively on the advice, cooperation, and information from other Federal, State, interstate, Tribal, and local agencies, nongovernmental organizations, industry, academia, and other stakeholder groups. The assistance and suggestions of all are greatly appreciated. 


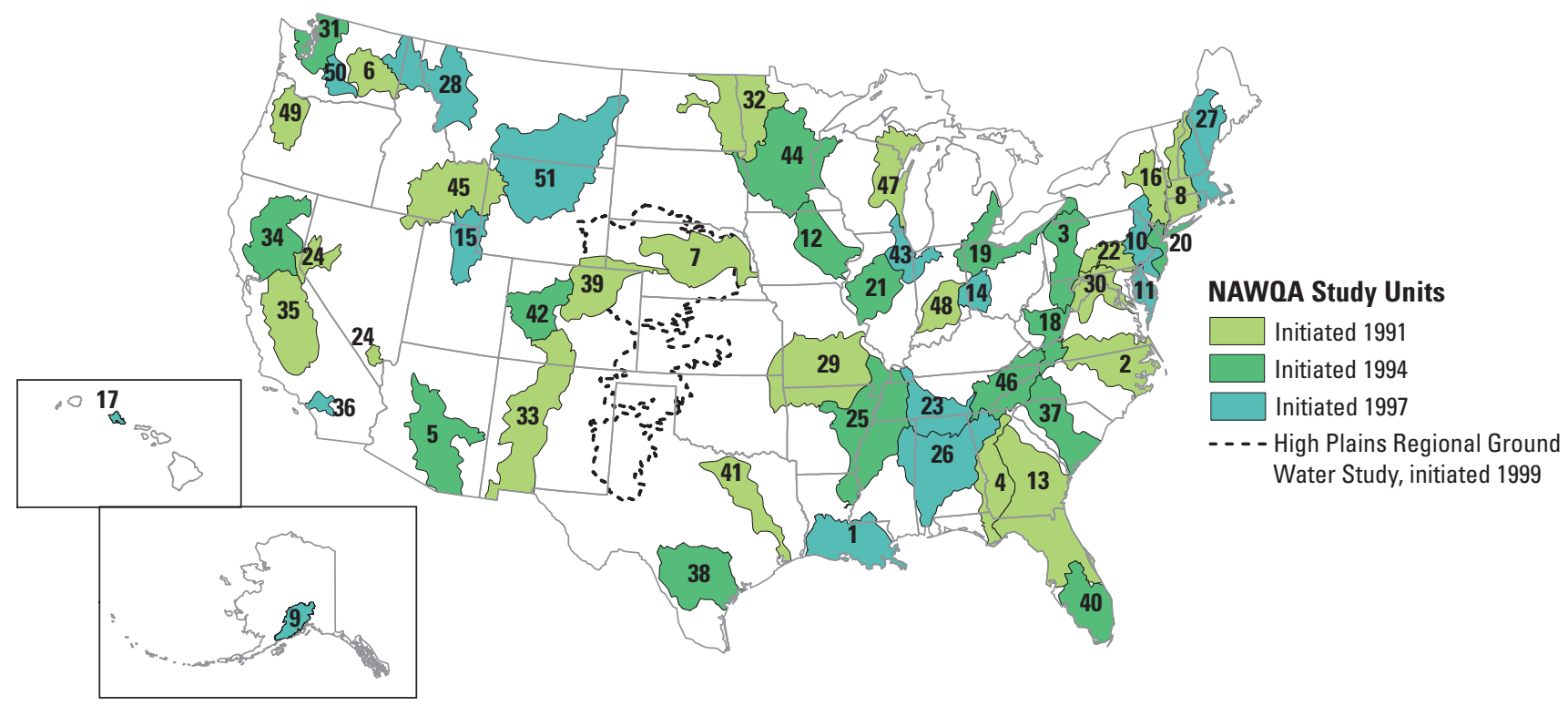

\section{NAWOA Study Units}

1 Acadian-Pontchartrain Drainages

2 Albemarle-Pamlico Drainage Basin

3 Allegheny and Monongahela River Basins

4 Apalachicola-Chattahoochee-Flint River Basin

5 Central Arizona Basins

6 Central Columbia Plateau

7 Central Nebraska Basins

8 Connecticut, Housatonic, and Thames River Basins

9 Cook Inlet Basin

10 Delaware River Basin

11 Delmarva Peninsula

12 Eastern lowa Basins

13 Georgia-Florida Coastal Plain

14 Great and Little Miami River Basins

15 Great Salt Lake Basins

16 Hudson River Basin

17 Island of Oahu

18 Kanawha-New River Basins

19 Lake Erie-Lake Saint Clair Drainages

20 Long Island-New Jersey Coastal Drainages

21 Lower Illinois River Basin

22 Lower Susquehanna River Basin

23 Lower Tennessee River Basin

24 Las Vegas Valley Area and the Carson and Truckee River Basins

25 Mississippi Embayment

26 Mobile River Basin
27 New England Coastal Basins

28 Northern Rockies Intermontane Basins

29 Ozark Plateaus

30 Potomac River Basin

31 Puget Sound Basin

32 Red River of the North Basin

33 Rio Grande Valley

34 Sacramento River Basin

35 San Joaquin-Tulare Basins

36 Santa Ana Basin

37 Santee River Basin and Coastal Drainages

38 South-Central Texas

39 South Platte River Basin

40 Southern Florida

41 Trinity River Basin

42 Upper Colorado River Basin

43 Upper Illinois River Basin

44 Upper Mississippi River Basin

45 Upper Snake River Basin

46 Upper Tennessee River Basin

47 Western Lake Michigan Drainages

48 White River Basin

49 Willamette Basin

50 Yakima River Basin

51 Yellowstone River Basin 


\section{Introduction to this report and the NAWQA series The Quality of Our Nation's Waters}

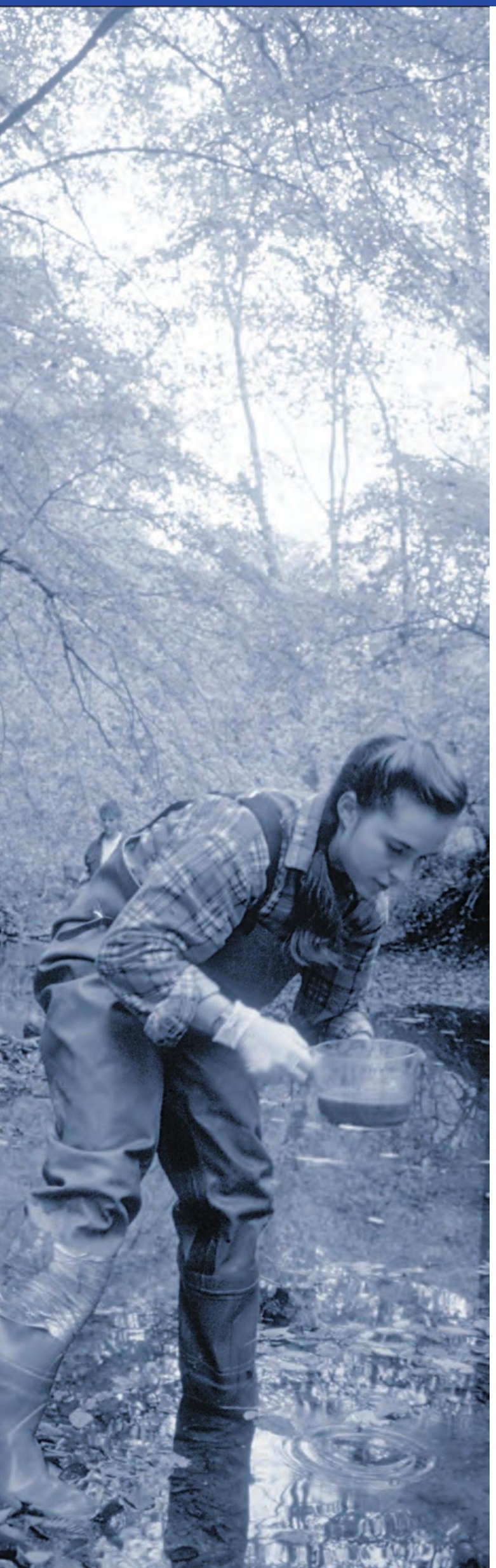

This report is one of a series of publications, The Quality of Our Nation's Waters, that describe major findings of the NAWQA Program on waterquality issues of regional and national concern. This report presents evaluations of pesticides in streams and ground water based on findings for the first decadal cycle of NAWQA. "Pesticides in the Nation's Streams and Ground Water, 1992-2001" greatly expands the analysis of pesticides presented in "Nutrients and Pesticides," which was the first report in the series and was based on early results from 1992 to 1995. Other reports in this series cover additional water-quality constituents of concern, such as volatile organic compounds and trace elements, as well as physical and chemical effects on aquatic ecosystems. Each report builds toward a more comprehensive understanding of regional and national water resources.

The information in this series is intended primarily for those interested or involved in resource management, conservation, regulation, and policymaking at regional and national levels. In addition, the information might interest those at a local level who wish to know more about the general quality of streams and ground water in areas near where they live and how that quality compares with other areas across the Nation.

\section{P. Patrick Leahy, Acting Director} U.S. Geological Survey 


\section{Contents}

Chapter 1 is a broad overview of key national findings and their implications. Chapters 2 and 3 provide background on pesticides and how they were assessed by NAWQA. Together, Chapters 4 and 5 provide a detailed assessment of findings regarding the occurrence and behavior of pesticides in streams and ground water. Chapter 6 evaluates the occurrence and distribution of pesticides in terms of the potential for effects on human health, aquatic life, and wildlife. Chapters 7 and 8 examine two important topics with implications for the future-prediction of pesticide levels for unmonitored areas and emerging evidence of long-term trends.

1 Overview of Findings and Implications ............................................. 1

2 Pesticide Primer..................................................................................2

3 NAWQA's Approach to Pesticide Assessment ......................................31

4 Occurrence and Distribution in Streams and Ground Water ...............41

5 Complexities: Seasonality, Mixtures, and Degradates..........................67

6 Potential for Effects on Human Health, Aquatic Life, and Wildlife .....87

7 Prediction Where Data are Inadequate ............................................. 119

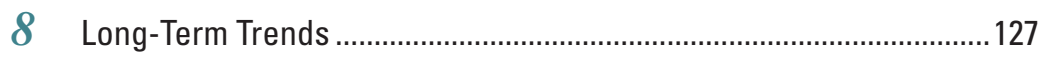

References Cited................................................................................ 137

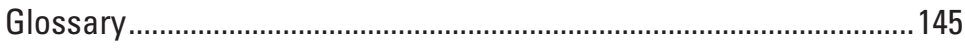

Appendix 1—Pesticide Compounds Analyzed ................................... 153

Appendix 2-Properties Affecting Transport and Fate ..................... 159

Appendix 3-Water-Quality Benchmarks ........................................... 161

Appendix 4-List of Abbreviations .....................................................171 



\title{
Overview of Findings and Implications
}

\begin{abstract}
A bout 1 billion pounds of conventional pesticides are used each year in the United States to control weeds, insects, and other pests. The use of pesticides has resulted in a range of benefits, including increased food production and reduction of insect-borne disease, but also raises questions about possible adverse effects on the environment, including water quality. The NAWQA assessment of pesticides provides the most comprehensive national-scale analysis to date of pesticide occurrence and concentrations in streams and ground water. NAWQA results show where, when, and why specific pesticides occur in streams and ground water across the Nation, and yield science-based implications for assessing and managing the quality of our water resources.
\end{abstract}

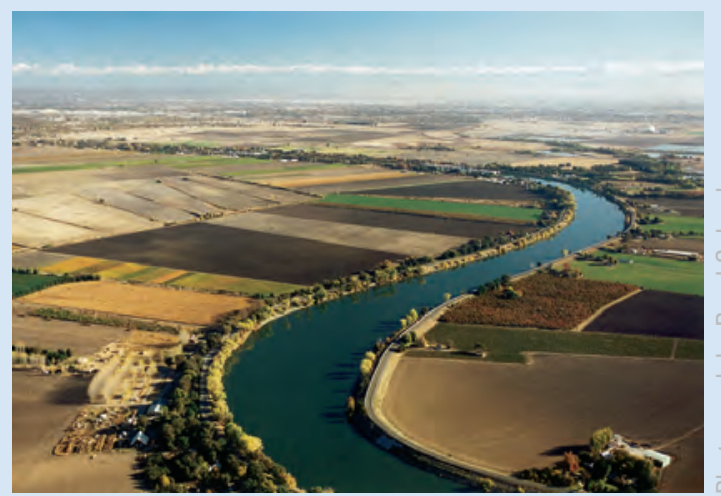

This chapter provides a broad overview of NAWOA findings about the occurrence and distribution of pesticides in the Nation's streams and ground water and summarizes the implications of these findings for water-quality assessment and management. Priorities for filling remaining information gaps also are addressed. Detailed discussions of each major topic are provided in subsequent chapters, including 


\section{Introduction-}

\section{New results confirm and expand findings from earlier NAWOA studies}

This report is based on the National WaterQuality Assessment (NAWQA) Program's first decade of water-quality assessments, which were completed on a rotational schedule during 19922001 in 51 major hydrologic systems across the country, referred to as Study Units (see p. iv and v). Assessments were conducted using a nationally consistent approach in 20 Study Units during 1992-1995; in 16 Study Units during 1996-1998; and in 15 Study Units during 1998-2001.

Nationally, water samples for pesticide analysis were collected from 186 stream sites within the 51 Study Units, bed-sediment samples were collected from 1,052 stream sites, and fish samples were collected from 700 stream sites. Ground-water samples were collected from 5,047 wells. In this report, most data analyses for stream water are based on the single year of most intensive sampling; data analyses for bed sediment and fish tissue are based on one composite sample per site; and data analyses for ground water are based on one sample per well. Sampling sites for streams and ground water were selected to represent the specific agricultural, urban, undeveloped, and mixed-land-use settings of greatest significance to water resources in the primary hydrologic settings within each of the Study Units. Shallow ground water (generally less than $20 \mathrm{ft}$ below the water table) was sampled in agricultural, urban, and undeveloped areas, whereas deeper ground water was sampled from wells that tap major aquifers, most of which

\section{Relation to Previous Studies}

Over the past 50 years, a vast amount of research has been conducted to investigate the spatial and temporal distributions of pesticides and their degradates in the hydrologic system, the biological effects of these compounds, and the myriad chemical, physical, and biological processes that control their transport and fate in the environment. Much of this previous work was summarized in a NAWOA book series entitled "Pesticides in the Hydrologic System," which examined these issues in relation to pesticides in the atmosphere (Majewski and Capel, 1995), ground water (Barbash and Resek, 1996), surface water (Larson and others, 1997), and bed sediment and aquatic biota (Nowell and others, 1999). In addition, since this book series was published, there have been many more studies and new reviews of specific topics by scientists in government, academia, corporations, and other organizations. This report is not intended to be a comprehensive review of all of these topics, although investigations directly relevant to the findings discussed in this report are cited in the text. The focus of this report is on the summary and interpretation of NAWOA data collected during 1992-2001. are affected by a mixture of land uses and are important as potential sources of drinking water.

Most NAWQA water samples were analyzed for 75 pesticides and 8 pesticide degradates, including 20 of the 25 most heavily used herbicides and 16 of the 25 most heavily used insecticides, but few fungicides, fumigants, or other types of pesticides were analyzed. Degradates are new compounds formed by transformation of a pesticide by chemical, photochemical, or biological reactions. In addition, 32 organochlorine pesticide compounds were analyzed in bed sediment and (or) fish tissue-19 parent pesticides and 13 degradates and manufacturing by-products (hereinafter referred to as by-products). Most of the organochlorine pesticides are no longer used in the United States, but the parent compounds, degradates, or by-products may persist in the environment. Pesticide compounds analyzed are listed in Appendix 1.

This analysis of NAWQA results for 1992-2001 builds upon an initial national assessment of pesticides in streams and ground water that was based on results from NAWQA's first 20 Study Unit investigations (summarized in the first report of this series, U.S. Geological Survey, 1999). The more extensive data and expanded geographic coverage available for this report confirm and reinforce many of the previously reported findings, allow more detailed analyses of each topic, and support new analyses, such as the development of statistical models that extend the results from targeted NAWQA studies to areas of the Nation that have not been assessed. In addition, water-quality benchmarks for assessing the potential significance of pesticide concentrations to aquatic life and fish-eating wildlife have been substantially updated to incorporate the most recent values available from the U.S. Environmental Protection Agency (USEPA) and other sources.

NAWQA findings are summarized below for major topics, each of which is identified with the chapter in this report where more detailed results, explanations, and references are provided. Key implications are also summarized for each topic, focusing on the extension of study results to national assessment of water quality, applications to water-quality management, and needs for additional information.

The NAWQA approach and design are summarized in Chapter 3. Details on data-analysis methods, as well as all data used in this report, are available at http://ca.water.usgs.gov/pnsp/ pubs/circ1291/. 


\section{Unique Features of the NAWOA Approach}

Water-quality assessments by NAWQA, which is a single program among many local, State, and Federal programs, were not designed to address all of the Nation's water-resource information needs and issues. Listed below are several characteristics and limitations of the NAWQA approach that are important to consider when interpreting the findings on pesticides presented in this report.

- NAWQA assessments characterized the quality of the available, untreated water resources, and not the quality of drinking water (as would be done by monitoring water from water-treatment plants or from household taps). By focusing on the quality of streams and ground water in their present condition (ambient water quality), NAWOA complements many Federal, State, and local drinking-water monitoring programs.

- NAWQA assessments did not focus on specific sites with known water-quality problems or narrowly defined "issues of the day," but rather on the condition of the total resource, including streams and ground water in a wide range of hydrologic and land-use settings across the country.

- NAWQA assessments of pesticides focused primarily on nonpoint sources resulting from applications for pest management in agricultural, urban, and other land-use settings, although some sites - particularly those downstream from major metropolitan areas-also may be influenced by point sources, such as discharges from wastewater treatment plants.

- NAWQA assessments targeted specific land-use settings that are most extensive or important to water quality in a wide range of hydrologic and environmental settings across the Nation. This targeted approach gives priority to understanding the most critical factors influencing water quality. Extension of results to national analysis, however, requires careful definition of each type of water resource and environmental setting for which conclusions are drawn and the use of statistical models to extrapolate results to resources that have not been measured.

- USGS analytical methods were designed to measure concentrations as low as economically and technically feasible. Studies of contaminant occurrence and behavior benefit from the most information possible at all concentration levels, and such data help to identify emerging issues and to track changes in concentrations over time. By this approach, however, pesticides were commonly detected at concentrations far below Federal or State standards and guidelines for protecting water quality. Detections of pesticides do not necessarily indicate that there are appreciable risks to human health, aquatic life, or wildlife, which must be assessed by comparing measured concentrations with those that may cause adverse effects.

- USGS methods for analyzing pesticides in water measured concentrations in filtered water samples and, thus, may underestimate concentrations of compounds that have strong affinities for suspended particles. The potential for underestimation is greater for stream water compared with ground water because of the generally greater amounts of suspended particles present in stream water-which are removed by filtration along with any pesticides contained in or on the particles.
- Pesticide compounds analyzed in water by NAWQA included many of the most heavily used herbicides and insecticides, but they included only a fraction of all pesticides currently in use and few of their degradates. NAWOA findings provide insights about what to expect for pesticides and degradates that were not measured, but must be considered as only a partial assessment of currently used pesticides.

- Organochlorine pesticide compounds analyzed by NAWQA in bed sediment and fish tissue are predominantly related to pesticides that were no longer in use by 1990 . Of the pesticide compounds measured in bed sediment and fish tissue, only dacthal, endosulfan, lindane, methoxychlor, and permethrin were used during all or part of the study period.
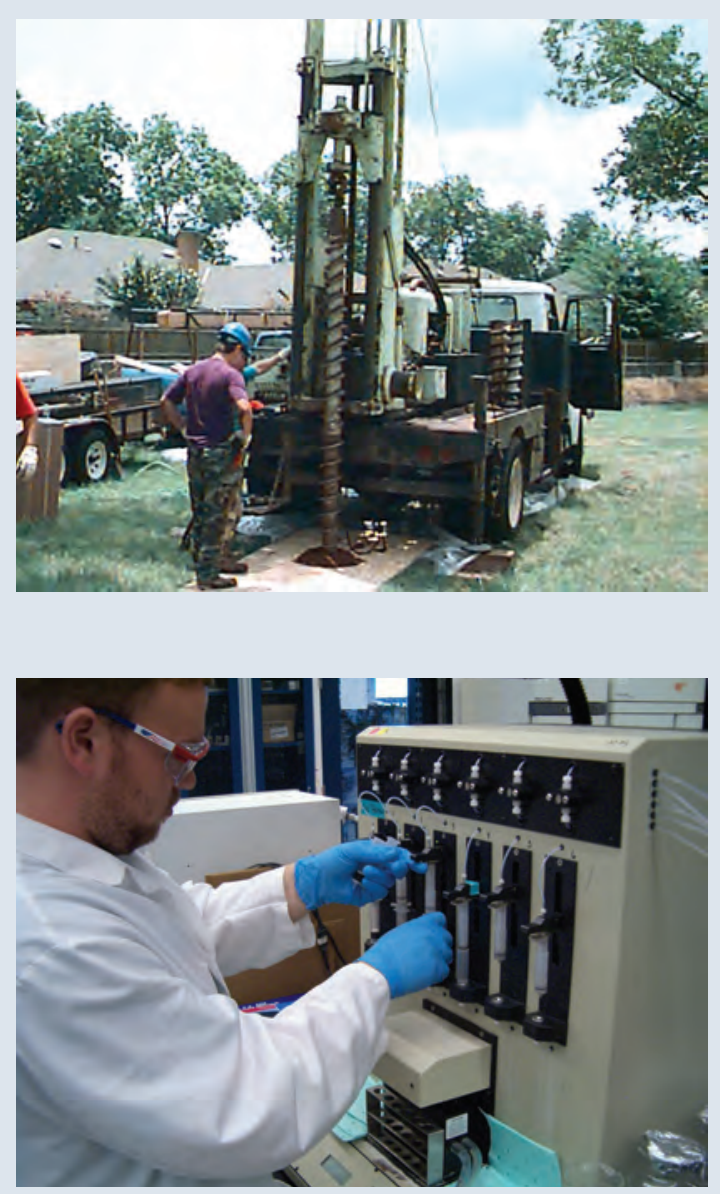

NAWOA studies used nationally consistent methods for sample collection and laboratory analysis. Urban groundwater studies, for example, often required the installation of new observation wells to ensure comparable data among studies. 


\section{Pesticide Occurrence-}

Pesticides were frequently detected in streams and ground water (Chapter 4)

Pesticides or their degradates were detected in one or more water samples from every stream sampled. One or more pesticides or degradates were detected in water more than 90 percent of the time during the year in agricultural streams, urban streams, and mixed-land-use streams (fig. 1-1). This finding is based on a timeweighted analysis of results for 4,380 water samples, which adjusts results for variable sampling frequencies to avoid biases that may be caused by differences in sampling intensity among sites and seasons. Undeveloped streams had one or more detectable pesticides or degradates 65 percent of the time. The presence of pesticide compounds in predominantly undeveloped watersheds may result from past or present uses within the watershed for purposes such as forest management or maintenance of rights-of-way, uses associated with small areas of urban or agricultural land, or atmospheric transport from other areas.
Organochlorine pesticides (such as DDT) and their degradates and by-products were found in fish or bed-sediment samples from most streams in agricultural, urban, and mixedland-use settings - and in more than half the fish samples from streams draining undeveloped watersheds (fig. 1-1). Most organochlorine pesticides had not been used in the United States for a number of years prior to the study period, but the continued occurrence of some historically used organochlorine pesticide compounds demonstrates their persistence in the environment.

Pesticides were less common in ground water than in streams (fig. 1-1). Nevertheless, more than half of the shallow wells sampled in agricultural and urban areas, and 33 percent of the deeper wells that tap major aquifers, which are influenced by a mixture of land uses, contained one or more pesticides or degradates.

\section{Overview of pesticide occurrence}
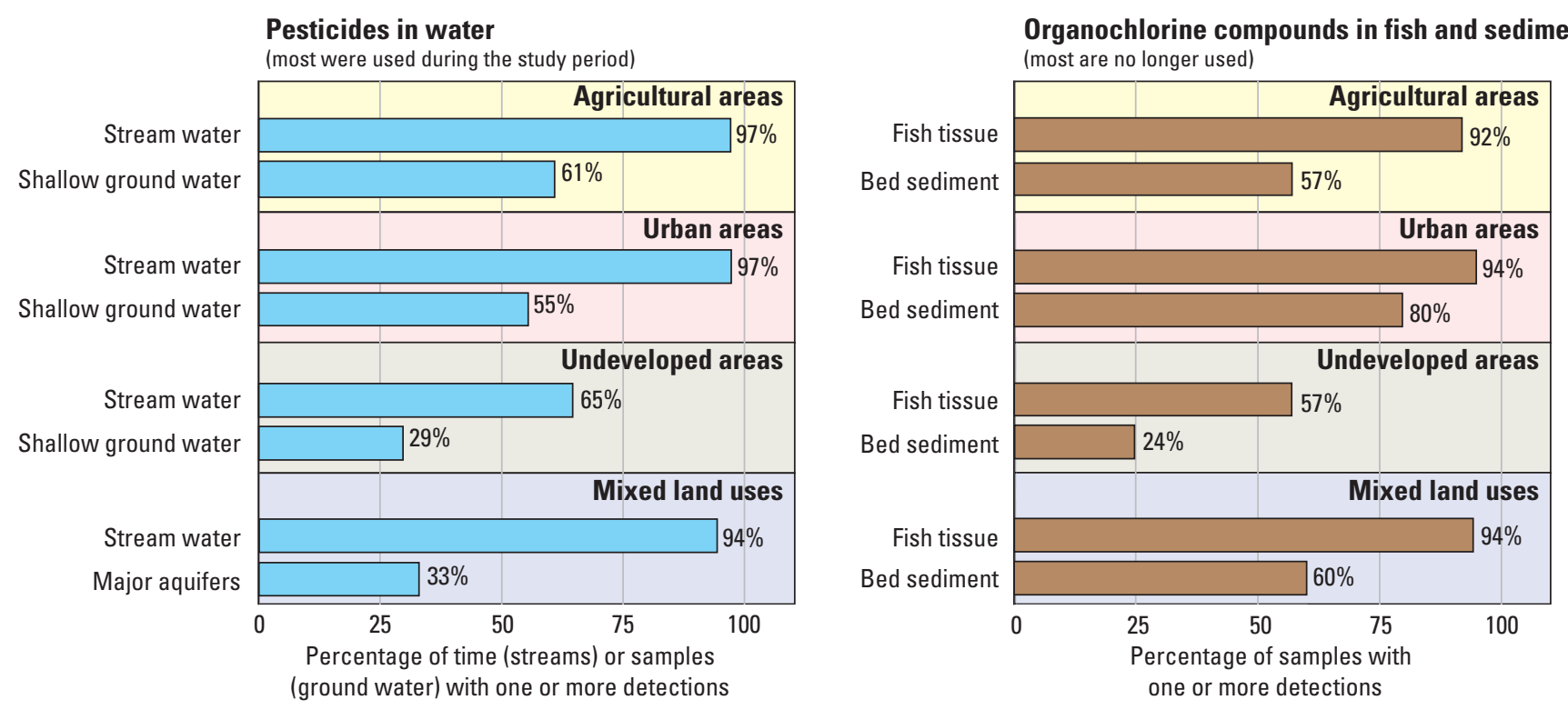

Figure 1-1. One or more pesticides or degradates were detected in water more than 90 percent of the time during the year in streams draining watersheds with agricultural, urban, and mixed land uses. In addition, some organochlorine pesticides that have not been used in the United States for many years were detected along with their degradates and by-products in most samples of whole fish or bed sediment from streams sampled in these land-use settings. Pesticides were less common in ground water, but were detected in more than 50 percent of wells sampled to assess shallow ground water in agricultural and urban areas. 


\section{Implications}

- Pesticides and degradates are likely to be present at detectable levels throughout most of the year in streams that have substantial agricultural or urban land use in their watersheds.

- Streams are more vulnerable to pesticide contamination than ground water in most hydrologic settings, as indicated by much more frequent detections in stream water.

- The frequent detection of pesticides and degradates in shallow wells in agricultural and urban areas indicates that ground water may merit special attention in these land-use settings. Shallow ground water is used in some areas for drinking water-and can also move downward into deeper aquifers. Early attention to potential ground-water contamination is warranted because the movement of ground water is usually slow and contamination is difficult to reverse.

- Pesticide occurrence in streams and ground water does not necessarily cause adverse effects on aquatic ecosystems or humans. The potential for effects can be assessed by comparing measured pesticide concentrations with water-quality benchmarks, which are based on the concentrations at which effects may occur.

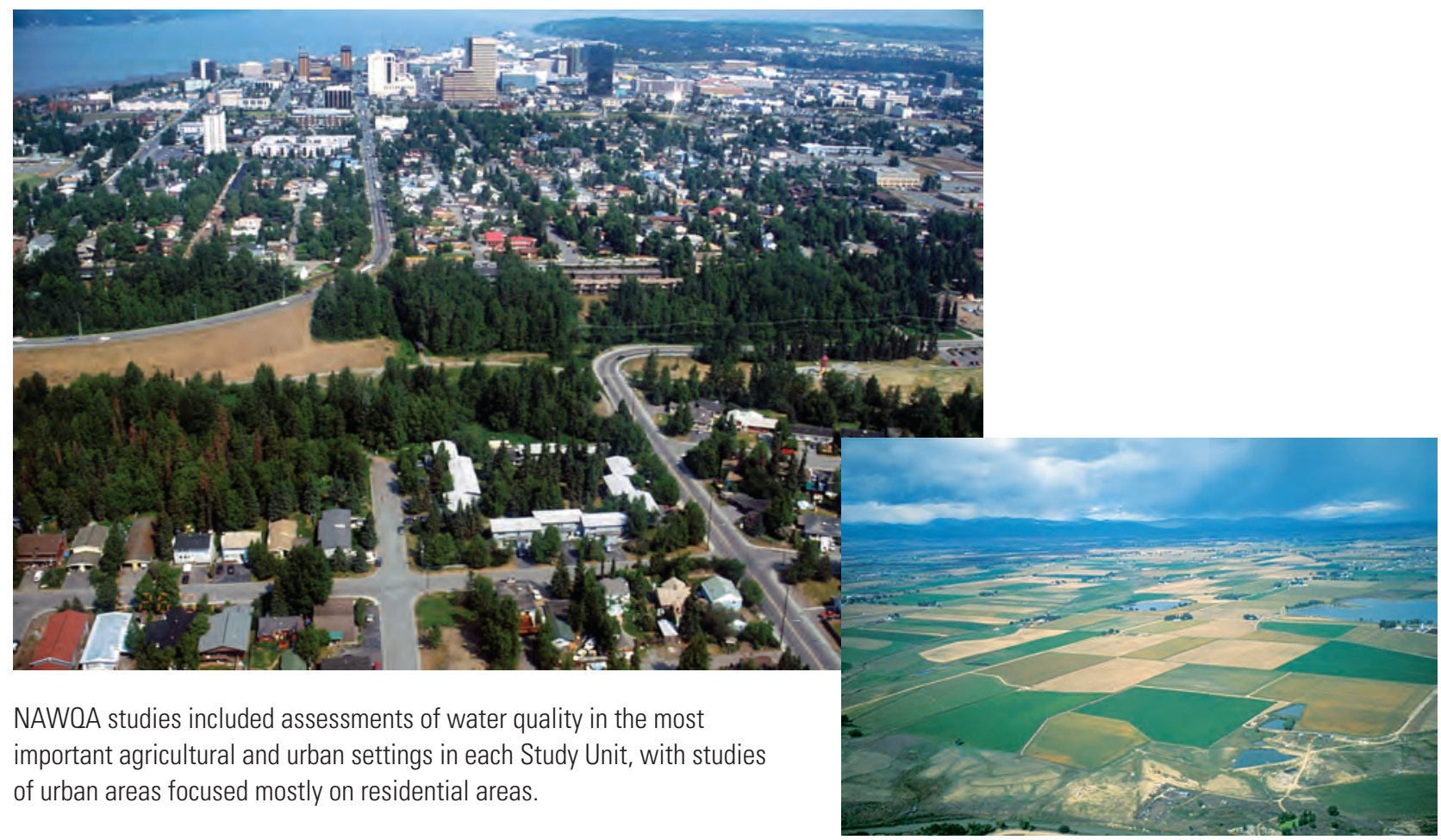




\section{Potential Significance to Human Health-}

Pesticides seldom occurred at concentrations greater than water-quality benchmarks for human health (Chapter 6)

A screening-level assessment of the potential significance of pesticides to human health was based on comparing measured concentrations in streams and ground water with waterquality benchmarks for human health. These human-health benchmarks were derived from standards and guidelines developed by USEPA for drinking water.

Although none of the NAWQA stream sites is located at actual drinking-water intakes, comparison of time-weighted annual mean concentrations to human-health benchmarks provides perspectives on (1) the likelihood that some current drinking-water intakes on streams may withdraw water with pesticide concentrations that exceed a benchmark, and (2) the potential long-term significance of pesticides to the quality of water that may be used as sources of drinking water in the future.

Annual mean concentrations of pesticides in streams studied by NAWQA were seldom

Concentrations greater than human-health benchmarks

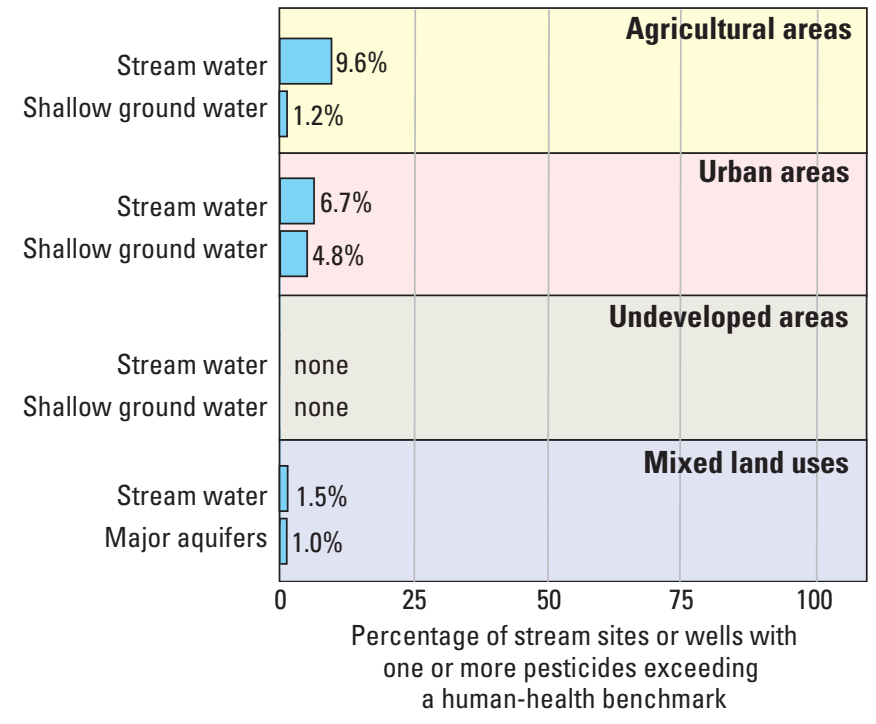

Figure 1-2. Concentrations of pesticides and degradates measured in streams and ground water usually were lower than human-health benchmarks for the pesticide compounds analyzed by NAWQA.

Many of the wells sampled for ground-water studies, but none of the stream sites sampled, were sources of domestic or public water supplies during the study period. greater than human-health benchmarks (fig. 1-2). No streams draining undeveloped land, and only one stream in a watershed with mixed land uses, had an annual mean concentration greater than a human-health benchmark. The annual mean concentrations of one or more pesticides exceeded a human-health benchmark in about 10 percent of the 83 agricultural streams and in about 7 percent of the 30 urban streams sampled by NAWQA. The 2 urban streams where benchmarks were exceeded are in Texas (diazinon) and Hawaii (dieldrin). Agricultural streams located in the Corn Belt (Illinois, Indiana, Iowa, Nebraska, Ohio, and parts of adjoining states) and Mississippi River Valley accounted for most concentrations that exceeded benchmarks, all involving atrazine (5 sites), cyanazine (4 sites), or dieldrin (2 sites). If, as examined in Chapter 6, the atrazine human-health benchmark were changed to values from the updated atrazine risk assessment (USEPA, 2003a), then there would be 2 sites rather than 5 sites with exceedances (although NAWQA did not measure 2 of the 3 degradates required for that benchmark).

Of pesticides accounting for most exceedances, atrazine use remains high, use of cyanazine has been reduced sharply since the mid-1990s (with corresponding decreases in stream concentrations; Chapter 8), and dieldrin and aldrin uses were discontinued before the 1992-2001 study period. Changes through the study period in the frequency of benchmark exceedances by atrazine and cyanazine were consistent with changes in agricultural use. As described in Chapter 6, the proportion of agricultural stream sites in the Corn Belt with atrazine concentrations that exeeded the human-health benchmark was greater for streams sampled during 1998-2000 than for streams sampled during either 1993-1994 or 1995-1997. In contrast, most sites where cyanazine exceeded its benchmark were sampled during 1993-1994, and no sites that were sampled during 1998-2000 had exceedances of the cyanazine benchmark.

For perspective on the relevance of NAWQA findings to drinking-water supplies, NAWQA land-use classifications for 1,679 public watersupply intakes that withdraw water from streams in the United States indicate that 55 percent of the intakes withdraw water from streams that drain watersheds with predominantly undeveloped land, 32 percent from streams with mixed land use, 12 percent from streams with agricultural land use, and 1 percent from streams with urban land use. Although the watershed land uses of NAWQA sites and water-supply intakes were 
classified in the same way, NAWQA sites tend to have more agricultural and urban land in their watersheds than do water-supply intakes in the same land-use categories.

Human-health benchmarks were exceeded less often in ground water than in streams (fig. 1-2). One or more pesticides exceeded a benchmark in about 1 percent of the 2,356 domestic wells and 364 public-supply wells sampled among studies in the three land-use settings and major aquifers. In contrast to the streams that were sampled, however, these wells are sources of drinking water-commonly without treatment in the case of domestic wells and with variable amounts and types of treatment for public-supply wells. Shallow ground water sampled in urban areas had the greatest proportion of wells with concentrations of one or more pesticides that were greater than a benchmark, including 1 of 9 public-supply wells, 3 of 17 domestic wells, and 37 of 835 observation wells, for a total of about 5 percent. About 1 percent of wells sampled in agricultural areas (shallow ground water) and in major aquifers had concentrations greater than one or more benchmarks. Wells with a concentration greater than a benchmark were scattered among 36 of the 187 ground-water studies. All concentrations greater than a benchmark were accounted for by dieldrin (72 wells), dinoseb (4), atrazine (4), lindane (2), and diazinon (1).

\section{Implications}

- Concentrations of pesticides measured in streams draining undeveloped and mixed-land-use watersheds indicate that public water-supply intakes on streams in these land-use settings, which compose about 87 percent of all intakes on the Nation's streams, are unlikely to withdraw water with concentrations that are greater than a human-health benchmark.

- The likelihood of pesticide concentrations exceeding a human-health benchmark in streams is greatest for those streams draining agricultural or urban watersheds, which account for about 12 and 1 percent, respectively, of public water-supply intakes on streams (based on NAWQA land-use classification). Such streams may warrant a priority for enhanced monitoring.

- The likelihood of pesticide concentrations exceeding a human-health benchmark in a public-supply well or domestic well is low on the basis of NAWQA results. About 1 percent of such wells sampled by NAWQA in all land-use settings had a pesticide concentration greater than a benchmark - most frequently dieldrin, which is no longer used.

\section{Characteristics and Limitations of the Screening- Level Assessment of Potential Effects}

The NAWOA screening-level assessment provides an initial perspective on the potential importance of pesticides to water quality in a national context by comparing measured concentrations with water-quality benchmarks. The screening-level assessment is not a substitute for risk assessment, which includes many more factors, such as additional avenues of exposure. The screening-level results are primarily intended to identify and prioritize needs for further investigation and have the following characteristics and limitations.

- Most benchmarks used in this report are estimates of no-effect levels, such that concentrations below the benchmarks are expected to have a low likelihood of adverse effects and concentrations above a benchmark have a greater likelihood of adverse effects, which generally increases with concentration.

- The presence of pesticides in streams or ground water at concentrations that exceed benchmarks does not indicate that adverse effects are certain to occur. Conversely, concentrations that are below benchmarks do not guarantee that adverse effects will not occur, but indicate that they are expected to be negligible (subject to limitations of measurements and benchmarks described below).

- The potential for adverse effects of pesticides on humans, aquatic life, and wildlife can only be partially addressed by NAWOA studies because chemical analyses did not include all pesticides and degradates. In addition, some compounds analyzed by NAWQA do not have benchmarks.

- Most benchmarks used in this report are based on toxicity tests of individual chemicals, whereas NAWQA results indicate that pesticides usually occur as mixtures. Comparisons to single-compound benchmarks may tend to underestimate the potential for adverse effects for some sites.

- Water-quality benchmarks for different pesticides and media are not always comparable because they have been derived by a number of different approaches, using a variety of types of toxicity values and test species.

- For some benchmarks, there is substantial uncertainty in underlying estimates of no-effect levels, depending on the methods used to derive them and the quantity and types of toxicity information on which they are based. This is especially true of fish-tissue benchmarks for the protection of fish-eating wildlife, for which there is no consensus on nationalscale benchmarks or toxicity values.

- Estimates of pesticide exposure derived from NAWQA concentration measurements are also uncertain-particularly estimates of short-term exposure of aquatic organisms to pesticides in stream water. Generally, short-term average concentrations in stream water, such as 4-day values, are underestimated from NAWOA data. 


\section{Potential Significance to Aquatic Life and Wildlife-}

\section{Concentrations of pesticides were frequently greater than water-quality benchmarks for aquatic life and fish-eating wildlife (Chapter 6)}

A screening-level perspective on the potential significance of pesticides to aquatic life and fish-eating wildlife was obtained by comparing concentrations measured in streams-including those in water, bed sediment, and whole fish-with water-quality benchmarks derived from guidelines established by USEPA, toxicity values from USEPA pesticide risk assessments, or selected guidelines from other sources.

Water-NAWQA findings for streams indicate that pesticides detected in water, most of which were in use during the study period, frequently exceeded aquatic-life benchmarks (fig. 1-3). Of 186 stream sites sampled nationwide:

- 57 percent of 83 agricultural streams had concentrations of at least one pesticide that exceeded one or more aquatic-life benchmarks at least one time during the year (68 percent of sites sampled during 1993-1994, 43 percent during 1995-1997, and 50 percent during 1998-2000).

- 83 percent of 30 urban streams had concentrations of at least one pesticide that exceeded one or more aquatic-life benchmarks at least one time during the year $(90$ percent of sites sampled during 1993-1994, 100 percent during 1995-1997, and 64 percent during 1998-2000).

- 42 percent of 65 mixed-land-use streams had concentrations of at least one pesticide that exceeded one or more aquatic-life benchmarks at least one time during the year (38 percent of sites sampled during 1993-1994, 40 percent during 1995-1997, and 46 percent during 1998-2000).

Streams in which concentrations of one or more pesticides exceeded an aquatic-life benchmark for water were distributed throughout the Nation in agricultural, urban, and mixed-land-use settings. In urban streams, most concentrations greater than a benchmark involved the insecticides diazinon ( 73 percent of sites), chlorpyrifos (37 percent), and malathion (30 percent). A potential revision of the acute invertebrate benchmark for diazinon from 0.1 micrograms per
Concentrations greater than aquatic-life benchmarks

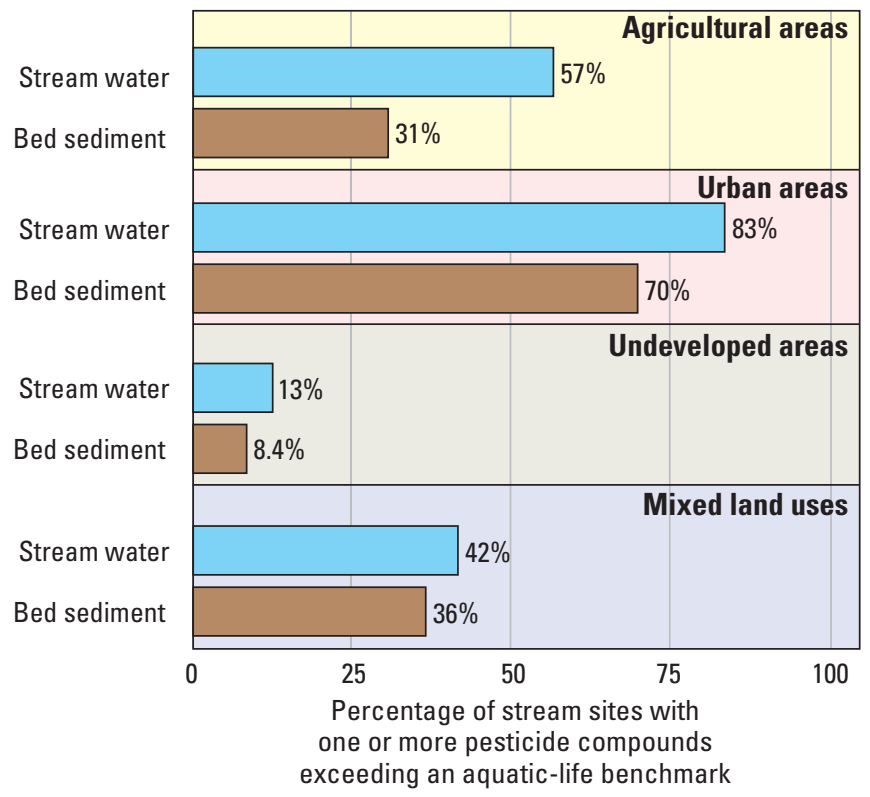

Concentrations greater than wildlife benchmarks

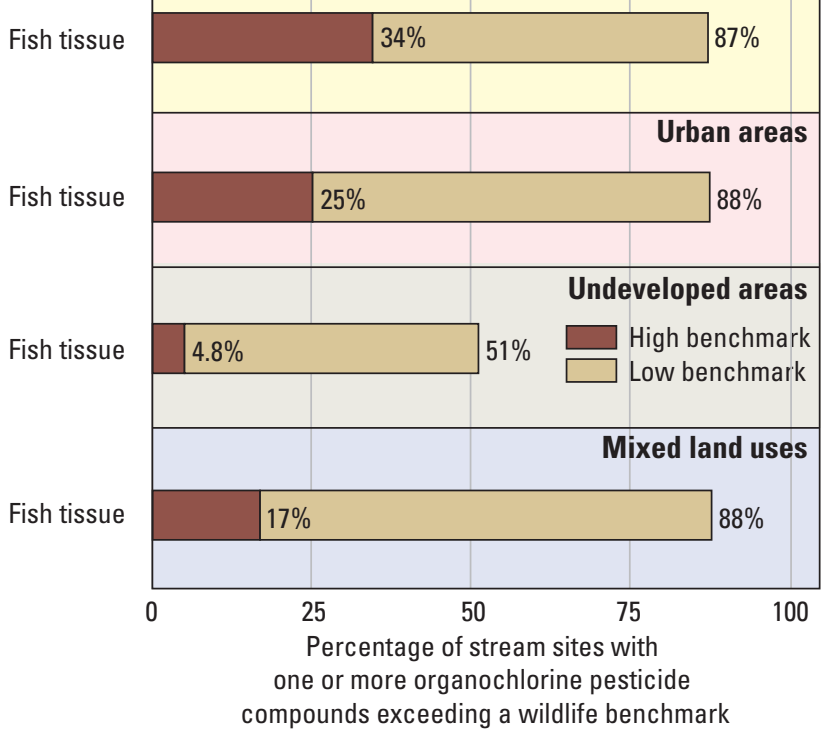

Figure 1-3. Pesticide concentrations measured in stream water and bed sediment frequently exceeded waterquality benchmarks for aquatic life. Concentrations of organochlorine pesticide compounds measured in whole-fish tissue were frequently greater than benchmarks for fish-eating wildlife, although the wide range of results for low and high benchmark values indicates relatively high uncertainty in the potential for effects, mainly because of uncertainty in the benchmark for total DDT. 
liter $(\mu \mathrm{g} / \mathrm{L})$ to $0.4 \mu \mathrm{g} / \mathrm{L}$, as discussed in Chapter 6 , would reduce the percentage of urban streams with exceedances by diazinon from 73 percent to 40 percent. As described in Chapter 6, all three of these insecticides exceeded aquatic-life benchmarks least frequently at urban sites sampled near the end of the study period (1998-2000), compared with sites sampled during 1993-1997. Agricultural and nonagricultural uses of diazinon and chlorpyrifos have been restricted to varying degrees since 2001, as discussed for diazinon in Chapter 8.

In agricultural streams, most concentrations greater than a benchmark involved chlorpyrifos (21 percent of sites), azinphos-methyl (19 percent), atrazine (18 percent), $p, p^{\prime}$-DDE (16 percent), and alachlor (15 percent). Findings for agricultural streams in the Corn Belt indicate that alachlor exceedances declined through the study period, with none during 1998-2000; atrazine exceedances increased, with the most frequent for sites sampled during 1998-2000; and chlorpyrifos exceedances varied through the study period, but were most frequent during 1998-2000.

Generally, insecticides most commonly exceeded benchmarks that are based on acute or chronic effects on aquatic invertebrates, or those that are based on ambient water-quality criteria for aquatic life. Herbicides most commonly exceeded benchmarks that are based on acute or chronic effects on vascular or nonvascular plants. Because of the wide variability in the number, type, and degree of benchmark exceedances among sites and the complexity of translating exceedances of screening-level benchmarks into specific potential for effects, the screening-level results should be used as the starting point for further site-specific investigation.

Bed Sediment-Concentrations of organochlorine pesticide compounds measured in bed sediment were greater than one or more aquaticlife benchmarks at 70 percent of urban stream sites, 31 percent of agricultural sites, 36 percent of sites with mixed land use, and 8 percent of undeveloped sites (fig. 1-3). The geographic distribution of sites where aquatic-life benchmarks for bed sediment were exceeded is similar to findings for water in many respects, including urban streams throughout the country, and many agricultural and mixed-land-use streams in the Southeast, East, and irrigated areas of the West. In urban streams, aquatic-life benchmarks were most frequently exceeded by individual compounds in the DDT group or total DDT (58 percent of sites), total chlordane (57 percent), and dieldrin (26 percent). Compounds in the DDT group are derived from 2 parent pesticides, DDT and DDD, and include several degradates and by-products (DDD is also a degradate of DDT). Total DDT is the sum of the concentrations of six individual compounds. Total chlordane concentration is the sum of concentrations of the cis and trans isomers of chlordane and nonachlor, plus the chlordane degradate oxychlordane. In agricultural streams, aquatic-life benchmarks were exceeded most often by individual compounds in the DDT group or by total DDT (28 percent of sites) and by dieldrin ( 8 percent).

Fish Tissue-Comparisons of concentrations of organochlorine pesticide compounds measured in whole fish with benchmarks for fish-eating wildlife indicate a wide range of potential for effects, depending on the type of wildlife benchmark used (fig. 1-3). Because there is no consensus on tissue-based benchmark values for wildlife, measured concentrations were compared with both the high and low benchmark values from the range available for each compound. The high benchmark values for fish tissue were exceeded most frequently in streams in the populous Northeast; in high-use agricultural areas in the upper and lower Mississippi River Basin; in high-use irrigated agricultural areas, such as eastern Washington and the Central Valley of California; and in urban streams distributed throughout the country. In urban streams, low benchmarks were exceeded most often by total DDT (88 percent of sites), dieldrin (18 percent), and total chlordane (10 percent). In agricultural streams, low benchmarks were exceeded most often by total DDT ( 87 percent of sites), dieldrin (11 percent), and toxaphene (9 percent).

\section{Implications}

- The screening-level assessment indicates that the most widespread potential impact of pesticides on water quality is adverse effects on aquatic life and fish-eating wildlife, particularly in streams draining watersheds with substantial agricultural and urban areas.

- Assessment and management of potential effects on aquatic life and wildlife are complicated by the combined presence of (1) currently used pesticides and their degradates, and (2) organochlorine pesticide compounds derived from pesticides that, for the most part, had their uses cancelled prior to 1990.

- The widespread potential for adverse effects shown by the screening-level assessment - and the uncertainty in this potential because of the preliminary nature of the assessment and the complexity of pesticide exposureindicate a continuing need to study the effects of pesticides on aquatic life and wildlife under the conditions of pesticide exposure that occur in the environment. 


\section{Frequently Detected Pesticides and Relations to Use-}

Pesticides detected most frequently were among those used most heavily during the study period or in the past (Chapter 4)

The pesticides detected most frequently in streams and ground water were primarily those with the greatest use-either during the study period or in the past - and with the greatest mobility and (or) persistence in the hydrologic system (fig. 1-4).

The pesticides detected most frequently in stream water included: (1) five agricultural herbicides that were among the most heavily used during the study period - atrazine (and its degradate deethylatrazine), metolachlor, cyanazine, alachlor, and acetochlor; (2) five herbicides extensively used for nonagricultural purposes, particularly in urban areas-simazine, prometon, tebuthiuron, 2,4-D, and diuron; and (3) three of the most extensively used insecticides during the study period-diazinon, chlorpyrifos, and carbaryl (fig. 1-4). Simazine, prometon, diuron, 2,4-D, diazinon, and carbaryl, which are commonly used to control weeds, insects, and other pests in urban areas, were frequently found at relatively high levels in urban streams throughout the Nation. The use of individual pesticides often changes over time, and may have increased or decreased during or since the end of the study period. For example, the uses of diazinon and chlorpyrifos have been substantially restricted since 2001, and analysis of recent data for diazinon shows that concentrations in some streams have now declined as well.

The pesticide compounds detected most frequently in fish and bed sediment were historically used organochlorine pesticides, along with their degradates and by-products (fig. 1-4). Most organochlorine pesticides were heavily used during the 1950s and 1960s, but had their agricultural uses cancelled during the 1970s and remaining urban uses cancelled by the late 1980s. Some organochlorine compounds, however, persist in soils, sediment, and biota. Several compounds in the DDT group, chlordane compounds, dieldrin (from use of both dieldrin and aldrin), and heptachlor epoxide (degradate of heptachlor), were found most frequently. Although quantitative information on urban pesticide use is limited, the relatively high concentrations found in fish and bed sediment from urban streams indicate that historical use of these pesticides in urban areas was probably intensive.

Compared with streams, ground-water detections were dominated by fewer compounds - mainly those with relatively high mobility and persistence, which allows them to move greater distances to and within the groundwater flow system (fig. 1-4). The most prevalent pesticides in both agricultural and urban areas were the herbicides atrazine (and deethylatrazine), metolachlor, prometon, and simazine.

\section{Implications}

- The correlations of the pesticides found most frequently in streams and ground water with the amounts and characteristics of pesticides used can help managers to anticipate and prioritize the pesticides most likely to affect water quality in different land-use settings.

- For pesticides that are still being applied, reducing their use is likely to be an effective way to reduce their concentrations in the hydrologic system, particularly for streams (other approaches may also be effective).

- For organochlorine pesticide compounds derived from past use, management practices that control the erosion of soil may help to reduce their transport to streams. 
Frequently detected pesticide compounds
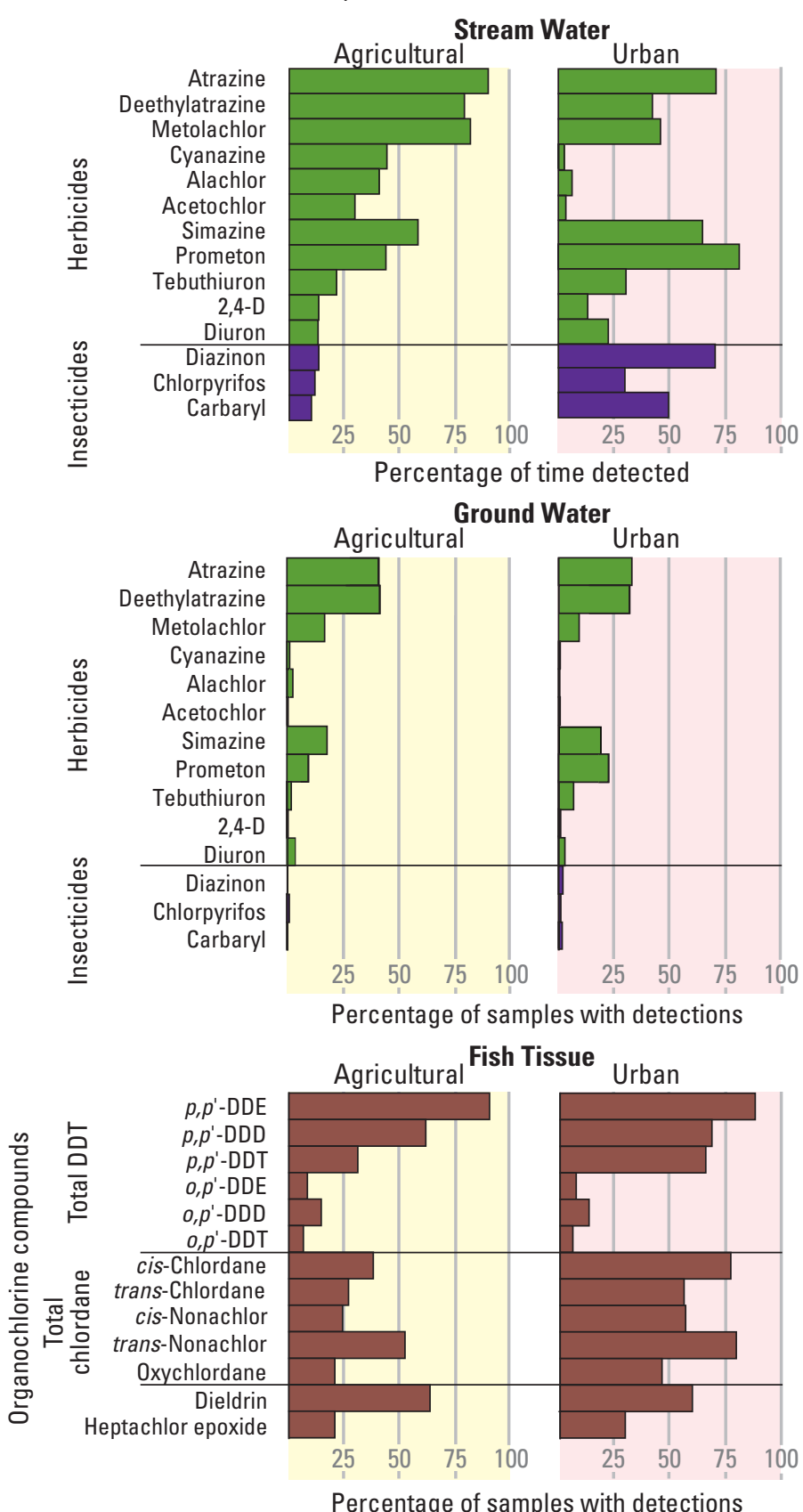

Figure 1-4. The pesticide compounds detected most frequently in streams and ground water in agricultural and urban areas were mainly those with the most extensive use-either during the study period or historically — and those with the greatest mobility and (or) persistence in the hydrologic system.
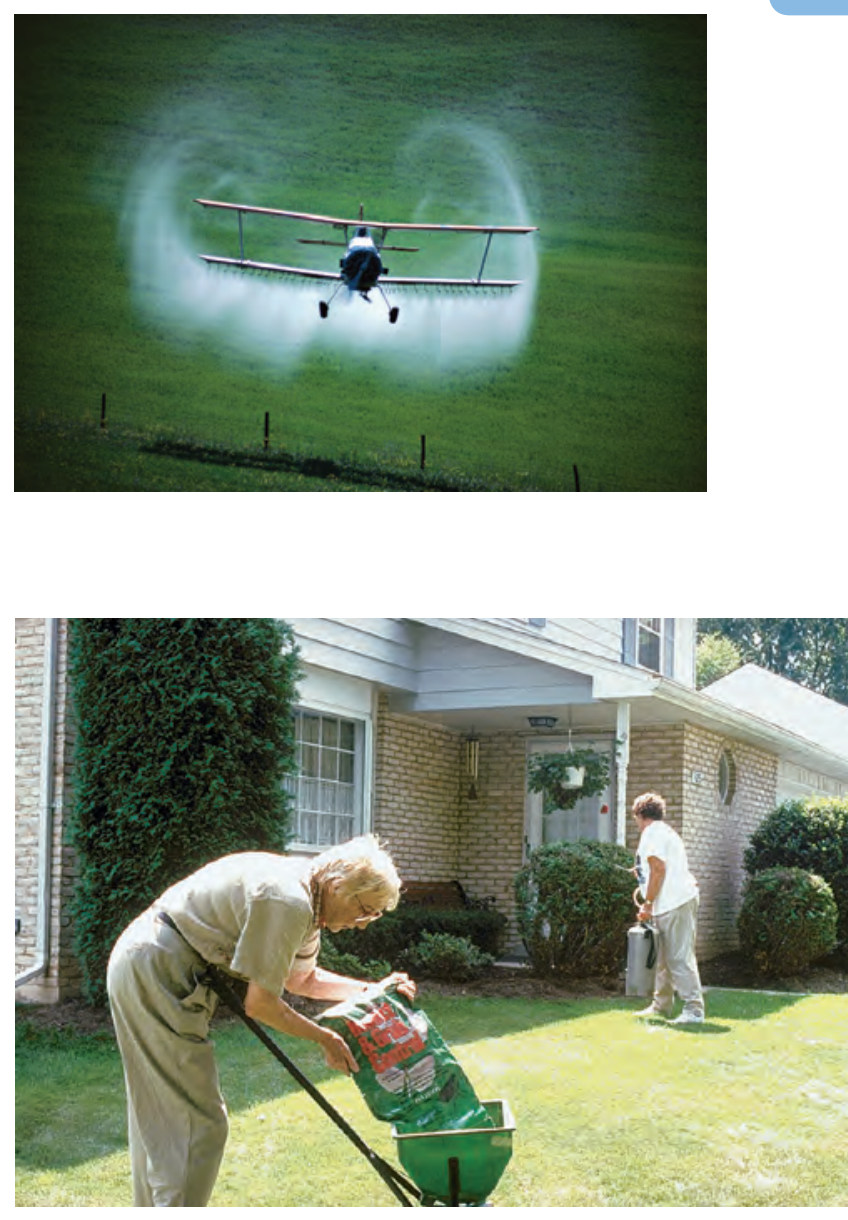

The most intensive pesticide applications are in agricultural and urban areas, including substantial use for home, lawn, and garden pest control in residential areas (photograph (2003 Corbis [top]). 


\section{Geographic Patterns-}

Patterns of pesticide occurrence in streams primarily followed the distribution of use, whereas patterns in ground water were more affected by management practices and natural susceptibility to contamination (Chapter 4)

The types and concentrations of pesticides found in agricultural streams primarily reflect the geographic distributions and intensity of use, along with additional influences by climate, soil characteristics, and water-management practices. For example, geographic patterns in stream concentrations of atrazine, metolachlor, simazine, acetochlor, 2,4-D, chlorpyrifos, and diazinon directly correlate with where they are used on crops. Some of the highest concentrations of atrazine were observed in streams within the Corn Belt and other areas where corn is a primary crop and where the herbicide is most heavily used (fig. 1-5). Total DDT was found at some of the highest concentrations in bed sediment and fish in parts of the Southeast, where DDT was historically used on cotton, tobacco, and peanuts, as well as in parts of California, Oregon, and Washington, where it was used extensively on orchards, potatoes, vegetables, and specialty crops. Dieldrin, on the other hand, was found most frequently and at some of the highest concentrations in the Corn Belt, where aldrin and dieldrin were extensively applied to corn.

The geographic distribution of pesticides in ground water also is influenced by the distributions of land use and pesticide use, but is more strongly affected by natural features, such as hydrogeology and soil characteristics, and by agricultural management practices, such as irrigation and drainage. For example, ground water is more susceptible to contamination in areas where the soil and unsaturated zone are more permeable than in areas where they are less permeable. A management practice that can influence pesticides in ground water is the use of subsurface tile-drain systems, which are buried networks of perforated pipes that collect shallow ground water for the purpose of lowering the water table and draining water-logged soils, as well as other subsurface drainage systems. These drain systems may reduce pesticide levels in underlying ground water by diverting shallow ground water to surface waters.

Detection frequencies of atrazine (fig. 1-6), metolachlor, and simazine generally were highest in ground water sampled in areas with permeable soils and geologic formations in parts of

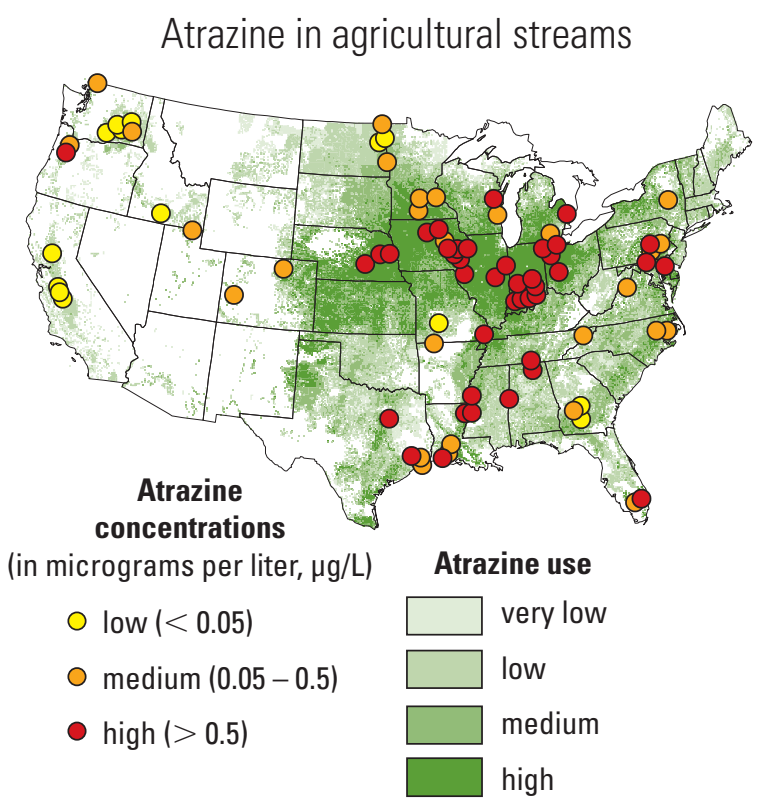

Figure 1-5. The concentrations of atrazine measured in agricultural streams correlated with the distribution of its use on crops-primarily corn. Some of the highest concentrations occurred in the corn-growing areas of Illinois, Indiana, lowa, Nebraska, and Ohio.

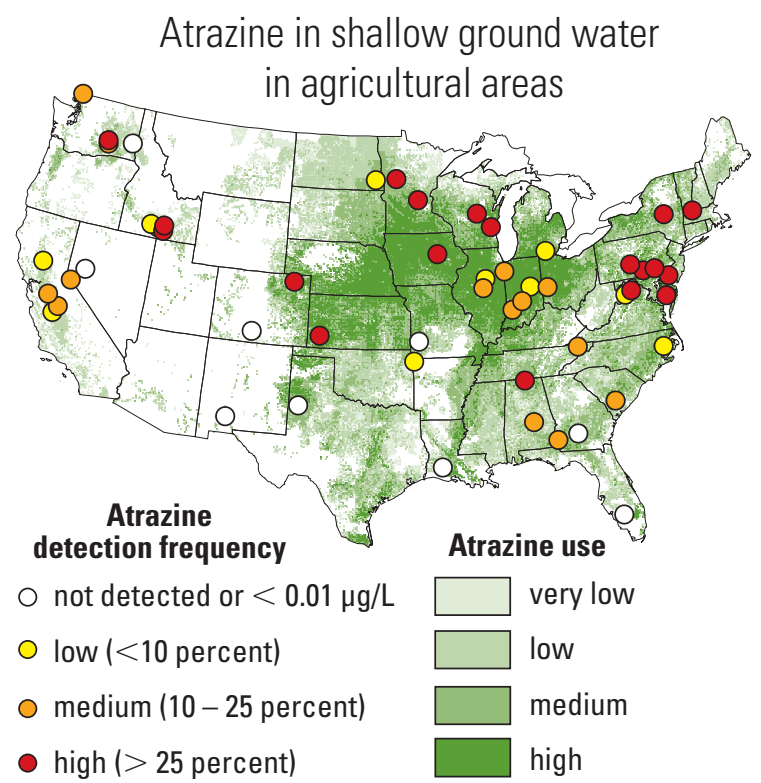

Figure 1-6. Atrazine was detected most frequently in shallow ground water in agricultural areas where soils and the underlying unsaturated zone are highly permeable and use is moderate to high, such as in parts of lowa, Minnesota, Pennsylvania, and Wisconsin. 
the country where these compounds are used for corn production - such as parts of Iowa, Minnesota, Pennsylvania, and Wisconsin. In contrast, these herbicides were found less frequently and at lower concentrations in ground water within many areas sampled in the central Corn Belt, despite some of the highest use in the Nation. This apparent anomaly, which has also been noted by other studies, is probably caused by the relatively impermeable soils and glacial till that cover much of this region, combined with the resulting widespread use of subsurface drainage systems. As observed for streams, each pesticide has a unique pattern and story regarding its occurrence in ground water, in large part resulting from its use on particular crops and its characteristic mobility and persistence. Pesticide properties more strongly control the occurrence of pesticides in ground water than in streams, however, because longer travel times in ground water and prolonged contact with soil and aquifer materials reduce concentrations of pesticides or degradates with low persistence or mobility.

\section{Implications}

- Pesticide occurrence in streams can be largely anticipated from the geographic distribution of land use, crops, and associated chemical use. Other factors, such as soil and runoff characteristics, also influence the amount and timing of the transport of pesticides to streams, but these factors are generally less important than the amount used in determining pesticide concentrations in streams.

- Compared with streams, natural features and management practices are more important considerations for anticipating the occurrence of pesticides in ground water. Ground water is most susceptible to contamination in areas where soils and the underlying unsaturated zone are most permeable and drainage practices do not divert recharge to surface waters.

- The entire hydrologic system and its complexities need to be considered in evaluating the potential for pesticide contamination of streams and ground water. Some hydrologic settings where ground water is least vulnerable to contamination are those where streams are most vulnerable, and vice versa. For example, subsurface drains may help protect deep ground water, but increase pesticide transport to streams.

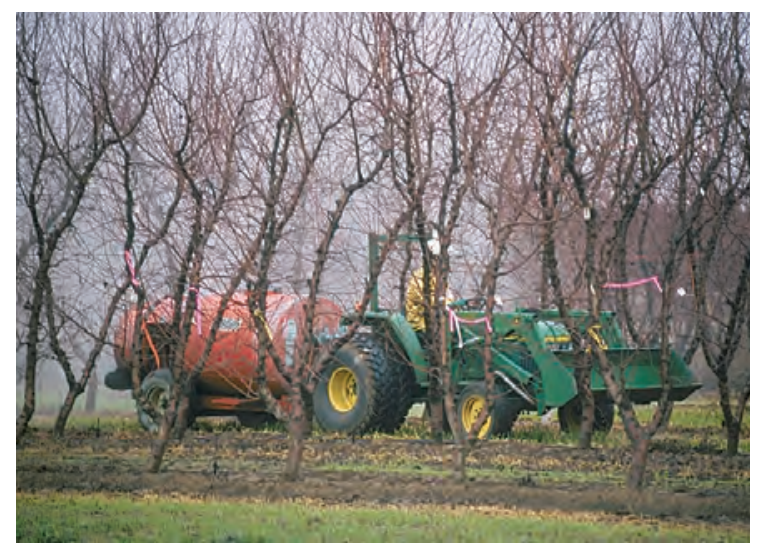

Different pesticides are applied during different seasons in each region of the country. In the San Joaquin Valley, California, many orchards were sprayed with diazinon during the winter when they are dormant, whereas herbicides were applied to corn fields before and after spring planting throughout much of the Corn Belt (photograph by Dave Kim, California Department of Pesticide Regulation [left]).

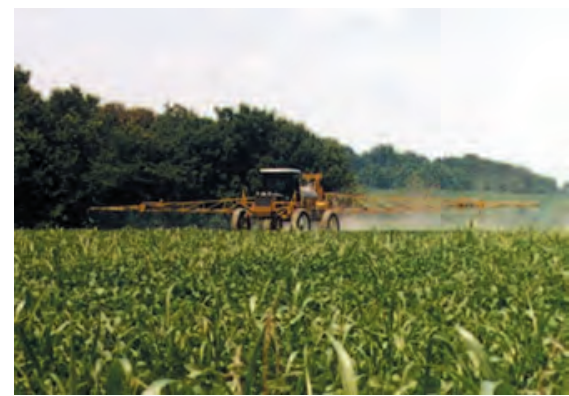




\section{Seasonal Patterns-}

Pesticide concentrations in streams followed distinct seasonal patterns (Chapter 5)

Pesticide concentrations in stream water vary through the year, usually characterized by long periods with low or undetectable concentrations of most pesticides, punctuated by seasonal pulses of much higher concentrations. The timing and magnitude of seasonal pulses were correlated with the timing and intensity of pesticide applications, the frequency and magnitude of runoff from rainstorms or snowmelt, and the timing and distribution of land-management practices such as irrigation and artificial drainage. Concentrations in agricultural streams generally were highest during periods of runoff resulting from precipitation or irrigation that occurred soon after pesticide applications - a combination that causes seasonal patterns that are unique to each region. Spray drift and other modes of atmospheric transport can also be sources of pesticides to streams during high-use periods within an agricultural region. Most streams that drain farmland in the Corn Belt and other corn-growing areas, for example, had elevated concentrations of herbicides during spring runoff that followed applications (fig. 1-7). In contrast, agricultural streams in parts of the San Joaquin-Tulare Basin had high concentrations of diazinon during the winter, resulting from applications on dormant almond orchards followed by rainfall. Patterns also may vary because of differences in the timing of local water-management practices, such as irrigation and reservoir releases.

\section{Implications}

- Effective management of streams may require increased monitoring —including high-frequency sampling during seasons when intense pesticide use coincides with periods of high runoff - so that the periods with the highest pesticide concentrations are adequately characterized.

- Seasonal patterns in pesticide concentrations are important to consider in managing the quality of drinking water withdrawn from streams in agricultural and urban settings. Knowledge of seasonal patterns may help managers to adapt treatment strategies, or avoid or minimize withdrawals in favor of alternative sources of water, during highconcentration seasons.

- Seasonal patterns may result in adverse effects on aquatic life in some streams. Both acute and chronic aquatic-life benchmarks for water were most frequently exceeded during seasonal periods of high concentrations. Concentration pulses of some pesticides during sensitive stages of aquatic life cycles may have the greatest effects in some streams, and site-specific assessments may be required.

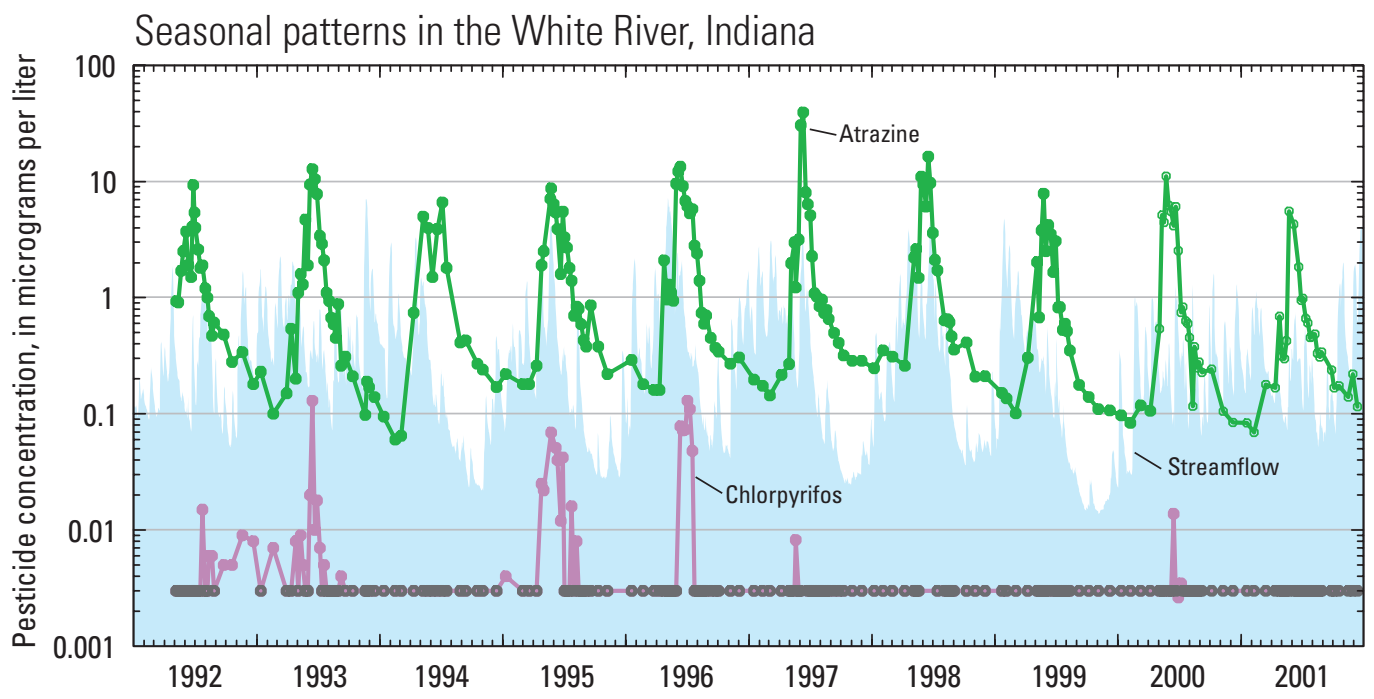

Figure 1-7. Atrazine concentrations in the White River, Indiana, were typical of streams throughout much of the Corn Belt, following similar seasonal patterns every year. Concentration pulses corresponded to the timing of runoff events and atrazine use on corn fields each spring. In contrast, seasonal patterns in concentrations of chlorpyrifos were more variable because of its more sporadic use. 


\section{Mixtures-}

Pesticides were most commonly detected as mixtures of multiple pesticide compounds (Chapter 5)

Samples from streams in areas with substantial agricultural or urban land use almost always contained mixtures of multiple pesticides and degradates (fig. 1-8). More than 90 percent of the time, water from streams with agricultural, urban, or mixed-land-use watersheds had detections of 2 or more pesticides or degradates, and about 20 percent of the time they had detections of 10 or more. In addition, samples of fish tissue and bed sediment from most streams contained mixtures of historically used organochlorine pesticides and their degradates and by-products.

Mixtures were less common in ground water than in streams, which is consistent with the lower frequencies of detection for individual pesticide compounds. Nevertheless, 47 percent of shallow wells in agricultural areas and 37 percent of shallow wells in urban areas contained 2 or more detectable pesticides or degradates. Less than 1 percent had detections of 10 or more compounds.

The environmental significance of mixtures is ultimately determined by the specific combinations of individual compounds-known as "unique mixtures"- their concentrations and combined toxicity, and how often and where they occur. A unique mixture is a specific combination of 2 or more compounds, regardless of the presence of other compounds. Thus, a single sample with several pesticides contains many unique mixtures. Depending on the specific compounds, the toxicity of a mixture to a particular type of organism may result from additive effects among the compounds, independent effects, antagonistic

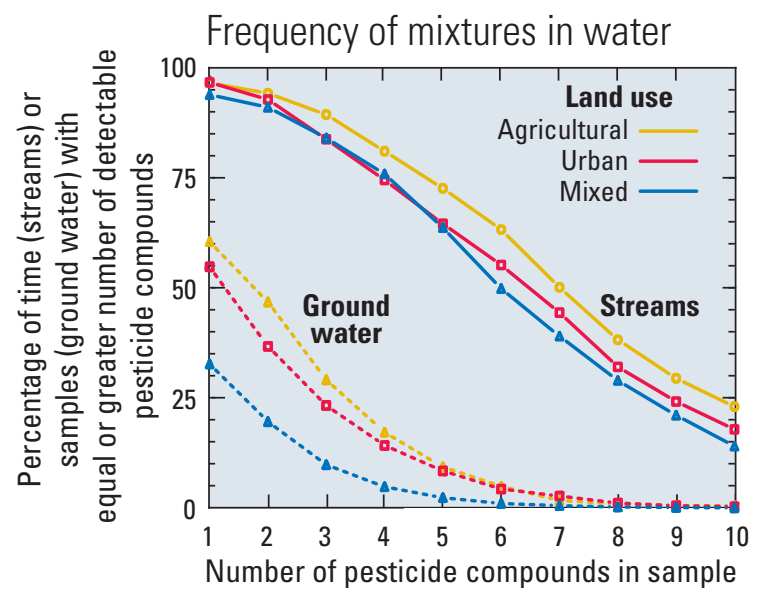

effects (less than additive), or synergistic effects (greater than additive). Each of these toxicity models, except for the antagonistic model, usually results in a toxicity of the mixture that is greater than any of its individual components.

More than 6,000 unique 5-compound mixtures were found at least 2 percent of the time in agricultural streams (only 1 unique 5-compound mixture was found in ground water). Evaluating the potential significance of mixtures can be simplified, however, because many mixtures do not occur very often at high concentrations, and the most frequently occurring mixtures are composed of relatively few pesticides. For example, the number of unique 5-compound mixtures found in agricultural streams is less than 100 when only concentrations greater than 0.1 micrograms per liter $(\mu \mathrm{g} / \mathrm{L})$ are considered. More than 30 percent of all unique mixtures found in streams and ground water in agricultural and urban areas contained the herbicides atrazine (and deethylatrazine), metolachlor, simazine, and prometon. The insecticides diazinon, chlorpyrifos, carbaryl, and malathion were common in mixtures found in urban streams.

\section{Implications}

- Because of the widespread and common occurrence of pesticide mixtures, particularly in streams, the total combined toxicity of pesticides in water or other media often may be greater than that of any single pesticide compound that is present.

- Continued systematic assessment is needed of the potential toxicity of pesticide mixtures to humans, aquatic life, and wildlife. NAWQA information on the occurrence and characteristics of mixtures can help to target and prioritize toxicity assessments.

Figure 1-8. Pesticides commonly occurred in streams and ground water as mixtures. For example, agricultural stream samples contained 10 or more different pesticides or degradates more than 20 percent of the time. 


\section{Degradates-}

Concentrations of degradates were often greater than concentrations of parent pesticides (Chapter 5)

Once released into the environment, pesticides undergo many types of transformation reactions that create degradates. Factors that govern the formation and distribution of degradates in the hydrologic system include the use and persistence of parent pesticides, the persistence and mobility of the degradates, and the physical, chemical, and biological conditions in the environment. In many cases, transformation results in the conversion of the parent compound to a compound that is less toxic, but some degradates have toxicities that are similar to, or greater than, that of their parent pesticide.

Some degradates were found more frequently and at higher concentrations than their parent pesticide. For example, DDT, which was first used more than 50 years ago and was discontinued about 20 years before this study

\section{Implications}

- Pesticide degradates should continue to be considered and accounted for in assessments of pesticide exposure and in evaluating the potential effects of pesticides on humans, aquatic life, and wildlife.

- Enhanced assessments of the occurrence and behavior of degradates in the hydrologic system require improved coverage of degradates in water-quality monitoring and continued research on pesticide transformations and transport in the hydrologic system. Enhanced assessments would supplement the toxicity testing of major degradates now required by USEPA as part of risk assessments for pesticide registration. began, was detected in fish from about 30 percent of agricultural streams sampled by NAWQA, whereas DDE, a more stable degradate of DDT, was detected in fish from 90 percent of sampled agricultural streams. Atrazine, the most heavily used herbicide in the Nation during the study period, was found together with one of its several degradates, deethylatrazine, in about 75 percent of stream samples and about 40 percent of ground-water samples collected in agricultural areas across the Nation. In the Eastern Iowa Basins, where NAWQA conducted special studies of herbicide degradates, an average of nearly 85 percent of the total mass of herbicide compounds in stream samples was composed of 10 degradates of the herbicides acetochlor, alachlor, atrazine, cyanazine, and metolachlor (fig. 1-9). The summed concentrations of degradates were more than 10 times higher than the summed concentrations of their parent compounds during much of the year, and the degradates accounted for the largest proportion of pesticide compounds that are transported by the Iowa River to the Mississippi River.

Degradates are particularly important in ground water, which moves relatively slowly through soils and aquifers, providing the extended time and conditions favorable for transformation of pesticides to their degradates. Ground water in the Delmarva Peninsula, for example, contained degradates of alachlor and metolachlor at median concentrations 10 times higher than those of the parent herbicides. Degradates in ground water can ultimately reach streams when ground-water discharge contributes to streamflow. In the Iowa River, substantial transport of herbicide degradates occurred during low streamflow conditions (fig. 1-9).

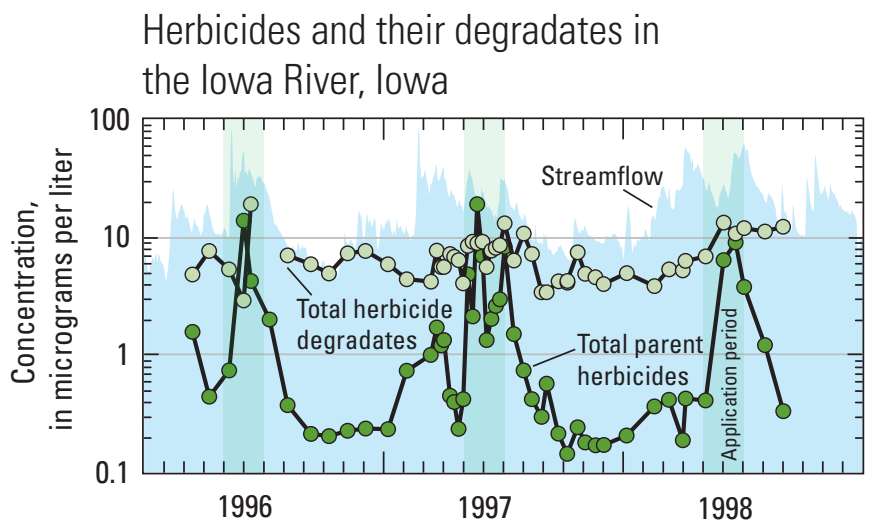

Figure 1-9. The total concentration of degradates commonly exceeded the total concentration of parent herbicides (acetochlor, alachlor, atrazine, cyanazine, and metolachlor) in the lowa River. 


\section{Prediction-}

Extensive data and improved understanding enable prediction of pesticide occurrence and concentrations for streams and ground water where they have not been measured (Chapter 7)

NAWQA data from 1992 to 2001 are sufficiently extensive to support statistical models that can be used to estimate the concentrations or occurrence of some pesticides in streams and ground water where they have not yet been assessed. Such spatial extrapolation is fundamental to extending NAWQA's targeted local and regional studies to a comprehensive national assessment. The statistical models were developed from measured pesticide concentrations, together with information on key factors and processes that affect pesticide occurrence, including pesticide use and land use, climate and soil characteristics, and other features.

The NAWQA approach to extrapolation for streams is illustrated by a model used to estimate concentrations of atrazine in stream water, specifically the likelihood that the annual average atrazine concentration in any particular stream in the Nation would exceed a humanhealth benchmark of $3 \mu \mathrm{g} / \mathrm{L}$ (fig. 1-10). The human-health benchmark used for atrazine is the USEPA drinking-water standard, or Maximum Contaminant Level (MCL). Predictions are for annual mean concentrations in untreated stream water (including consideration of predictive uncertainty), regardless of whether a stream is presently a source of drinking water. Atrazine concentrations were predicted to be highest in the Corn Belt and parts of the southern Mississippi River Valley, where use is high and natural features favor the transport of pesticides by runoff to streams. In these areas, many streams are estimated to have more than a 5-percent chance of having a mean annual concentration of atrazine that is greater than the benchmark (shown in red in figure 1-10). In other words, more than 1 out of 20 of these streams are predicted to have mean concentrations greater than the human-health benchmark, and thus, may not be suitable as sources of drinking water without the use of strategies to lower concentrations. Similar analyses can be developed for other probability criteria or concentration estimates.

\section{Implications}

- The development of national-scale predictive models with quantified reliability is increasingly possible for some pesticides, particularly for streams. Expanding this capability is a critical step for national water-quality assessment, as well as for cost-effective management of water resources, because both require more information (compounds, places, and times) than can be directly measured under current technology and budget constraints.

- Model estimates can be used to identify locations that have the greatest likelihood of water-quality problems and that are, therefore, the highest priority for additional monitoring.

- Future success with development and application of statistical models—as well as more complex simulation models - will depend upon continued, carefully targeted monitoring of pesticide concentrations in the hydrologic system, coupled with continued and improved collection of supporting data on pesticide use, natural features, and other explanatory factors needed to update and validate the models.

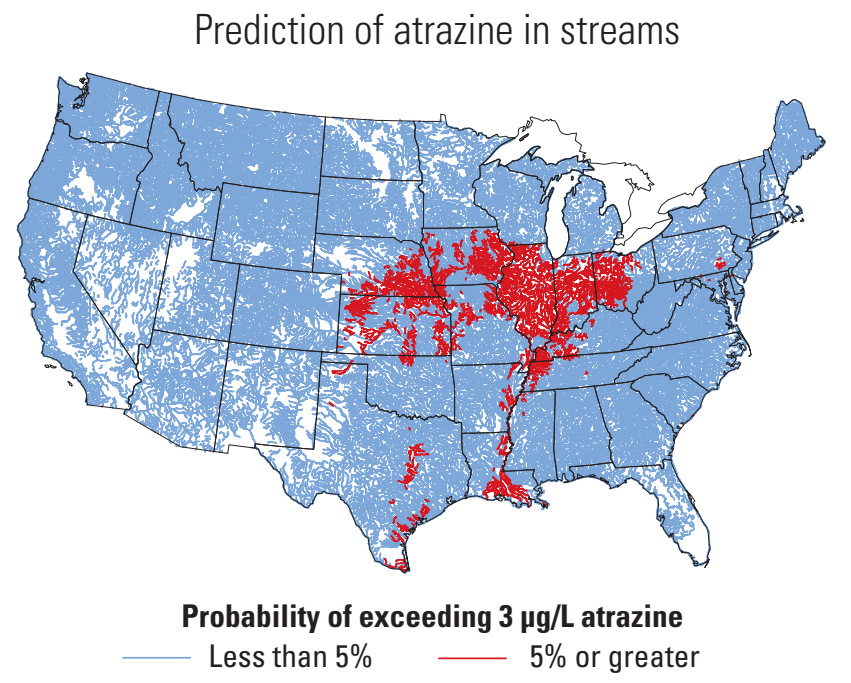

Figure 1-10. Streams predicted to have a 5 percent or greater chance of having annual mean atrazine concentrations that are higher than its human-health benchmark of $3 \mu \mathrm{g} / \mathrm{L}$-USEPA's Maximum Contaminant Level for drinking water-are located throughout much of the Corn Belt and in other high-use areas such as the southern Mississippi River Valley. These estimates were based on 1997 atrazine use for agriculture and will change if use changes. 


\section{Trends-}

A first look at trends shows examples of both decreasing and increasing levels of pesticides in streams and ground water (Chapter 8)

NAWQA results from 1992 to 2001 provide a framework for assessing whether pesticide levels in the Nation's streams and ground water are increasing or decreasing over time. For many pesticides and locations, it is too early to discern changes because historical data are insufficient to measure trends. Some trends, however, are already evident and others are just emerging.

The most complete story of trends in response to regulatory action and reduced pesticide use is the decline in concentrations of organochlorine pesticide compounds that followed reductions in use during the 1960s and bans on their uses in the 1970s and 1980s. For example, concentrations of total DDT in fish decreased rapidly from the 1960s through the 1970s, then more slowly during the 1980s and 1990s, as documented by data for 1969-1986 from the U.S. Fish and Wildlife Service (Schmitt and Bunck, 1995), and by data for the 1990s from NAWQA (fig. 1-11). The trends in concentrations of organochlorine compounds in fish, however, also show that responses to reductions in sources can take a long time for chemicals that are persistent in the environment.
More recent regional changes in corn herbicide use have resulted in corresponding trends in concentrations in Corn Belt streams. For example, in response to the partial replacement of alachlor by the new herbicide acetochlor in 1994, streams quickly — generally within 1 to 2 years — showed increasing acetochlor concentrations and decreasing alachlor concentrations. Findings show that concentrations of relatively mobile and short-lived pesticides in stream water will respond rapidly to changes in use-much more quickly than the less mobile and more persistent organochlorine compounds in fish tissue.

Ground water responds more slowly than streams to changes in pesticide use - taking years and even decades for changes in quality to occur. A persistent pesticide or degradate can remain in ground water long after its use has been discontinued because of the slow rates of ground-water flow and the resulting long residence time of water and contaminants in groundwater flow systems. This is evident from a number of studies in different parts of the country. For example, bromacil remained at detectable levels in ground water in parts of Florida for several years after it was no longer used. Similarly, dieldrin, which was no longer used during the study period, was still detectable at concentrations greater than its human-health benchmark in 72 wells sampled by NAWQA.

Continued NAWQA studies and monitoring will build on the baseline assessment established during the 1990s to assess trends in basins across the Nation. Assessment of trends is a primary objective during the second decade of the NAWQA Program when study areas are systematically reassessed and an increasing number of stream and ground-water sampling sites will have had 10 years of monitoring. Equally important, the NAWQA studies will continue to link changes in pesticide occurrence and concentrations over time with those factors that control the timing of trends, such as changes in pesticide use, land management, and natural factors.

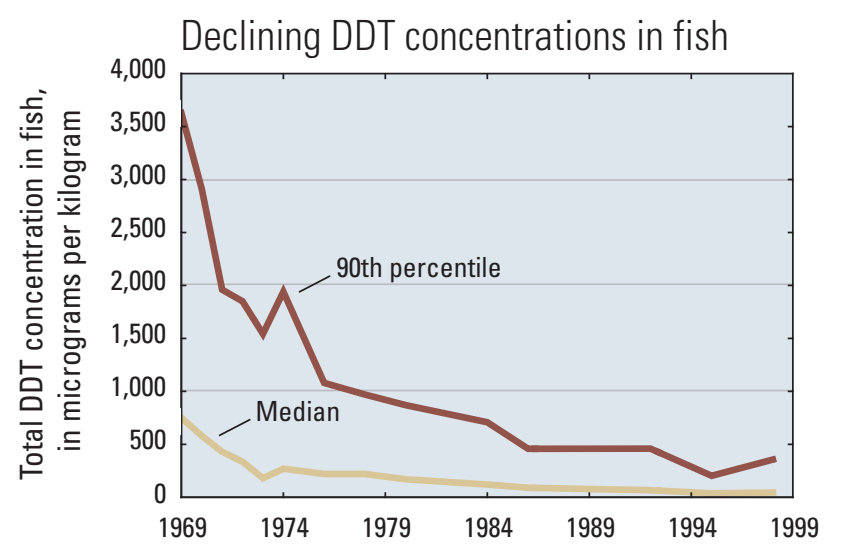

Figure 1-11. Total DDT concentrations in whole fish (wet weight) from rivers and streams throughout the Nation that drain watersheds with mixed land uses decreased rapidly from the 1960s through the 1970s, and then more slowly during the 1980 s and 1990 s.

\section{Implications}

- Increases or decreases in pesticide use can result in rapid corresponding changes in pesticide concentrations in stream watergenerally within 1 to 2 years. In contrast, pesticide occurrence in ground water, and the occurrence of persistent compounds in aquatic organisms or sediment, may change slowly_-sometimes taking decades to respond to changes in use.

- Long-term and consistent monitoring of pesticides in streams and ground water is essential for distinguishing actual trends from short-term fluctuations and for accurately tracking changes.

- Assessment of trends in stream-water concentrations of most currently used pesticides requires consistent annual data, with a particular focus on critical seasons of high use and transport. Assessment of trends in more persistent pesticides, such as organochlorine compounds in fish tissue, can rely on samples collected several years apart.

- Assessment of trends in concentrations of pesticides in ground water usually requires estimation of ground-water age and an understanding of the ground-water flow system because of the slow rate of ground-water flow and the uncertainty in flow paths. 


\section{Priorities for Filling Information Gaps}

The NAWOA assessment provides the most comprehensive analysis to date of pesticides in streams and ground water at the national scale and serves as a foundation for improving water-resource assessment and management. Nevertheless, major gaps in critical information about pesticides still persist and continue to present challenges to scientists, managers, and policy makers. As present-day knowledge is brought to bear on decision making, there is a continuing need to improve the data and scientific understanding required for future decisions. Some of the most important steps needed to fill information gaps for pesticides are outlined below:

- Improve tracking of pesticide use. Existing data on pesticide use are sparse (infrequent, with coarse geographic coverage) for agricultural uses and virtually nonexistent for nonagricultural uses. Given the direct relations between pesticide use and occurrence, improvement in the extent, frequency, and quality of quantitative data on agricultural use - and development of comparable and reliable data sources for nonagricultural pesticide use-would have major benefits for assessment and management of pesticides in streams and ground water.

- Add assessments of pesticides not yet studied. Many important pesticides have not yet been assessed in the Nation's streams and ground water using a nationally consistent approach because of budget constraints and limitations of current analytical methods. These pesticides include most fungicides and fumigants in current use, as well as many new or increasingly used herbicides and insecticides, such as glyphosate and pyrethroid insecticides. Pesticides targeted for analysis need to be re-evaluated regularly as use changes over time and new pesticides are introduced.

- Improve assessment and understanding of degradates. Closely related to the gaps in pesticides that have been assessed, are the even greater gaps in information about the distribution of degradates in streams and ground water. Specific needs include the development of analytical capabilities for measurement of a broader suite of pesticide degradates, continued research on pesticide transformations and the implications for transport and persistence in the hydrologic system, and improved assessment of potential exposure to degradates and their potential to affect humans, aquatic life, and wildlife. This information is needed to supplement the information on the toxicity and environmental behavior of major degradates that is now developed as part of the pesticide registration process.
- Evaluate toxicities of mixtures. Existing standards and guidelines for exposure to individual pesticides may not address all potential effects because actual exposure is most often to mixtures of multiple pesticides and degradates. Additional research is needed regarding the toxicities of mixtures to humans, aquatic life, and wildlife.

- Evaluate the performance of management practices. Evaluations are needed for making direct links between management practices-such as irrigation methods, subsurface drains, integrated pest management, and retention of wetlands and buffers - and the concentrations and transport of pesticides in streams and ground water. Field-scale studies have shown that certain management practices can influence pesticides in streams and ground water, but the effectiveness of these practices has not been systematically assessed at regional and national scales.

- Improve methods for prediction. Successful assessment and management of the Nation's water quality requires a commitment not only to monitoring pesticides and their degradates in streams and ground water, but also to the continued development of predictive tools, such as statistical and simulation models. NAWQA assessments demonstrate that models can play an important role in the assessment of water quality and provide a cost-effective approach for extrapolating measured waterquality conditions to unsampled areas. Predictive capabilities are critical because the expense of monitoring prevents direct assessment of pesticides for all of the places and times required. Models, however, are successful only if they are developed and verified on the basis of measured data. Thus, the integration of monitoring and modeling, which is heavily emphasized in NAWQA's second decade of assessments, is critical to expanding and improving methods for prediction.

- Sustain and expand long-term monitoring for trends. Long-term, consistent data for assessing trends is essential for tracking water-quality response to changes in pesticide use and management practices, for providing early warning of unanticipated problems, and for updating and improving models. The second decade of NAWQA assessments will include long-term monitoring of a broad range of pesticides and degradates in water at a national network of selected sampling locations, but the geographic coverage and range of pesticides measured should be increased in cooperation with other agencies. 


\section{Pesticide Primer}

$\mathrm{P}_{\text {esticides are used to control weeds, insects, and other pests }}$ in agricultural areas, urban areas, and a variety of other landuse settings. Once released into the environment, pesticides and their degradates can move through the hydrologic system to streams and ground water, where they may affect humans, aquatic life, or wildlife if concentrations occur at toxic levels. Many factors affect the transport and concentrations of pesticides in streams and ground water, including the intensity and distribution of their use; natural factors, such as climate and soil characteristics; and the physical and chemical properties of the pesticide compounds themselves.

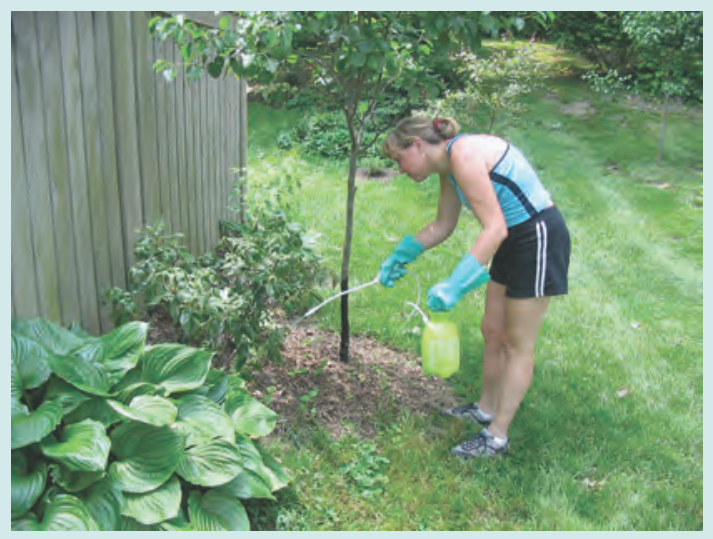

This chapter provides a

basic overview of the use of

pesticides and the factors that control their transport and fate in streams and ground water, thus serving as a foundation for understanding the occurrence and significance of pesticides in the hydrologic system-topics that are examined in subsequent chapters. 


\section{Pesticides and Their Uses}

A pesticide is any substance used to kill or control insects, weeds, fungi, rodents, bacteria, or other unwanted organisms. Pesticides provide a range of benefits, including increased food production and reduction of insect-borne disease, but their use also raises questions about possible adverse impacts on the environment, including potential effects on drinking-water sources and aquatic life.

All pesticide products contain one or more active ingredients, which are referred to as pesticides in this report. Most pesticide products also contain adjuvants, which are usually referred to as inert ingredients on product labels. Active

\section{Trends in pesticide use}

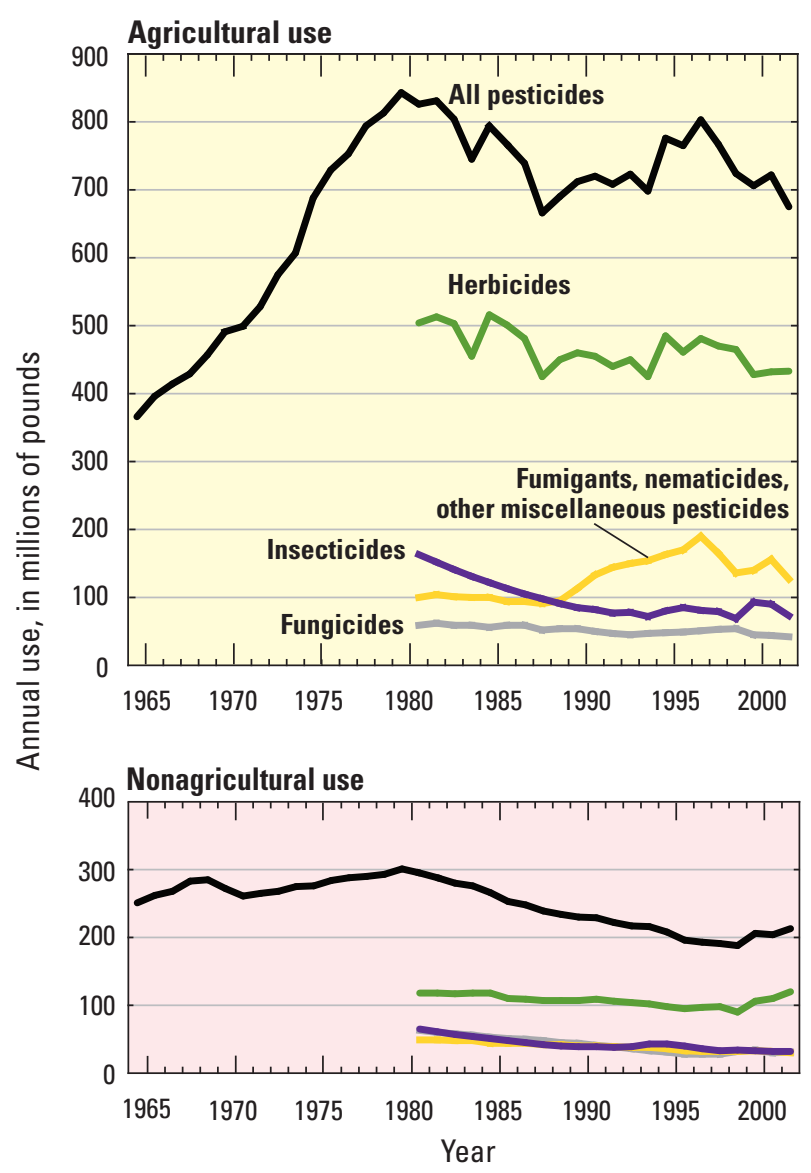

Figure 2-1. Total agricultural use of pesticidesmore than half of which was accounted for by herbicides-increased from 1964 until about 1980 and then varied between about 700 and 800 million $\mathrm{lb} / \mathrm{yr}$ until 2001. Nonagricultural use of pesticides, much of which occurs in urban settings, remained relatively steady from 1964 to 1979 , gradually declined from 1979 to 1998, and then increased through 2001. (Data from Donaldson and others, 2002; and Kiely and others, 2004.) ingredients specifically target the pest organism, whereas adjuvants are used to increase the effectiveness of the active ingredient. Adjuvants were not extensively assessed as part of NAWQA studies and are not addressed in this report, although some may have toxicological importance. As of 1997, about 900 pesticides were registered in the United States for use in more than 20,000 different pesticide products (Aspelin and Grube, 1999). New pesticides are introduced every year-for example, typically 10 to 20 new active ingredients were registered each year from 1967 to 1997 (Aspelin and Grube, 1999).

Conventional pesticides include four major groups: herbicides, insecticides, fungicides, and a mixed group of fumigants, nematicides and other pesticides. An average of almost 1 billion pounds (lb) of conventional pesticides was used each year in the United States during the 19922001 study period (fig. 2-1). NAWQA studies focused primarily on herbicides and insecticides, as described further in Chapter 3. In addition to conventional pesticides, about 4 billion $\mathrm{lb}$ of other registered pesticides are used each year, including chlorine disinfectants, wood preservatives, and other specialty products. These other types of pesticides were not included in NAWQA assessments.

Pesticide names used in this report are the scientific names of the active ingredients, such as atrazine and diazinon - rather than product names-in order to minimize confusion among the vast array of products and their names. For example, a 1994 analysis identified a total of 7,340 different product names associated with 386 commonly used pesticides - an average of 19 different product names per pesticide (Milne, 1995).

Pesticides are released into the environment primarily through their application to agricultural lands, such as croplands and orchards, and for nonagricultural pest control, such as on lawns and gardens, commercial areas, and rightsof-way. In 2001, agriculture accounted for 76 percent of total national use, with the remaining 24 percent being applied for a wide range of nonagricultural purposes (Kiely and others, 2004).

The nature and extent of pesticide use for agriculture in the United States has continually changed over the past 40 years. Total use for agriculture steadily increased from 1964 to 1980 - from less than 400 million to more than 800 million pounds per year (lb/yr) — and then varied between about 700 and 800 million lb/yr from 1980 to 2001 (fig. 2-1). From 1980 to 2001, the use of herbicides and fungicides decreased 
slightly, insecticide use decreased by about half, and the combined use of fumigants, nematicides, and other pesticides increased.

By comparison, nonagricultural use of pesticides remained relatively constant from 1964 to 1979 , in the range of 250-300 million $\mathrm{lb} / \mathrm{yr}$, and then gradually decreased to about 190 million lb/yr by 1998. From 1998 to 2001, nonagricultural use increased, driven primarily by increases in the amounts of herbicides, insecticides, and fungicides applied for home and garden pest control (Kiely and others, 2004).

Trends in the use of individual pesticides applied for agricultural or nonagricultural purposes commonly vary from these overall patterns, depending on factors such as market conditions, regulatory actions, and the introduction of new pesticides or approaches (for example, genetically engineered crops or organic agriculture). Selected trends are discussed in Chapter 8 as part of an evaluation of changes in pesticide occurrence in streams and ground water.

Most agricultural use of conventional pesticides is accounted for by fewer than 100 active ingredients. In 1997, for example, 25 herbicides accounted for approximately 92 percent of total herbicide use, 25 insecticides accounted for 91 percent of total insecticide use, 25 fungicides accounted for 99 percent of total fungicide use, and 20 pesticides accounted for 100 percent of total fumigant and nematicide use (Gianessi and Marcelli, 2000). The national use of a pesticide, however, does not necessarily indicate the importance of its use in a particular area. For example, some pesticides are used in small quantities nationally (ranking them outside the top pesticides by weight), but are used intensively or frequently in certain areas. Pesticide use within a particular agricultural area is determined by many factors, including the types of weeds, insects, and other pests of concern, the potency and application rates of specific pesticides, climate, regulatory limits, and cost. These factors are closely related to the types of crops and the extent of their production. For example, more than 50 percent of all agricultural pesticide use in the Nation (by weight) is for pest control on only three crops-corn, soybeans, and cotton. Applications to corn alone account for about 30 percent of total pesticide use in the United States (fig. 2-2). Estimates of pesticide use for agricultural purposes are available for more than 200 pesticides by crop and county for all States except Alaska and Hawaii (Thelin and Gianessi, 2000; see http://ca.water.usgs.gov/pnsp/).
Pesticides are used for nonagricultural purposes in urban and suburban areas to control weeds, insects, and other pests around homes and gardens, in parks and golf courses, along roads and other rights-of-way, and in commercial and industrial areas. Pesticides are also used for nonagricultural purposes in undeveloped and agricultural areas to control weeds, insects and other pests along fence rows and roadsides, in parks, and around rural residences. Nationally, total nonagricultural use is estimated to exceed the amount applied to any single crop except for corn (fig. 2-2). Data on nonagricultural use of pesticides, however, are much more limited than those for agricultural use. The only current published national data on nonagricultural use of specific pesticides are for 10 of the pesticides most commonly applied in each of two nonagricultural market sectors: (1) home and garden use by homeowners, and (2) use for industrial,

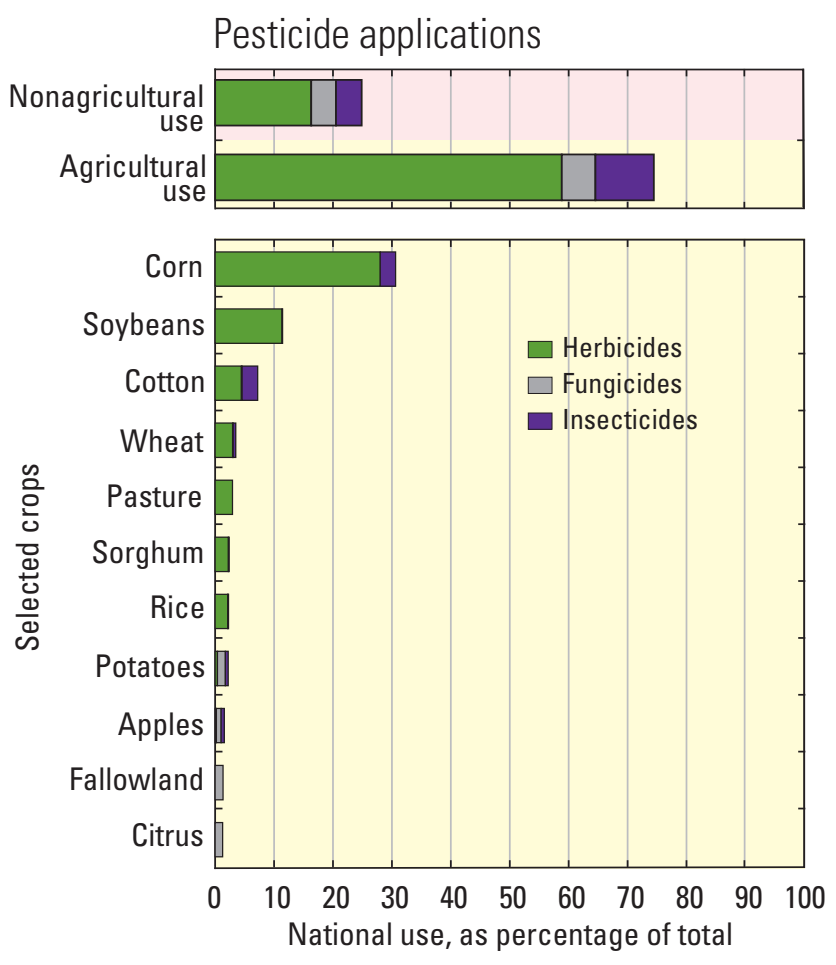

Figure 2-2. Agricultural use of pesticides in 2001 was about three times greater than nonagricultural use. However, nonagricultural uses, such as applications to control weeds and insects in urban and suburban areas, were second only to corn when compared with individual crops. (Pesticide use estimates for individual crops are for 1997 and are from Gianessi and Marcelli, 2000; use estimates for total agricultural and nonagricultural uses are for 2001 and are from Kiely and others, 2004.) 
commercial, and government applications (Kiely and others, 2004).

In addition to total use, the intensity of pesticide applications-expressed as the amount applied per unit of land area (such as pounds per acre)_also is an important consideration in assessing possible effects on water quality. For example, land devoted to corn production constitutes only about 8 percent of the total national area of agricultural and urban land uses, and yet pesticide applications to corn account for 30 percent of total national use. In contrast, pasture lands constitute about 50 percent of the total national area of agricultural and urban land, but account for only 4 percent of the total pesticide use. Collectively, urban areas across the Nation cover about the same area of land as corn (about 8 percent of the total agricultural and urban land area) and account for much of the 24 percent of total pesticide use that is attributed to nonagricultural purposes (Kiely and others, 2004). Estimates from the early 1990s indicate that the intensities of applications of herbicides to turf grass at sod farms, golf courses, and residencesand of applications of fungicides to turf at golf courses - are greater than the intensities of applications to most crops (Barbash and Resek, 1996). Available information indicates a relatively high intensity of nonagricultural use in urban areas.

The specific pesticides applied in a particular area differ by land use, crop type, and targeted pests. For example, during the 1992-2001 study period, certain pesticides, such as 2,4-D, diuron, diazinon, and chlorpyrifos, were more intensively used in urban and suburban areas across the Nation than in most agricultural settings. The types of crops largely determine which pesticides are applied in agricultural areas, resulting in distinct geographic patterns of use (fig. 2-3).
The use of each pesticide during 1997 was estimated by combining the 1997 state-level use data reported by Gianessi and Marcelli (2000), with county crop acreages from the 1997 Census of Agriculture (U.S. Department of Agriculture, 1999), using methods described by Thelin and Gianessi (2000). Use intensity was mapped for agricultural land using land-cover data from the early 1990s (Vogelmann and others, 2001) as described by Nakagaki and Wolock (2005). For example, molinate is used only on rice, which is grown primarily in the lower Mississippi River Valley and in parts of Louisiana, Texas, and California. Diazinon, atrazine, and diuron also have their own unique patterns of application. Considering the combined use of all pesticides, the overall intensity of pesticide application for agriculture is greatest in the croplands of the Corn Belt, the Mississippi River Valley, Florida, the coastal plain of the Southeast and Mid-Atlantic states, and irrigated areas of the West.

Although the amounts and intensities of pesticide applications largely define the sources of pesticides to the environment in a particular location, the potential of a pesticide to affect water quality is also influenced by its sources and pathways in the hydrologic system, its chemical and physical properties (which determine mobility and persistence), and its toxicity to humans, aquatic life, and wildlife. A basic background on the influences of sources, transport pathways, and pesticide properties on the behavior of pesticides in hydrologic systems - and some of the potential implications for water quality - is summarized below and these factors are further explored in Chapters 4 and 5. The potential effects of pesticides on humans, aquatic life, and wildlife are examined in Chapter 6. 
Agricultural use of selected pesticides
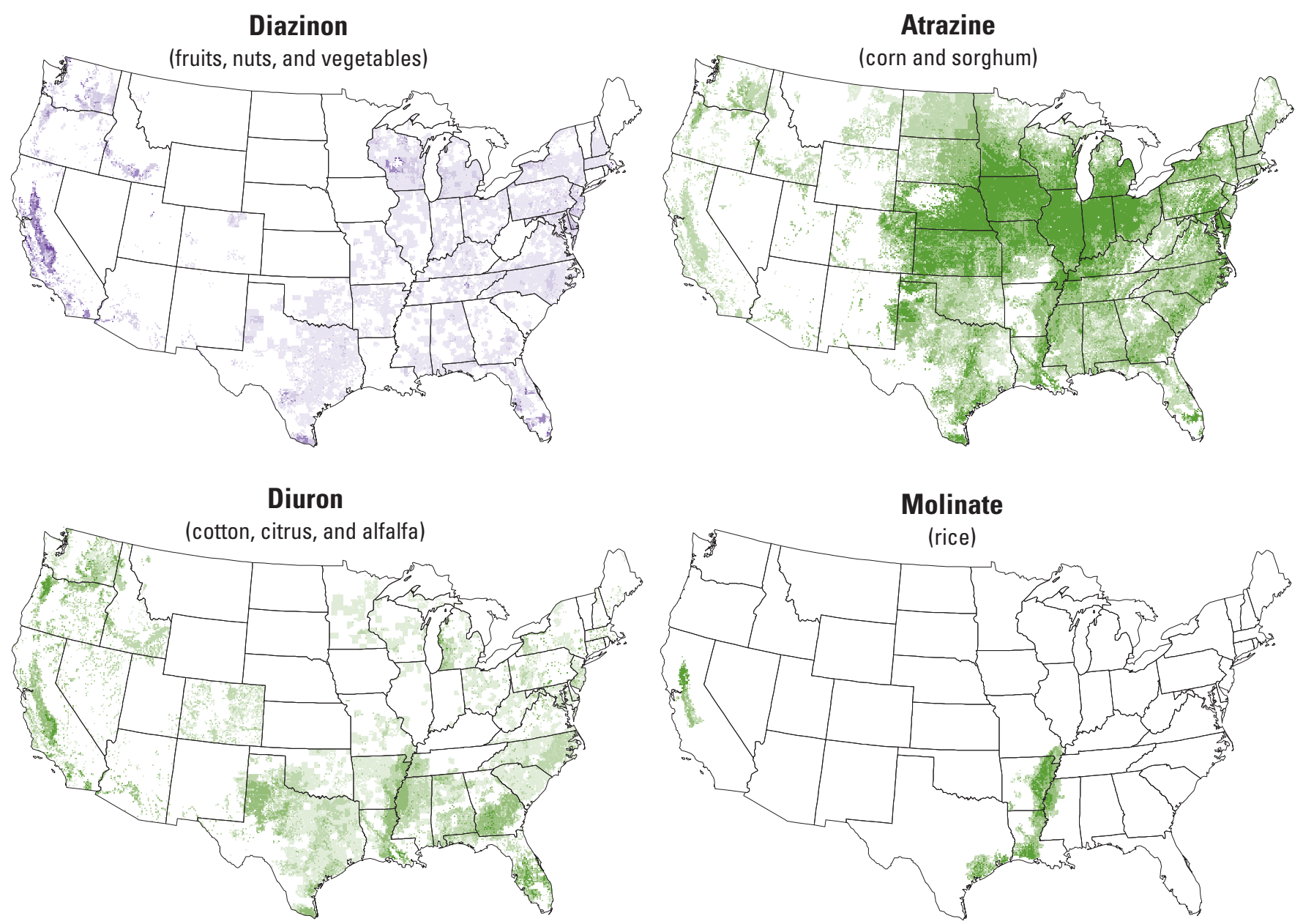

Estimated 1997 agricultural use intensity, in pounds per square mile per year

Insecticides

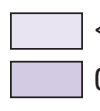

$<0.09$

$0.09-4.5$ $\begin{aligned} \square & >4.5-45 \\ \square & >45\end{aligned}$
Herbicides

\begin{tabular}{ll}
$\square<0.09$ & $\square>4.5-45$ \\
$\square$ & $\square .09-4.5$ \\
\hline
\end{tabular}

Figure 2-3. The geographic distribution of the use of each pesticide follows the distributions of crops and pests for which it is applied. Examples for the 1997 agricultural use of the insecticide diazinon and the herbicides atrazine, diuron, and molinate show four distinctly different geographic patterns of use. (Use intensity for 1997 was mapped for agricultural land using methods described on p. 24.) 


\section{Sources and Pathways in the Hydrologic System}

Pesticides, like most other water contaminants, enter the hydrologic system from point sources, which are associated with specific points of release, and from nonpoint sources, which are diffuse and widely dispersed. Nonpoint sources are the dominant sources of pesticides found in streams and ground water (fig. 2-4). Nonpoint sources include runoff to streams from agricultural and urban land, seepage to ground water in areas where pesticides are used, and deposition of pesticides from the atmosphere. Potential point sources of pesticides include pesticide manufacturing plants, mixing-and-loading facilities, spills, wastewater recharge facilities (wells or basins), waste disposal sites, and sewage treatment plants. Once pesticides and their degradates (new compounds formed by the transformation of a pesticide by chemical or biological reactions) reach the atmosphere, streams, or ground water, they move through the hydrologic system with air, water, or particles, depending on the chemical and physical properties of the compounds.

\section{Atmosphere}

The atmosphere is an important part of the hydrologic system in which pesticides can be transported substantial distances from where they are applied (for example, Goolsby and others, 1997; Cromwell and Thurman, 2000). In fact, atmospheric transport can be global and is thought to be responsible for the detection of long-lived organochlorine pesticides such as chlordane, DDT, and dieldrin in remote areas of Scandinavia and the Arctic-locations where these pesticides probably were never used (Majewski and Capel, 1995; Nowell and others, 1999; Hermanson and others, 2005).

Pesticides can be transported from the atmosphere to streams and ground water with precipitation or the deposition of particles. For example, studies in the Upper Tennessee River Basin showed that atrazine and metolachlor

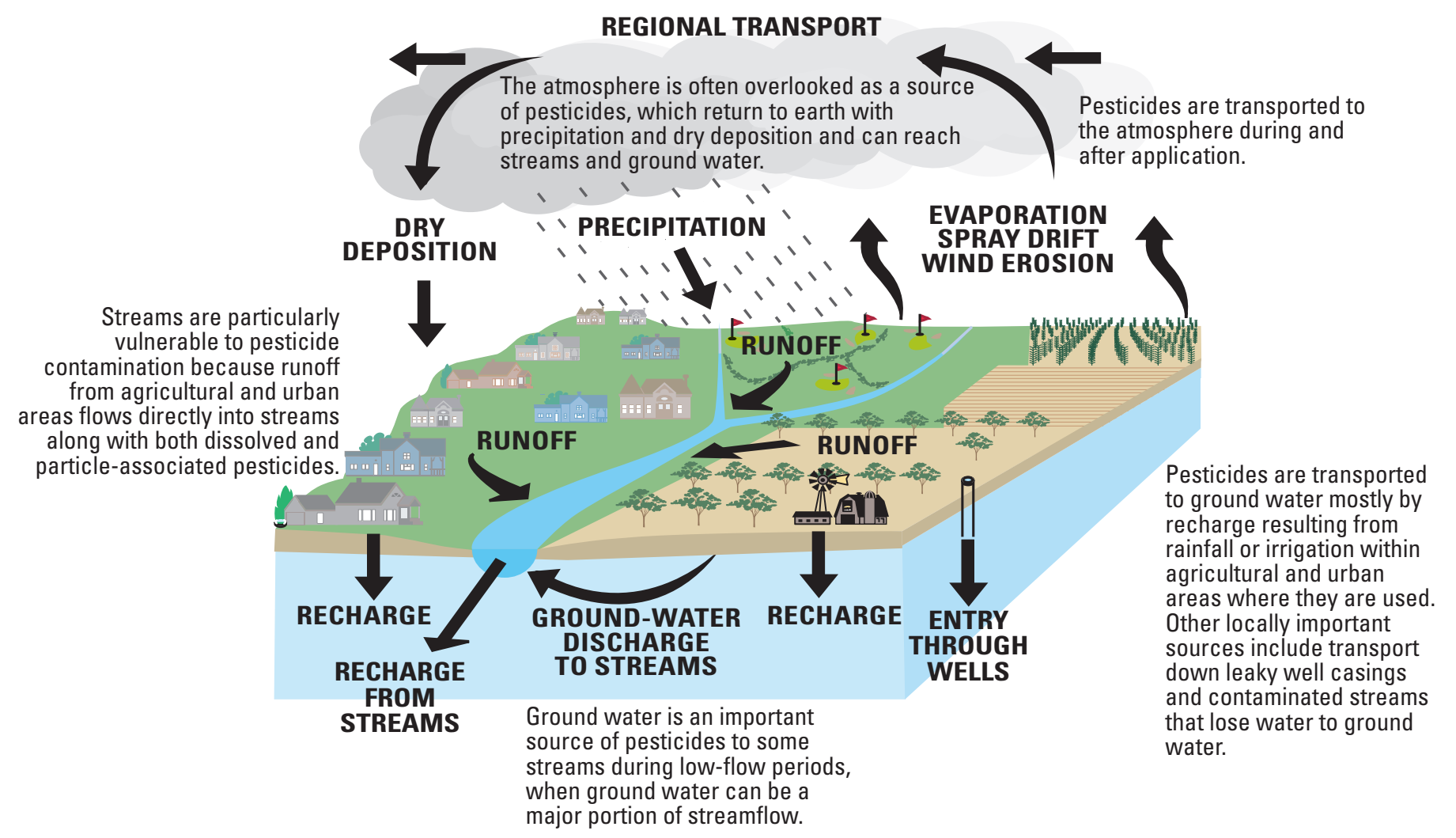

Figure 2-4. Pesticides are transported to streams and ground water primarily by runoff and recharge. Nonpoint sources of pesticides originating from areas where they were applied — rather than point sources such as wastewater discharges—are the most widespread causes of pesticide occurrence in streams and ground water. (Modified from Majewski and Capel, 1995.) 
were frequently detected in Clear Creek in the Obed National Wild and Scenic River watershed (fig. 2-5). Seasonal patterns of occurrence of these two compounds matched those in nearby agricultural streams, indicating an atmospheric source from agricultural areas (Hampson and others, 2000). Similarly, metolachlor, EPTC, and atrazine were detected in rainwater within the Minneapolis-St. Paul metropolitan area-where they had not been applied-also indicating that these pesticides had been transported from nearby agricultural areas (Andrews and others, 1998; Capel and others, 1998). All three pesticides were found in rainwater at concentrations that were usually higher than those measured in the ground water of the Minneapolis-St. Paul study area; thus, atmospheric inputs alone could have accounted for most of their occurrence in the ground water.

\section{Streams}

Pesticides are transported from land into streams primarily by runoff or drainage resulting from rainfall or irrigation. These event-generated inflows to streams can occur by surface runoff, shallow subsurface flow, or flow through drainage ditches and subsurface tile-drain systems. Some compounds, such as atrazine, readily dissolve in and move with water. Other compounds, such as chlorpyrifos, more strongly associate with soil particles and organic matter and are transported primarily with eroded soil, particularly during times of high runoff from precipitation or irrigation.

Transport to streams is controlled, in large part, by the timing of precipitation and associated runoff and drainage relative to pesticide applications (Leonard, 1990). For example, figure 2-6 shows elevated concentrations of atrazine in the White River during runoff events that occurred soon after spring applications in May and June, but lower concentrations in response to runoff events of comparable or greater magnitude at other times of the year when use was lower, such as in April or August. The phenomenon of high herbicide concentrations in spring runoff has been extensively documented, especially in the Midwest (for example, Thurman and others, 1991).

Pesticides also enter streams with inflowing ground water-which can be a continuous source of pesticides and degradates throughout the year in some areas (Squillace and others, 1993). For example, during baseflow conditions on the
Delmarva Peninsula, Shedlock and others (1999) measured pesticide concentrations in streams that were similar to those found in nearby wells. Baseflow conditions occur during periods of minimal precipitation, when streamflow is dominated by ground-water discharge. Similarly, in Waikele Stream, which drains a watershed with mixed land use on the Island of Oahu, Hawaii, concentrations of the herbicides bromacil, atrazine, and diuron were highest during baseflow conditions (Anthony and others, 2004).

Once in a stream, a pesticide may transform, be taken up by aquatic organisms, attach

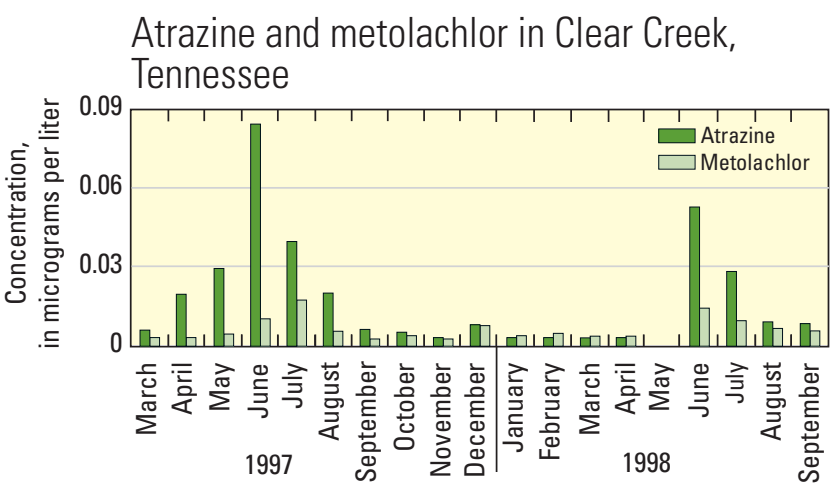

Figure 2-5. Atrazine and metolachlor were frequently detected in Clear Creek in the Obed National Wild and Scenic River watershed (Upper Tennessee River Basin). The seasonal patterns in concentrations followed those of applications in nearby agricultural areas, suggesting atmospheric transport (Hampson and others, 2000).

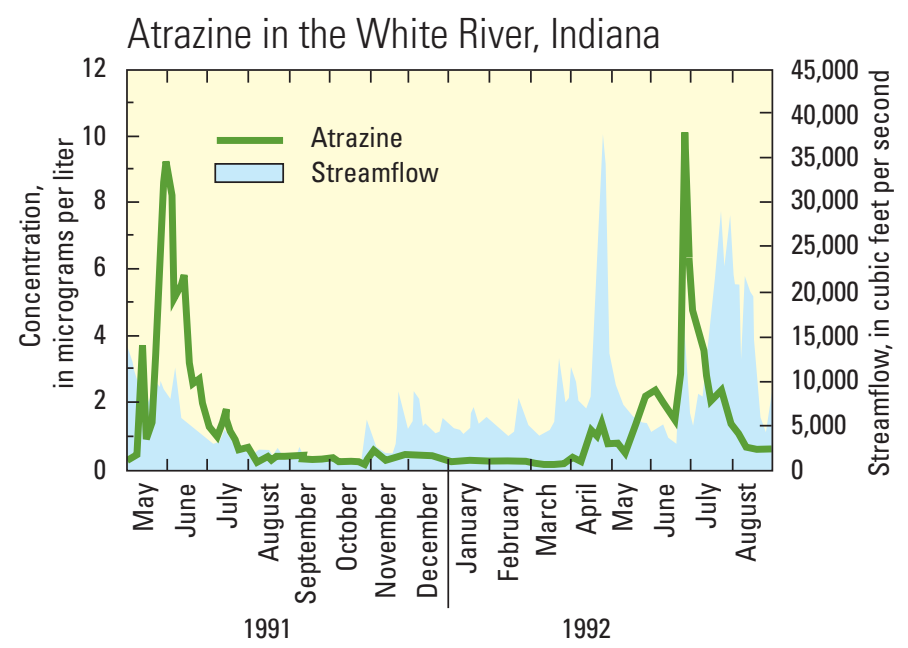

Figure 2-6. Atrazine concentrations in the White River (White River Basin) rose rapidly and peaked during the first runoff events that occurred soon after spring applications of atrazine in May and June. High runoff and streamflow either before or substantially after the high-use period typically did not result in similarly high concentrations (Carter and others, 1995). 
to suspended particles and be deposited in bed sediment, or volatilize to the atmosphere-all resulting in losses of the parent compound from stream water. Model calculations by Capel and others (2001) for 39 high-use pesticides indicated that transformations are the dominant cause of pesticide losses from streams, accounting for most of the predicted losses for 27 of the 39 compounds, compared with 4 pesticides lost mostly by volatilization, and 8 pesticides lost by multiple processes.

\section{Ground Water}

Pesticides reach ground water primarily in water that infiltrates the soil and passes through the underlying unsaturated zone to the water table. As with streams, most pesticide transport to ground water is driven by rainfall or irrigation when one or both result in ground-water recharge. Ground-water transport is different from transport in streams because only dissolved forms of pesticides and their degradates move substantial distances with ground water. Particlebound compounds are largely retained by soil and aquifer materials. In addition, transport of pesticide compounds to and within ground water is much less predictable than transport in streams because the flow of ground water is considerably slower and more complex than the flow of stream water.

Pesticides and their degradates can move readily to ground water through mobile zones, such as cracks, worm holes, or permeable sediments, but a portion of pesticide compounds is retained in immobile zones within the subsurface where flow is minimal. Pesticide compounds that are retained in immobile zones can be released gradually to ground water by diffusion and subsequent leaching, sometimes long after application. Much as a soap-filled sponge must be repeatedly rinsed and wrung before all of the soap is removed, the soil acts as a reservoir from which pesticides and their degradates continue to leach after application. As a result, pesticides may be found in ground water much sooner than expected after application (because of rapid movement through mobile zones), as well as for extended periods afterward (because of gradual release from immobile zones).

Pesticides generally are detected most frequently in ground water where the permeability of the soil and the hydraulic conductivity of the aquifer are highest, allowing relatively rapid transport. Deep aquifers usually have less pesticide contamination than shallow ground water because: (1) it takes a long time-decades or more, in many cases-for water to move from the land surface to deep ground water (resulting in long residence times for ground water and any solutes it may contain); (2) long travel distances increase the likelihood that pesticides will transform or attach to aquifer materials; (3) protective, low-permeability deposits (which inhibit flow and transport) may be present between the land surface and deep aquifers; and (4) the mixing of water from complex flow paths over long distances and time periods tends to result in a mixture of land-use influences on the quality of deep ground waters, commonly including contributions from areas of undeveloped land.

\section{Influence of Pesticide Properties on Environmental Behavior}

The occurrence and transport of pesticides in the environment are strongly influenced by the chemical and physical properties that affect their persistence and partitioning. Persistence refers to the tendency of a compound to remain in its original chemical form in the environment. Partitioning is the process by which pesticides become distributed among different environmental media, such as water, sediment, biota, and air, generally resulting in higher concentrations in some media than in others.

Pesticides with high persistence remain in their original chemical form in the environment for long periods, whereas those with low persistence rapidly transform following their release. Transformations proceed at widely varying rates, depending on the structure of the compound and environmental conditions (Barbash, 2004). As a result, the persistence of a pesticide - which is commonly expressed in terms of a half-life for transformation (the amount of time that it takes for half of the compound to transform) — can vary from hours to decades. Some transformations of pesticides in the hydrologic system result in degradates whose chemical properties, toxicities, and ultimate fate are not well known, although much information on the properties of major degradates has begun to emerge in recent years as part of pesticide registration studies in the United States and Europe (Sinclair and Boxall, 2003). Generally, persistent pesticides or degradates may be transported for long distances or accumulate in soils, sediment, or biota. In some cases_as with several of the historically used organochlorine pesticides - both long-distance transport and accumulation have been observed. 
The tendency of a pesticide or degradate to partition into water, sediment, or other media determines where it is most likely to be detected in the environment, and how it is transported through the hydrologic system. Two of the parameters used most often to describe the partitioning of a compound among environmental media are (1) the Henry's law constant $\left(\mathrm{K}_{\mathrm{H}}\right)$, which describes partitioning between air and water, and (2) the soil organic carbon-water partition coefficient $\left(\mathrm{K}_{\mathrm{oc}}\right)$, which describes partitioning between water and the organic matter in soil or sediment. Values of $\mathrm{K}_{\mathrm{H}}$ and $\mathrm{K}_{\mathrm{oc}}$ for the pesticides and degradates that were detected most frequently in NAWQA studies are provided in Appendix 2. These values were compiled from a variety of sources, including the U.S. Environmental Protection Agency (USEPA) and the U.S. Department of Agriculture (USDA). A pesticide with a high $\mathrm{K}_{\mathrm{H}}$ is volatile and thus, primarily tends to reside in and be transported by air. As a result, such compounds are rarely retained for long in streams or soil, but if they reach ground water, these compounds may remain for substantial periods of time because there is comparatively little exposure to the atmosphere. A pesticide with a high $\mathrm{K}_{\mathrm{oc}}$ has a greater tendency to accumulate in soil or sediment than to remain dissolved in water. Because they associate more strongly with organic matter than with water, pesticides with high $\mathrm{K}_{\mathrm{oc}}$ values are sometimes referred to as hydrophobic. Compounds with low $\mathrm{K}_{\mathrm{oc}}$ values (which therefore tend to favor water over organic matter) are described as hydrophilic. As a result of their affinity for organic matter, the more persistent hydrophobic pesticides are likely to accumulate not only in soils and sediments, but also in fish, birds, mammals, and other biota (Nowell and others, 1999).

Understanding the factors that affect the persistence of a pesticide and its occurrence in different environmental media is key to evaluating and anticipating its potential effects on water quality. For example, atrazine, which moves readily with water and is relatively persistent, reached streams in 10 times greater proportions than EPTC, which is less persistent, more volatile, and, unlike atrazine, usually incorporated into the soil when applied. Nationally, an average of about 1 percent of the atrazine applied to the land in watersheds of sampled streams reached its associated stream outlet, as opposed to only about 0.1 percent for EPTC (fig. 2-7) (Larson and others, 1999; Capel and others, 2001). Similarly, NAWQA data from agricultural areas across the Nation indicate that pesticides with

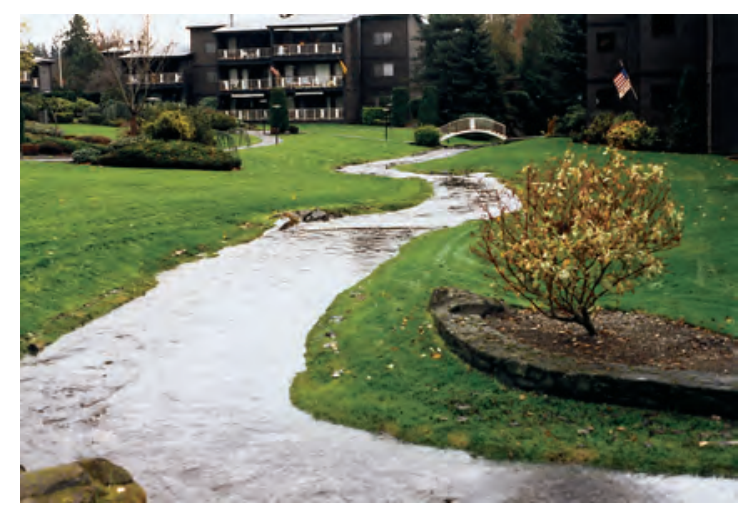

Pesticides with high $\mathrm{K}_{\mathrm{Oc}}$ values attach to sediment particles and are transported during runoff events when suspendedsediment concentrations are high.

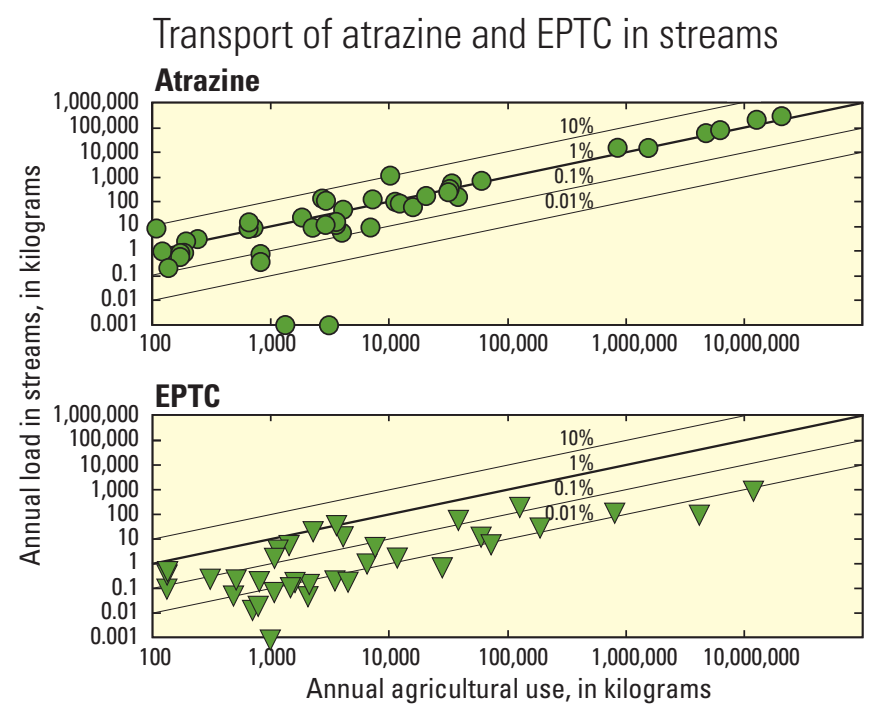

Figure 2-7. The annual transport of atrazine in streams was typically equivalent to about 1 percent of the amount applied in a particular watershed (percentages are shown by diagonal lines), whereas annual transport of EPTC in streams, which is less persistent and more volatile than atrazine, was less than 0.1 percent of annual use for more than half of the sites (Larson and others, 1999). 
greater persistence in soil are more likely to be detected in shallow ground water than compounds that are less persistent (Barbash and others, 1999). For example, within areas of relatively equal use, atrazine (soil half-life of 146 days) was detected in shallow ground water much more frequently than the less persistent metolachlor (soil half-life of 26 days) (fig. 2-8).

The effects of chemical and physical properties on the environmental behavior of pesticides were also illustrated by the differences between hydrophobic and hydrophilic pesticides in their transport within streams of the Yakima River
Basin. Hydrophobic pesticides $\left(\mathrm{K}_{\mathrm{oc}} \geq 300\right.$ milliliters per gram, $\mathrm{mL} / \mathrm{g}$ ) were found to be most readily transported in basins dominated by rill irrigation - a management practice that involves distributing large volumes of water across the land surface, and which often causes soil erosion (fig. 2-9). In contrast, annual loads of hydrophilic pesticides $\left(\mathrm{K}_{\mathrm{oc}}<300 \mathrm{~mL} / \mathrm{g}\right)$ were not affected by the extent of rill irrigation because the compounds are, for the most part, transported in the water rather than in suspended sediment (Fuhrer and others, 2004).

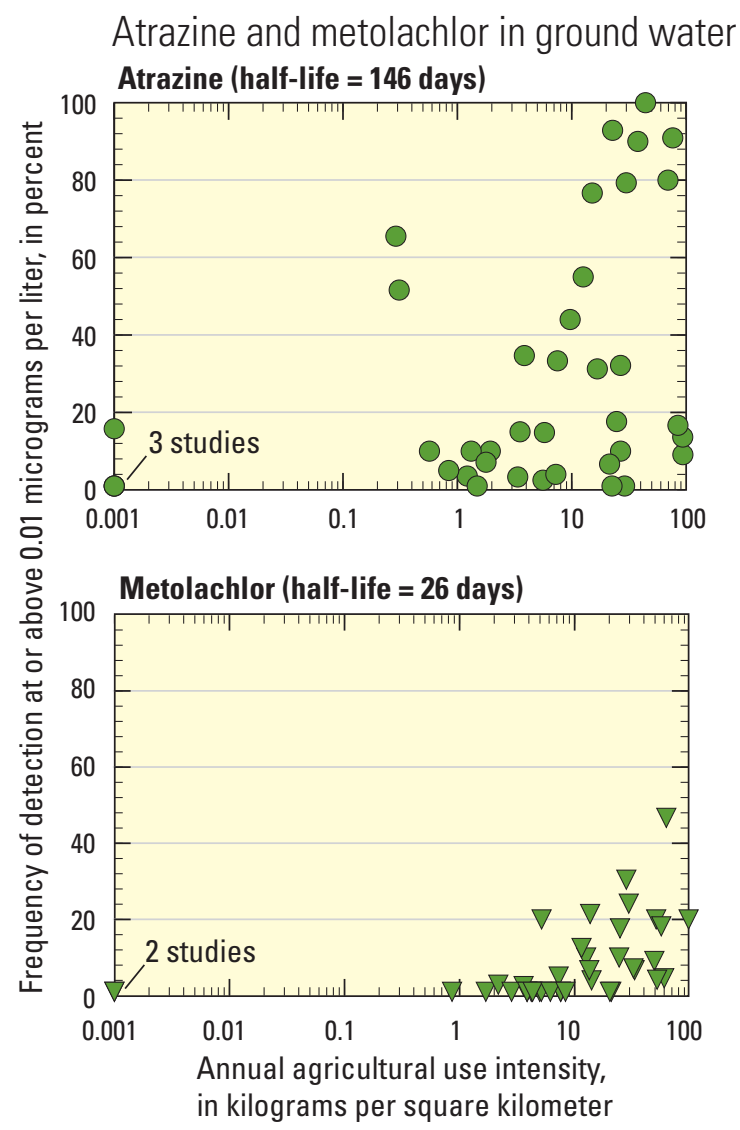

Figure 2-8. Frequencies of detection in shallow ground water beneath agricultural areas were usually greater for atrazine than for metolachlor given equivalent annual use rates, in part because of the greater persistence of atrazine in soil (Barbash and others, 1999).

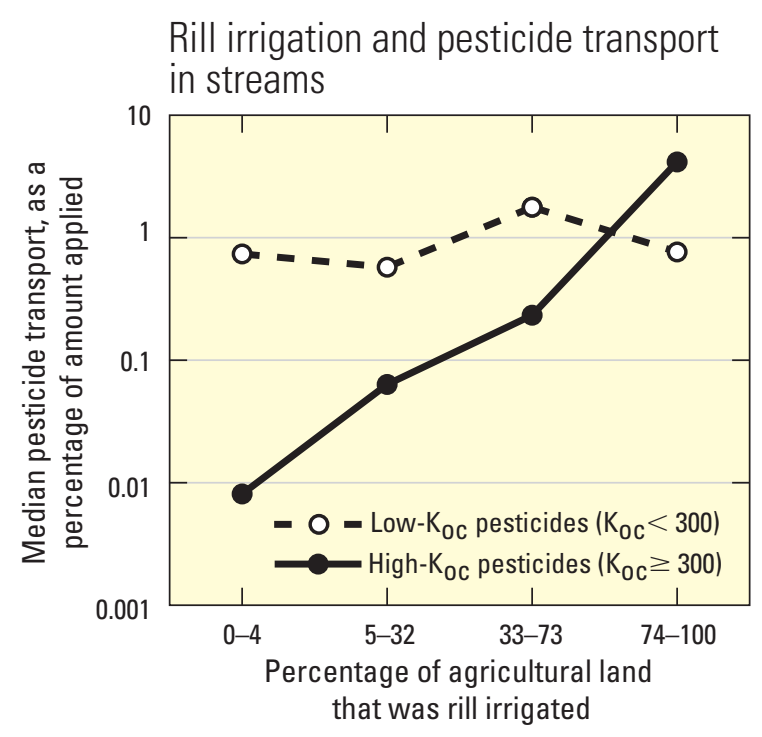

Figure 2-9. In the Yakima River Basin, transport of pesticides with high $\mathrm{K}_{\mathrm{oc}}$ values (high affinity for soil particles) was greater in streams draining larger proportions of farmland that was rill irrigated, a practice that results in soil erosion. In contrast, the amount of rill irrigation had little effect on low- $\mathrm{K}_{\mathrm{oc}}$ pesticides, which have lower affinities for soil particles and are not as affected by soil erosion. (modified from Fuhrer and others, 2004.) 


\section{NAWQA's Approach to Pesticide Assessment}

NaWQA's assessment of pesticides during 1992-2001 provides the most comprehensive analysis to date of pesticide occurrence in streams and ground water of the United States. The assessment followed a national study design in which the most important hydrologic systems were studied on a rotational schedule using nationally consistent sampling and analytical methods. This approach yields an understanding of waterquality conditions in a national context, while also supporting comparisons and assessments within and among individual watersheds, aquifers, and geographic regions. By systematically relating pesticide occurrence and transport to key factors that control contamination - such as pesticide use and properties, land use, hydrology, and other environmental featuresNAWQA provides information needed for managing pesticides within the Nation's diverse land-use and environmental settings.

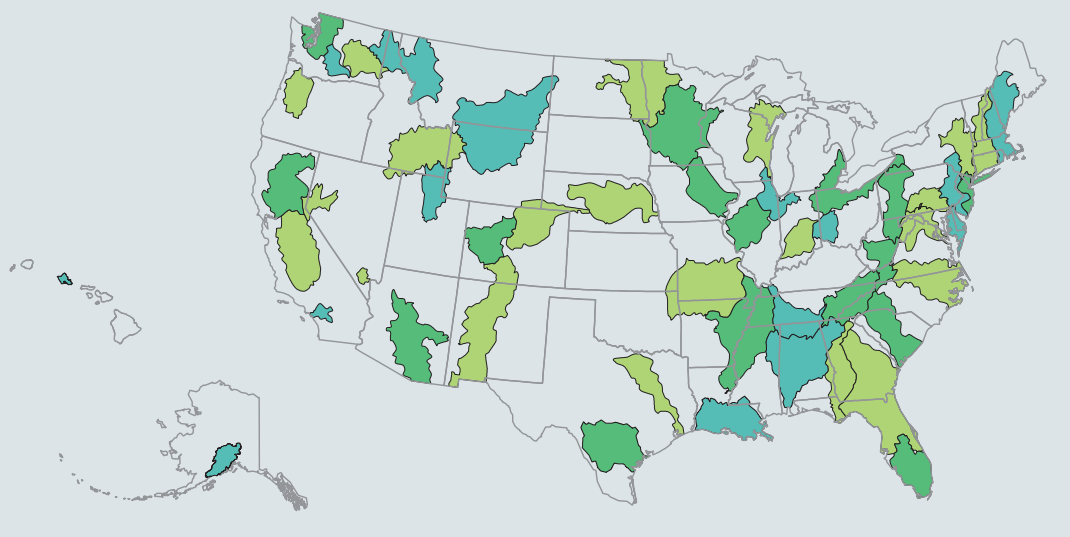

This chapter summarizes the

primary features of the NAWOA study design, providing the context for understanding findings about pesticides in the Nation's streams and ground water. 


\section{Targeted Sampling Across the Nation's Diverse Land Uses and Environmental Settings}

This report is based on results from NAWQA's first decade of water-quality assessments, which were completed on a rotational schedule from 1992 to 2001 in 51 major hydrologic systems across the country-referred to as Study Units-as well as the High Plains Regional Ground Water Study, using a nationally consistent study design (see p. iv-v). Assessments were conducted in 20 Study Units during 1992-1995; in 16 during 1996-1998; and in 15 Study Units during 1998-2001. Collectively, the 51 NAWQA Study Units and the High Plains Study cover a substantial portion of the Nation's land area; account for more than 70 percent of total water use and more than 50 percent of the population served by public water supplies and domestic wells; and are representative of the Nation's diverse landscapes, hydrologic systems, ecological resources, and land uses.

The primary objectives of the NAWQA pesticide assessment were to determine: (1) the occurrence and concentrations of pesticides in streams (ranging from small streams to large rivers) and ground water; (2) where and when pesticides occur in relation to factors that govern their sources and transport in the hydrologic system; (3) whether any pesticides may be present at concentrations that could affect human health, aquatic life, or fish-eating wildlife; and (4) how concentrations are changing over time.

Table 3-1. Each stream sampled by NAWQA was classified according to the dominant land uses in its watershed. The land-use data set used for these classifications was an enhanced version of the USGS 1992 National Land Cover Data (NLCD), which classified land use for each 30-by-30-meter area of land in the conterminous United States. The original and enhanced versions of the NLCD are described, respectively, by Vogelmann and others (2001) and Nakagaki and Wolock (2005).

\begin{tabular}{lc}
\hline \multicolumn{1}{c}{ Land-use classification } & \multicolumn{1}{c}{ Watershed land-use criteria } \\
\hline Agricultural & $\begin{array}{c}50 \text { percent agricultural land and } \leq 5 \text { percent } \\
\text { urban land }\end{array}$ \\
& 25 percent urban land and $\leq 25$ percent \\
Urban & agricultural land \\
& 5 percent urban land and $\leq 25$ percent \\
Undeveloped & agricultural land \\
Mixed & $\begin{array}{c}\text { All other combinations of urban, agricultural, and } \\
\text { undeveloped land }\end{array}$ \\
\hline
\end{tabular}

To address these goals, NAWQA employed a targeted assessment focusing on studies of:

- streams and shallow ground water in specific, relatively homogeneous land-use and environmental settings to relate pesticide occurrence to individual types of nonpoint sources; and

- streams and major aquifers (regionally extensive aquifers that are important ground-water resources for water supply) in areas of mixed land uses to evaluate the integrated effects of multiple sources of pesticides on their occurrence and concentrations.

Details on the sampling design and analytical methods, as well as all data used in this report are available at: http://ca.water.wr.usgs.gov/pnsp/ pubs/circ1291/.

For the targeted assessment by land use, streams and shallow ground water were sampled in agricultural and urban areas, and in undeveloped areas dominated by forest or rangeland. As described in more detail below and in the accompanying sidebar, streams and ground water were sampled most intensively in agricultural and urban areas because of the importance of assessing pesticide occurrence in areas where the compounds are used most intensively. The agricultural areas are diverse in climate, geography, and crop types, and span coastal, desert, and temperate environmental settings. They include, for example, areas dominated by production of corn and soybeans in the Midwest; wheat and other grains in the Great Plains; mixed row crops and poultry in the East; rangeland in the Southwest; rice in Louisiana; pineapple in Hawaii; and areas of grain, fruits and nuts, vegetables, and specialty crops in California and the Pacific Northwest. The areas sampled in urban settings were primarily residential, typically with low-to-medium population densities ( 300 to 5,600 people per square mile). Some commercial or industrial areas also were included, but point sources and extensive industrial and downtown urban areas generally were not assessed.

\section{NAWQA Stream Assessment in a National Context}

Potential land-use influences on the quality of water sampled at NAWQA stream sites were characterized by determining the proportions of each major land use within each stream's contributing watershed. Table 3-1 lists the criteria used by NAWQA to classify each stream sampling site by its predominant land-use category. Streams classified as "mixed land use" drain mixtures of 


\section{Unique Features of the NAWOA Approach}

Water-quality assessments by NAWOA, which is a single program among many local, State, and Federal programs, were not designed to address all of the Nation's water-resource information needs and issues. Listed below are several characteristics and limitations of the NAWQA approach that are important to consider when interpreting the findings on pesticides presented in this report.

- NAWQA assessments characterized the quality of the available, untreated water resources, and not the quality of drinking water (as would be done by monitoring water from water-treatment plants or from household taps). By focusing on the quality of streams and ground water in their present condition (ambient water quality), NAWOA complements many Federal, State, and local drinking-water monitoring programs.

- NAWQA assessments did not focus on specific sites with known water-quality problems or narrowly defined "issues of the day," but rather on the condition of the total resource, including streams and ground water in a wide range of hydrologic and land-use settings across the country.

- NAWQA assessments of pesticides focused primarily on nonpoint sources resulting from applications for pest management in agricultural, urban, and other land-use settings, although some sites - particularly those downstream from major metropolitan areas-also may be influenced by point sources, such as discharges from wastewater treatment plants.

- NAWQA assessments targeted specific land-use settings that are most extensive or important to water quality in a wide range of hydrologic and environmental settings across the Nation. This targeted approach gives priority to understanding the most critical factors influencing water quality. Extension of results to national analysis, however, requires careful definition of each type of water resource and environmental setting for which conclusions are drawn and the use of statistical models to extrapolate results to resources that have not been measured.
- USGS analytical methods were designed to measure concentrations as low as economically and technically feasible. Studies of contaminant occurrence and behavior benefit from the most information possible at all concentration levels, and such data help to identify emerging issues and to track changes in concentrations over time. By this approach, however, pesticides were commonly detected at concentrations far below Federal or State standards and guidelines for protecting water quality. Detections of pesticides do not necessarily indicate that there are appreciable risks to human health, aquatic life, or wildlife. The potential for such risks must be assessed by comparing measured concentrations with those that may cause adverse effects.

- USGS methods for analyzing pesticides in water measured concentrations in filtered water samples and, thus, may underestimate concentrations of compounds that have strong affinities for suspended particles. The potential for underestimation is greater for stream water compared with ground water because of the generally greater amounts of suspended particles present in stream water-which are removed by filtration along with any pesticides contained in or on the particles.

- Pesticide compounds analyzed in water by NAWOA included many of the most heavily used herbicides and insecticides, but they included only a fraction of all pesticides currently in use and few of their degradates. NAWQA findings provide insights about what to expect for pesticides and degradates that were not measured, but must be considered as only a partial assessment of currently used pesticides.

- Organochlorine pesticide compounds analyzed by NAWQA in bed sediment and fish tissue are predominantly related to pesticides that were no longer in use by 1990. Of the pesticide compounds measured in bed sediment and fish tissue, only dacthal, endosulfan, lindane, methoxychlor, and permethrin were used during all or part of the study period. 
two or more land-use settings and do not meet the criteria described in table 3-1 for individual agricultural, urban, or undeveloped settings. Land-use classifications were adjusted for a small number of streams that have watersheds with substantial areas that did not contribute streamflow during the study period. Most streams that were classified as agricultural, urban, or undeveloped also commonly have small amounts of other land uses in their watersheds. For example, and of particular importance to findings for pesticides, many streams classified as undeveloped have some agricultural or urban activity in their watersheds.

Consistent with the sampling design, which was targeted by land use, the NAWQA pesticide findings discussed in this report generally are presented by land-use category. Aggregation of NAWQA findings for streams across all landuse categories would not accurately represent all streams in the conterminous United States (fig. 3-1), which were characterized by classifying the watersheds of all stream segments in the USEPA river reach file (Nolan and others, 2003) using NAWQA land-use criteria (table 3-1). For example, nearly 40 percent of the streams sampled by NAWQA were agricultural streams, whereas agricultural streams represent about 15 percent of all streams in the conterminous United States. Furthermore, as shown in figure 3-1, agricultural streams represent only about 10 percent of all streams with public water-supply intakes. There are 1,679 public water-supply intakes on streams across the Nation for which land use

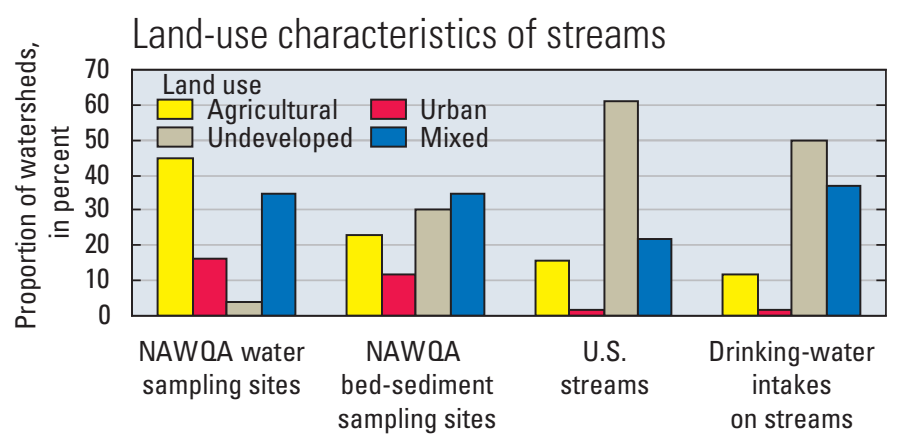

Figure 3-1. The NAWQA design for stream assessments placed greater emphasis on sampling streams that drain agricultural and urban watersheds (as defined in table 3-1), relative to those in undeveloped watersheds. Streams sampled by NAWOA included higher proportions of agricultural and urban streams - and lower proportions of undeveloped streams - compared with all streams in the conterminous United States and those with drinking-water intakes. could be characterized. The NAWQA design also over-represented urban streams and under-represented undeveloped streams compared with the national occurrence of streams in these land-use settings (fig. 3-1).

Even when grouped by land-use category, the watersheds of NAWQA sampling sites that were classified as agricultural and urban still tend to have higher proportions of agricultural and urban land than most streams nationwide in the same land-use groups, as well as streams with public water-supply intakes in the same land-use groups. For example, about 25 percent of agricultural streams sampled by NAWQA had watersheds with more than 90 percent agricultural land, compared with about 18 percent of all agricultural streams in the United States with more than 90 percent agricultural land. This indicates that NAWQA estimates of pesticide occurrence for agricultural and urban streams (for water and, to a lesser degree, bed sediment) are likely, as groups, to be high relative to those for other streams nationwide in these same land-use classes.

\section{NAWQA Ground-Water Assessment in a National Context}

NAWQA assessed pesticides in groundwater within specific land-use settings and in major aquifers with influences of a mixture of land uses. Land-use studies focused on shallow ground water primarily within agricultural and urban land-use settings, and to a lesser extent in undeveloped areas. Each of these studies involved the sampling of about 20 to 30 randomly located wells (using either existing or newly installed wells) within each targeted land-use area. Most of the wells selected or installed for the land-use studies sampled ground water from less than 20 feet below the water table, thus indicating as directly as possible the influence of each land use on shallow ground-water quality.

Major aquifer studies involved the sampling of about 20 to 30 domestic or public-supply wells that withdraw water from aquifers or aquifer systems that are major current or future sources of water supply. Wells that were sampled for these studies were randomly selected throughout the areas underlain by each major aquifer, without regard to land use. Thus, the ground water sampled for the major aquifer studies reflects the effects of a mixture of different land uses and ground-water ages on water quality, often including water that recharged long distances 
from the sampled wells and in a variety of different land-use settings. The nature and extent of each major aquifer sampled for these studies is described in the summary report for the NAWQA Study Unit in which it occurs (see http://water. usgs.gov/nawqa/).

NAWQA findings for ground water, as for streams, are grouped by land use in this report. NAWQA's targeted sampling design for ground water over-represented areas with urban and mixed land use, somewhat over-represented agricultural areas, and under-represented undeveloped areas when compared with the national distribution of these land-use settings by land area (fig. 3-2). Comparisons of land-use distributions for the NAWQA ground-water studies with those for the entire Nation were based on NAWQA land-use classifications (as defined in table 3-1) for every square kilometer in the conterminous United States. Although NAWQA agricultural and urban stream sites, as discussed above, tend to have greater proportions of agricultural and urban land in their watersheds than other streams in the same land-use groups, ground-water studies are not expected to have this tendency within these land-use groups because each well was selected by site-specific land-use criteria designed to meet the land-use objective for each study. Such site-specific control of land-use characteristics was not possible for streams because of the relatively large areas included in each watershed.

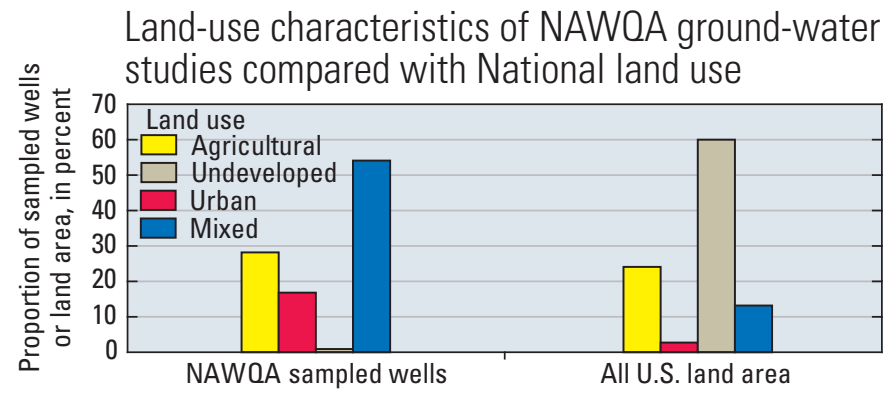

Figure 3-2. NAWQA's targeted sampling design for ground water emphasized areas with urban, mixed, and agricultural land useand under-represented undeveloped areas - when compared with the national distribution of land uses. All wells sampled for major aquifer studies were classified as mixed land use for this graph.

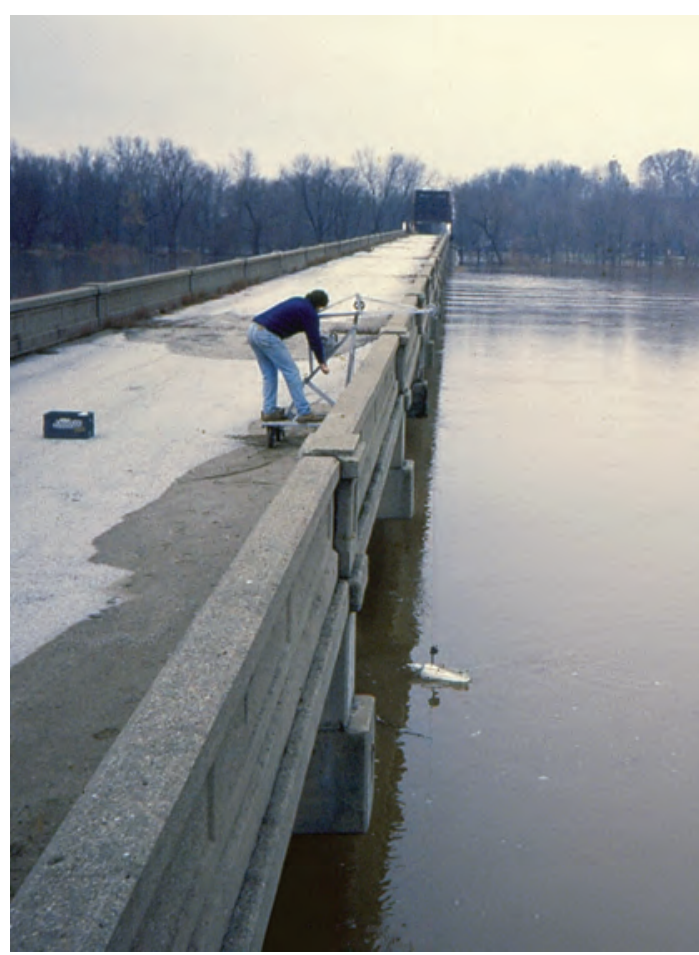

Large streams and rivers required sampling from bridges, boats, or cableways.

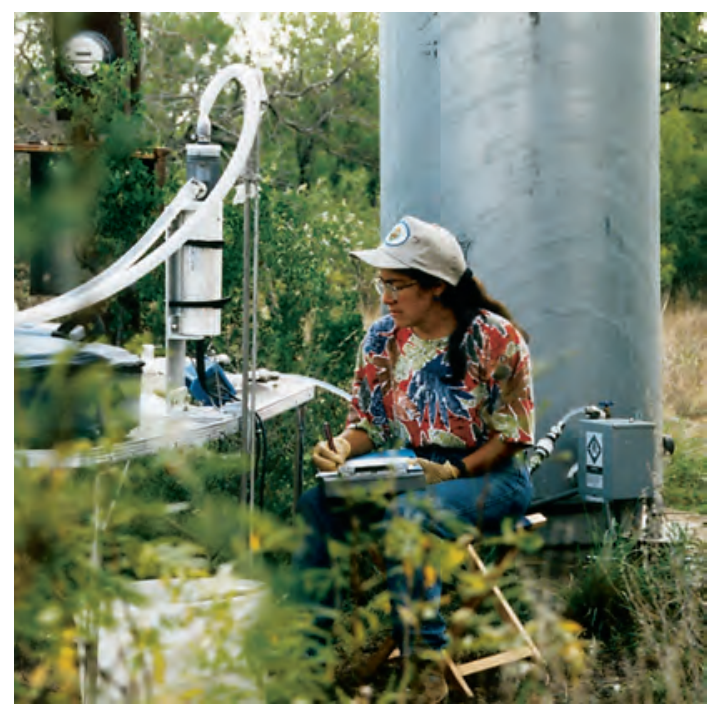

Most wells sampled for major aquifer studies were existing water-supply wells. 


\section{Sampling Design}

The NAWQA national assessment of pesticides is based on results from the analysis of more than 10,000 samples of water, bed sediment, and fish tissue from thousands of locations within the 51 NAWQA Study Units. Water-soluble pesticides, most of which were in use during the study period, were assessed in stream water and ground water. Organochlorine pesticides, which are no longer used in the United States, but remain persistent in the environment, were assessed in bed sediment and fish tissue-environmental media in which they accumulate.

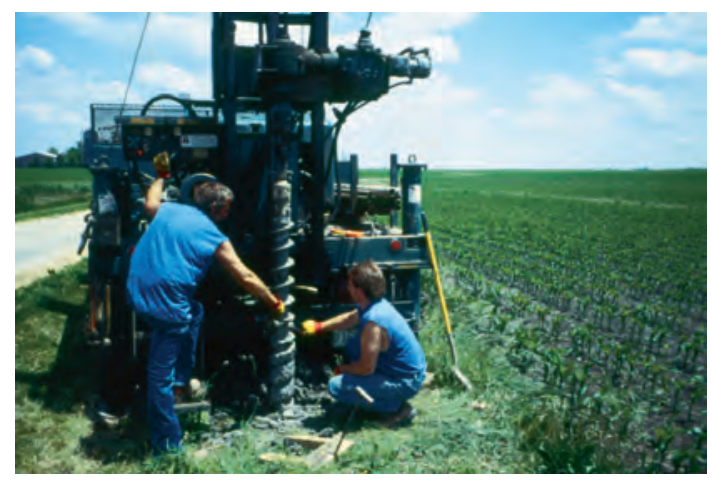

Most wells sampled for agricultural and urban land-use studies were observation wells installed by NAWQA.

\section{Stream Water}

Water samples were collected at 186 stream sites for analysis of pesticides and degradates dissolved in water (fig. 3-3). The samples were collected from streams throughout the year, including high-flow and low-flow conditions. Sampling was most intensive during the time of highest pesticide use and runoff-generally weekly or twice monthly for a 4- to 9-month period. Most analyses in this report are based on 1 year of data for each site (generally representing the single most complete year of sampling) to give equal influence to each stream. Because of the rotational assessment approach, the most complete year of sampling for each stream ranged from 1993 to 2000, depending on the particular site.

\section{Bed Sediment and Fish}

Samples of bed sediment were collected at 1,052 sites (fig. 3-3) and fish-tissue samples were collected at 607 of the bed-sediment sites (plus 93 additional sites not shown on the map) for analysis of organochlorine pesticides and selected degradates and by-products. At each site, fine-grained surficial bed sediment (sieved to $<2$ millimeters [mm]) was collected from multiple depositional areas within a stream reach on a single date-usually during low-flow conditions-and combined into a single composite sample for chemical analyses. For fish, multiple individuals of the same species were collected at a site, also on a single date, and whole fish were composited for chemical analyses of tissue.

\section{Ground Water}

Water samples were collected from 5,047 wells in 187 land-use and major aquifer studies for analysis of pesticides and degradates dissolved in water (fig. 3-3). For the land-use studies, most of the wells sampled were new or existing observation wells or domestic supply wells. The major aquifer studies focused almost exclusively on existing wells used either for domestic or public supply. Repeated sampling, such as that conducted at stream sites, was not included for ground water because of the comparatively slow rate of change in most ground-water systems, relative to streams. Data analyses were based on one sample per well. 
NAWQA sampling design

Stream-Water Sampling Sites

Watershed land use

○ Agricultural (83 sites)

$\square$ Urban (30)

$\diamond \quad$ Undeveloped (8)

$\triangle \quad$ Mixed (65)

NAWQA Study Unit

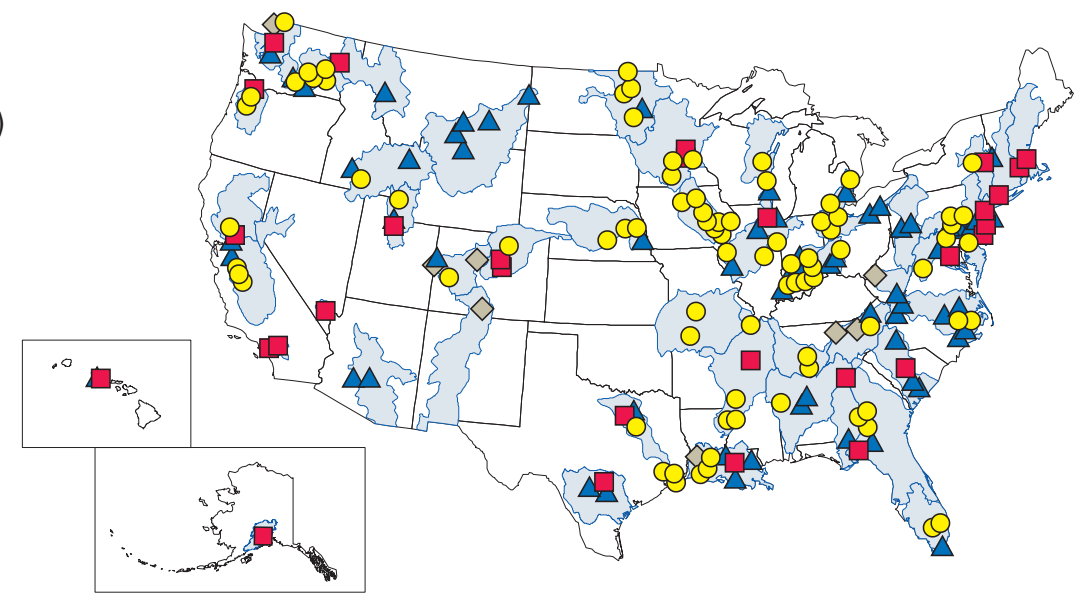

Bed-Sediment Sampling Sites

Watershed land use

O Agricultural (242 sites)

Urban (127)

$\diamond \quad$ Undeveloped (316)

$\triangle \quad$ Mixed (367)

NAWQA Study Unit

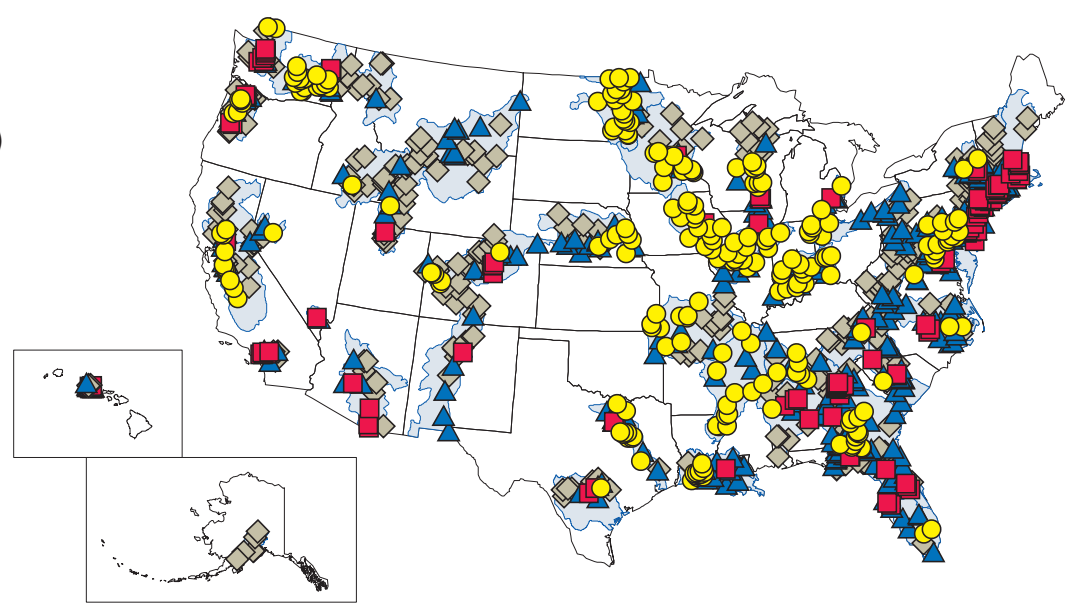

\section{Ground-Water Studies}

Land-use studies of shallow ground water

○ Agricultural (53 studies)

- Urban (33)

$\diamond \quad$ Undeveloped (9)

Major aquifer studies

$\Delta \quad$ Mixed land use (92)

NAWQA Study Unit

- - - High Plains Regional Ground Water Study

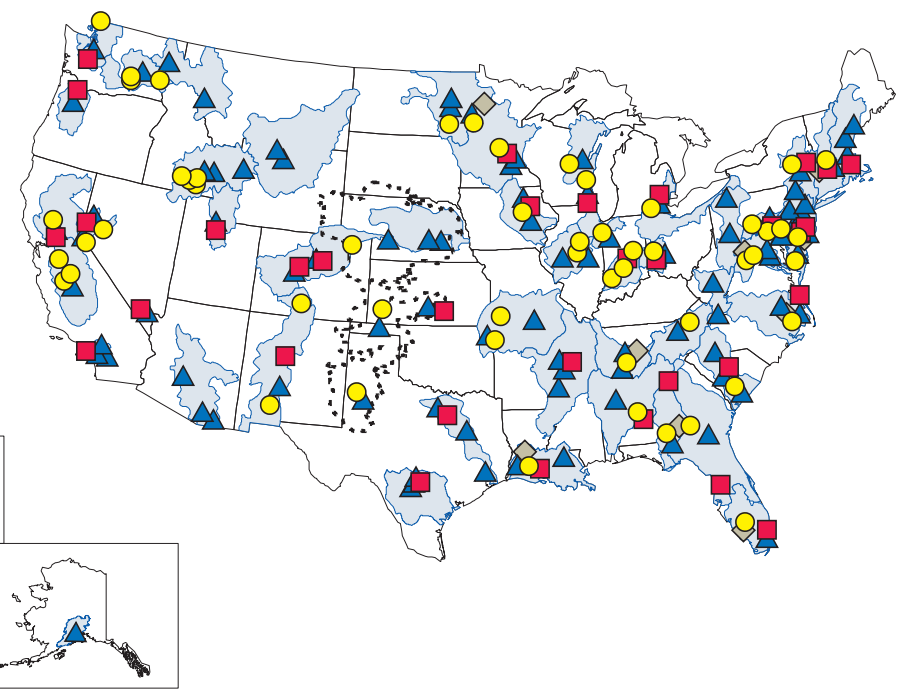

Figure 3-3. Stream sampling sites and ground-water studies in agricultural, urban, and undeveloped areas were distributed across the Nation's diverse environmental settings to evaluate the occurrence of pesticides within areas of specific land uses. Pesticides also were assessed in streams and major aquifers that represent the water-quality effects of mixed land uses and varied environmental settings. 


\section{Chemical Analyses}

NAWQA chemical analyses encompassed the most complete range of pesticides ever measured in a single assessment, and included many of the Nation's most heavily used pesticides (Appendix 1). Most NAWQA water samples were analyzed for 75 pesticides and 8 pesticide degradates, which during the study period accounted for about 78 percent of the Nation's agricultural use of conventional pesticides, by weight of active ingredient (fig. 3-4). The analytical strategy resulted in relatively thorough coverage of the major herbicides and insecticides in use for agricultural purposes during the period of study, including 20 of the 25 most heavily used herbicides and 16 of the 25 most heavily used insecticides (fig. 3-5). All water samples were filtered prior to analysis. As a result, reported pesticide concentrations, particularly in stream water, may underestimate concentrations of some compounds that have

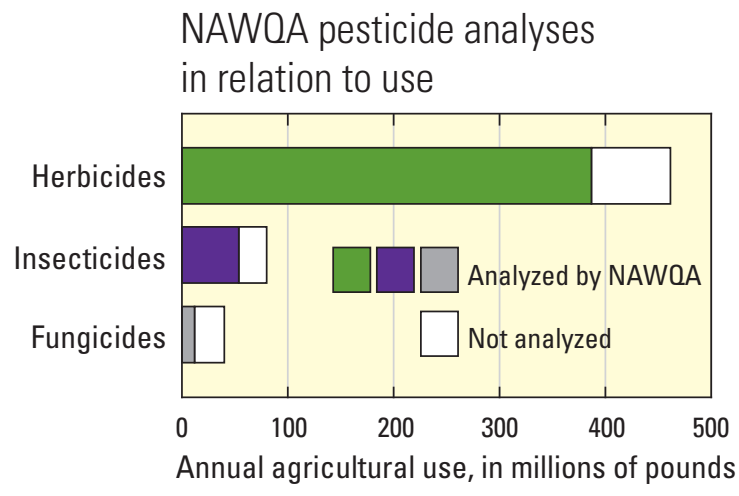

Figure 3-4. The NAWQA analytical strategy for water samples included 75 pesticides that accounted for about 78 percent of total national agricultural use during the study period, with relatively thorough coverage of the major herbicides and insecticides, but sparse coverage of fungicides, fumigants, and nematicides. (Use estimates are for 1997, as reported by Gianessi and Marcelli, 2000.)

\section{High-use pesticides analyzed by NAWQA}
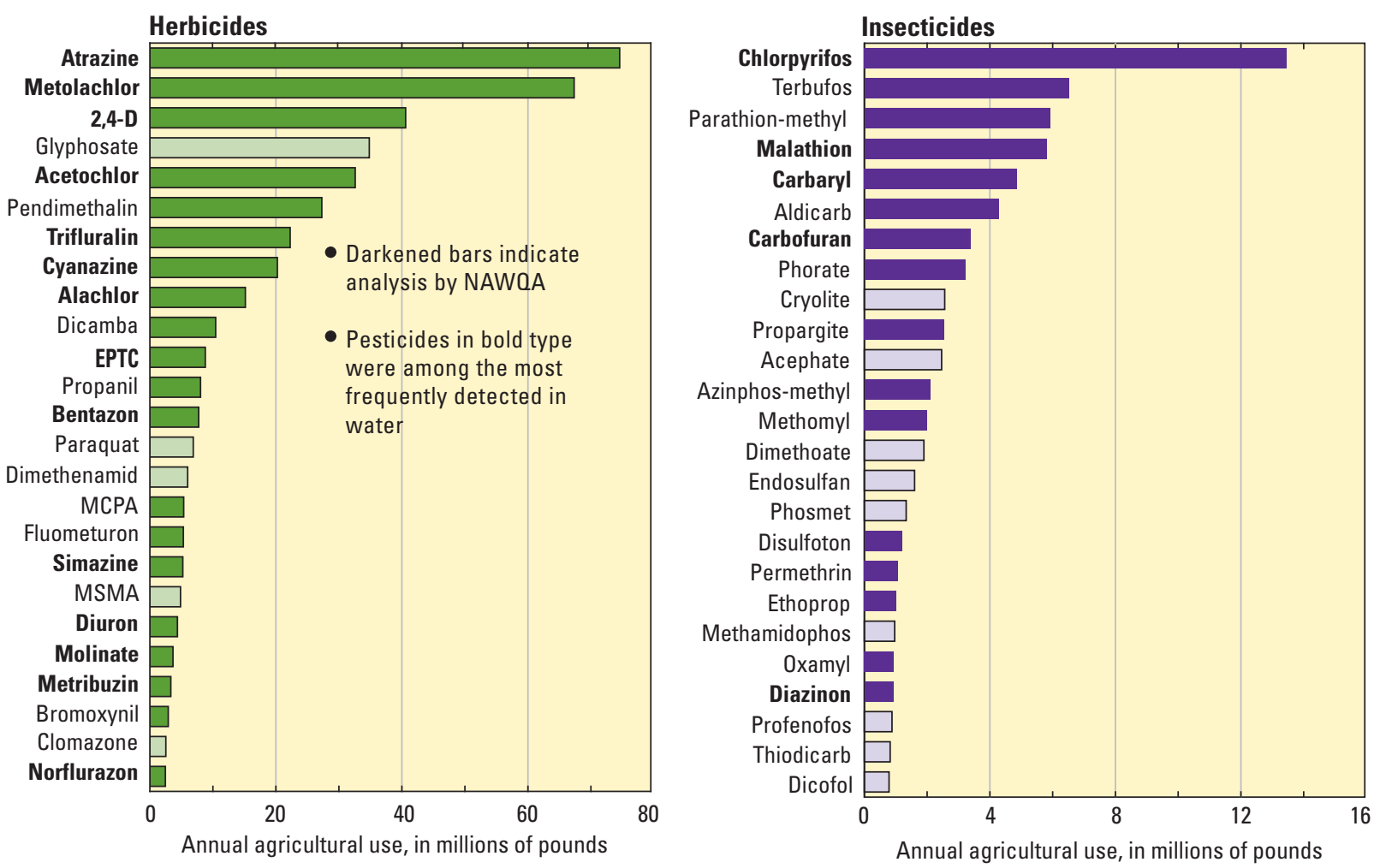

Figure 3-5. The NAWQA analytical strategy for water samples included 20 of the 25 most heavily used herbicides and 16 of the 25 most heavily used insecticides during the study period. More than half of these 36 high-use pesticides included in NAWQA analyses (dark bars) were among those most frequently detected in water (bold type), as described in Chapter 4. Some high-use pesticides, such as glyphosate, were omitted because no suitable analytical method was available, or because of budget constraints. (Use estimates are for 1997, as reported by Gianessi and Marcelli, 2000.) 
strong affinities for suspended particles because of removal by filtration.

Historically used organochlorine insecticides (such as DDT) and selected degradates and by-products were analyzed in bed sediment and fish tissue-environmental media in which they continue to persist long after the uses of the parent compounds were discontinued in the United States. Bed-sediment and fish-tissue samples were analyzed for up to 32 pesticide compounds, consisting of 19 parent pesticides and 13 degradates and by-products. Results for organochlorines are sometimes described for pesticide groups (such as "total DDT") because all compounds in the group are derived either from common parent pesticides (for example, the isomers p,p'-DDD and p,p'-DDE are degradates of $\left.p, p^{\prime}-D D T\right)$, or from indistinguishable pesticide products (for example, dieldrin may originate from application of dieldrin or or as a degradate of aldrin). Pesticide groups are identified and defined in Appendix 1B. Together, the organochlorine pesticides examined by NAWQA account for more than 90 percent of the Nation's historical use (by weight) of organochlorine pesticides in agriculture.

Some pesticides and degradates were assessed only in selected study areas or for limited periods of time. For example, several degradates of alachlor and metolachlor were measured at selected sites in different parts of the Nation, including streams draining parts of the Great and Little Miami River Basins, where use of the parent pesticides was high. Some pesticides were included in newly developed analytical methods late in the study period and were examined only in selected high-use areas, as was the case for fipronil in the Acadian-Pontchartrain Drainages. These and other pesticides with limited data are described for selected case studies in this report, but are not included in the national analysis.

\section{Pesticides Not Assessed}

Many potentially important pesticides and degradates were not assessed because of limited analytical methods or budget constraints. For example, glyphosate, the pesticide that ranked fourth among the top 10 herbicides used in 1997 , was not routinely analyzed because its chemical structure and properties require analytical methods that are different from NAWQA methods, which were designed to cost-effectively measure large suites of compounds simultaneously. As a result, a separate method was developed for glyphosate and it was added as an analyte in selected studies late in the study period. Similarly, cryolite — an inorganic insecticide used on grapes and that ranked ninth among the top 10 insecticides used in 1997-was also not routinely analyzed in NAWQA samples. Of all the fungicides used, only chlorothalonil (ranked highest in use among fungicides) was included, and there were no nationally consistent analyses of any fumigants or nematicides. Other pesticide compounds that were not assessed by NAWQA include other inorganic pesticides (such as sulfur and copper), oil, biological pesticides, and numerous pesticide degradates, manufacturing by-products, and adjuvants.

Although NAWQA included the broadest and most complete range of pesticides measured in a single national assessment, it still must be considered selective. Consequently, NAWQA results should be expected to underestimate the overall occurrence of pesticides and degradates in many of the hydrologic systems that were studied. 



\section{Occurrence and Distribution in Streams and Ground Water}

$\mathrm{P}_{\text {esticides were found at detectable concentrations in streams }}$ and ground water within most areas sampled that have substantial agricultural or urban land uses. Pesticides were detected in almost every water sample from streams, but were less common in ground water. Organochlorine pesticide compounds were detectable in fish andwom most streams, despite the fact that most of the parent pesticides have not been used in the United States for years. Although more than 100 pesticide compounds were analyzed in water, fish, or sediment, less than 40 of these compounds accounted for most of the detections. The distributions of the most prevalent pesticides in streams and ground water largely follow geographic patterns in land use and associated present or past pesticide use.

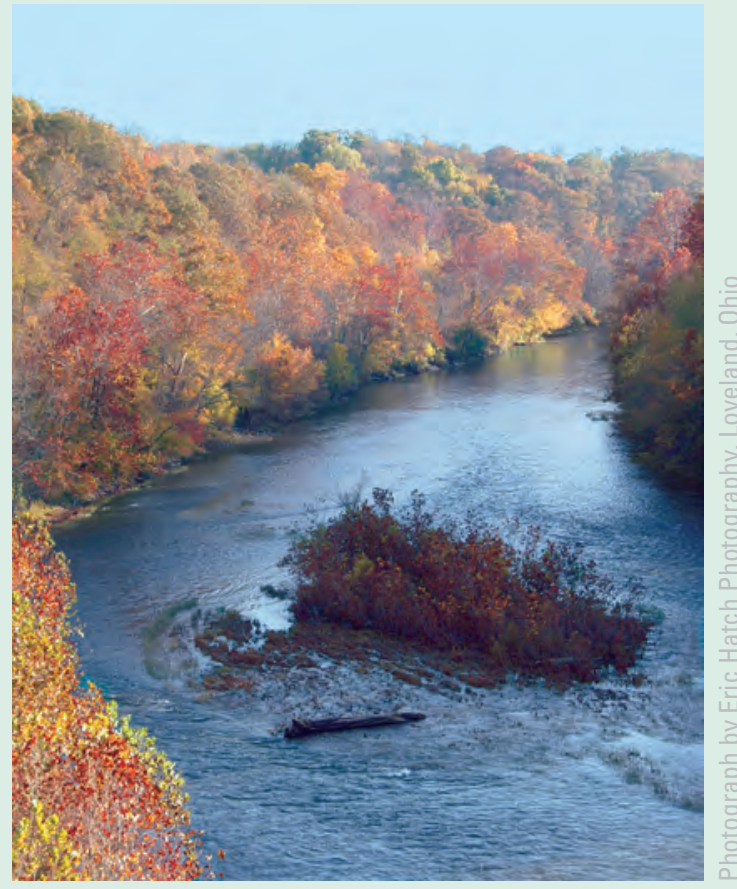

This chapter summarizes NAWOA results from 1992 to 2001

focusing on the pesticides that were most frequently detected in streams and ground water. Pesticide detections are assessed in relation to land use, pesticide use, hydrologic settings, and the properties of the pesticides themselves. More detailed examination of seasonal patterns, pesticide mixtures, and degradates is included in Chapter 5, and a screening-level assessment of the potential significance of pesticides to human health, aquatic life, and wildlife is provided in Chapter 6 . 


\section{Overview of Pesticide Occurrence}

NAWQA results show that pesticides occurred at detectable concentrations in streams and ground water within most areas that have substantial agricultural or urban land uses. These findings build upon an extensive body of previous research, demonstrating that pesticides and their degradates are present in ground water (for example, Barbash and Resek, 1996; Kolpin and others, 1996), surface waters (for example, Larson and others, 1997; Battaglin and others, 2003), and stream sediments and aquatic biota (for example, Nowell and others, 1999; Seiler and others, 2003) in a wide variety of hydrologic, ecological, and land-use settings across the United States.

In streams sampled by NAWQA, at least one pesticide or degradate was detected more than 90 percent of the time in water, in more than 80 percent of fish samples, and in more than 50 percent of bed-sediment samples collected during 19922001 (fig. 4-1). Pesticides analyzed in water were primarily those that are currently used, whereas those analyzed in fish and sediment were predominantly pesticides (or their degradates and by-products) that are no longer used in the United States, such as DDT and other organochlorine pesticides. Detections in stream water were evaluated on a time-weighted basis and results are expressed as the percentage of time that concentrations were detectable. For both fish tissue and bed sediment, one sample was analyzed per site and detections are expressed as a percentage of samples or sites analyzed. Detectable concentrations occurred in water more than 90 percent of the time for streams draining watersheds with agricultural, urban, and mixed land use. Similarly, organochlorine pesticide compounds were detected in more than 90 percent of fish-tissue samples and in more than 50 percent of bed-sediment samples from streams in watersheds with agricultural, urban, and mixed land use. In water, fish tissue, and bed sediment, detections were the least frequent, but not absent, for streams draining undeveloped watersheds-where pesticide use is lowest.

Pesticides were detected distinctly less often in ground water than in streams (fig. 4-1). Detections in ground water are based on one sample per well. Streams are generally more vulnerable to contamination than ground water because of the direct and relatively rapid overland transport of pesticides that occurs with surface runoff (see Chapter 2). Ground water in most areas is less vulnerable because water infiltrates the land surface and moves slowly through soil and aquifer materials before reaching most wells. This extended travel time allows more opportunities for the concentrations of pesticides in water to

\section{Overview of pesticide occurrence}
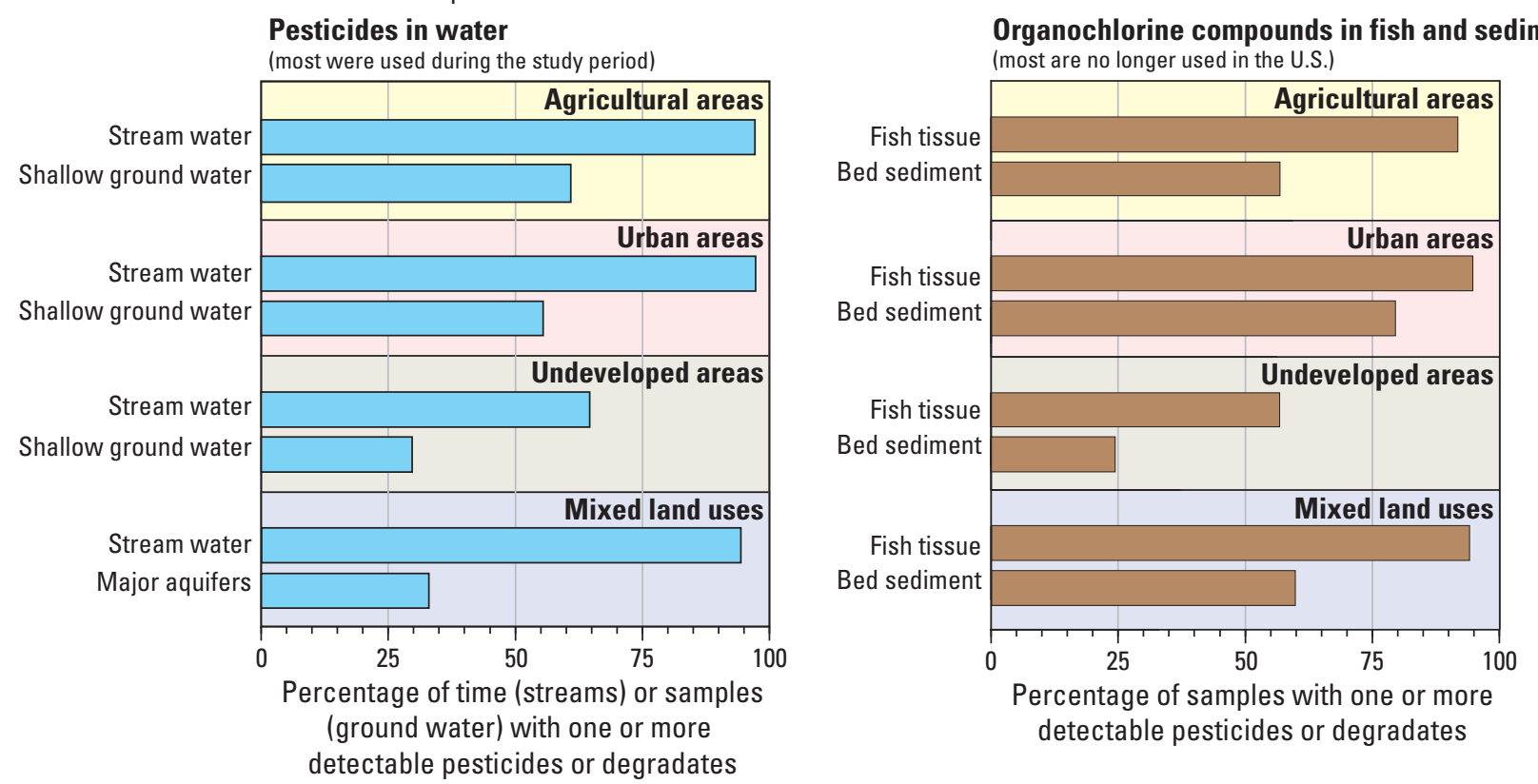

Figure 4-1. Considering all streams sampled across all land uses, one or more pesticides or their degradates were detectable more than 90 percent of the time in water, and were detected in more than 80 percent of fish samples and in more than 50 percent of bed-sediment samples. Less than half of all ground-water samples contained one or more detected pesticides or their degradates, with the most frequent detections occurring in shallow ground water beneath agricultural and urban areas. 
be reduced from the combined action of sorption, dispersion, dilution, and transformation. The slow movement of water and solutes through the subsurface, however, also makes contamination of ground water more difficult to reverse once it occurs. The highest frequencies of detection were in shallow ground water beneath agricultural and urban areas, where almost 60 percent of samples had detections of one or more pesticides or degradates. The lowest frequencies of detection were found in shallow ground water beneath undeveloped areas and in deeper ground water in major aquifers. Samples from major aquifers generally represent older ground water that originated as recharge in areas of mixed land use, sometimes before the current land uses were present.

\section{Pesticides Detected Most Frequently}

About 40 pesticide compounds, of the more than 100 examined by NAWQA, accounted for most detections in water, fish, or bed sediment. Understanding the occurrence and distribution of these most prevalent pesticides-both spatially and temporally - in relation to their use and properties, land use, and hydrologic settings is critical for evaluating the potential significance of pesticides to water quality.

\section{Water}

Twenty-five pesticide compounds, including 24 pesticides and 1 degradate, were each detected more than 10 percent of the time in streams in agricultural, urban, or mixed-land-use settings, or in more than 2 percent of wells in agricultural or urban settings (fig. 4-2). These 25 pesticide compounds include 11 of the herbicides used most heavily in agriculture during the study period (plus the atrazine degradate, deethylatrazine)hereinafter referred to collectively as agricultural herbicides; 7 herbicides used extensively (though not exclusively) for nonagricultural purposesreferred to as urban herbicides; and 6 insecticides used in both agricultural and urban settings, but most intensively in urban settings (fig. 4-3).

The broad patterns of pesticide occurrence in streams generally corresponded to land use and pesticide use. For example, major agricultural herbicides, such as atrazine and metolachlor, were found most often in agricultural settings, whereas herbicides frequently used in urban areas, such as simazine and prometon, were found most often in urban settings. Urban herbicides also were detected in some agricultural areas, either because of agricultural uses (such as for simazine), or their use for nonagricultural weed control (such as for prometon). Insecticides were generally found most often in urban settings where, with the exception of carbofuran, they are used more intensively than in most agricultural settings. Patterns of detection in ground water also generally corresponded with patterns of land use, although not as closely as for streams. For example, atrazine and metolachlor were among the pesticides detected most frequently in both streams and shallow ground water in agricultural areas.

Pesticides were detected least often in streams and shallow ground water in undeveloped areas. The occurrence of atrazine, deethylatrazine, and metolachlor in undeveloped streams was likely caused by one or more of several factors: (1) most undeveloped watersheds include small areas of agricultural or urban land; (2) pesticides are used in many undeveloped areas for a variety of purposes, such as pest control in forest lands or weed control along utility and roadside rights-of-way; and (3) pesticides can be transported in the atmosphere from other areas.

Not surprisingly, the pesticides that were most commonly detected in streams draining watersheds with mixed land use reflected multiple sources from agricultural and urban applications. The overall frequency of pesticide occurrence in mixed-land-use streams was similar to those observed in both agricultural and urban streams. Likewise, the pesticides detected in major aquifers indicate the influences of both agricultural and urban sources, but overall detection frequencies were lower in major aquifers than in shallow ground water in agricultural and urban areas.

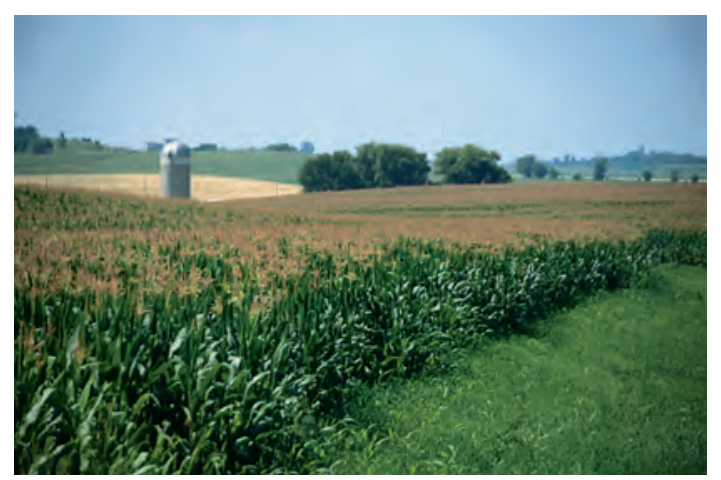

The pesticide detected most frequently in streams and ground water was atrazine, an herbicide used to control weeds in corn fields. 
Pesticides detected most frequently in water
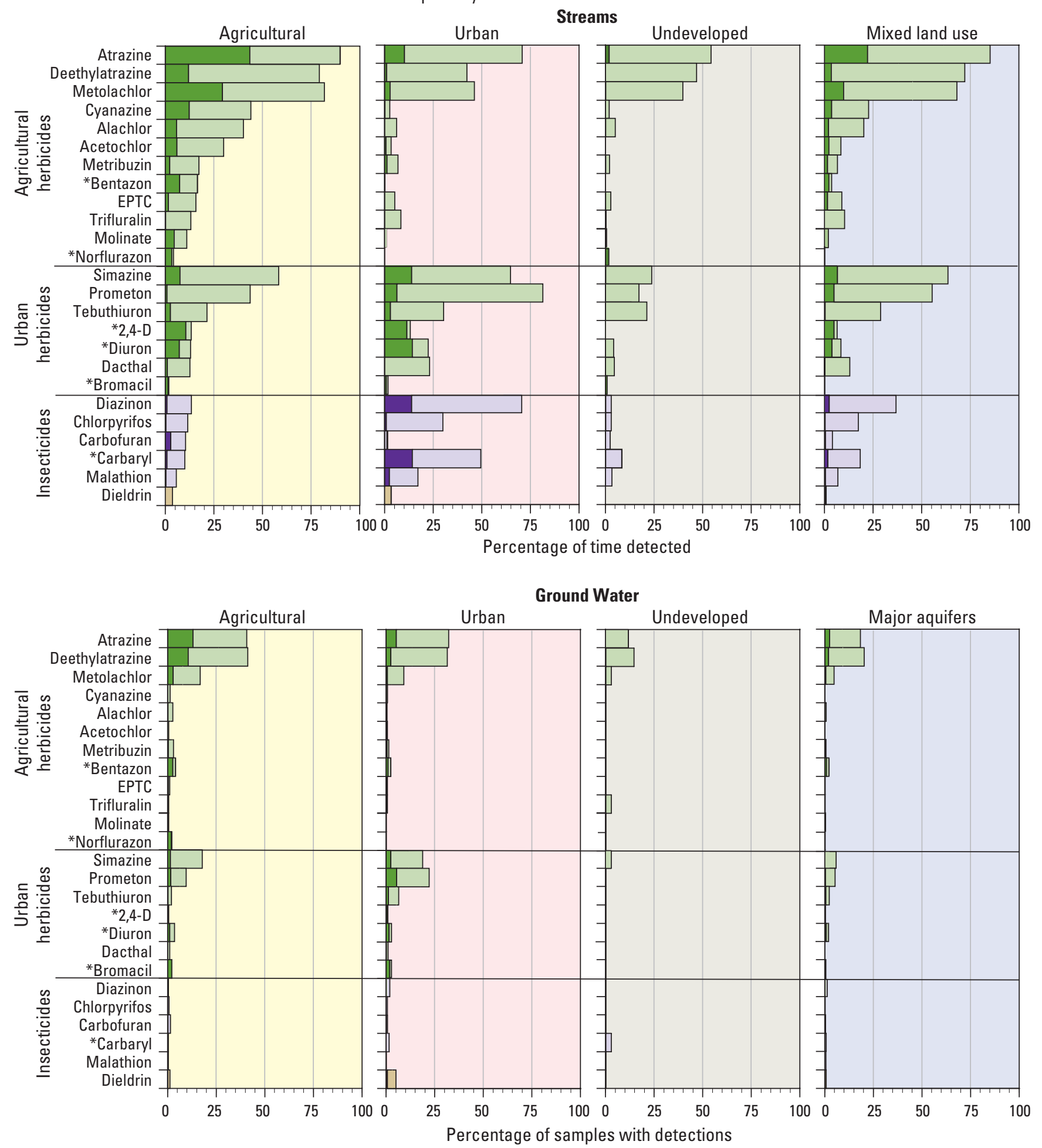

Figure 4-2. Consistent with their patterns of use during the study period, agricultural herbicides—most commonly atrazine (and its degradate deethylatrazine), metolachlor, cyanazine, alachlor, and acetochlor-were detected more frequently in agricultural areas than in urban areas; urban herbicides were found most often in urban areas; and most insecticides, such as diazinon and carbaryl, were detected more frequently in urban streams than in agricultural streams. Two different detection levels are used in this analysis. The dark portion of each bar indicates detections at concentrations greater than or equal to $0.1 \mu \mathrm{g} / \mathrm{L}$, the light portion indicates detections less than $0.1 \mu \mathrm{g} / \mathrm{L}^{*}$, and the end of each bar is the total for all detections.

*The pesticides 2,4-D, bentazon, bromacil, carbaryl, diuron, and norflurazon could not be detected reliably at concentrations less than $0.1 \mu \mathrm{g} / \mathrm{L}$; consequently, the reported frequencies below this level for these compounds are minimum estimates. 


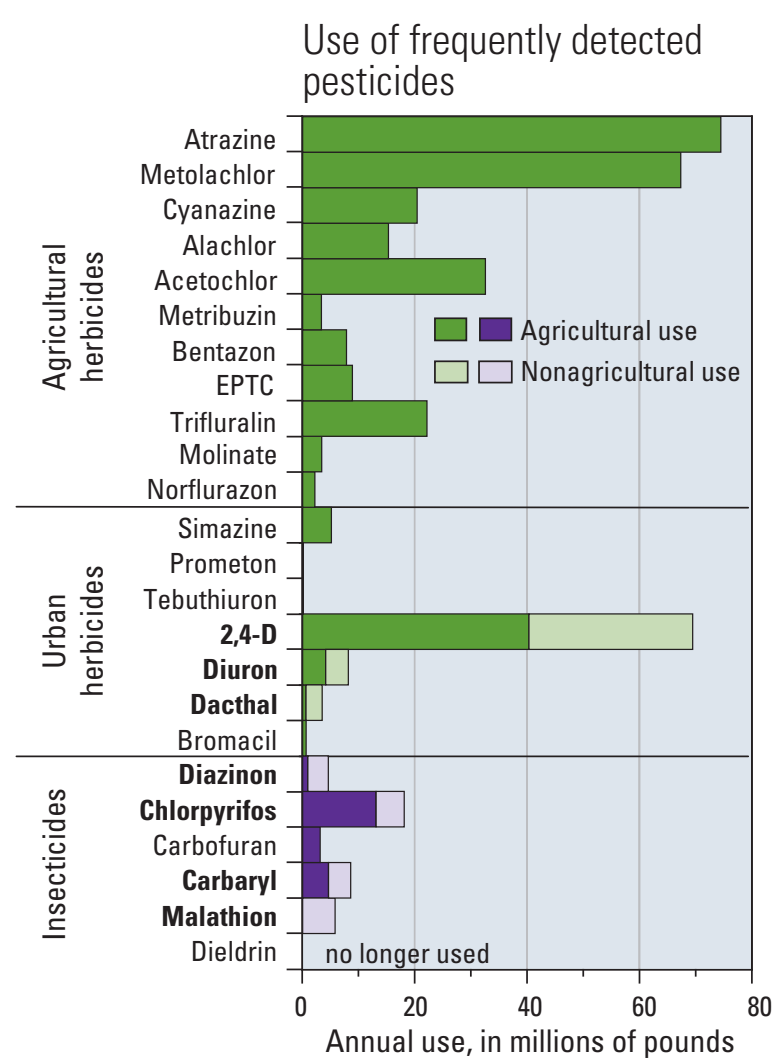

Figure 4-3. The pesticides detected most frequently in water include 11 of the herbicides used most heavily for agriculture during the study period, 7 herbicides used extensively for nonagricultural purposes (mostly in urban areas, but with some agricultural applications), and 6 insecticides. (Agricultural-use estimates are from Gianessi and Marcelli [2000] for 1997; nonagriculturaluse estimates are from Kiely and others [2004] for 1999, but were available only for 2,4-D, carbaryl, chlorpyrifos, dacthal, diazinon, diuron, and malathion-indicated by bold type.)

\section{Understanding the Occurrence Assessment}

The overview described in this chapter serves as a broad first step toward understanding the distribution and importance of pesticides that were detected in streams and ground water. As explained in Chapter 3 , the NAWOA assessment did not include samples from all parts of the Nation or include all pesticides currently used. To provide a national perspective, the occurrence of pesticide compounds in streams and ground water is summarized by land use, environmental medium and component of the hydrologic system sampled, and detection level—all of which have important influences on how results are interpreted.

- Land use-Grouping results by land use follows the NAWQA design by combining data from sites expected to have similar influences of land use on water quality (see Chapter 3 ). Within each general land-use setting, however, there can be substantial variability among sampling sites in specific land-use conditions and pesticide use, as well as hydrologic settings. A pesticide that is common in agricultural streams as a national group, such as a corn herbicide, may never occur in some particular agricultural streams, whereas another pesticide that is uncommon nationally, such as a rice herbicide, may be frequently detected in a few particular streams.

- Media and hydrologic component sampled-Grouping results by the different environmental media that were sampled from streams clearly separates organochlorine compounds-which were derived primarily from past use and which, because of their hydrophobic nature, were assessed by their occurrence in fish tissue and bed sediment-from predominantly water-soluble pesticides, most of which were in use during the study period and were measured in water. Grouping results by hydrologic component further distinguishes between streams and ground water for analysis of pesticides in water. The occurrence and concentration results for stream water, unless noted otherwise, were evaluated on a timeweighted basis for each site to eliminate biases caused by more frequent sampling during high-use seasons. Ground-water results are based on one sample per well, and bed-sediment and fishtissue results are based on one composite sample per site.

- Detection level-Analyses of pesticide occurrence in this chapter are based on two different detection levels: (1) detection at any concentration - as low as $0.001 \mu \mathrm{g} / \mathrm{L}$ in water-referred to as total detection frequency, and (2) detections greater than or equal to a common detection level for all compounds in a particular medium$0.1 \mu \mathrm{g} / \mathrm{L}$ for water, 5 micrograms per kilogram $(\mu \mathrm{g} / \mathrm{kg})$ wet weight for fish tissue, and $2 \mu \mathrm{g} / \mathrm{kg}$ dry weight for bed sediment. Two detection levels are necessary for certain data analyses because variations in analytical sensitivity result in differences in minimum detectable concentrations among different compounds. Consequently, direct comparisons of detection frequencies among compounds should be based on a common detection level. For example, of the 25 pesticide compounds most frequently detected in water, 2,4-D, bentazon, bromacil, carbaryl, diuron, and norflurazon could not be reliably detected at concentrations less than about $0.1 \mu \mathrm{g} / \mathrm{L}$, whereas the other 19 compounds were detectable at levels substantially less than $0.1 \mu \mathrm{g} / \mathrm{L}$. The reported total detection frequencies of the 6 less-detectable pesticides are thus underestimates of occurrence compared with the total frequencies for the other 19 compounds. Variations in detection sensitivity must be carefully considered when interpreting data on occurrence-the absence of detections does not indicate with certainty that pesticides are not present. 


\section{Fish Tissue and Bed Sediment}

Thirteen organochlorine pesticide compounds, including historically used parent pesticides and their degradates and by-products, were each found in more than 10 percent of fish or bed-sediment samples from streams draining watersheds with either agricultural, urban, or mixed land use. Figure 4-4 summarizes findings for these 13 compounds, as well as for 2 additional compounds derived from DDT use$o, p^{\prime}$-DDT and its degradate, $o, p^{\prime}$-DDE, which were detected less frequently than the others. The fish and bed-sediment data for organochlorine compounds provide complementary types of information for understanding the presence of these compounds in streams.

The 15 organochlorine pesticide compounds included in figure 4-4 are derived from 8 parent pesticides. The parent pesticides applied were the insecticides DDT, DDD (also known as TDE), dieldrin, aldrin, chlordane, and heptachlor-each of which had all agricultural and nonagricultural uses cancelled by 1988 or earlier, and the fungicides hexachlorobenzene and pentachlorophenol-most uses of which were discontinued by the mid 1980s or before. DDT and chlordane were applied as technical mixtures containing the parent pesticides and other compounds. For example, technical DDT was typically composed

\section{Organochlorine compounds detected most frequently}
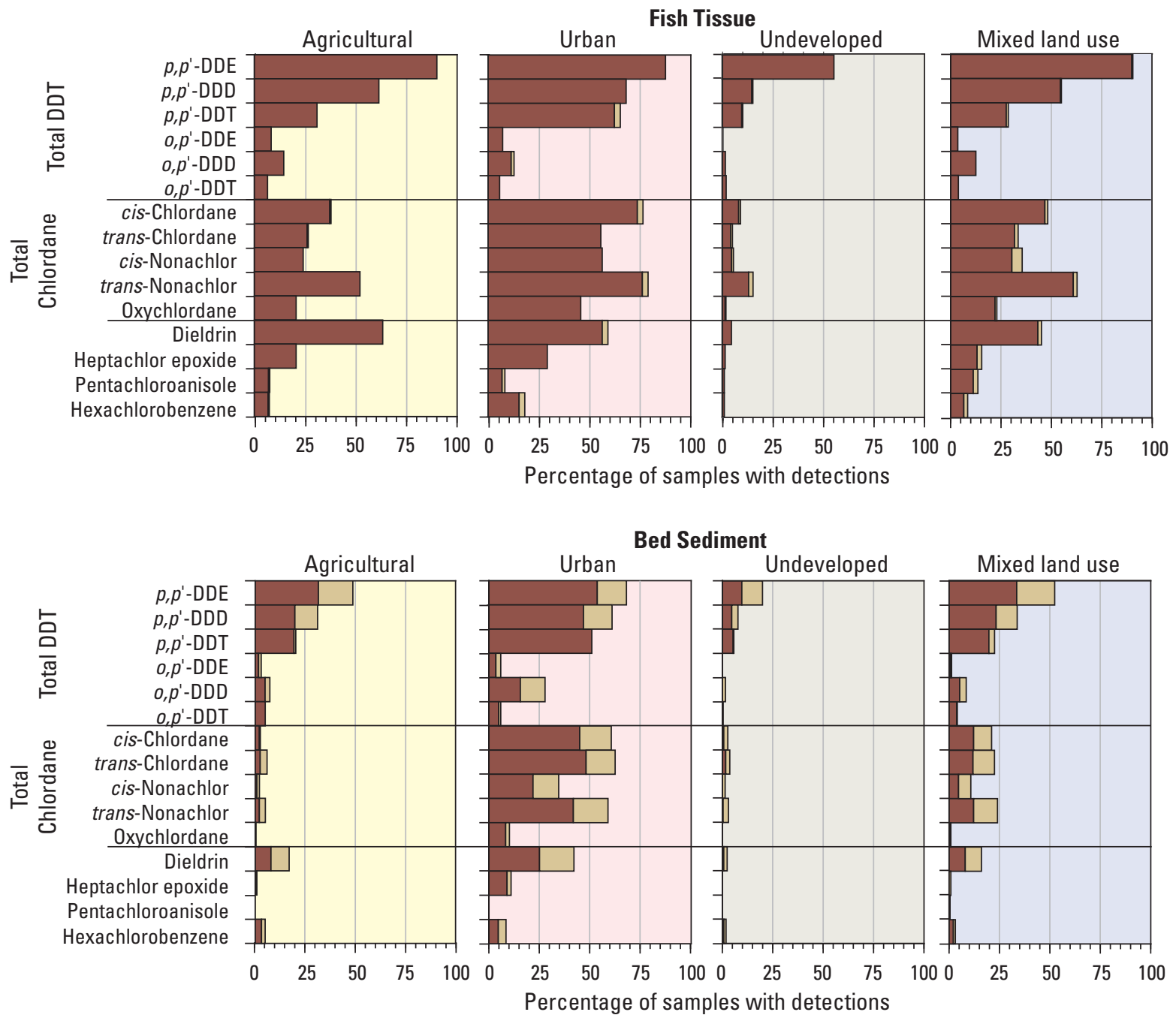

Figure 4-4. Historically used organochlorine pesticides and their degradates were generally detected more frequently in whole fish and bed sediment in urban streams than in agricultural streams, thus matching the pattern found for currently used insecticides in water. DDT and chlordane compounds, as well as dieldrin, were relatively widespread. The dark portion of each bar indicates detections at concentrations greater than or equal to $5 \mu \mathrm{g} / \mathrm{kg}$ (wet weight) for fish tissue and $2 \mu \mathrm{g} / \mathrm{kg}$ (dry weight) for bed sediment, the light portion indicates detections at concentrations less than these levels, and the end of each bar is the total for all detections. 
of about 80 percent $p, p^{\prime}$-DDT (the active ingredient) and 20 percent $o, p^{\prime}$-DDT ( $o, p^{\prime}$ and $p, p^{\prime}$ indicate different isomers of DDT). Furthermore, in addition to being applied as pesticides, DDD and dieldrin are also formed in the environment from the transformation of DDT and aldrin, respectively. Dieldrin that originated from the application of aldrin could not be distinguished from dieldrin applied as dieldrin. Thus, for the purposes of certain data analyses, parent pesticide compounds were grouped together with their corresponding degradates and by-products, reflecting their common or indistinguishable origins.

Six compounds were analyzed in the DDT group (the $p, p^{\prime}$ and $o, p^{\prime}$ isomers of DDT, DDE, and DDD). The sum of the concentrations of these compounds is referred to as the total DDT concentration. Five compounds were analyzed in the chlordane group, with total chlordane concentration calculated as the sum of concentrations of the cis and trans isomers of chlordane and nonachlor, plus the chlordane degradate oxychlordane. Additional individual compounds frequently found in streams included dieldrin; pentachloroanisole, a degradate of pentachlorophenol; heptachlor epoxide, a degradate of heptachlor; and hexachlorobenzene. Historically, DDT, DDD, aldrin, and dieldrin were used widely in both agricultural and urban areas, whereas chlordane use for urban applications was greater than its agricultural use. As shown in figure 4-5, the agricultural uses of DDT plus DDD, and of dieldrin plus aldrin, were higher than the uses of heptachlor and chlordane. Most organochlorine insecticides had their agricultural uses discontinued in the 1970s, whereas some urban applications (including termite control) were permitted until the late 1980s.

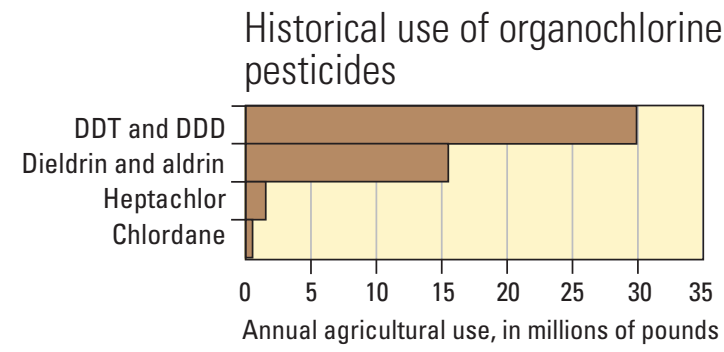

Figure 4-5. In 1966, the agricultural uses of DDT plus DDD (mostly as DDT), and of dieldrin plus aldrin (mostly as aldrin), were greater than the presentday agricultural use of any individual insecticide. Heptachlor and chlordane had much lower agricultural use. (Use estimates are from Eichers and others, 1970.)
Results for fish tissue and bed sediment show generally similar patterns of detection among the organochlorine pesticide compounds (fig. 4-4), but detections were more frequent in fish tissue because these compounds typically accumulate to higher concentrations in biological tissues (wet-weight concentrations) than in sediment (dry-weight concentrations). Patterns of occurrence of organochlorine compounds in fish and bed sediment generally match the patterns in relation to land use that are evident for currently used insecticides in water. Frequencies of detection were higher for most organochlorine pesticide compounds in urban streams than in agricultural streams. The most frequently detected compounds were those composing the DDT group, the chlordane group, and dieldrin.

Streams with undeveloped watersheds had the lowest frequencies of detection of organochlorine compounds in either fish or bed sediment, yet more than half of the fish-tissue samples from these streams had detectable levels of $p, p^{\prime}$-DDE, a principal degradate of DDT. The frequent presence of $p, p^{\prime}$-DDE in fish from undeveloped streams may be explained by factors similar to those believed to result in the presence of currently used pesticides in water from undeveloped streams: (1) past use in small areas of developed land within their watersheds, (2) past use for control of insects in undeveloped areas (such as for forest management), and (3) atmospheric transport from other areas.

Fish and bed sediment from streams draining watersheds with mixed land use had frequencies of detection of DDT, dieldrin, and chlordane that generally reflected a mixture of agricultural and urban influences, and were higher than in undeveloped streams (fig. 4-4). 


\section{Influence of Land Use}

The preceding overviews of detection frequencies clearly show that pesticide occurrence in streams and ground water is strongly influenced by land use and associated pesticide use. These relations are explored in more detail below, focusing on the occurrence of some of the pesticides that were detected most frequently in agricultural and urban settings.

\section{Agricultural Areas}

The pesticides detected most often in water from agricultural streams (fig. 4-2) were among the agricultural herbicides used most heavily during the study period (figs. 4-3 and 3-5). The top five, from highest to lowest frequency of detection at concentrations at or above $0.1 \mu \mathrm{g} / \mathrm{L}$, were atrazine (ranked 1st in national agricultural use; deethylatrazine was also frequently detected), metolachlor (2nd in use), cyanazine (8th in use), 2,4-D (3rd in use), and simazine (18th in use). Prometon was detected frequently at low levels (rarely at concentrations greater than $0.1 \mu \mathrm{g} / \mathrm{L}$ ) and ranked only behind atrazine, metolachlor, simazine, and cyanazine in total detection frequency. Prometon is not registered for use on crops, but is used for weed control around fences, buildings, and roads within agricultural areas.

As with streams, the pesticides most commonly found in shallow ground water within agricultural areas were atrazine (and deethylatrazine) and metolachlor, the two herbicides used most heavily for agriculture during the study period. Although atrazine and metolachlor had about the same total use, atrazine and deethylatrazine were found in ground water more than twice as often as metolachlor, probably because atrazine is considerably more persistent than metolachlor (as discussed in more detail later in this chapter). Deethylatrazine was detected in ground water about as frequently as atrazine, whereas in streams it was found less often than atrazine and usually at lower levels. The greater proportional occurrence of deethylatrazine in ground water reflects the greater opportunity for atrazine degradation over the longer periods of time that water in the subsurface spends in contact with microbes, especially in the soil zone (as discussed further in Chapter 5). Cyanazine, alachlor, and acetochlor-which are used on corn and other crops, but in less than half the amounts of atrazine and metolachlor-were seldom detected in ground water, most likely because of their lower use and relatively low persistence (Appendix 2). In contrast, simazine and prometon were among the pesticides found most often in ground water, despite even lower agricultural use than cyanazine, alachlor, or acetochlor. Simazine and prometon are more persistent in soil than these other herbicides, and thus have greater opportunities for transport to ground water.

Currently used insecticides were found less frequently than herbicides in most agricultural streams and were rarely found in ground water. This finding results from their relatively low application rates in most agricultural settings, compared with herbicides (fig. 3-5), and their generally lower mobility and persistence in the environment (Appendix 2). The insecticide used most heavily for agricultural purposes during the study period was chlorpyrifos. Yet, annual use of chlorpyrifos was only about 20 percent that of atrazine use, and chlorpyrifos is also less mobile in the hydrologic system. Although the annual agricultural use of each of the other four major insecticides examined-diazinon, carbofuran, carbaryl, and malathion - was less than half that of chlorpyrifos during the study period, the total detection frequencies of all five insecticides in agricultural streams were notably similar.

Historically used organochlorine pesticides and their degradates and by-products remained a common occurrence in fish and bed sediment in agricultural streams, although most were detected less frequently in samples from agricultural streams than from urban streams-especially in sediment (fig. 4-4). The compounds found most commonly in agricultural streams were those in the DDT group, followed by dieldrin and the chlordane group. Relative frequencies of detection corresponded to their rankings of historical use in agriculture (fig. 4-5). The frequency of occurrence of compounds in the chlordane group in agricultural streams was higher than expected from its low historical agricultural use compared with DDT plus DDD and dieldrin plus aldrinpossibly because of extensive nonagricultural applications in agricultural areas (such as termite control). In addition, chlordane was a minor component (10-20 percent) of technical-grade heptachlor, which was also used extensively both in agriculture and as a termiticide (IARC, 2001).

Although these broad patterns in pesticide occurrence across all agricultural areas that were sampled provide a useful national perspective, the aggregated results obscure many substantial differences among different agricultural settings in the types and levels of pesticides that were detected. The many diverse agricultural settings 
of the United States that were sampled-each with its own unique combination of climate, crops, and pests-have distinctive patterns in pesticide use that resulted in different patterns of pesticide occurrence. These patterns of occurrence are complex because of the wide ranges of different use practices, pesticide properties, and hydrologic processes that govern the sources, movement, and persistence of pesticides in streams and ground water.

Comparisons of patterns in pesticide occurrence among three of the Nation's major cropgroup settings illustrate the variability among settings. Classification of the Nation's agricultural areas for the NAWQA water-quality studies identified 21 major crop-group settings of varying areal extent (Gilliom and Thelin, 1997). This classification is based on combinations of one to three crops that account for most of the harvested acreage in each of the Nation's counties. Three crop-group settings were selected as examples for comparison in this report: "corn and soybeans," "wheat and alfalfa," and "rice." Each crop-group setting has a different geographic distribution and extent (fig. 4-6). Other crops are also present to varying degrees in each of the three settings; thus, the estimated use of a pesticide in a particular crop setting may also include its estimated use for other crops in the same area.

Estimates of pesticide use intensity, expressed as an annual average rate of application on all cropland in each crop-group setting, show clear differences between the settings (fig. 4-7). Overall rates of use were highest in the corn-and-soybeans setting and lowest in the wheatand-alfalfa setting. Use in each setting is dominated by the particular herbicides and insecticides needed to control the pests specific to the crops grown in that setting. For example, atrazine and metolachlor dominated herbicide use in the corn-and-soybeans setting; 2,4-D was the top herbicide used in the wheat-and-alfalfa setting

\section{Distribution of study sites by crop setting}

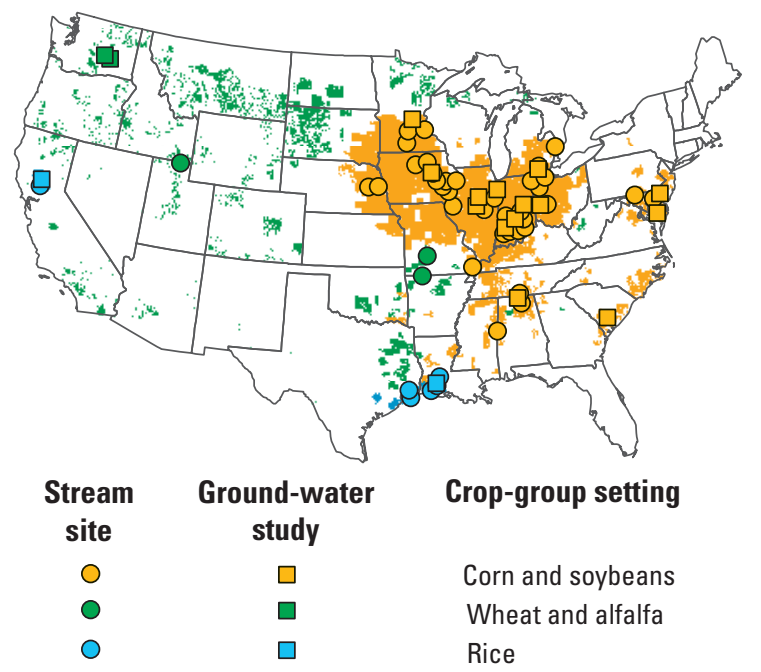

Figure 4-6. The distributions of crop-group settings and study sites for the corn-and-soybeans, wheat-andalfalfa, and rice crop groups show distinct differences in the locations and extent of the three agricultural settings. (Crop groups are from Gilliom and Thelin, 1997.)

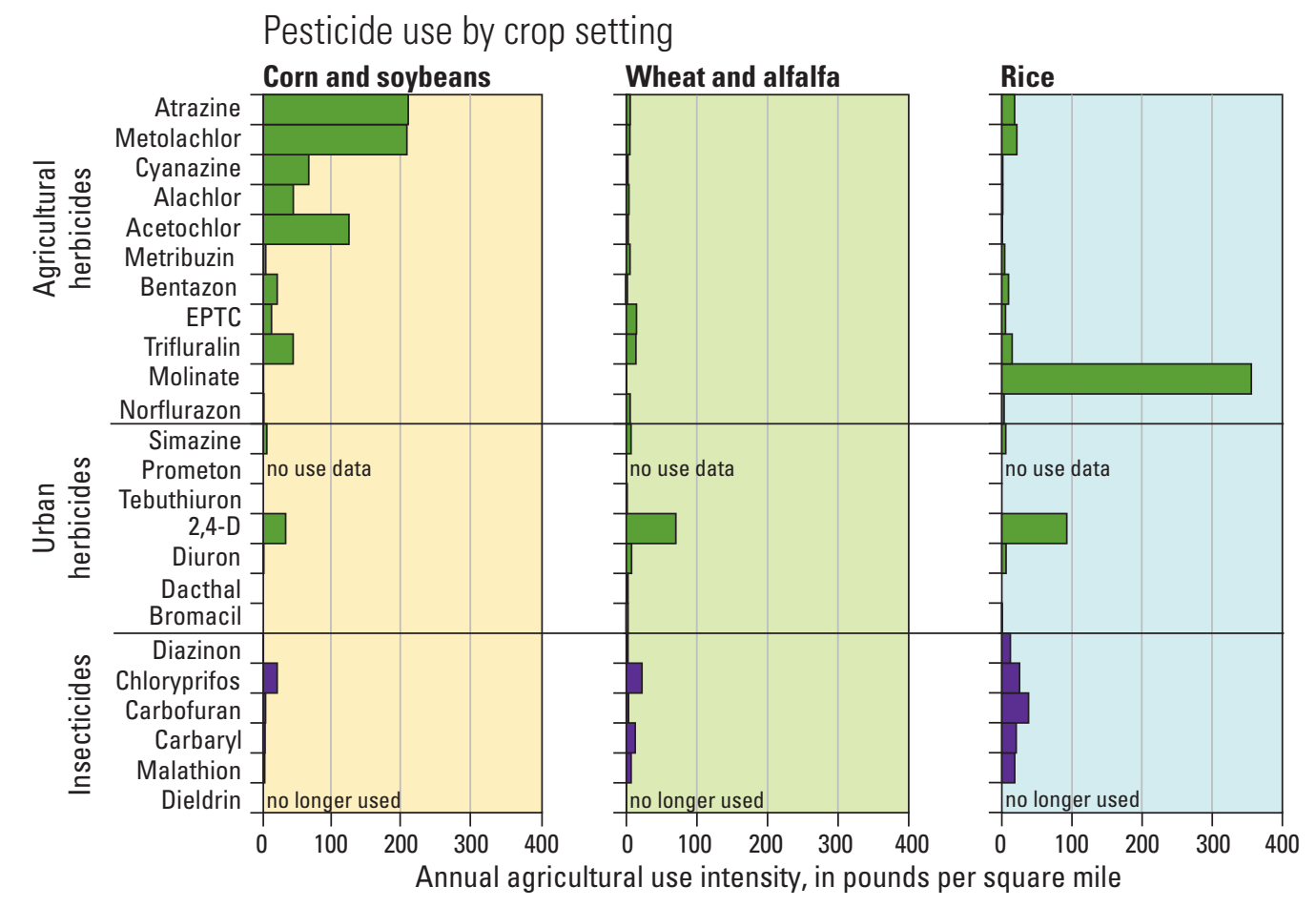

Figure 4-7. Different pesticides dominated use in each of the crop-group settings, as illustrated by the estimated 1997 agricultural use. The herbicides atrazine, metolachlor, acetochlor, and cyanazine were the most intensively used pesticides in the corn-and-soybeans setting; molinate, 2,4-D, and several insecticides were most intensively used in the rice setting; and 2,4-D and chlorpyrifos were the most intensively used pesticides in the wheat-and-alfalfa setting, where overall use was least. 
(but at less than half the intensity of atrazine and metolachlor use in the corn-and-soybeans setting); and molinate was the top herbicide used in the rice setting (with use intensity that was 70 percent greater than that of either atrazine or metolachlor in the corn-and-soybeans setting).

The occurrence of pesticides in streams and ground water within these three crop settings (fig. 4-8) corresponded to the estimated agricultural-use patterns in many respects (fig. 4-7), but also showed some unexpected results, as summarized below. These examples of results for specific crop-group settings illustrate both the degree of predictability and the complexity of pesticide occurrence and transport in the hydrologic system. Each crop setting has unique characteristics, and each specific study area within a crop setting is unique as well, resulting in variability within crop-group settings as well as among them. Nonetheless, organizing the assessment of pesticides by crop-group setting can help to link the occurrence of pesticides in streams and ground water with specific management practices and can provide the foundation for customizing pesticide management to individual settings.

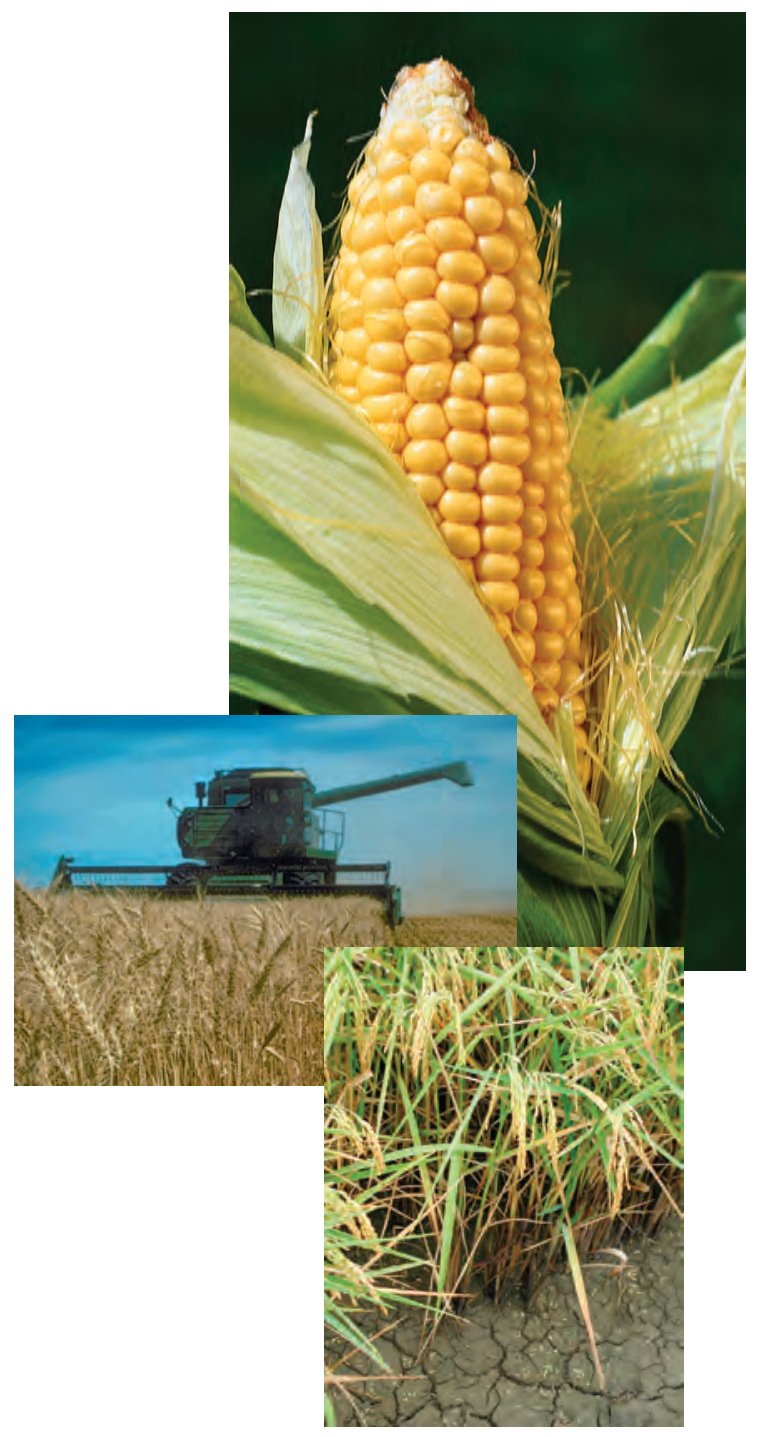

Photographs by Don Brennemen, University of Minnesota Agricultural Extension Service (middle), and (C) 2003 Corbis (top).

\section{Expected results:}

- Corn and soybeans - The two herbicides used most heavily for corn and soybeans - atrazine and metolachlor-were those detected most frequently in streams and ground water. In addition, deethylatrazine was detected at about the same frequency as atrazine in both streams and ground water within this setting. Chlorpyrifos was both the most frequently detected and the most heavily used insecticide.

- Wheat and alfalfa-Overall detection frequencies were low in the wheatand-alfalfa setting, consistent with relatively low pesticide use. The herbicide used most heavily in the wheat-and-alfalfa setting, 2,4-D, was one of the most frequently detected pesticides in streams at concentrations at or above $0.1 \mu \mathrm{g} / \mathrm{L}$.

- Rice-Molinate, the herbicide used most heavily on rice, was among those detected most frequently in streams. Detections of molinate were far more frequent in the rice setting than in the other agricultural settings. The insecticide used most intensively on rice, carbofuran, was the one detected most frequently at or above $0.1 \mu \mathrm{g} / \mathrm{L}$ in both streams and ground water. Carbofuran and the other four insecticides used mostly in the rice setting were detected more frequently in the rice setting than in the other two crop-group settings, where their use was less intensive.

\section{Unexpected results:}

- Corn and soybeans-Simazine and prometon were found more frequently than was expected from their low agricultural use, indicating relatively substantial use of these herbicides for noncrop purposes within agricultural areas (although most concentrations were low).

- Wheat and alfalfa-Atrazine and prometon were the herbicides detected most frequently in streams and ground water, despite little (atrazine) or no (prometon) agricultural use on either wheat or alfalfa (although most concentrations were low).

- Rice-Low-use pesticides, including atrazine (and deethylatrazine), metolachlor, and tebuthiuron, were frequently detected, probably because of noncrop uses within this setting. Bentazon was frequently detected in streams and particularly in ground water. Bentazon was detected most frequently in the rice-growing area of California, where it was used heavily until it was banned in 1989. 
Patterns of detections in water by crop setting

Streams

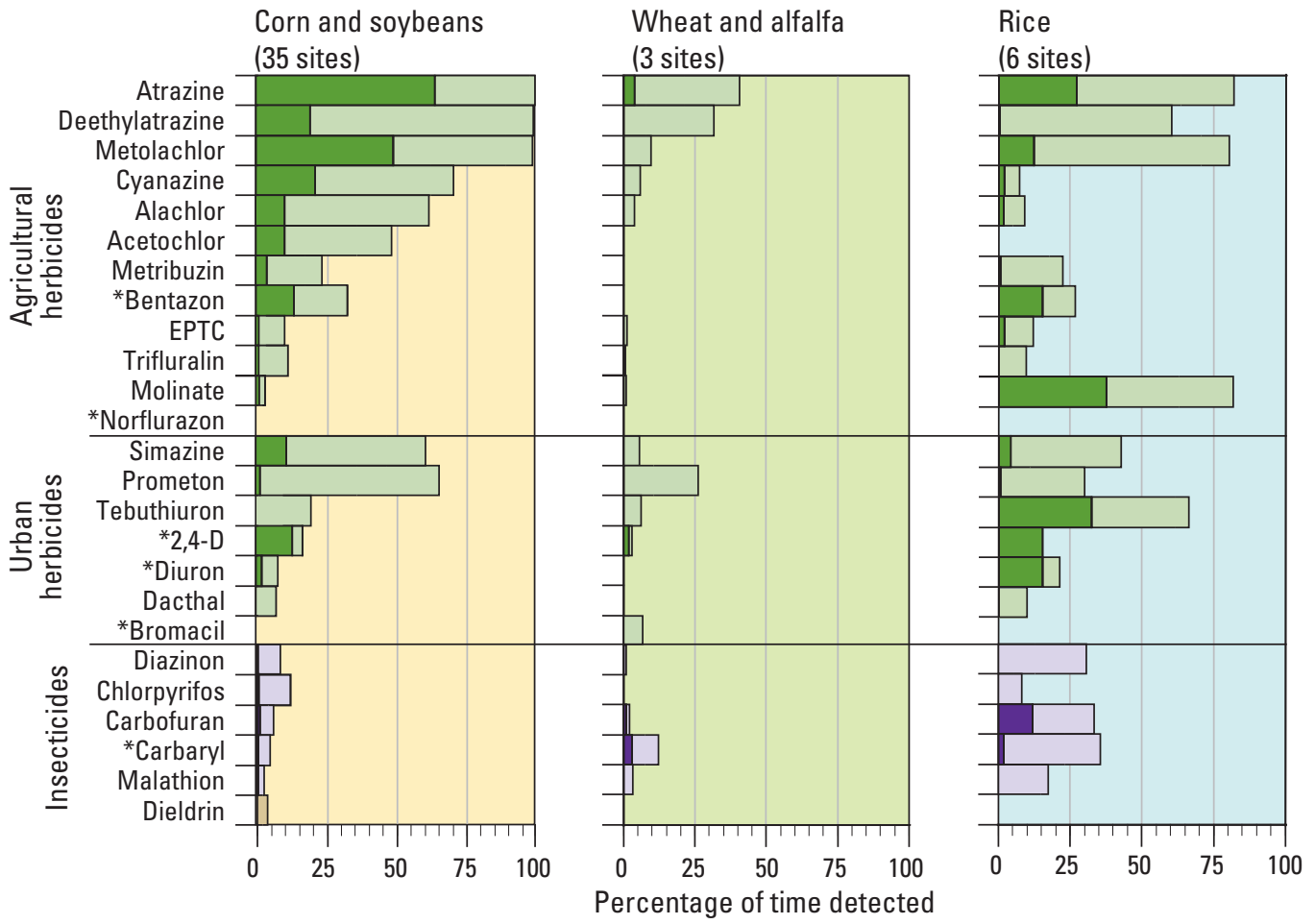

Percentage of time detected

Ground Water

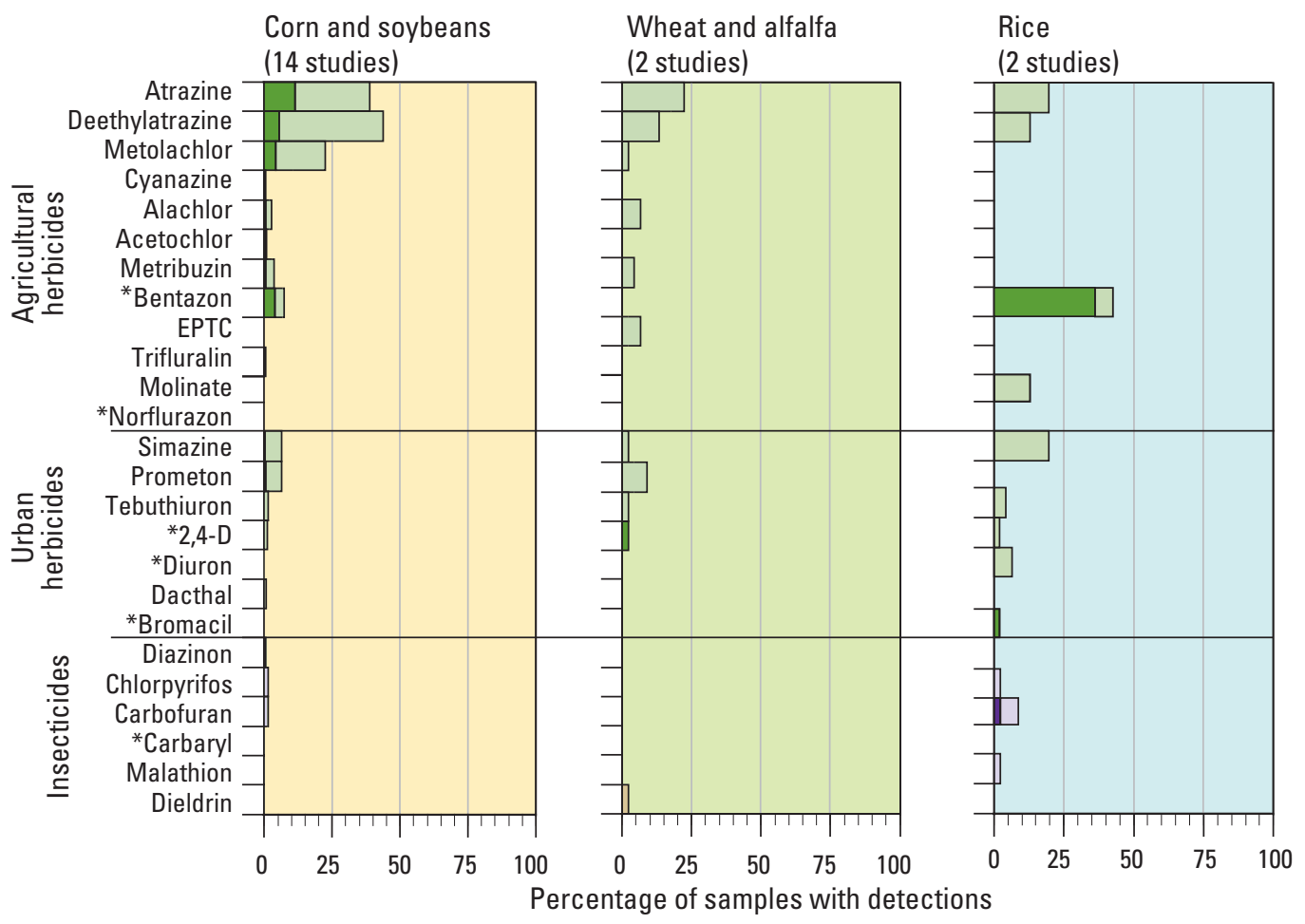

Figure 4-8. The occurrence of pesticides in streams and ground water sampled within the corn-and-soybeans, wheat-and-alfalfa, and rice crop-group settings corresponded to the patterns of estimated agricultural use in many respects (see fig. 4-7), but nonagricultural uses also influence occurrence. The dark portion of each bar indicates detections at concentrations greater than or equal to $0.1 \mu \mathrm{g} / \mathrm{L}$, the light portion indicates detections less than $0.1 \mu \mathrm{g} / \mathrm{L}^{*}$, and the end of each bar is the total for all detections (see sidebar on p. 45.)

*The pesticides 2,4-D, bentazon, bromacil, carbaryl, diuron, and norflurazon could not be detected reliably at concentrations less than $0.1 \mu \mathrm{g} / \mathrm{L}$, and the reported frequencies below this level for these compounds are minimum estimates. 


\section{Urban Areas}

The most distinct differences between pesticides found in urban and agricultural areas were the more frequent detections and higher concentrations of insecticides in urban streams, and the frequent detections of urban herbicides in streams and shallow ground water sampled in urban areas.

Diazinon, chlorpyrifos, carbaryl, and malathion, which nationally ranked $2 \mathrm{nd}$, 4 th, 8 th, and 15 th among pesticides in frequencies of outdoor applications for home-and-garden use at the beginning of the study period (Whitmore and others, 1992), accounted for most detections of insecticides in urban streams (fig. 4-2). Diazinon and carbaryl were by far the most frequently detected and were found at frequencies and levels comparable to those for the common herbicides. The use of diazinon and chlorpyrifos has been substantially curtailed since the end of the study period, and analysis of recent data for diazinon (Chapter 8) shows that concentrations in some streams have now declined as well. Historically used insecticides also were found most frequently in fish and bed sediment from urban streams, which had among the highest detection frequencies for chlordane compounds, DDT compounds, and dieldrin (fig. 4-4). Urban streams also had the highest concentrations of total chlordane and dieldrin in both sediment and fish tissue. Chlordane and aldrin were widely used for termite control until the mid-to-late 1980s, although their agricultural uses were restricted during the 1970s.
Insecticides were seldom detected in ground water beneath urban areas (fig. 4-2). The most commonly detected insecticide in shallow ground water in urban areas, however, was dieldrin, which was found in about 5 percent of the wells sampled. Although dieldrin is not very mobile in water, its environmental persistence and the extensive historical use of dieldrin and aldrin have apparently combined to yield detectable concentrations in some wells 5 to 15 years after all uses of dieldrin and aldrin were discontinued.

The most frequently detected herbicides in streams and shallow ground water in urban areas were atrazine (and deethylatrazine), simazine, prometon, and metolachlor, although metolachlor was seldom detected in ground water-probably because of its lower urban use and lower persistence compared with the other herbicides. Considering only detections at or above $0.1 \mu \mathrm{g} / \mathrm{L}$, however, the herbicides detected most frequently in urban streams were diuron (14 percent of the time), simazine (14 percent), 2,4-D (11 percent), and atrazine (10 percent).

The herbicides found more often in urban areas than in most agricultural areas-considering detections at all concentrations-were simazine, prometon, diuron, 2,4-D, tebuthiuron, and dacthal. The use of 2,4-D and prometon ranked 1 st and 14th among herbicides in frequency of outdoor home-and-garden applications at the beginning of the study period (Whitmore and others, 1992). Although 2,4-D, simazine, and diuron also ranked 3rd, 18th, and 23rd among herbicides in national use for agriculture, no agricultural use was reported for prometon or tebuthiuron.
Pesticides are used extensively in residential areas and associated recreational and commercial areas, including golf courses.

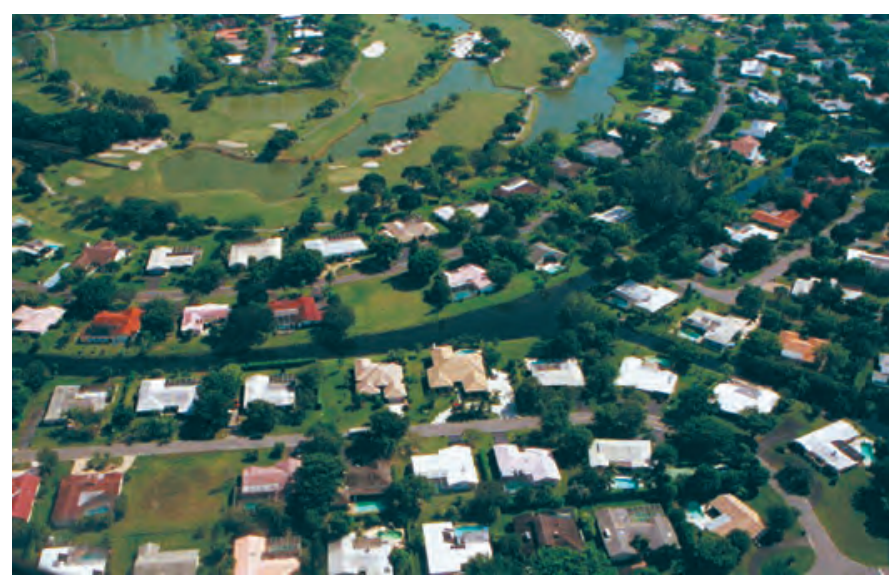




\section{Geographic Distribution}

The geographic distribution of each pesticide in streams and ground water is governed by the intensity and distribution of its use, its chemical and physical properties, and the characteristics of the hydrologic system. The interactions among these factors are illustrated by comparing the findings for several different pesticides in relation to their uses and proper- ties. Results for five pairs of the most frequently detected pesticides are presented—atrazine and metolachlor; simazine and prometon; acetochlor and 2,4-D; diazinon and chlorpyrifos; and total DDT and dieldrin-representing a wide range of use patterns and properties (figs. 4-9 to 4-16). These comparative stories provide insights about some of the most important pesticides, while also illustrating the types and magnitudes of influences that affect all pesticides.

\section{Methods and Statistics for Assessing Geographic Distributions of Pesticides}

Consistent measures and scales are used to represent concentration levels appropriate to each medium in the comparisons of geographic distributions among pesticides (figs. 4-9 to 4-16):

- For pesticides in stream water, maps in this chapter are based on the time-weighted 95th-percentile concentration at each site for the selected year of data, which is the concentration exceeded about 5 percent of the time, or about 18 days per year (generally not consecutive). Use of the 95th percentile for comparisons reduces the influence of different detection levels among compounds because it is usually higher than the lowest detectable concentration.

- For pesticides in ground water, maps in this chapter are based on the frequency of detections at or above $0.01 \mu \mathrm{g} / \mathrm{L}$ within each study area. Evaluation of each of the pesticides using only detections at or above the detection level of $0.01 \mu \mathrm{g} / \mathrm{L}$ yields results that are directly comparable among all pesticides mapped for ground water. Symbols representing ground-water studies are shown at the centroid of each study area.

- For total DDT and dieldrin in streams, data for bed sediment are used because fish were not collected in all parts of the country. One composite bed-sediment sample was collected at each site-maps are based on the concentration in each individual sample.

- For all maps, the distribution of agricultural use for each pesticide is shown by a consistent set of categories of 1997 use intensity — or historical use intensity for total DDT and dieldrin—so that maps can be directly compared among the 10 pesticides. Use was estimated for 1997 by combining the 1997 state-level use data reported by Gianessi and Marcelli (2000) with county crop acreages from the 1997 Census of Agriculture (U.S. Department of Agriculture, 1999), using methods described by Thelin and Gianessi (2000). Use intensity was mapped for agricultural land using land-cover data from the early 1990s (Vogelmann and others, 2001) as described by Nakagaki and Wolock (2005). Historical use of DDT (including DDD) and dieldrin (including aldrin) was estimated by a similar approach, but using regional use estimates for 1966 (Eichers and others, 1970) and 1971 (Andrilenas, 1974), and the 1964 and 1969 Censuses of Agriculture for crop distributions (Nowell and others, 2006). Use intensity was mapped for agricultural land using land-cover data from the mid-1970s (Fegeas and others, 1983).

- Chemical and physical properties that help explain observed patterns were introduced in Chapter 2 and are tabulated in Appendix 2. The properties emphasized are environmental persistence (soil halflife) and mobility in water (represented by the soil organic carbon-water partition coefficient, or $\mathrm{K}_{\text {oc }}$. The higher the $\mathrm{K}_{\mathrm{oc}}$ value, the greater the affinity of the compound for soil organic matter, suspended particles, and bed sediment-and, thus, a lower tendency to be transported in water. 


\section{Atrazine and Metolachlor-}

The two most heavily used herbicides occurred at similar levels in streams, but atrazine was more prevalent than metolachlor in ground water, probably because of its greater persistence.

Atrazine and metolachlor were the two most heavily used herbicides in the United States during the 1990s. Most of their agricultural use was associated with corn production - about 85 percent of 75 million $1 \mathrm{~b} / \mathrm{yr}$ for atrazine and 75 percent of 67 million lb/yr for metolachlor (fig. 4-3). Both herbicides also have relatively low and poorly quantified nonagricultural useatrazine is estimated at less than 1 million $\mathrm{lb} / \mathrm{yr}$ (USEPA, 2003a). Uses of metolachlor include turf, nurseries, fence rows, and landscaping, and uses of atrazine include conifer forestry, Christmas tree farms, sod, golf courses, and residential lawns (particularly in the South). Both atrazine and metolachlor are highly soluble and mobile in water, but atrazine is more persistent than metolachlor, with a soil half-life of 146 days, compared with 26 days for metolachlor (Appendix 2).

Concentrations of both atrazine and metolachlor in agricultural streams closely matched the geographic distribution of corn cultivation, where applications are greatest (fig. 4-9). Both atrazine and metolachlor were also frequently detected in urban streams, but at substantially lower concentrations compared with agricultural streams in high-use areas, except in parts of the South where atrazine is used on turf grasses. Concentrations in streams draining watersheds with mixed land use most closely resembled those in agricultural streams, in large part because many of these streams have watersheds with relatively high proportions of agricultural land.

In contrast to their similarity in streams, patterns of atrazine and metolachlor were different from each other in ground water (fig. 4-10). Metolachlor was detected less frequently than atrazine, regardless of land use or depth of ground water. This difference probably occurs because metolachlor transforms more quickly in soil than does atrazine. Metolachlor, therefore, is less likely to be transported to ground water, although the opposite may be true for some of its degradates that appear to be more persistent than the parent compound (Kalkhoff and others, 1998). Neither metolachlor nor atrazine was detected at the highest frequencies ( $>25$ percent) in ground water underlying large areas of Illinois, Indiana, and Ohio, despite their high use in this region. This distinct regional pattern, which has been noted by several previous studies (Hallberg, 1989; Burkart and Kolpin, 1993; Baker and others, 1994), is most likely a consequence of the widespread use of subsurface drainage systems in this area (which move shallow ground water rapidly to streams and reduce transport to deeper ground water), as well as the presence of lowpermeability glacial till.

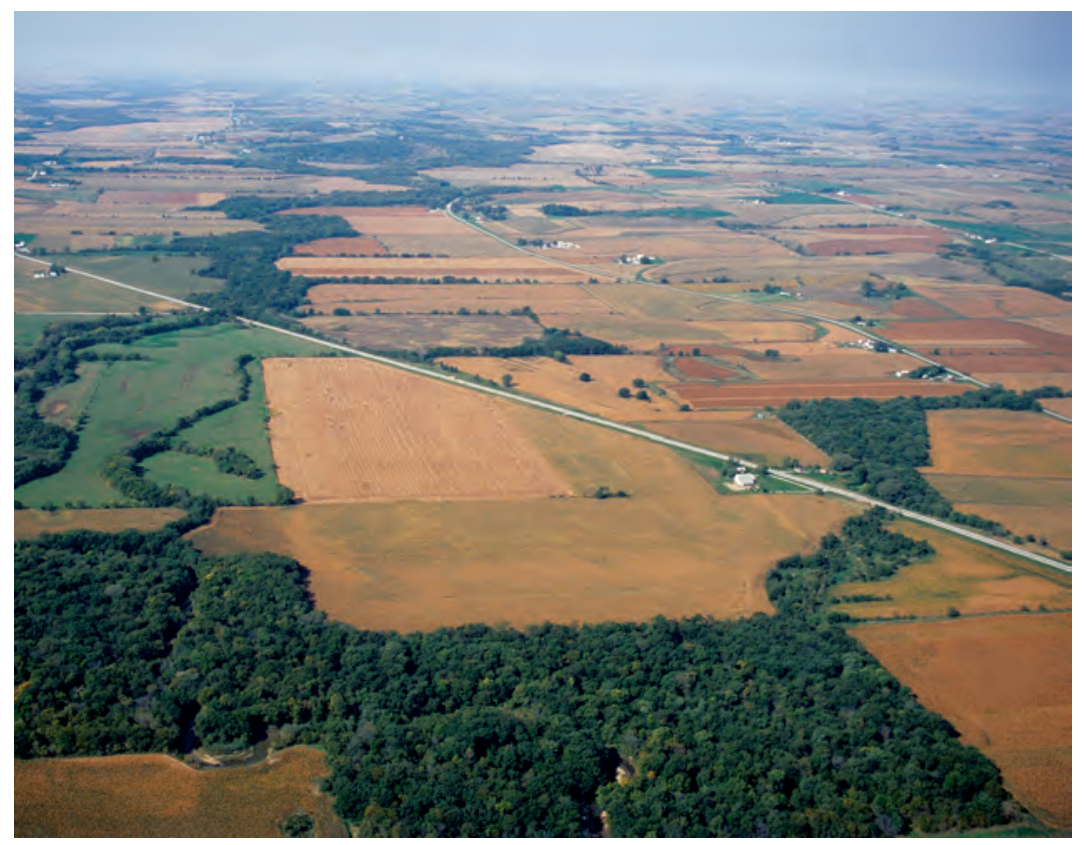




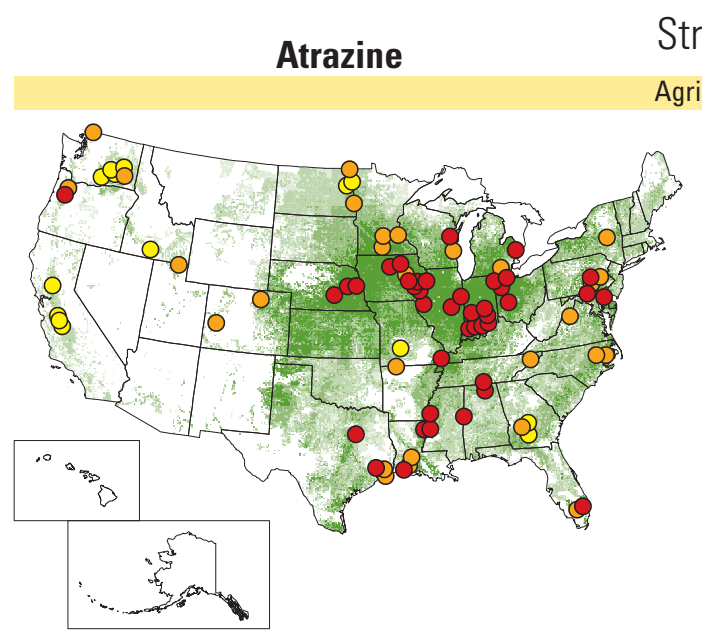

Streams Metolachlor

Agricultural
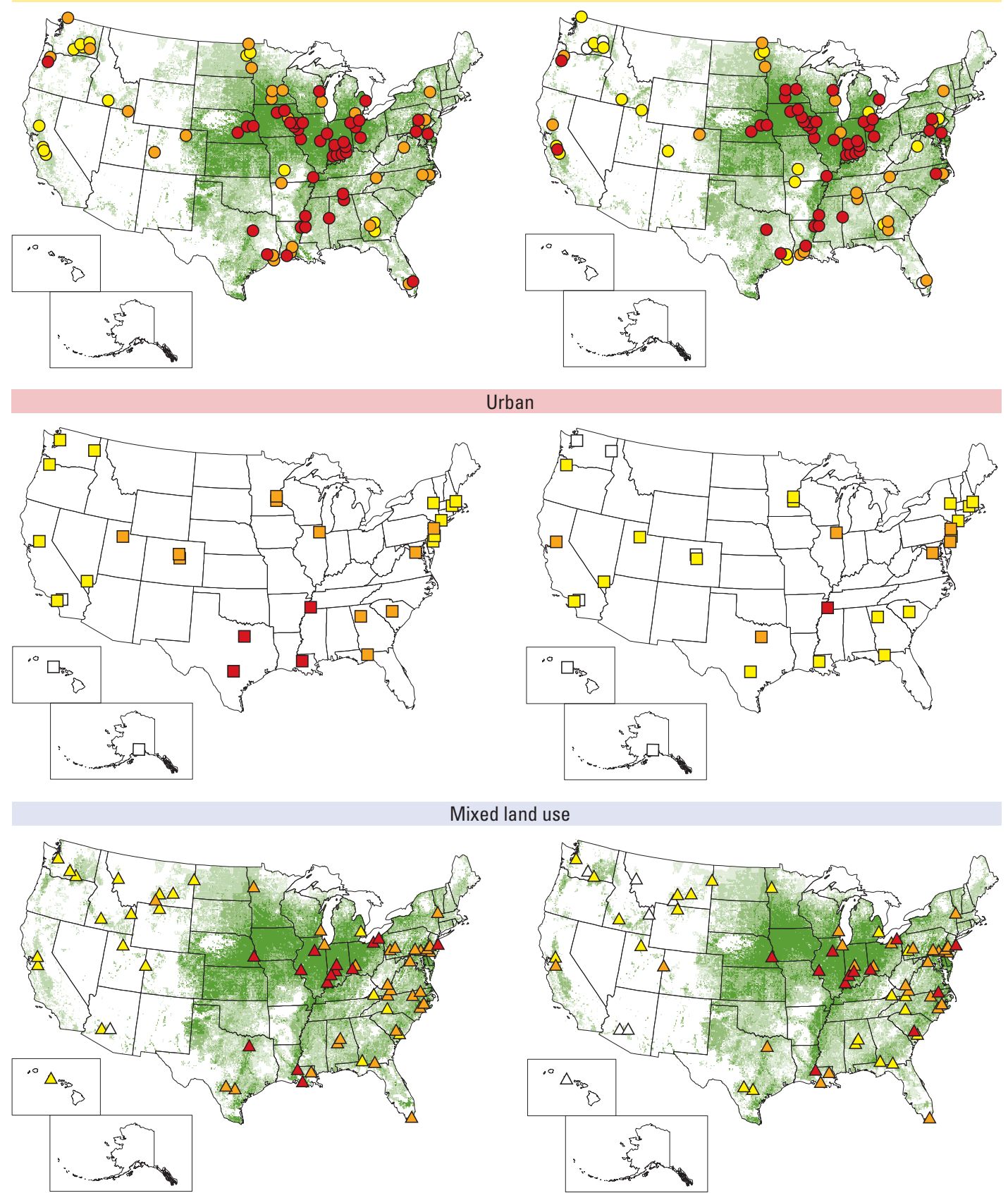

EXPLANATION

Estimated 1997 agricultural use intensity, Stream sites, by watershed land use in pounds per square mile per year

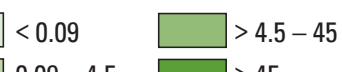

Agricultural Urban Mixed

$0.09-4.5 \square>45$

$\begin{array}{ll}\circ & \square \\ \circ & \square \\ \circ & \square \\ 0 & \square\end{array}$

$\square$
$\square$
$\square$
$\square$

95th percentile concentration, in $\mu \mathrm{g} / \mathrm{L}$

$\triangle \quad$ Not detected

$\triangle \quad<0.05$

$\triangle \quad 0.05-0.5$

Figure 4-9. Concentrations of both atrazine and metolachlor in agricultural streams closely matched the geographic distribution of their use on crops. Both atrazine and metolachlor were also often found in urban streams, but at substantially lower concentrations compared with most agricultural streams. An exception is atrazine in some urban streams in parts of the South where atrazine was used on turf grasses. Agricultural use for 1997 was estimated as described in the "Methods" sidebar on p. 53. 


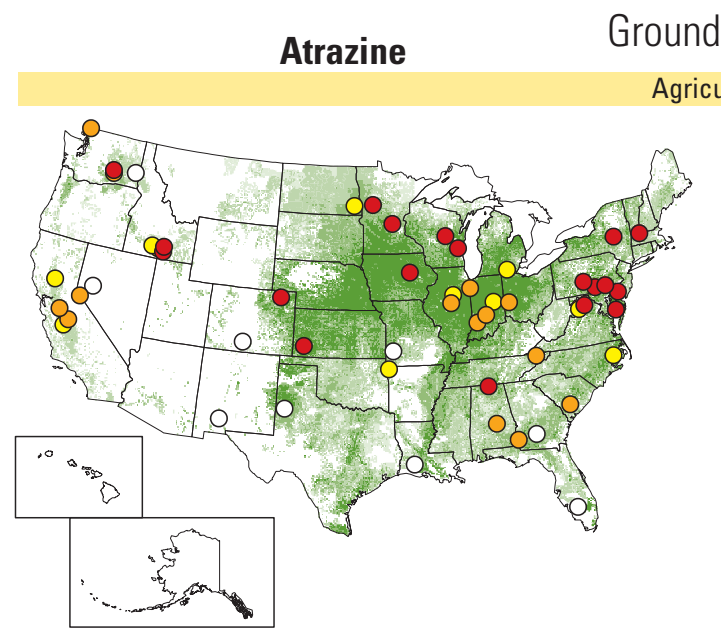

Agricultural

Metolachlor

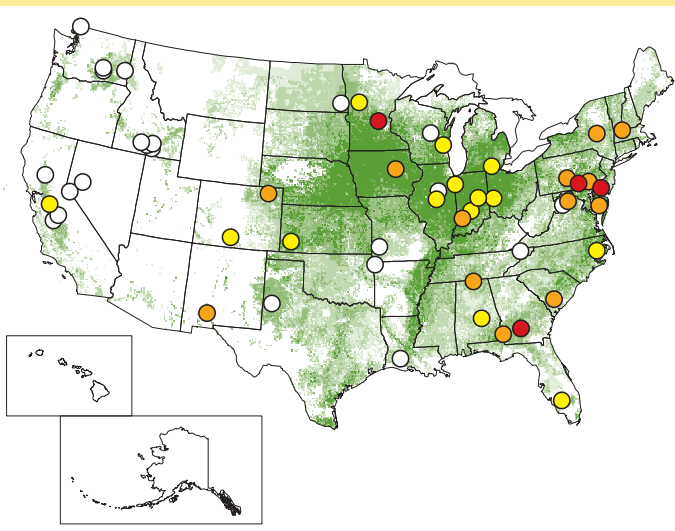

Urban
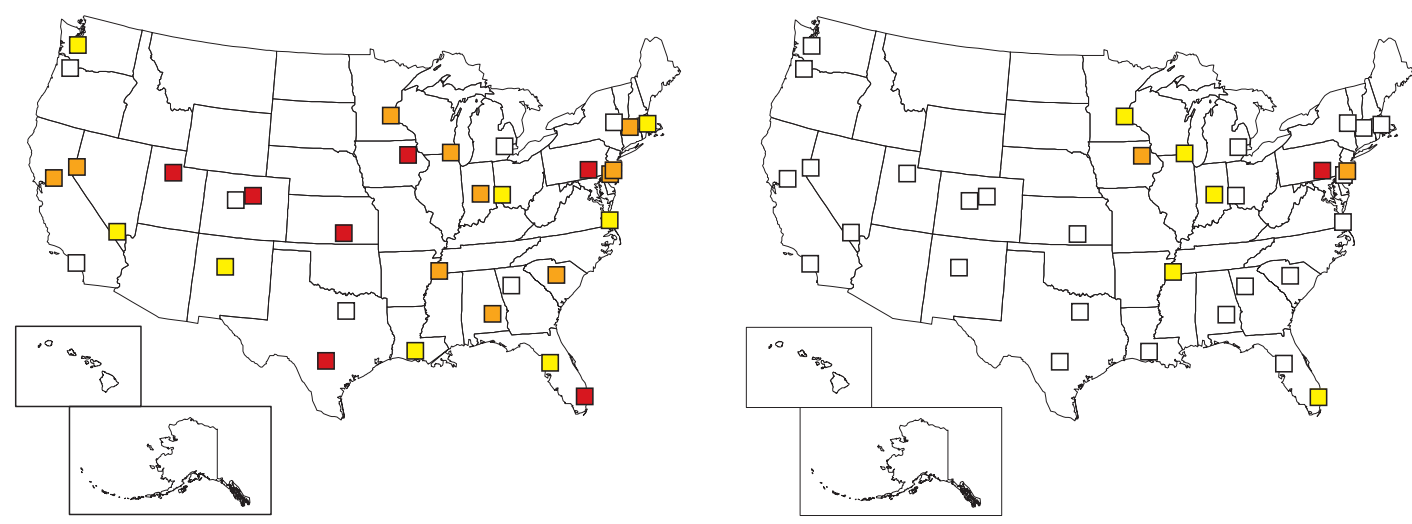

Major aquifers
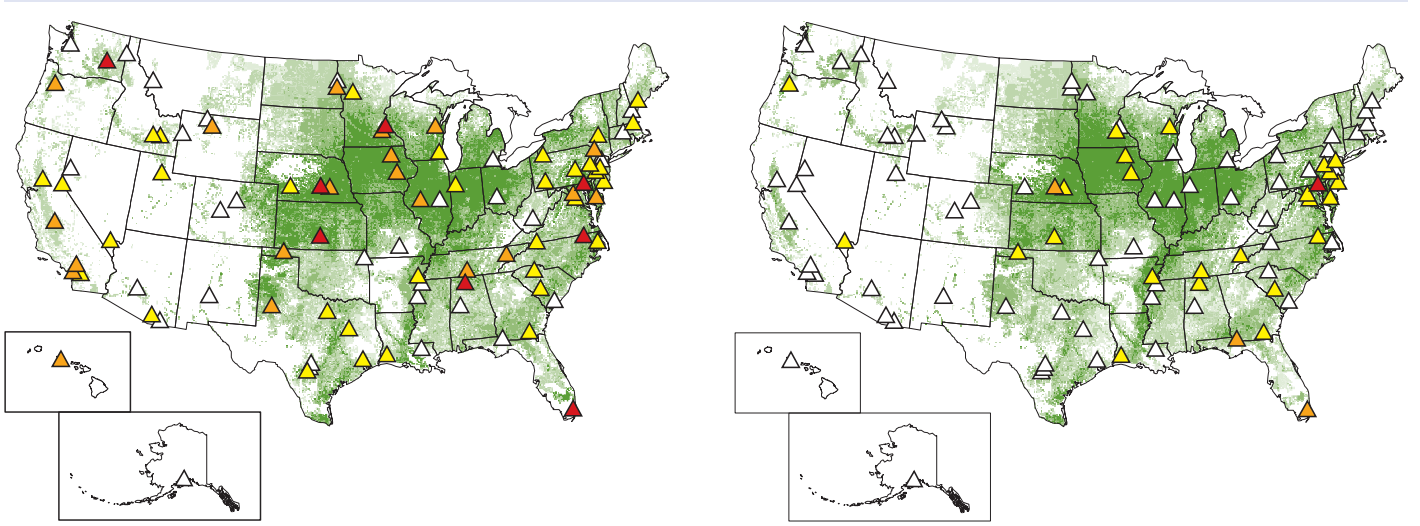

EXPLANATION

\begin{tabular}{|c|c|c|c|c|c|}
\hline \multicolumn{2}{|c|}{$\begin{array}{l}\text { Estimated } 1997 \text { agricultural use intensity, } \\
\text { in pounds per square mile per year }\end{array}$} & \multicolumn{2}{|c|}{$\begin{array}{l}\text { Shallow ground-water studies, } \\
\text { by land use }\end{array}$} & \multirow[t]{2}{*}{$\begin{array}{l}\text { Major } \\
\text { aquifers }\end{array}$} & \multirow{2}{*}{$\begin{array}{l}\text { Frequency of detection at } 0.01 \mu \mathrm{g} / \mathrm{L} \text { or } \\
\text { greater, as percentage of wells in study }\end{array}$} \\
\hline$]<0.09$ & $>4.5-45$ & Agricultural & Urban & & \\
\hline \multirow[t]{4}{*}{$0.09-4.5$} & $>45$ & O & $\square$ & $\triangle$ & Not detected \\
\hline & & 0 & $\square$ & $\triangle$ & $<10$ \\
\hline & & 0 & $\square$ & $\triangle$ & $10-25$ \\
\hline & & 0 & $\square$ & $\Delta$ & $>25$ \\
\hline
\end{tabular}

Figure 4-10. Patterns of atrazine and metolachlor detections were different from each other in ground water, although both were detected less frequently than expected in the central Corn Belt where the intensity of use was greatest. Metolachlor was detected less frequently than atrazine, regardless of land use or depth of ground water, probably because metolachlor is less persistent in soil than atrazine. Agricultural use for 1997 was estimated as described in the "Methods" sidebar on p. 53. 


\section{Simazine and Prometon-}

Although prometon is not registered for

agricultural use, it frequently occurred in

agricultural streams and ground water, probably

because of use for nonagricultural purposes in

those areas and its high persistence.

Simazine and prometon are commonly used herbicides that, compared with atrazine and metolachlor, had lower total use and higher proportions of nonagricultural use during the study period. About 5 million lb/yr of simazine were applied for agricultural purposes nationwide (fig. 4-3), compared with about 75 and 67 million lb/yr of atrazine and metolachlor, respectively. Relative to atrazine and metolachlor, simazine is used on a wider variety of crops-including corn (about 40 percent of total use), citrus orchards (about 35 percent), and other orchards and vineyards (about 20 percent). Nonagricultural uses of simazine include applications to turf grasses and lawns, roadsides and other rights-of-way, and nurseries. Prometon is not registered for agricultural use, but is applied for nonagricultural purposes-albeit in small amounts-for bare-ground weed control around buildings, storage areas and fences, as well as along roadways, railroads, and other rights-of-way. Both simazine and prometon are highly soluble and mobile in water, but prometon is more persistent than simazine, with a soil half-life of 932 days, compared with 91 days for simazine (Appendix 2).

The occurrence of simazine in agricultural and urban streams was consistent with its geographic patterns of use (fig. 4-11), particularly in comparison to the more heavily used atrazine (fig. 4-9). For example, concentrations of simazine in agricultural streams in the Corn Belt were notably lower than concentrations of atrazine, reflecting the lower use of simazine on corn. On the other hand, detection frequencies and concentrations of simazine in urban streams were nearly identical to those of atrazine, reflecting generally similar nonagricultural use. Prometon was detected less frequently than simazine in agricultural streams, at lower concentrations, and without the geographic patterns that follow use on crops. The prometon detections in agricultural areas probably result from nonagricultural applications in these areas. In urban streams, prometon was detected at frequencies similar to those observed for simazine, atrazine, and diazinon-although at somewhat lower concentrations (see figs. 4-11, 4-9, and 4-14, respectively). The most likely explanation for the frequent occurrence of prometon is that its high persistence (10 times that of simazine and more than 5 times that of atrazine) results in its prolonged presence in watersheds.

The occurrence and concentrations of simazine in ground water (fig. 4-12) were consistent with patterns observed for atrazine and metolachlor (fig. 4-10). Like atrazine and metolachlor, detection frequencies were relatively low in shallow ground water beneath agricultural areas in Illinois, Indiana, and Ohio relative to other high use areas-probably because of the common use of subsurface drainage systems and widespread presence of glacial till in this region (noted earlier). Simazine was generally detected more frequently than atrazine and metolachlor in Florida and California, which is consistent with its higher use in orchards and vineyards in those areas. Prometon, consistent with its lack of registered agricultural uses, was detected less frequently than simazine in shallow ground water in agricultural areas. In most urban study areas, prometon was detected at similar or greater frequencies than simazine in shallow ground water. 


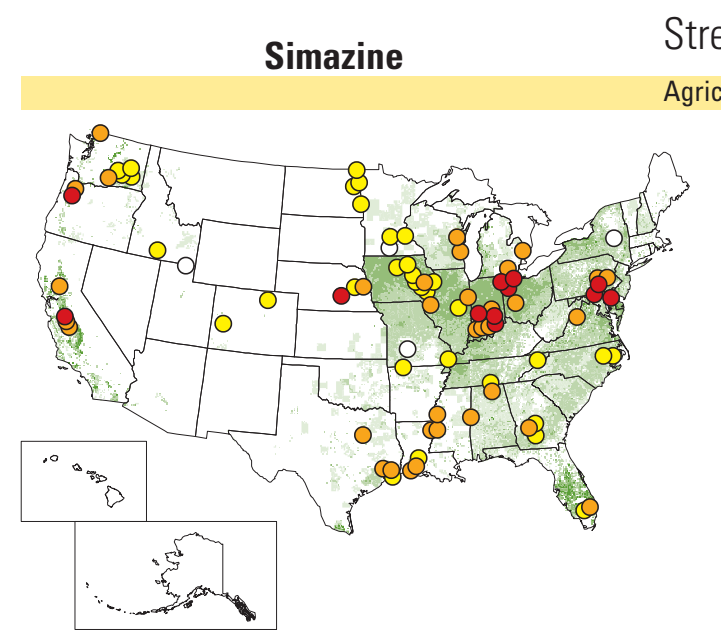

Streams

Agricultural

\section{Prometon}
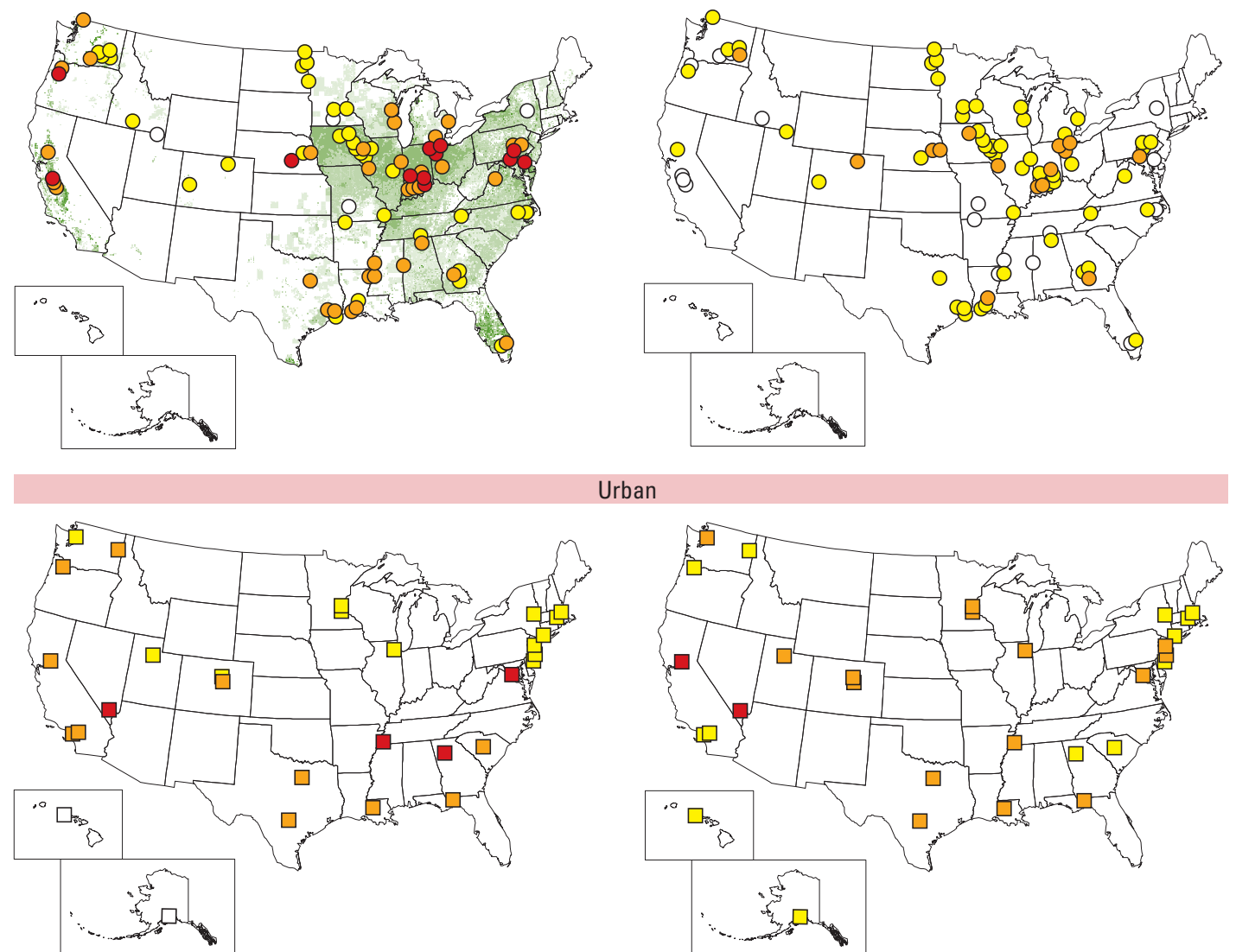

Urban
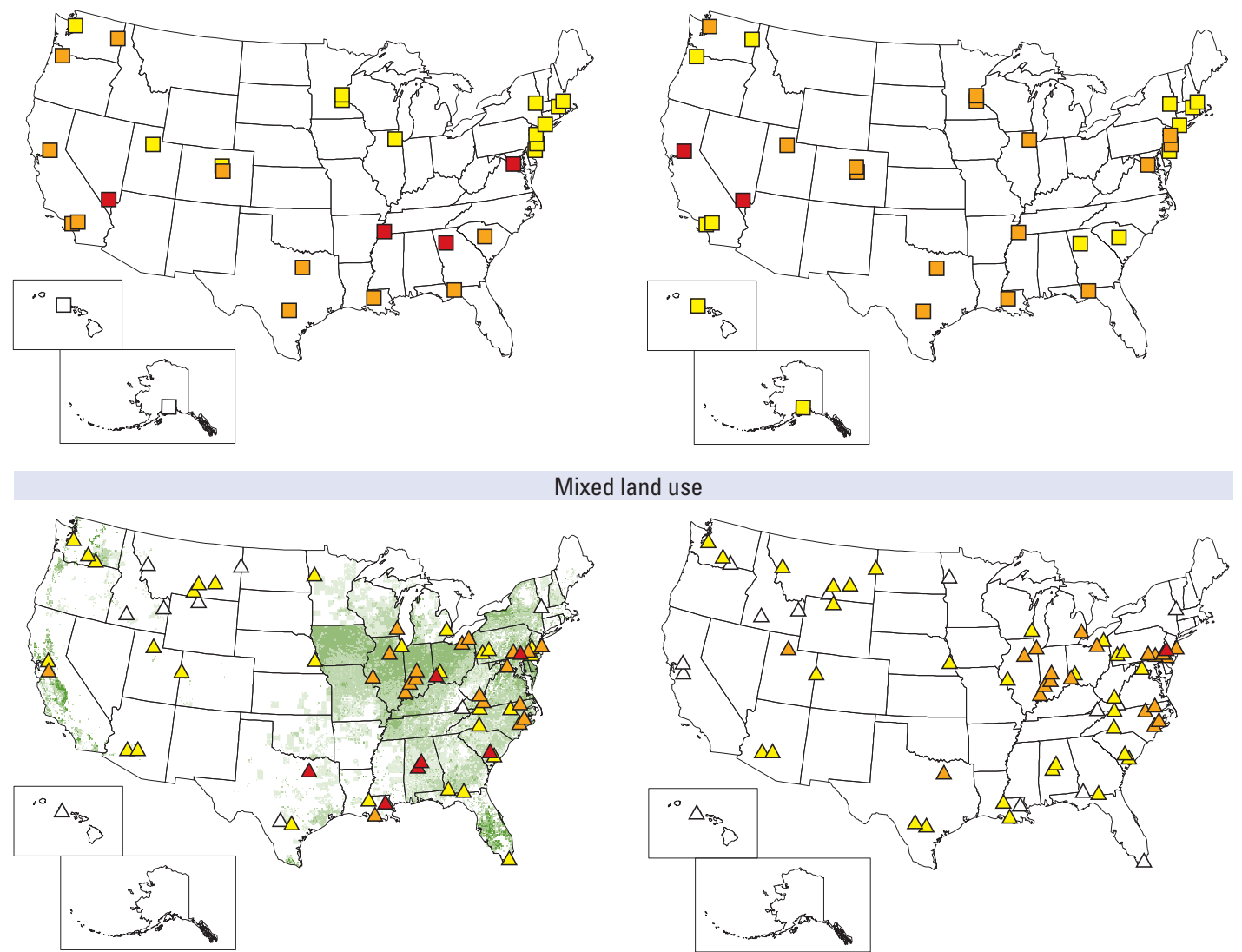

Mixed land use

\section{EXPLANATION}

Estimated 1997 agricultural use intensity, Stream sites, by watershed land use in pounds per square mile per year

$\begin{array}{ll}\square<0.09 & \square>4.5-45 \\ \square 0.09-4.5 & \square>45\end{array}$

Agricultural Urban

○

0

○

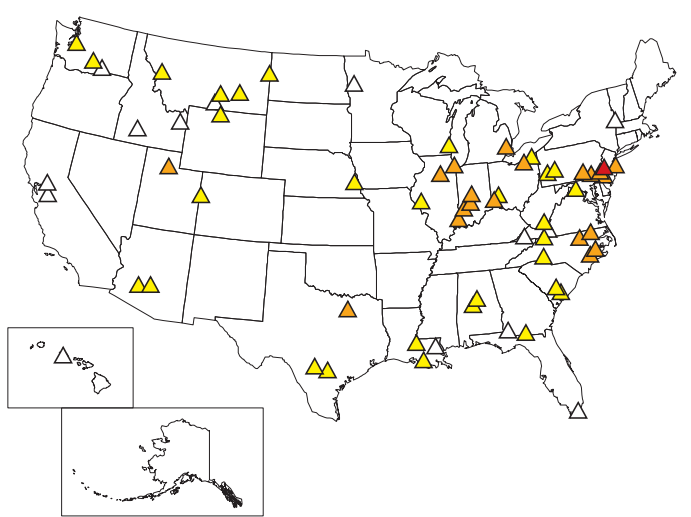




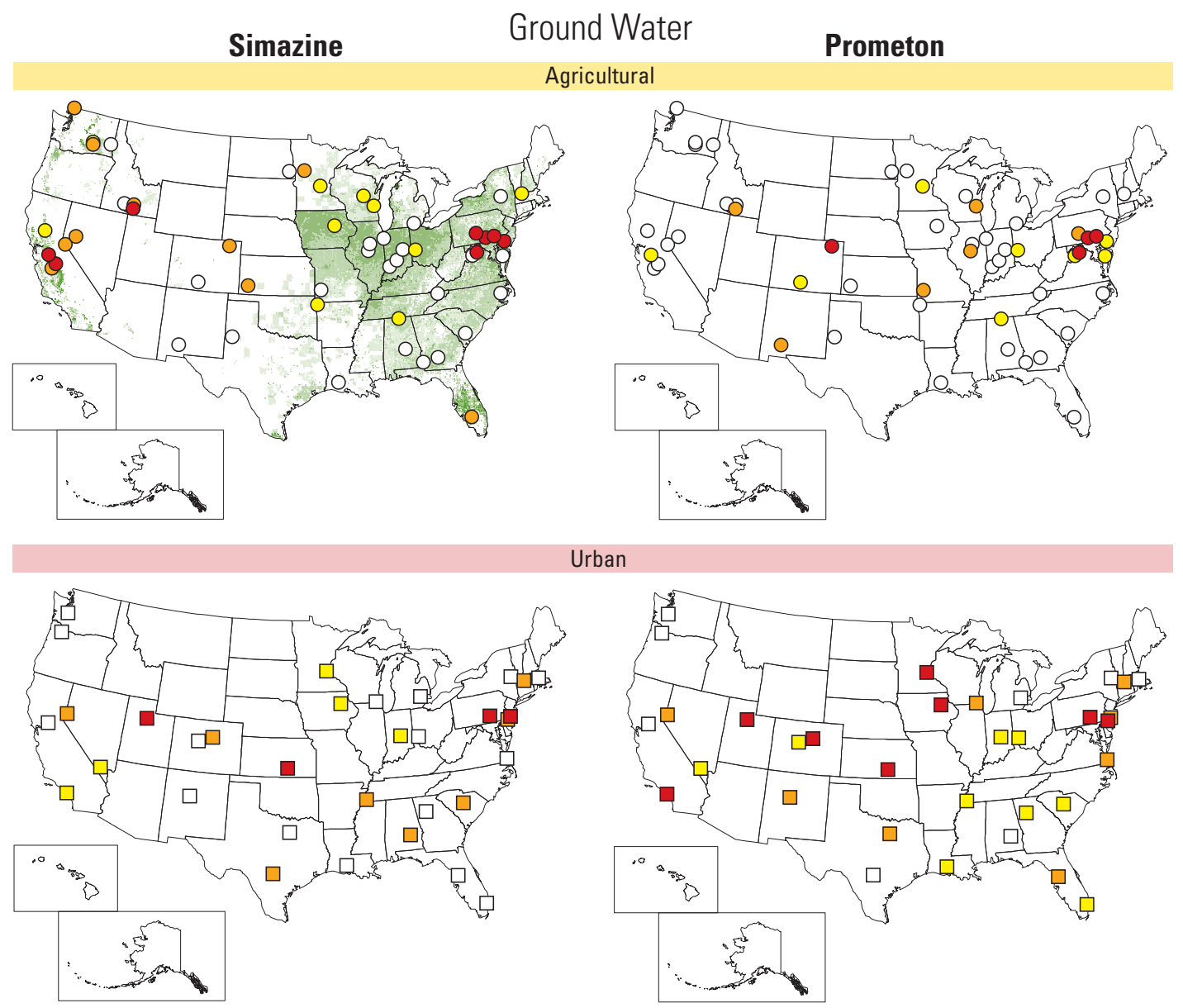

Major aquifers
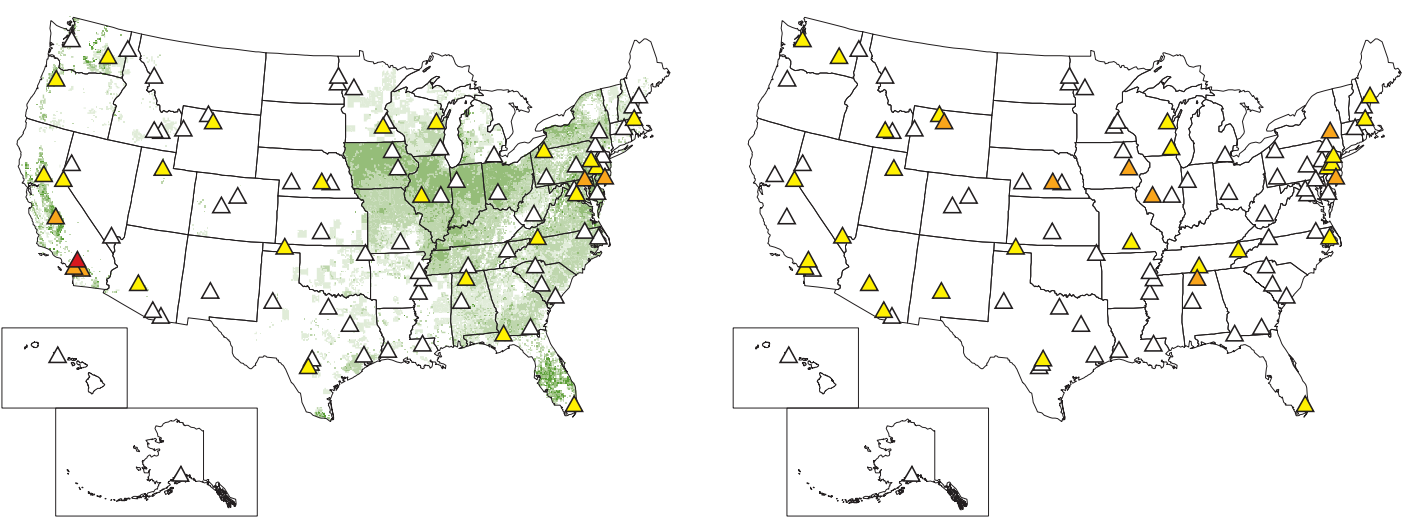

EXPLANATION

\begin{tabular}{|c|c|c|c|c|c|}
\hline \multicolumn{2}{|c|}{$\begin{array}{l}\text { Estimated } 1997 \text { agricultural use intensity, } \\
\text { in pounds per square mile per year }\end{array}$} & \multicolumn{2}{|c|}{$\begin{array}{l}\text { Shallow ground-water studies, } \\
\text { by land use }\end{array}$} & \multirow[t]{2}{*}{$\begin{array}{l}\text { Major } \\
\text { aquifers }\end{array}$} & \multirow{2}{*}{$\begin{array}{l}\text { Frequency of detection at } 0.01 \mu \mathrm{g} / \mathrm{L} \text { or } \\
\text { greater, as percentage of wells in study }\end{array}$} \\
\hline$]<0.09$ & ]$>4.5-45$ & Agricultural & Urban & & \\
\hline \multirow[t]{4}{*}{$0.09-4.5$} & $>45$ & O & $\square$ & $\triangle$ & Not detected \\
\hline & & 0 & $\square$ & $\triangle$ & $<10$ \\
\hline & & 0 & $\square$ & $\Delta$ & $10-25$ \\
\hline & & 0 & $\square$ & $\Delta$ & $>25$ \\
\hline
\end{tabular}

Figure 4-12. The occurrence of simazine in ground water was less frequent than atrazine and metolachlor (fig. 4-10), but the relative patterns were similar, including relatively low detection frequencies in shallow ground water beneath agricultural areas in Illinois, Indiana, and Ohio, compared with other high-use areas around the Nation. Prometon was detected less frequently than simazine in shallow ground water within agricultural areas. Prometon is not registered for agricultural use and no estimates of agricultural use are shown. Agricultural use of simazine for 1997 was estimated as described in the "Methods" sidebar on p. 53. 


\section{2,4-D and Acetochlor-}

These two herbicides, which have relatively similar chemical and physical properties, have different geographic patterns of occurrence in streams because of their different use patterns.

The herbicides 2,4-D and acetochlor ranked 3 rd and 5th in national agricultural use during the study period (about 41 and 33 million lb/yr, respectively, in 1997; fig. 4-3), but their use is distributed differently. Acetochlor, which is a relatively new pesticide introduced in 1994, is used only on corn, whereas 2,4-D is widely applied for multiple agricultural purposes, including weed control for pasture (accounting for about 40 percent of use), wheat ( 20 percent), corn and soybeans (17 percent), as well as other crops and fallow land. In addition, 2,4-D has the highest documented nonagricultural use of any pesticide

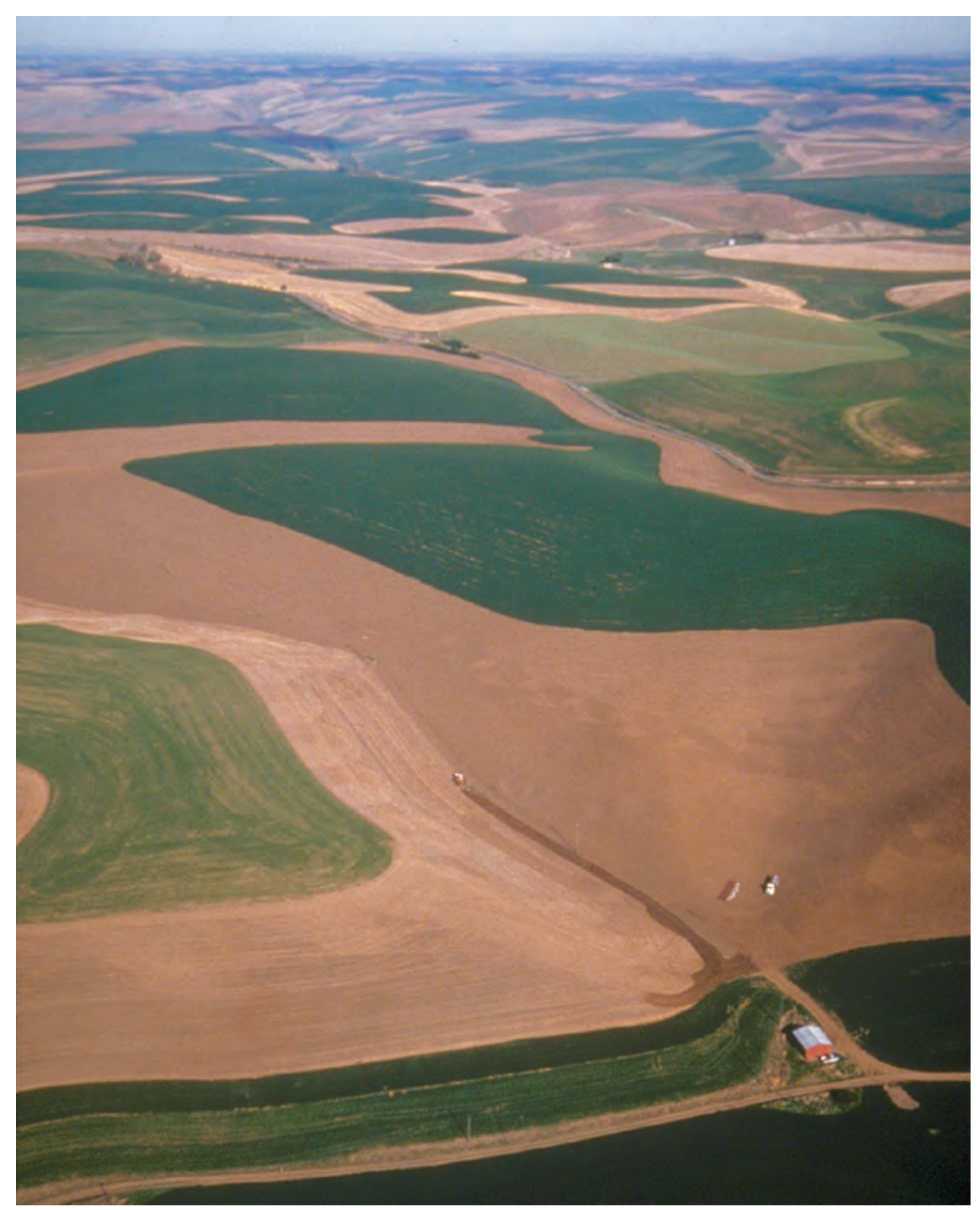

(nearly 30 million lb/yr; fig. 4-3). Both 2,4-D and acetochlor are relatively soluble and mobile in water and neither is particularly persistent, with soil half-lives of 7 and 14 days, respectively.

The occurrence and concentrations of these two compounds in agricultural and urban streams were generally consistent with their patterns of use (fig. 4-13). Specifically, relatively high concentrations of 2,4-D occurred in agricultural streams across the Nation in various high-use areas, whereas the highest concentrations of acetochlor were generally in the heart of the Corn Belt and in other corn-growing areas. Also consistent with their use patterns, 2,4-D concentrations were higher in urban streams than concentrations of acetochlor. Infrequent low-level detections of acetochlor in some urban streams may result from relatively minor agricultural use within the predominantly urban watersheds or atmospheric transport from nearby agricultural areas.

Geographic results for 2,4-D and acetochlor are not presented for ground water because both pesticides were detected in less than 1 percent of the wells sampled (fig. 4-2). Their infrequent occurrence in ground water is probably a result of their low persistence. For acetochlor, this hypothesis is supported by the more frequent detection of at least two of its degradates in ground water-relative to acetochlor itself-in some studies (for example, Kalkhoff and others, 1998; Groschen and others, 2004). used herbicide during the study period on croplands

where wheat is grown (Photograph copyright by Phil Schofield). 

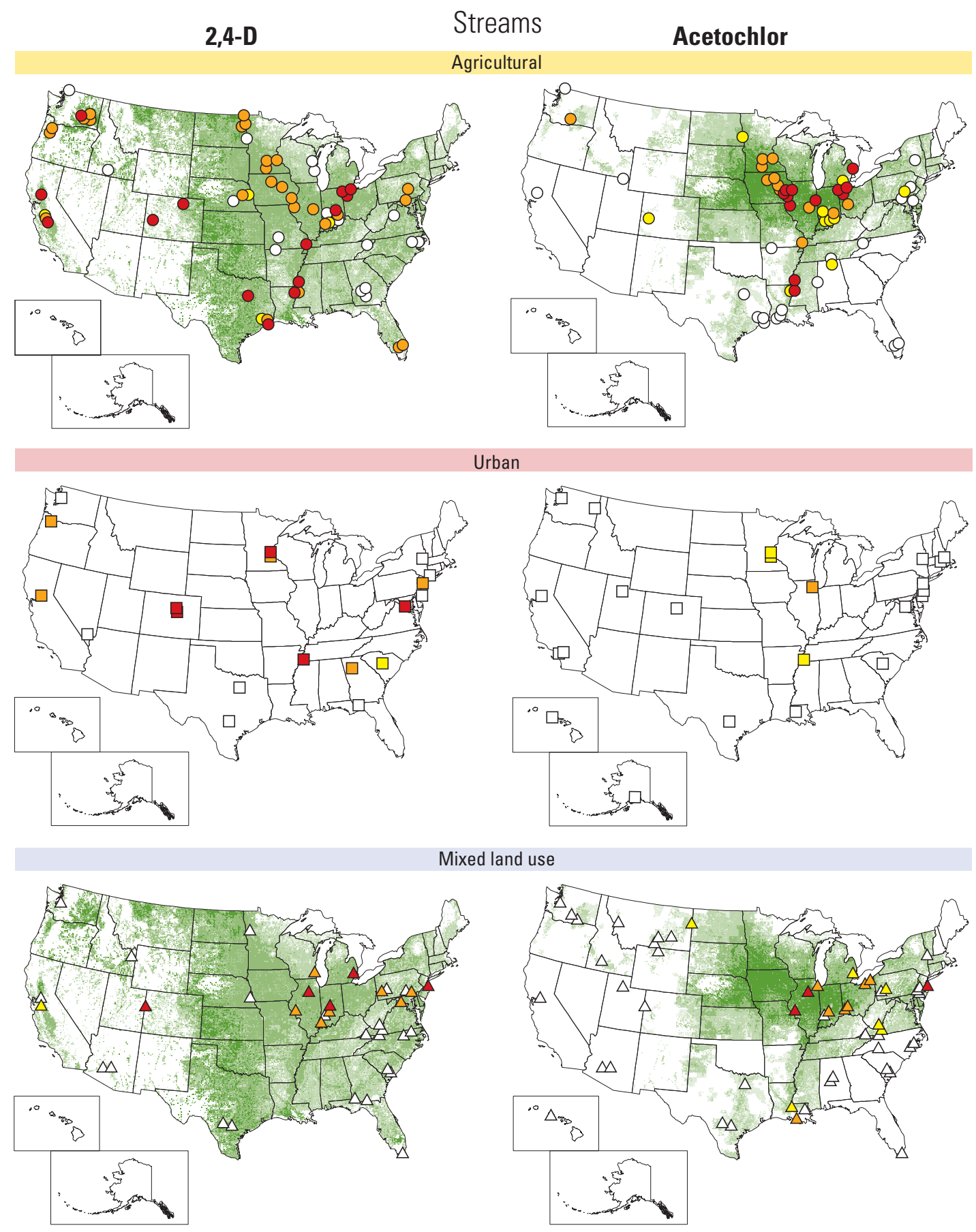

Mixed land use

\section{EXPLANATION}

Estimated 1997 agricultural use intensity, Stream sites, by watershed land use in pounds per square mile per year

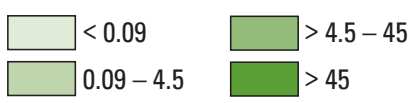

$\begin{array}{cc}\text { Agricultural } & \text { Urba } \\ \bigcirc & \square \\ \bigcirc & \square \\ \circ & \square \\ \bigcirc & \square\end{array}$

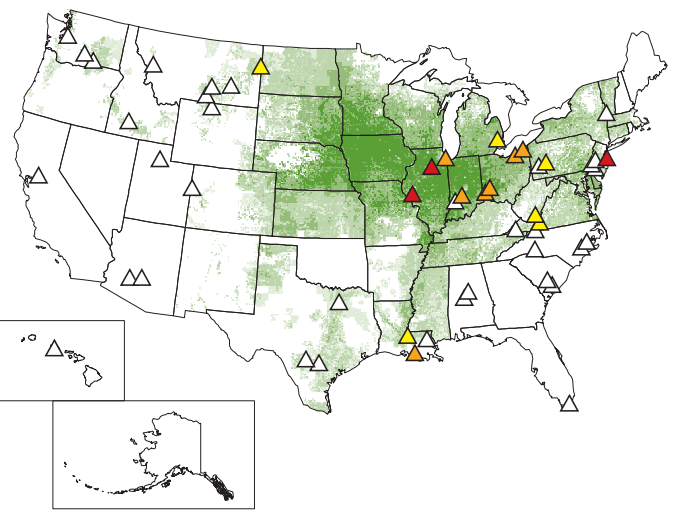




\section{Chlorpyrifos and Diazinon-}

Despite greater use, chlorpyrifos was found less frequently than diazinon in water, probably because of its greater affinity for particles and resulting lower mobility in water.

Chlorpyrifos and diazinon are insecticides that were commonly used in both agricultural and urban areas during the study period. About 13 million $\mathrm{lb}$ of chlorpyrifos were applied to crops in 1997, mostly on corn and cotton (accounting for more than 50 percent of national use), with the remainder on alfalfa, peanuts, wheat, tobacco, and orchards. Less diazinon was used for agriculture (about 1 million lb in 1997), mostly for a wide variety of fruits, nuts, and vegetables (fig. 4-3). Nonagricultural uses of chlorpyrifos and diazinon totaled about 5 million and 4 million lb/yr in 2001, respectively (fig. 4-3). Both diazinon and chlorpyrifos are substantially less mobile in water than the six herbicides just discussed, but chlorpyrifos has a greater affinity for soil organic matter and particles (higher $\mathrm{K}_{\mathrm{oc}}$ ) than diazinon and, thus, a lower solubility and mobility in water. Both pesticides have similar half-lives in soil-39 days for diazinon and 31 days for chlorpyrifos (Appendix 2).

The geographic distributions of these insecticides in agricultural and urban streams were consistent with their patterns of use (fig. 4-14). Of agricultural streams, the highest concentrations of chlorpyrifos were in streams draining the corn-growing areas of the central United States and the lower Mississippi River Basin, where both corn and cotton are grown, and in streams draining orchard areas in the West. Concentra-

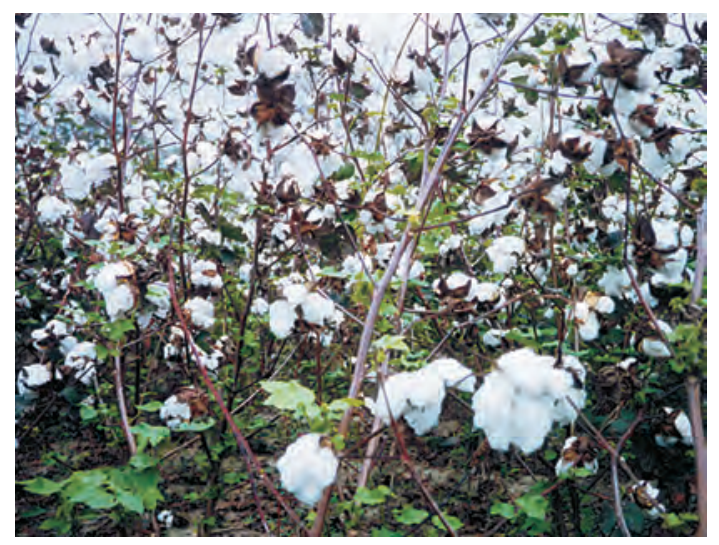

Chlorpyrifos was commonly used on cotton during the study period. tions of diazinon in agricultural streams were highest in parts of the West where it is intensively used on fruits, nuts, and vegetables. For both insecticides, concentrations in most urban streams were higher than in most agricultural streams, and were similar to those found in agricultural areas with the greatest intensities of use.

In urban streams, diazinon was detected about 75 percent of the time, compared with about 30 percent for chlorpyrifos (fig. 4-2), even though their nonagricultural use was similar. In addition, 95th-percentile concentrations equaled or exceeded $0.05 \mu \mathrm{g} / \mathrm{L}$ in 23 of 30 urban streams for diazinon, compared with only 3 streams for chlorpyrifos. In agricultural streams, both chlorpyrifos and diazinon were found at relatively similar frequencies and concentrations, despite the 10 -fold higher use of chlorpyrifos. The markedly greater occurrence of diazinon in proportion to use, compared with chlorpyrifos, may be explained by the greater solubility and mobility of diazinon in water. Because chlorpyrifos has a greater affinity for organic matter than diazinon, however, there may have been substantial occurrence and transport of chlorpyrifos in suspended sediment in streams that was not observed. As discussed in Chapter 3, all NAWQA stream-water samples were filtered prior to analysis.

Chlorpyrifos and diazinon were rarely detected in ground water (less than 1 percent of samples; fig. 4-2), so their geographic distributions are not shown. This infrequent occurrence is explained by their relatively low persistence and low water solubility, as well as their low use compared with the major herbicides.

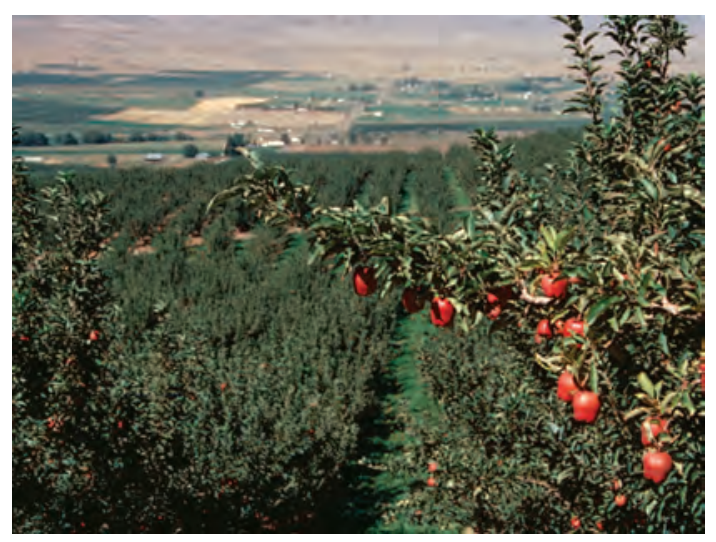

Both chlorpyrifos and diazinon were used on apples and other orchard crops during the study period. 

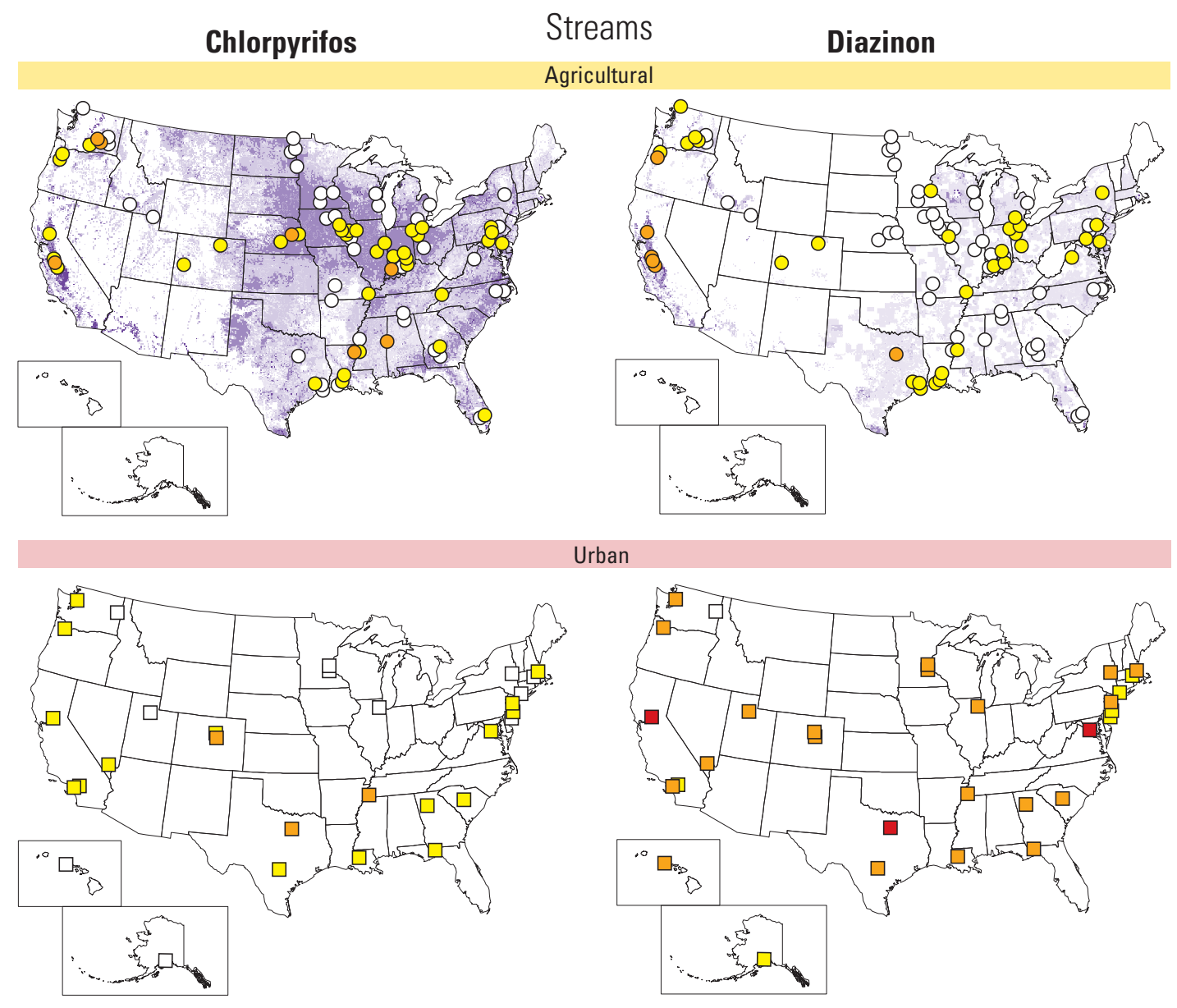

Mixed land use
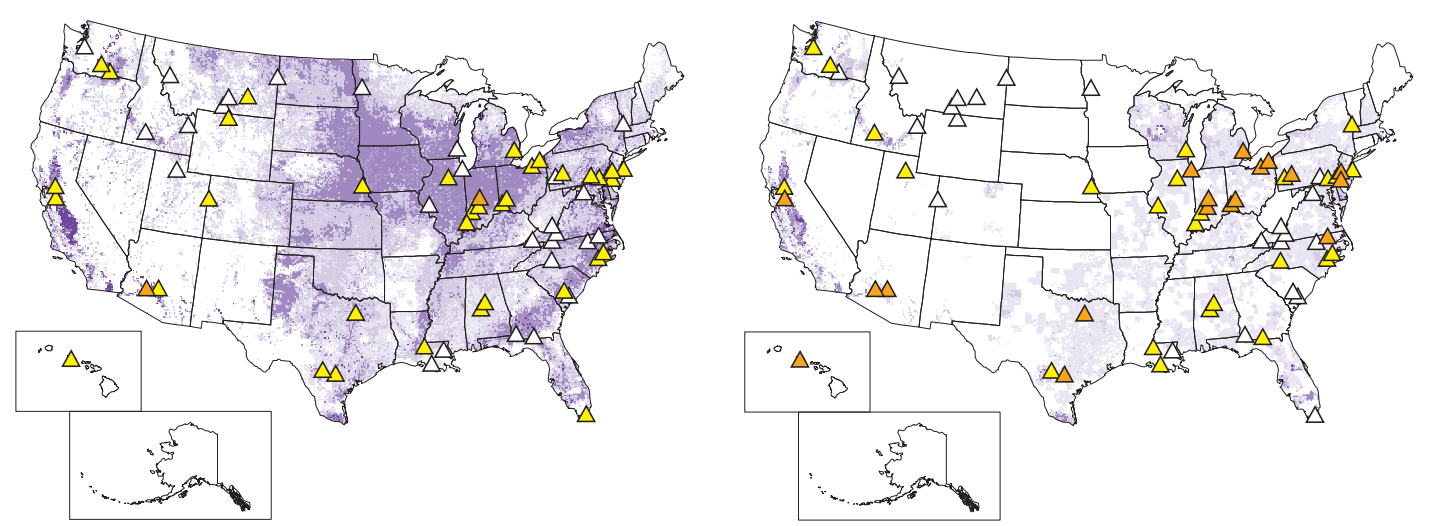

\section{EXPLANATION}

Estimated 1997 agricultural use intensity, in pounds per square mile per year

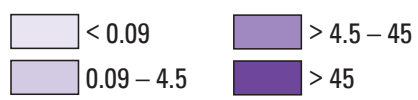

\section{Stream sites, by watershed land use}

Agricultural Urban Mixed 95th percentile concentration, in $\mu \mathrm{g} / \mathrm{L}$

$\begin{array}{llll}\circ & \square & \Delta & \text { Not detected } \\ \circ & \square & \Delta & <0.05 \\ \circ & \square & \Delta & 0.05-0.5 \\ \circ & \square & \Delta & >0.5\end{array}$

Figure 4-14. Concentrations of diazinon, and to a lesser degree chlorpyrifos, in most urban streams were greater than concentrations in most agricultural streams. Concentrations of diazinon in urban streams were generally similar to those found in agricultural areas with the greatest intensities of agricultural use. The highest concentrations of diazinon in agricultural streams were found in the West where it was used on fruits, nuts, and vegetables. The highest concentrations of chlorpyrifos in agricultural streams were detected in corn-growing areas of the central United States; the lower Mississippi River Basin, where both corn and cotton are grown; and in streams draining orchard areas in the West. Agricultural use for 1997 was estimated as described in the "Methods" sidebar on p. 53. 


\section{DDT and Dieldrin in Bed Sediment-}

The geographic distributions of these historically used insecticides follow their past agricultural use and indicate that use in urban areas probably was substantial.

Although the parent pesticides were not used in the United States for about 5-20 years prior to the beginning of the study period, compounds in the DDT group and dieldrin were frequently detected in bed sediment. In 1966, the combined agricultural use of DDT and DDD was about 30 million $\mathrm{lb}$ (fig. 4-5), with 66 percent used on cotton, 9 percent on tobacco, 8 percent on peanuts, and 17 percent on orchards, soybeans, vegetables, potatoes, and other crops. The combined agricultural use of dieldrin and aldrin (aldrin rapidly transforms to dieldrin in the environment) was about 15 million $\mathrm{lb}$ in 1966 , with 92 percent used on corn and 6 percent on orchards, vegetables, tobacco, and cotton. Agricultural uses of these insecticides decreased after the mid-1960s, and were discontinued by the mid-1970s. In addition to their agricultural use, aldrin and dieldrin were also widely used for termite control, most intensively in urban areas. Use of these compounds as termiticides continued until the late 1980s. Although quantitative data are not available, DDT also was used extensively in nonagricultural applications to control insects deemed to be a risk to public health (such as mosquitoes), as well as in forestry (U.S. Department of Health and Human Services, 2005; Larson and others, 1997). Compounds in the DDT group and dieldrin are all highly persistentmost with field-dissipation half-lives greater than 1,000 days (Nowell and others, 1999)—and all have a high affinity for soil organic matter (Appendix 2).

Concentrations of total DDT and dieldrin in bed-sediment samples from agricultural streams correspond reasonably well to both the total amounts and the distributions of their historical agricultural use (figs. 4-15 and 4-16). Reflecting the higher use of their parent pesticides, compounds in the DDT group were detected in bed sediment at 49 percent of agricultural stream sites, compared with 17 percent for dieldrin. The highest total DDT concentrations occurred in high-use areas of the Southeast-where cotton, tobacco, and peanuts were grown - and in a number of other high-use areas where orchard crops, potatoes, vegetables, or specialty crops were grown. Dieldrin was found at the highest overall concentrations in the Corn Belt, where use of aldrin on corn was most intensive.

Although there are few historical data on the urban use of organochlorine insecticides, the NAWQA bed-sediment results indicate that it probably was substantial. Compounds in the DDT group and dieldrin were found at higher frequencies and generally higher concentrations in urban streams than in agricultural streams, with the exception of DDT in some streams draining agricultural watersheds that had high DDT use in the past. Compounds in the DDT group were detected in 72 percent of samples from urban streams, compared with 42 percent for dieldrin.

For most streams with mixed land use in their watersheds, the concentrations of total DDT and dieldrin were generally similar to those in agricultural streams, but lower than those in urban streams. Streams in undeveloped watersheds had the lowest concentrations of these compounds.

In addition to agricultural uses, DDT also was applied to wetlands and marshes to control mosquitoes (photograph courtesy of the Tennessee Valley Authority Historic Collection, 1938).

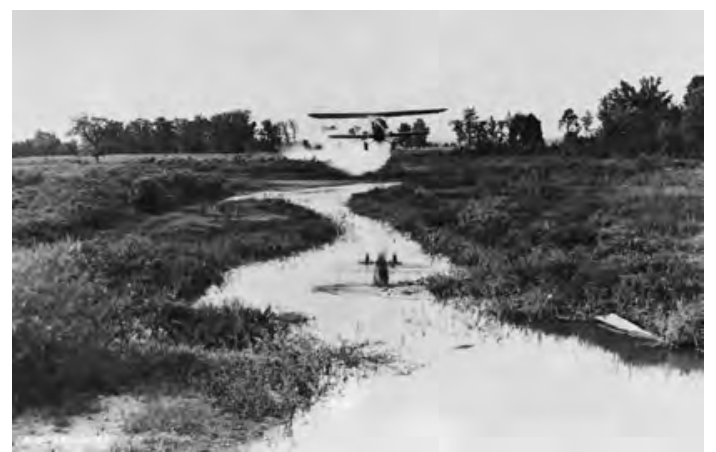


Total DDT in bed sediment
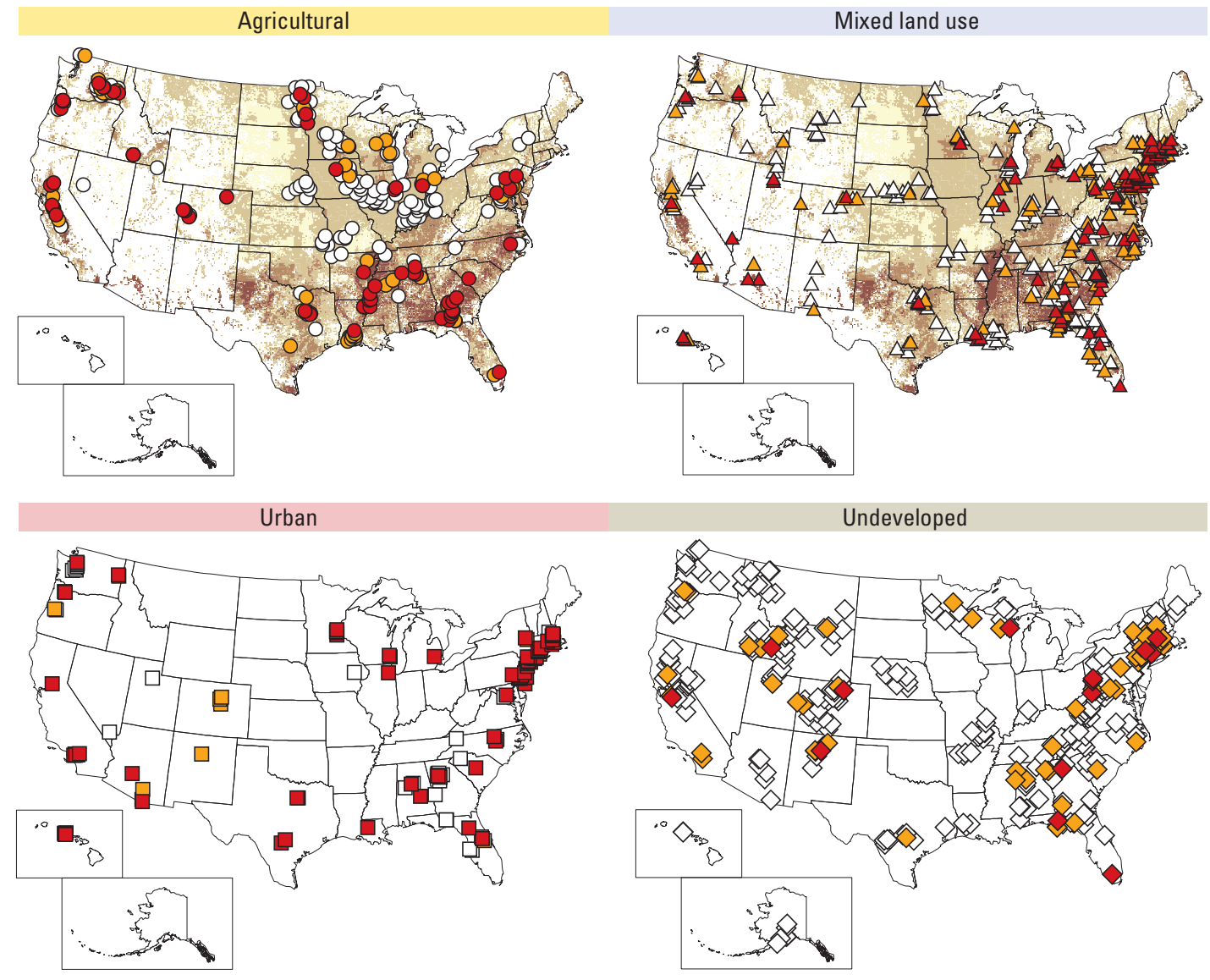

\section{EXPLANATION}

Estimated historical agricultural use intensity, in pounds per square mile per year

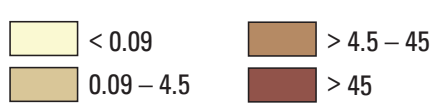

\begin{tabular}{ccccl}
\multicolumn{2}{c}{ Stream sites, by watershed land use } & \multicolumn{2}{l}{$\begin{array}{l}\text { Concentration, in } \mu g \\
\text { dry weight }\end{array}$} \\
Agricultural & Urban & Mixed & Undeveloped & \\
$\bigcirc$ & $\square$ & $\Delta$ & $\diamond$ & Not detected or $<1$ \\
$\circ$ & $\square$ & $\Delta$ & $\diamond$ & $1-5$ \\
$\bullet$ & $\square$ & $\Delta$ & $\diamond$ & $>5$
\end{tabular}

Figure 4-15. Total DDT concentrations in bed sediment were generally higher in urban streams than in agricultural and mixed-land-use streams, with the exception of a few streams draining watersheds in areas that had high agricultural use of DDT plus DDD in the past. The distribution of concentrations of total DDT found in bed sediment of agricultural streams corresponded reasonably well to both the total amount and the distribution of historical agricultural use of DDT plus DDD. Total DDT concentrations were highest in high-use areas of the Southeast where cotton, tobacco, and peanuts were grown, and in a number of other high-use areas where orchard crops, potatoes, vegetables, or specialty crops were grown. Historical use for the late 1960s was estimated as described in the "Methods" sidebar on p. 53. 
Dieldrin in bed sediment
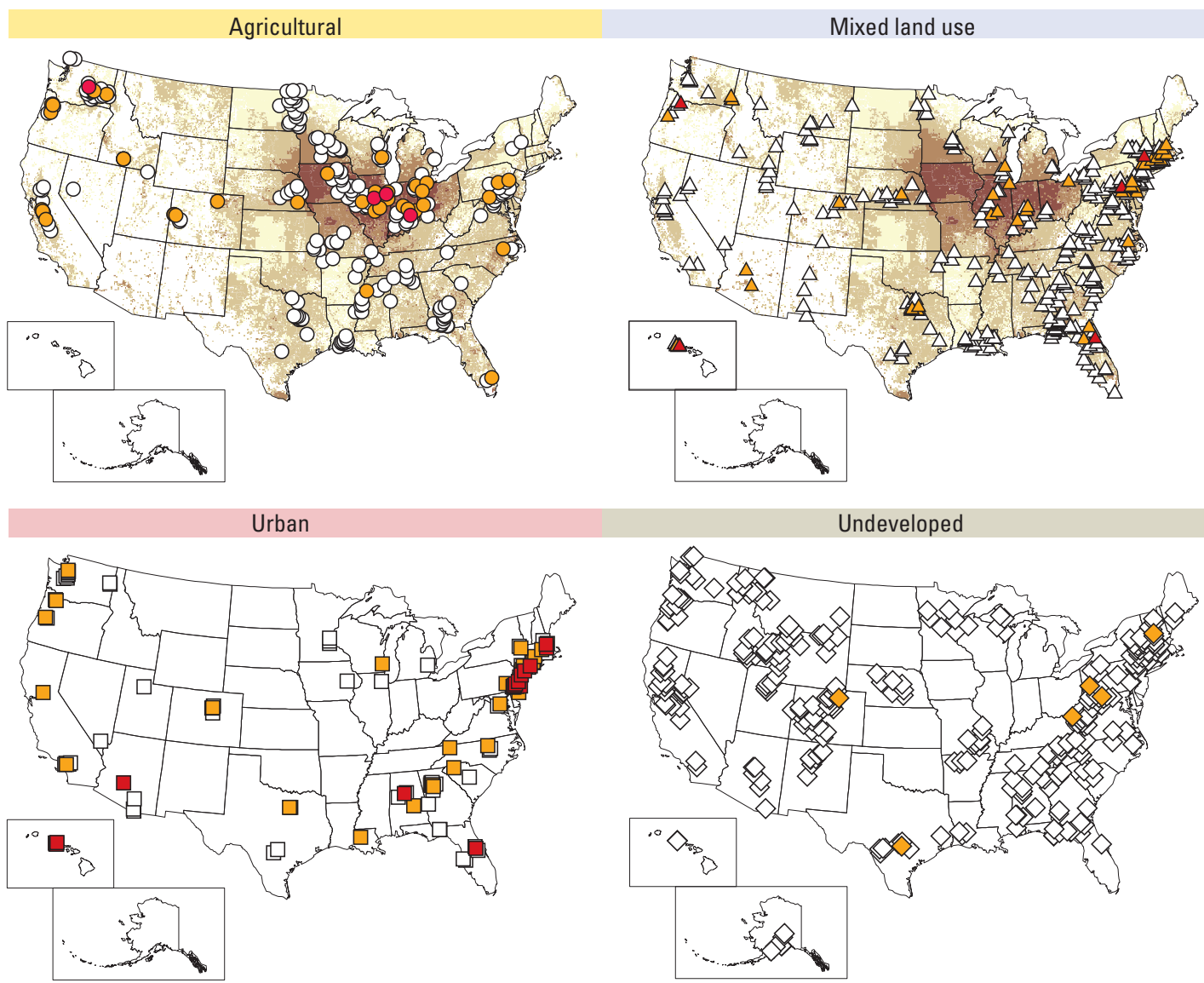

\section{EXPLANATION}

\section{Estimated historical agricultural use intensity, in pounds per square mile per year}

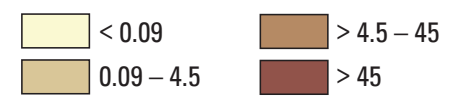

\begin{tabular}{ccc}
\multicolumn{3}{c}{ Stream sites, by wate } \\
Agricultural & Urban \\
$\bigcirc$ & $\square$ & \\
$\bigcirc$ & $\square$ & \\
$\bigcirc$ & $\square$ &
\end{tabular}

Concentration, in $\mu \mathrm{g} / \mathrm{kg}$ dry weight

Not detected or $<1$

$1-5$

$>5$

Figure 4-16. Dieldrin in bed sediment generally occurred at higher frequencies and higher concentrations in urban streams than in most agricultural streams. Concentrations of dieldrin found in bed sediment of agricultural streams corresponded reasonably well to the distribution of historical agricultural use of aldrin plus dieldrin. In agricultural streams, dieldrin was detected most frequently and at the highest overall concentrations in the Corn Belt, where past use of aldrin on corn was most intensive. Historical use for the late 1960s was estimated as described in the "Methods" sidebar on p. 53. 


\title{
Complexities: Seasonality, Mixtures, and Degradates
}

\author{
$T_{\text {he occurrence of pesticides in streams and ground water, }}$ \\ which was characterized in relation to land use and the geo- \\ graphic patterns in pesticide use in Chapter 4, is further compli- \\ cated by three additional factors: strong seasonal patterns, the \\ prevalence of mixtures of pesticides, and the frequent occur- \\ rence of degradates. Seasonal patterns occur year after year \\ in most streams and dictate the timing of the highest pesticide \\ concentrations; mixtures of multiple pesticide compounds \\ are found more often than individual pesticides; and pesticide \\ degradates may occur more frequently and at higher concentra- \\ tions than their parent compounds, particularly in ground water. \\ These complexities need to be understood and considered when \\ assessing the potential effects of pesticides on water quality.
}

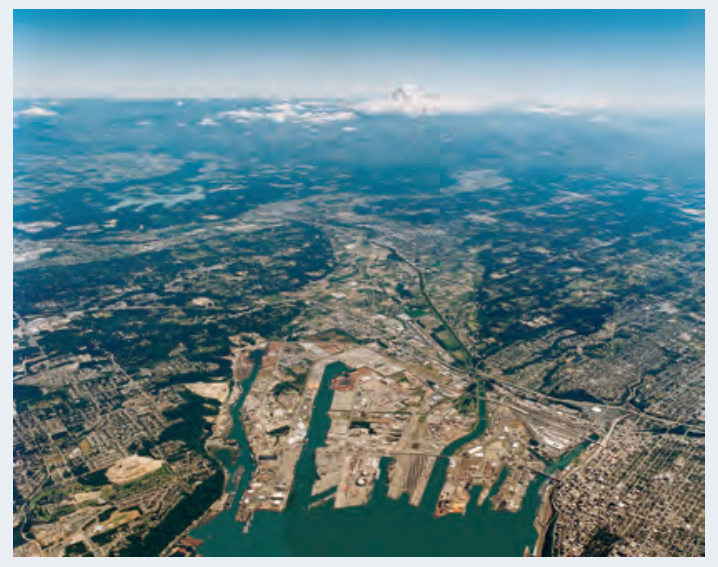

This chapter provides an overview of national findings and selected case studies regarding seasonal patterns, mixtures, and degradates of pesticides. 


\section{Seasonal Patterns in Streams}

Concentrations of pesticides in streams typically follow marked seasonal patterns year after year. These patterns generally are characterized by long periods of low or undetectable concentrations, punctuated by a few weeks or months of higher concentrations-a seasonal pulse. Such patterns are governed primarily by the timing and intensity of pesticide use in relation to hydrologic factors that affect the transport of pesticides to streams. Key hydrologic factors include the timing and amount of runoff from rainfall and irrigation, the presence or absence of surface or subsurface drainage systems, and the degree of interaction between streams and ground water. Seasonal patterns are important to characterize because they dictate the timing and duration of the highest concentrations of pesticides that may affect the suitability of water for humans, aquatic life, and wildlife.

NAWQA findings show that concentrations of pesticides in agricultural and urban streams across the Nation usually were highest during the growing season and lowest during the winter (fig. 5-1). The highest concentrations of herbicides-generally higher in agricultural streams than in urban streams-usually occurred during

\section{National overview of seasonal patterns in streams}
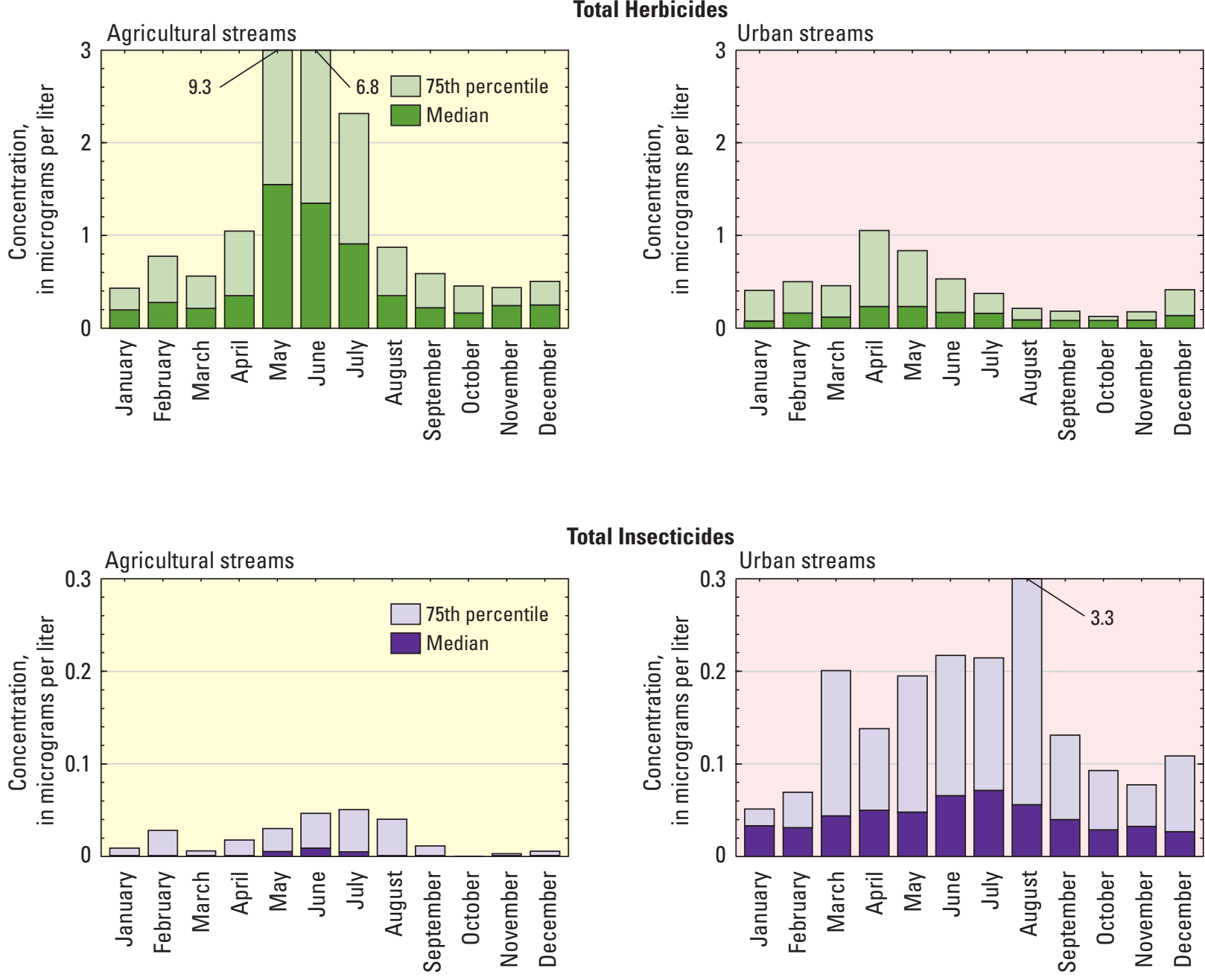

Total Insecticides

Figure 5-1. The timing and magnitude of seasonal pulses in the concentrations of herbicides and insecticides differed between agricultural and urban streams. Herbicide concentrations tended to be higher and seasonal patterns more pronounced in agricultural streams, but insecticide concentrations generally were higher in urban streams. Median and 75th percentile concentrations were determined after aggregating the total concentrations of herbicides and insecticides for all samples from agricultural streams and for all samples from urban streams. 
April-July. In contrast, the highest concentrations of insecticides - generally higher in urban streams than in most agricultural streams-usually occurred at various times over a longer period, from March through September. Differences that may occur in seasonal patterns between agricultural and urban streams, even within the same geographic area, are illustrated by findings from the Mobile River Basin (fig. 5-2). Numerous additional examples of seasonal patterns have been characterized for streams in different parts of the country in individual NAWQA studies (see reports for the 51

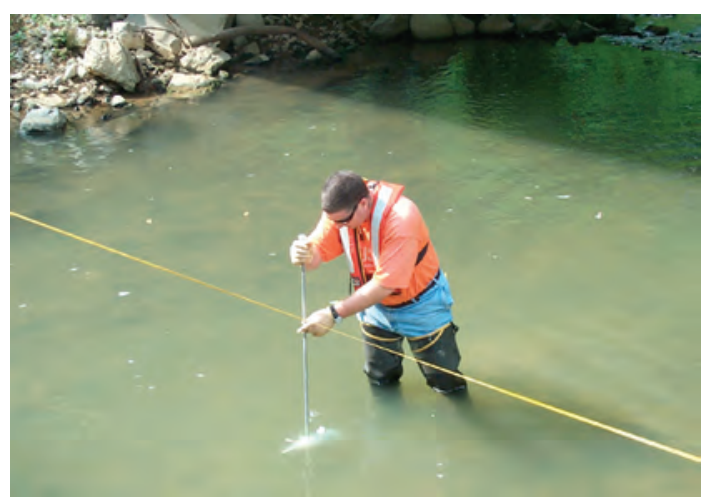
from Cahaba Valley Creek.

NAWQA Study Units: http://water.usgs.gov/ nawqa/nawqasum/).

Seasonal patterns of herbicides in an agricultural and an urban stream
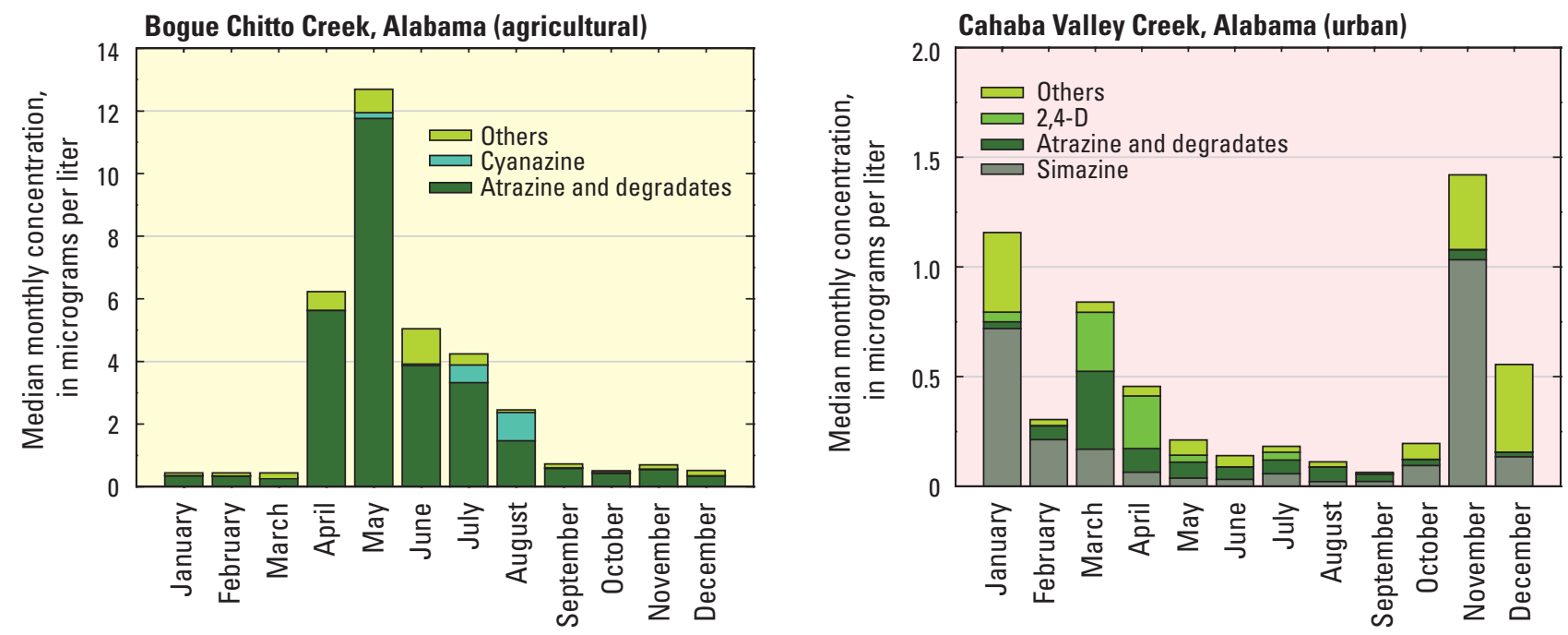

Figure 5-2. Atrazine and its degradates dominated herbicide concentrations in Bogue Chitto Creek, an agricultural stream (Mobile River Basin), with concentrations peaking in the spring following applications on corn fields and gradually declining throughout the summer and winter. In nearby Cahaba Valley Creek, an urban stream, herbicide concentrations were highest during November-April, and the dominant herbicide was simazine (Atkins and others, 2004). 


\section{Geographic Variability of Seasonal Patterns}

Although the occurrence and concentrations of pesticides followed distinct seasonal patterns in most of the agricultural and urban streams sampled, the specific timing and magnitude of the observed patterns varied regionally and locally. This variability results from differences in such factors as the timing and amounts of pesticide use, climate, and the frequency and magnitude of runoff from rainstorms or irrigation. Seasonal patterns were particularly consistent within regions in which climate, land use, and crop types are relatively uniform, such as in the Corn Belt. The accompanying map and graphs (fig. 5-3) show examples that illustrate regional consistency, variability among streams, and land-use influences on seasonality using findings for atrazine, prometon, and diazinon in selected streams.

- Corn Belt Streams-Concentrations of atrazine, the dominant herbicide used in the Corn Belt during the study period, typically peaked after applications in the spring, as shown in four streams draining parts of Iowa, Indiana, Ohio, and Mississippi. Atrazine use generally is consistent from year to year, closely following annual patterns of weather and weed growth. Concentrations of prometon in these streams had weaker seasonal patterns and were lower than concentrations of atrazine, because prometon is used in smaller quantities and for a variety of nonagricultural purposes. Concentrations of diazinon were low or undetectable during most or all of the year in all Corn Belt streams except the Maumee River. The Maumee River has more urban land in its watershed compared with the other Corn Belt streams shown and was probably influenced more by nonagricultural diazinon use than the other streams.
- Urban Streams-Seasonal concentration patterns in three streams draining urban areas in Virginia, Georgia, and Nevada were more erratic than those observed in most agricultural areas. This was typical of the urban streams sampled nationwide, probably because pesticides are applied more sporadically in residential and commercial settings to control outbreaks of insects and weeds as they occur. Prometon and diazinon were generally detected at higher concentrations than atrazine in Las Vegas Wash and Accotink Creek, with the highest concentrations occurring during spring or summer. Sope Creek had higher concentrations of atrazine and lower concentrations of prometon than the other urban streams. The higher atrazine concentrations in Sope Creek may have resulted from the use of atrazine for treating turf grass in Georgia.

- Palouse River-Concentrations of prometon and atrazine were highest during winter and spring in the Palouse River in Washington, but were low overall compared with agricultural streams draining the Corn Belt. The Palouse River drains mostly nonirrigated cropland where wheat and other grains are the primary crops and pesticide use is relatively low.

- Orestimba Creek-Diazinon concentrations peaked during early winter and midsummer in Orestimba Creek, California, which drains irrigated farmlands dominated by orchards, vegetables, and alfalfa. Diazinon was used extensively in this watershed on almond orchards in January and February and on vegetable crops during the summer. 
Seasonal patterns of atrazine, prometon, and diazinon in selected streams

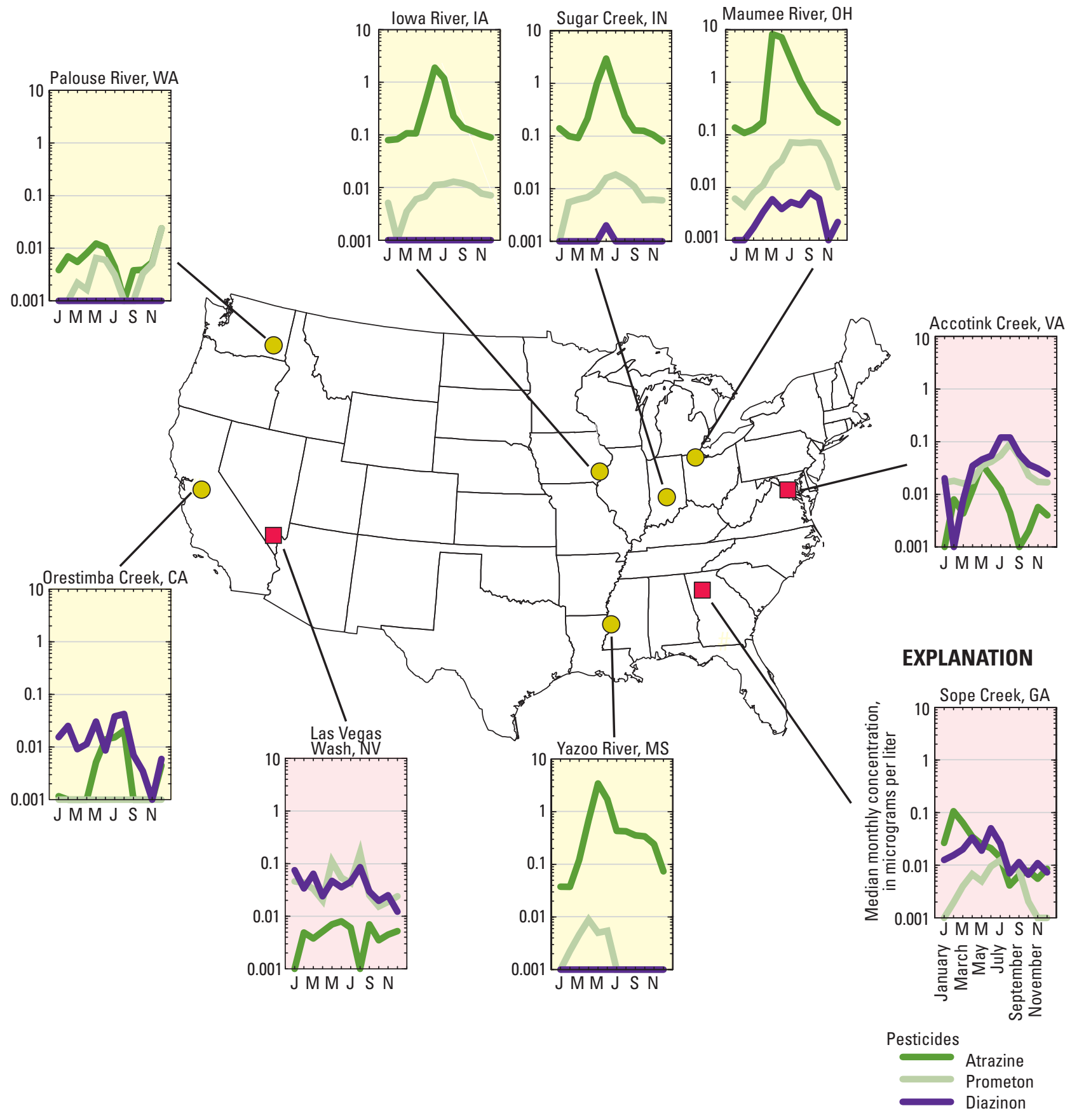

Stream site

Agricultural

Urban

Figure 5-3. Examples of seasonal patterns in concentrations of atrazine, prometon, and diazinon in selected agricultural and urban streams illustrate (1) the regional consistency of patterns for atrazine within the Corn Belt, an area that has relatively uniform agricultural practices; (2) the variability among streams in different regions of the country; and (3) the differing influences of land use on seasonality. Median concentrations for each month were computed from at least 6 years of data for each site and nondetections are plotted at $0.001 \mu \mathrm{g} / \mathrm{L}$. 


\section{Repetition of Seasonal Patterns}

Seasonal patterns of pesticide concentrations in each particular stream generally repeat with varying degrees of consistency each year, as long as the pesticides are still in use. For example, atrazine concentrations in the White River followed the same pattern each year from 1992 to 2001 (fig. 5-4). Corn is planted in the region between mid-April and the end of May, and atrazine is applied each year to nearly all of the corn acreage during this time period. Runoff resulting from rainfall in May and June transports atrazine to streams, giving rise to the highest concentrations of the year during and after application. In contrast, patterns in chlorpyrifos concentrations in the White River were less regular (fig. 5-4) because the insecticide is generally applied only if and when it is needed to control outbreaks of corn root worm.

\section{Importance of Seasonal Patterns}

Seasonal patterns in pesticide concentrations are important to understand because they may affect the management of water quality for some drinking-water supplies and often define critical conditions of pesticide exposure for aquatic life in a stream. Although NAWQA did not measure pesticide concentrations at drinking-water intakes, NAWQA results for the wide range of streams sampled indicate that seasonal pulses of pesticide concentrations probably occur in some streams that are used as sources of drinking water-primarily those with substantial agricultural or urban land use in their watersheds. For drinking-water sources where seasonal patterns are evident, seasonal monitoring is important to support water-quality management decisions. For example, some drinking-water utilities that withdraw water from streams in agricultural areas employ specific management strategies to avoid use of stream water, or to increase treatment of the water, during known seasonal periods of high concentrations in source waters.

The seasonal timing of elevated pesticide concentrations in relation to the timing of changes in populations and life stages of aquatic organisms may largely determine whether pesticides have a substantial effect on aquatic life in a stream. USEPA's Office of Pesticide Programs, for example, evaluates potential acute effects of exposure on the basis of peak concentration, and potential chronic effects on the basis of the peak 21-day average for invertebrates and the peak 60day average for fish (see Chapter 6). As indicated by figures $5-1$ through $5-4$, in most streams, these daily and multiday average concentrations are most likely to be approached or exceeded during relatively distinct seasonal periods for each pesticide. Knowledge of the seasonal timing of the highest concentrations for each pesticidetogether with an understanding of the life stages of aquatic organisms present in each season-can be used to target and refine assessments of potential effects, and to design efficient pesticide monitoring strategies that will yield reliable estimates of the concentration statistics required for site-specific risk assessments.

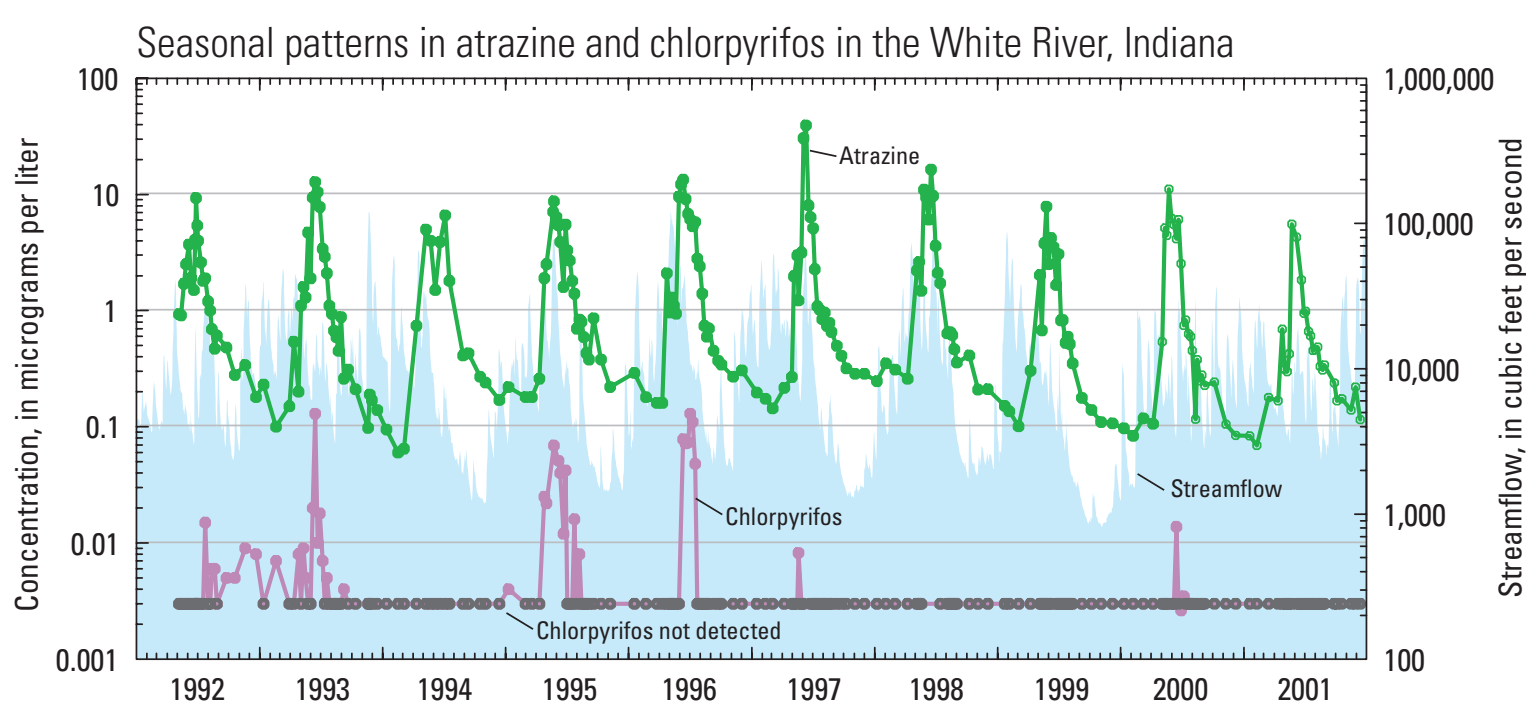

Figure 5-4. Atrazine concentrations in the White River (White River Basin) followed the same pattern each year during 1992-2001, corresponding to its use for weed control on nearly all of the corn acreage in the watershed each spring. In contrast, seasonal patterns in concentrations of chlorpyrifos and other insecticides tend to be more variable because insecticides are typically applied more sporadically than herbicides. 


\section{Mixtures of Pesticides}

Assessment of the effects of pesticides on water quality is further complicated by the simultaneous occurrence of multiple pesticides and degradates as mixtures. The mixtures result from the use of different pesticides for multiple purposes within a watershed or ground-water recharge area. Pesticides generally occur more often as mixtures than as individual compounds. As a result, evaluation of the potential effects of mixtures of pesticides and other contaminants is an increasingly important component of the risk assessment methods used by USEPA, the Agency for Toxic Substances and Disease Registry (ATSDR), and other agencies (see Chapter 6).

Consistent with the results for individual compounds discussed in Chapter 4, mixtures of pesticides were detected more often in streams than in ground water (fig. 5-5) and at relatively similar frequencies in streams draining areas of agricultural, urban, and mixed land use. More than 90 percent of the time, water from streams in these developed land-use settings had detections of 2 or more pesticides or degradates; about 70 percent of the time, streams had 5 or more, and about 20 percent of the time, streams had detections of 10 or more pesticides or degradates. Mixtures also were found in streams draining undeveloped watersheds, but with far fewer compounds - about 25 percent of the time, undeveloped streams had detections of 5 or more pesticides or degradates, and no samples had more than 10 .

In ground water, pesticide mixtures were detected most frequently in shallow wells in agricultural and urban areas - 47 percent of wells sampled in agricultural areas and 37 percent of wells in urban areas had detections of 2 or more pesticides or degradates. Only about 9 percent of the wells sampled in these areas contained 5 or more pesticides or degradates, and less than 1 percent contained more than 10. Consistent with the slow rate of ground-water movement and the resulting greater opportunities for sorption and transformation with increasing residence time, co-occurrences of multiple pesticides and degradates were less frequent in wells that tap major aquifers-only about 20 percent of such wells had detections of 2 or more pesticides or degradates. Mixtures were least prevalent in wells sampled in undeveloped areas.

Mixtures of organochlorine pesticide compounds also were common in fish-tissue samples from most streams (fig. 5-6). About 90 percent of fish samples collected from urban streams contained 2 or more pesticide compounds and 33 percent contained 10 or more. Similarly, 75 percent of fish samples from streams draining watersheds with agricultural and mixed land use contained 2 or more pesticide compounds and 10 percent had 10 or more. As with water samples, mixtures were detected least often in fish from undeveloped streams, in which 2 or more compounds were detected in about 25 percent of the fish-tissue samples.

The potential for effects of mixtures on humans, aquatic life, and fish-eating wildlife is ultimately determined by the specific combinations of compounds that occur together, their concentrations, and when and where they occur. A unique mixture is defined in this report as a combination of 2 or more particular compounds detected in a given sample, regardless of whether other compounds were also detected in the same sample (Squillace and others, 2002). For example, a sample containing compounds A, B, and

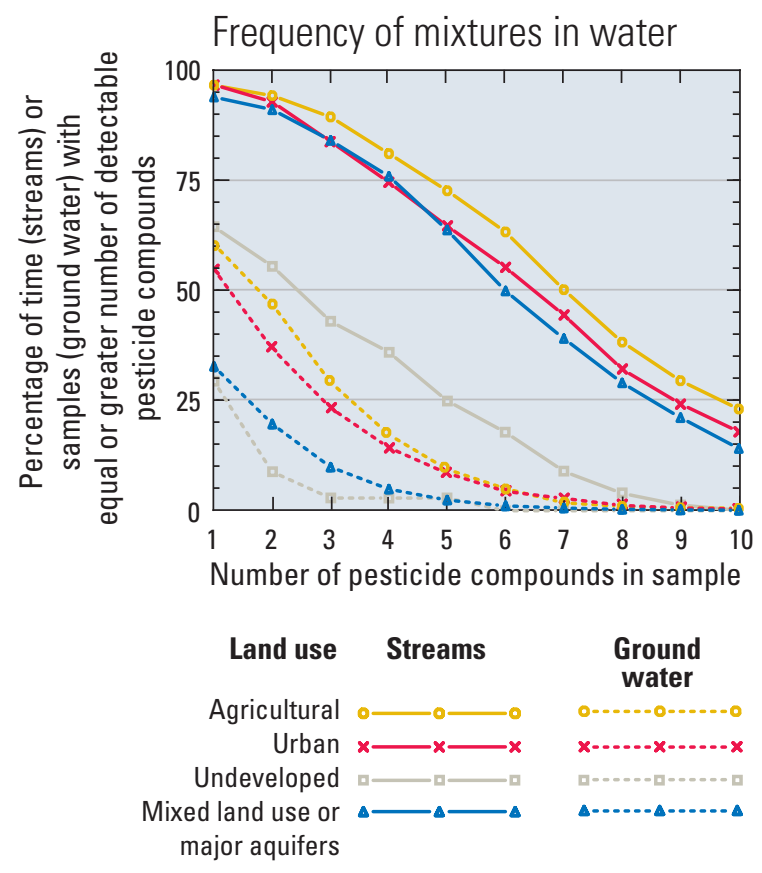

Figure 5-5. Mixtures of pesticide compounds analyzed in water were common in streams draining watersheds with agricultural, urban, and mixed land use. More than 90 percent of the time, water from streams in these land-use settings had detections of 2 or more pesticides or degradates, and almost 20 percent of the time, streams had detections of 10 or more. Mixtures were less common in ground water, but shallow wells in agricultural and urban areas had the most frequent occurrences of mixtures among all ground-water samples. 
$\mathrm{C}$ contains four unique mixtures- $\mathrm{AB}, \mathrm{AC}, \mathrm{BC}$, and $\mathrm{ABC}$. The number of unique mixtures in one sample can be very large if many compounds are detected. A sample with 2 compounds has only one mixture, but a sample with five compounds contains 26 unique mixtures. Unique mixtures examined in this report were limited to those composed of the most commonly detected pesticide compounds-specifically, 25 compounds in water and 15 in fish tissue (figs. 4-2 and 4-4)and were further limited to unique mixtures that occurred at least 2 percent of the time in streams or in at least 2 percent of samples for ground water and fish tissue.

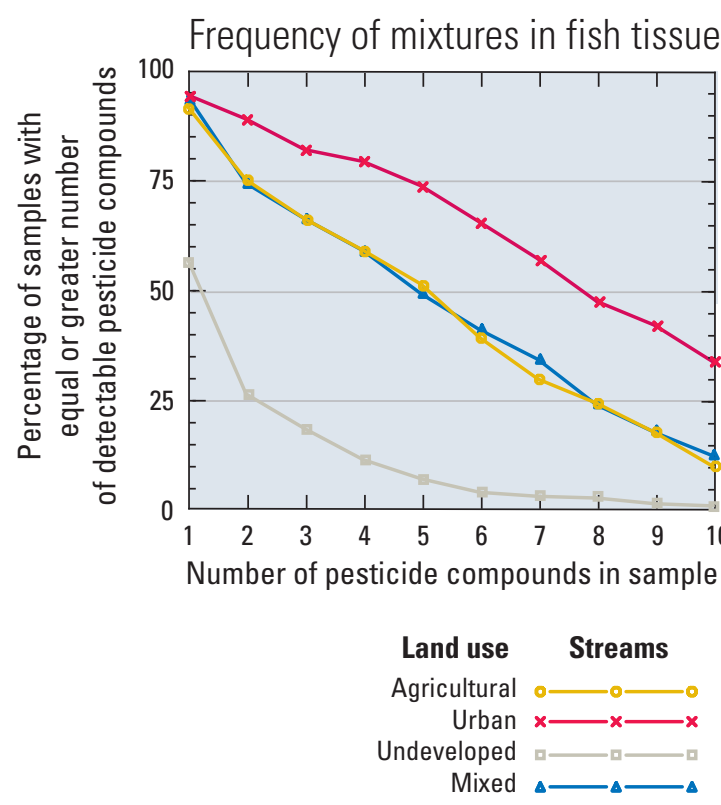

Figure 5-6. Mixtures of organochlorine pesticide compounds were detected in samples of whole fish from most streams. Fish in urban streams had the greatest numbers of organochlorine compounds detected, with about 90 percent of fish samples containing 2 or more compounds and 33 percent containing 10 or more. Streams in areas of agricultural and mixed land use had about 75 percent of fish-tissue samples with 2 or more compounds and 10 percent with 10 or more.

\section{Unique Mixtures in Water}

Streams have more unique mixtures than ground water (fig. 5-7), which is consistent with the more frequent detection of pesticides and their degradates in stream water compared with ground water. Analysis of all detections indicates that more than 6,000 unique mixtures of five pesticides were detected in agricultural streams, compared with only one unique mixture of five pesticides detected in shallow ground water within agricultural areas.

The number of unique mixtures varied with land use. For example, the greatest number of unique mixtures occurred in agricultural streams, probably because of the wide variety of agricultural settings represented, each involving the use of different combinations of pesticides (note the logarithmic scale in fig. 5-7). In ground water, however, the greatest number of unique mixtures occurred in shallow wells within urban areas, resulting primarily from the detection of urban herbicides that were not used or detected as frequently in agricultural settings. Major aquifers had the fewest mixtures, consistent with the lower frequencies of detection for individual compounds in these deeper ground waters.

The number of unique mixtures that can be detected is strongly influenced by the detection level for individual pesticides. In ground water, where pesticide concentrations usually are low, only 1 unique mixture of 2 compounds (atrazine and deethylatrazine in agricultural areas) was identified when the analysis was restricted to detected concentrations greater than $0.1 \mu \mathrm{g} / \mathrm{L}$. In streams, however, many unique mixtures were detected-even when evaluating only detections greater than $0.1 \mu \mathrm{g} / \mathrm{L}$ (fig. 5-7). At the $0.1 \mu \mathrm{g} / \mathrm{L}$ detection level, greater distinctions were evident between land-use settings. For example, about 50 unique 5-compound mixtures were detected in agricultural streams when only individual pesticides at concentrations greater than $0.1 \mu \mathrm{g} / \mathrm{L}$ are considered (compared with more than 6,000 when including all detections at any concentration). In urban streams, only 6 unique 5 -compound mixtures were detected above the $0.1 \mu \mathrm{g} / \mathrm{L}$ level.

The most frequent contributors to mixtures, not surprisingly, are the individual pesticides that were detected most often (fig. 5-8). These include the herbicides atrazine (and its degradate deethylatrazine), metolachlor, simazine, and prometon, each of which was present in more than 30 percent of all mixtures found in agricultural and urban areas, and in both streams and ground water. Also present in more than 30 percent of the mixtures were cyanazine, alachlor, metribuzin, and trifluralin in agricultural streams, and dacthal and the insecticides diazinon, chlorpyrifos, carbaryl, and malathion in urban streams. The most notable difference between urban and agricultural streams was the more common occurrence of insecticides in mixtures found in urban streams-consistent with the generally more frequent occurrence of insecticides in urban 

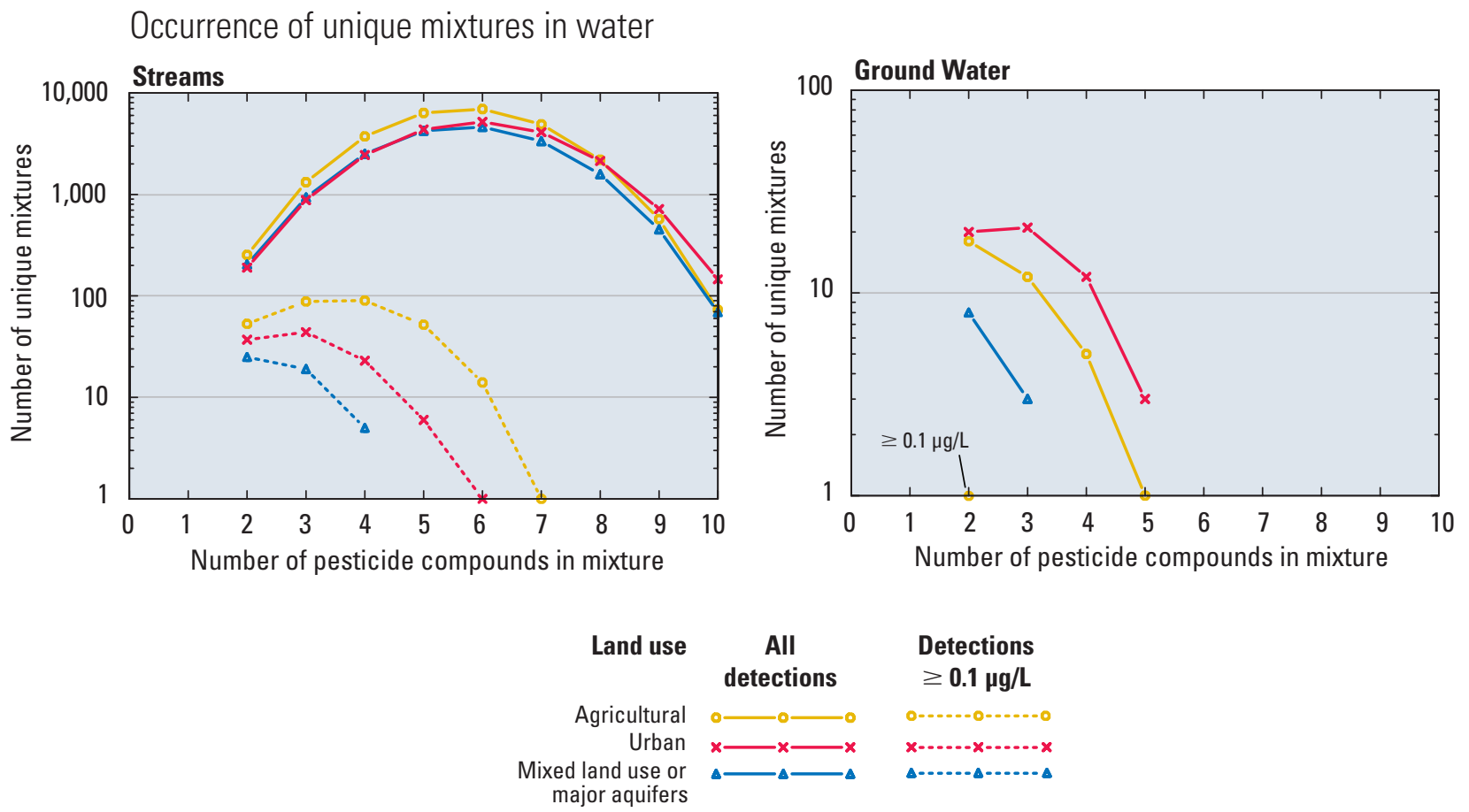

Figure 5-7. The number of unique mixtures detected in water was much greater in streams than in ground water. Considering all detections, more than 6,000 unique 5-compound mixtures were found in samples from agricultural streams, whereas only 1 unique 5-compound mixture was detected in shallow ground water beneath agricultural areas. Considering only pesticides detected at concentrations greater than or equal to $0.1 \mu \mathrm{g} / \mathrm{L}$, the number of unique mixtures was far less. These graphs include only those unique mixtures that were composed of the 25 most prevalent pesticides and were detected in at least 2 percent of the samples.

streams. A notable difference in ground water between urban and agricultural areas was the occurrence of tebuthiuron, which was present in about 35 percent of the mixtures detected in wells in urban areas, but in less than 2 percent of the mixtures in wells in agricultural areas.

The unique mixtures detected most frequently in streams and ground water are summarized in table $5-1$. This assessment is limited to the pesticides measured by NAWQA and by the sensitivity of the analytical method for each pesticide. For example, the analysis under-represents the contributions of 2,4-D, bentazon, bromacil, carbaryl, diuron, and norflurazon to mixtures, relative to the other pesticides, because these compounds were only detectable at higher concentrations. Most notably, 2,4-D was one of the most prevalent components of mixtures in both agricultural and urban streams at concentrations of $0.1 \mu \mathrm{g} / \mathrm{L}$ or greater. This implies that 2,4-D is also likely to be one of the most important contributors to mixtures at lower concentrations as well, but the low concentrations could not be measured.

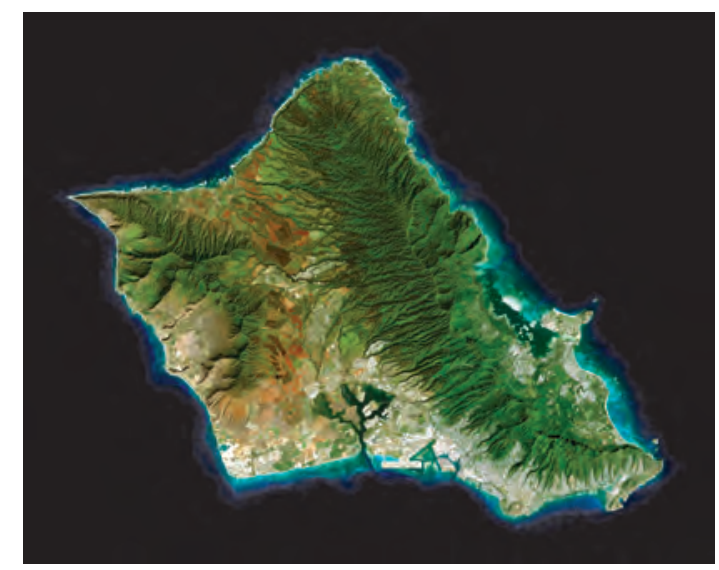

Combinations of agricultural and urban land uses, such as those on Oahu, Hawaii, result in use of many different pesticides, leading to complex mixtures of pesticide compounds in streams and ground water (Landsat satellite image from the Pacific Disaster Center). 


\section{Composition of unique mixtures in water}

Streams

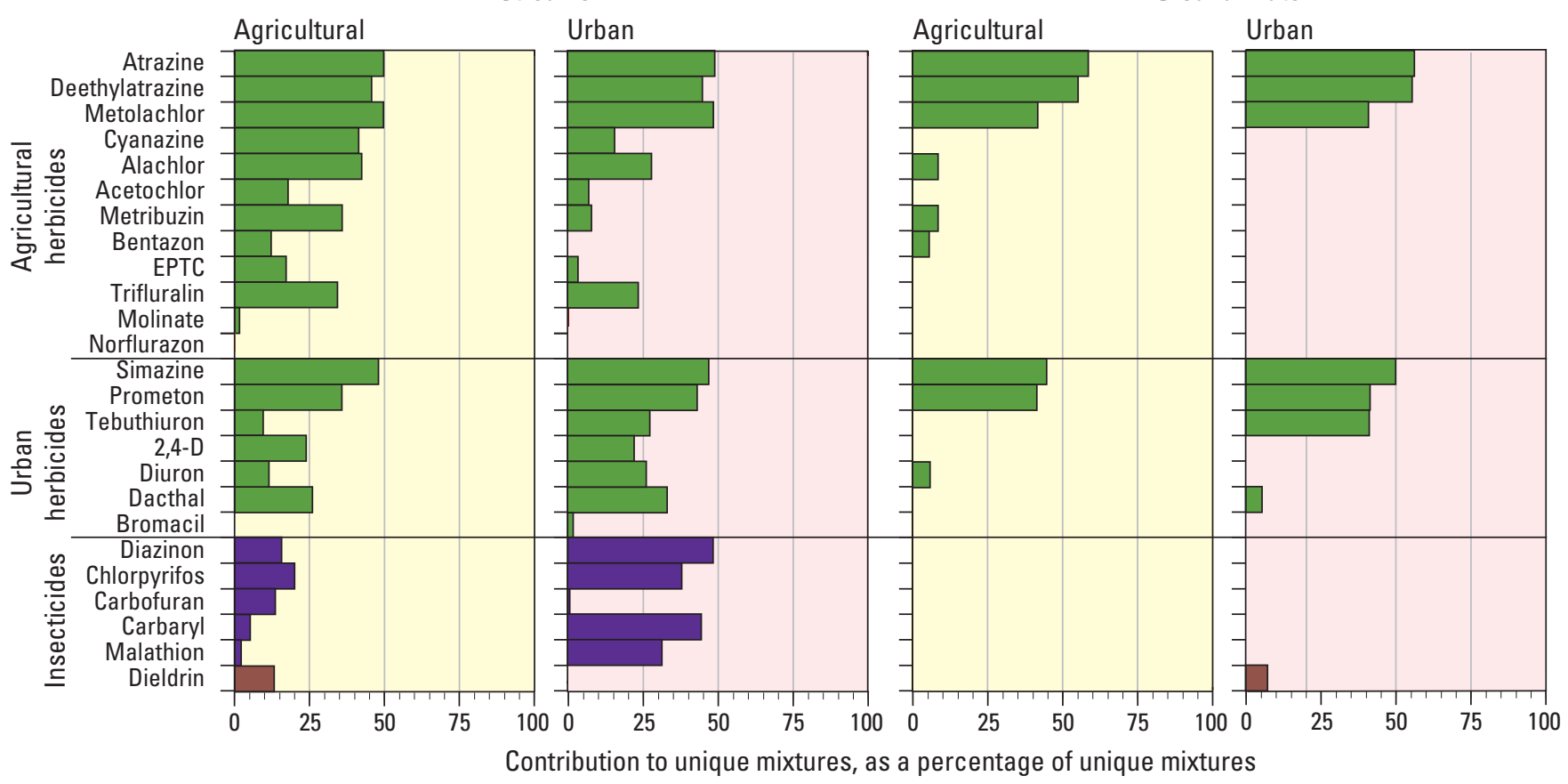

Figure 5-8. The most common components of mixtures, not surprisingly, were the pesticides and degradates that were detected most often. The most frequent contributors to unique mixtures were the herbicides atrazine (and deethylatrazine), metolachlor, simazine, and prometon-all of which were detected in more than 30 percent of all unique mixtures found in agricultural and urban areas and in streams and ground water. The most notable differences between agricultural and urban areas were (1) the greater contribution of insecticides to the mixtures detected in urban streams, and (2) the greater contribution of tebuthiuron to the mixtures found in shallow ground water in urban areas. This analysis is based on detections at any concentration, but includes only those unique mixtures that were composed of the 25 most prevalent pesticides and were detected in at least 2 percent of samples. 
Table 5-1. The most common unique mixtures of pesticides and degradates found in stream water and ground water illustrate the diversity and complexity of mixtures that occur in agricultural and urban areas. The mixtures detected most frequently for each number of compounds are shown for each land use, with all detections included, regardless of concentration. These most common unique mixtures serve as examples, rather than as a comprehensive compilation of all the most important mixtures, because other mixtures occurred almost as frequently.

\begin{tabular}{|c|c|c|c|c|}
\hline \multirow{3}{*}{ Mixture } & \multicolumn{4}{|c|}{$\begin{array}{c}\text { Frequency of detection } \\
\text { (percentage of time for streams, or samples for } \\
\text { ground water) }\end{array}$} \\
\hline & \multicolumn{2}{|c|}{ Streams } & \multicolumn{2}{|c|}{ Ground water } \\
\hline & Urban & Agricultural & Urban & Agricultural \\
\hline \multicolumn{5}{|l|}{ 2-compound mixtures } \\
\hline Atrazine Prometon & 79 & 50 & 15 & 10 \\
\hline Prometon Simazine & 75 & 41 & 10 & 7 \\
\hline Atrazine Simazine & 74 & 64 & 17 & 18 \\
\hline Atrazine Metolachlor & 55 & 77 & 8 & 15 \\
\hline Atrazine Deethylatrazine & 53 & 77 & 26 & 39 \\
\hline Deethylatrazine Simazine & 49 & 57 & 15 & 17 \\
\hline Deethylatrazine Metolachlor & 42 & 69 & 7 & 14 \\
\hline \multicolumn{5}{|l|}{ 3-compound mixtures } \\
\hline Atrazine Prometon Simazine & 68 & 41 & 9 & 7 \\
\hline Atrazine Diazinon Prometon & 60 & 10 & 1 & 0 \\
\hline Atrazine Diazinon Simazine & 59 & 16 & 1 & 0 \\
\hline Diazinon Prometon Simazine & 59 & 9 & 1 & 0 \\
\hline Atrazine Deethylatrazine Prometon & 50 & 48 & 12 & 9 \\
\hline Atrazine Deethylatrazine Simazine & 48 & 57 & 15 & 16 \\
\hline Atrazine Metolachlor Simazine & 48 & 57 & 6 & 7 \\
\hline Atrazine Deethylatrazine Metolachlor & 41 & 69 & 7 & 14 \\
\hline \multicolumn{5}{|l|}{ 4-compound mixtures } \\
\hline Atrazine Diazinon Prometon Simazine & 53 & 9 & 1 & 0 \\
\hline Atrazine Deethylatrazine Prometon Simazine & 46 & 39 & 8 & 7 \\
\hline Atrazine Metolachlor Prometon Simazine & 43 & 38 & 4 & 4 \\
\hline Atrazine Deethylatrazine Metolachlor Prometon & 39 & 45 & 5 & 6 \\
\hline Atrazine Deethylatrazine Metolachlor Simazine & 37 & 52 & 5 & 7 \\
\hline Alachlor Atrazine Deethylatrazine Metolachlor & 14 & 42 & 0 & 2 \\
\hline \multicolumn{5}{|l|}{ 5-compound mixtures } \\
\hline Atrazine Carbaryl Diazinon Prometon Simazine & 36 & 2 & 0 & 0 \\
\hline Atrazine Deethylatrazine Diazinon Prometon Simazine & 35 & 8 & 1 & 0 \\
\hline Atrazine Deethylatrazine Metolachlor Prometon Simazine & 35 & 37 & 4 & 4 \\
\hline Atrazine Diazinon Metolachlor Prometon Simazine & 35 & 8 & 0 & 0 \\
\hline Atrazine Deethylatrazine Prometon Simazine Tebuthiuron & 28 & 16 & 2 & 1 \\
\hline Atrazine Deethylatrazine Metolachlor Simazine Tebuthiuron & 22 & 19 & 2 & 1 \\
\hline Alachlor Atrazine Deethylatrazine Metolachlor Prometon & 13 & 33 & 0 & 1 \\
\hline Alachlor Atrazine Deethylatrazine Metolachlor Simazine & 13 & 33 & 0 & 1 \\
\hline Alachlor Atrazine Deethylatrazine Prometon Simazine & 12 & 26 & 0 & 1 \\
\hline Atrazine Cyanazine Deethylatrazine Metolachlor Simazine & 5 & 33 & 1 & 1 \\
\hline
\end{tabular}




\section{Unique Mixtures in Fish Tissue}

The numbers of unique mixtures of organochlorine pesticide compounds found in fish tissue are summarized in figure 5-9. Each individual parent compound, degradate, and by-product included in figure 4-4 was counted separately. Urban streams had more unique mixtures of these compounds in fish than streams draining areas with agricultural or mixed land use. For example, about 1,400 unique 5-compound mixtures were found in fish from urban streams, whereas streams in areas with agricultural or mixed land use had fewer than 800 unique 5-compound mixtures.

The relative contributions of most organochlorine compounds to mixtures in fish were about the same for urban and agricultural streams
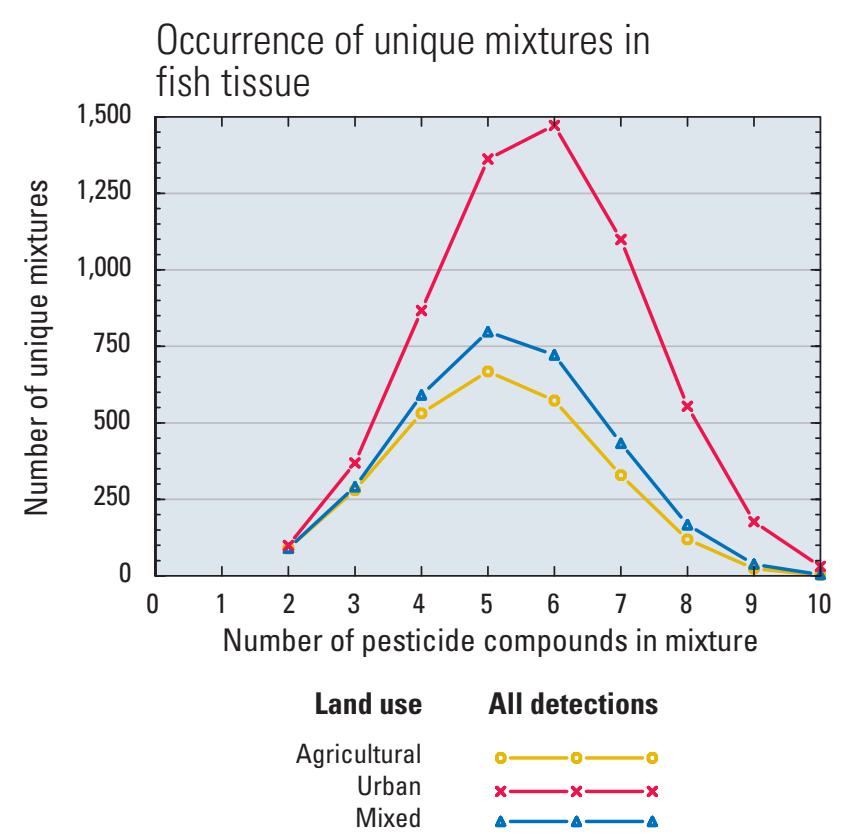

Figure 5-9. The numbers of unique mixtures of organochlorine pesticide compounds found in whole-fish tissue samples were greater in urban streams than in streams with agricultural or mixed-land-use watersheds. For example, about 1,400 unique 5-compound mixtures were found in fish from urban streams, whereas fewer than 800 unique 5-compound mixtures were detected in fish from agricultural and mixed-land-use streams. This analysis includes all detections, but only those unique mixtures that were composed of the 15 organochlorine pesticide compounds included in figure $4-4$ and that were detected in at least 2 percent of samples. (fig. 5-10). This reflects the fact that most of these compounds originated with a small number of pesticide products that were applied many years ago in both land-use settings. The most frequent contributors were compounds derived from formulations of DDT and DDD (especially the $p, p^{\prime}$ isomers), dieldrin (resulting from use of either aldrin or dieldrin), chlordane, and heptachlor epoxide (resulting from use of heptachlor)(table 5-2). The most notable difference between agricultural and urban streams was the greater importance in urban streams of hexachlorobenzene (an industrial compound, as well as a fungicide) and both $o, p^{\prime}$ - and $p, p^{\prime}$-DDT. The greater prevalence of DDT isomers in mixtures in urban streams, relative to agricultural streams, is consistent with the finding that the parent compounds ( $o, p^{\prime}$ - and $p, p^{\prime}$-DDT) made up a higher proportion of total DDT residues in fish from urban streams (16 percent) than in fish from streams with agricultural, undeveloped, or mixed-land-use watersheds ( $2-3$ percent). These results indicate either that DDT was applied more recently in urban watersheds, or that there has been more recent transport of DDT-contaminated soils to the streams in urban areas than to streams in most agricultural watersheds. (DDT breaks down more rapidly in the absence of dissolved oxygen and is, in general, less persistent in aquatic sediment than in soil.)

\section{Composition of unique mixtures in} fish tissue

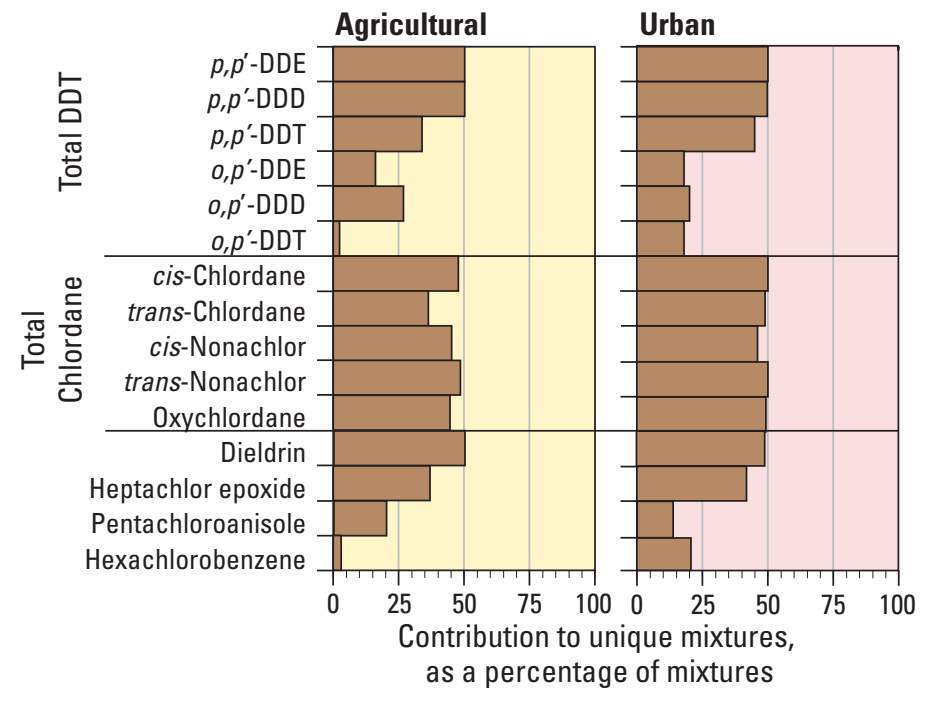

Figure 5-10. For the most part, compounds that contributed to unique mixtures found in fish tissue were similar for agricultural and urban streams, and 10 of the 15 compounds included in the analysis contributed to more than 30 percent of the mixtures in both land-use settings. 
Table 5-2. The most common unique mixtures of organochlorine pesticide compounds found in fish tissue were dominated by compounds derived from commercial formulations of DDT, DDD, and chlordane, as well as dieldrin. The mixtures detected most frequently for each number of compounds are shown for each land use. These most common mixtures serve as examples, rather than having unique importance, because many other mixtures occur almost as frequently.

\begin{tabular}{|c|c|c|}
\hline \multirow[t]{2}{*}{ Mixture } & \multicolumn{2}{|c|}{$\begin{array}{c}\text { Frequency of detection } \\
\text { (percentage of samples) } \\
\text { Fish tissue }\end{array}$} \\
\hline & Urban streams & $\begin{array}{l}\text { Agricultural } \\
\text { streams }\end{array}$ \\
\hline \multicolumn{3}{|l|}{ 2-compound mixtures } \\
\hline$p, p^{\prime}$-DDE trans-Nonachlor & 72 & 49 \\
\hline cis-Chlordane $p, p^{\prime}$-DDE & 72 & 37 \\
\hline cis-Chlordane trans-Nonachlor & 72 & 35 \\
\hline$p, p^{\prime}-\mathrm{DDD} p, p^{\prime}-\mathrm{DDE}$ & 64 & 59 \\
\hline Dieldrin $p, p^{\prime}$-DDE & 53 & 59 \\
\hline \multicolumn{3}{|l|}{ 3-compound mixtures } \\
\hline cis-Chlordane $p, p^{\prime}$-DDE trans-Nonachlor & 68 & 35 \\
\hline cis-Chlordane $p, p^{\prime}-\mathrm{DDD} p, p^{\prime}$-DDE & 60 & 28 \\
\hline cis-Chlordane $p, p^{\prime}$-DDD trans-Nonachlor & 57 & 27 \\
\hline$p, p^{\prime}$-DDD $p, p^{\prime}$-DDE trans-Nonachlor & 57 & 37 \\
\hline Dieldrin $p, p^{\prime}$-DDE trans-Nonachlor & 53 & 42 \\
\hline Dieldrin $p, p^{\prime}$-DDD $p, p^{\prime}$-DDE & 40 & 47 \\
\hline \multicolumn{3}{|l|}{ 4-compound mixtures } \\
\hline cis-Chlordane $p, p^{\prime}$-DDD $p, p^{\prime}$-DDE trans-Nonachlor & 56 & 27 \\
\hline cis-Chlordane $p, p^{\prime}$-DDE trans-Chlordane trans-Nonachlor & 51 & 25 \\
\hline cis-Chlordane $p, p^{\prime}$-DDE $p, p^{\prime}$-DDT trans-Nonachlor & 51 & 9 \\
\hline cis-Chlordane Dieldrin $p, p^{\prime}$-DDE trans-Nonachlor & 50 & 33 \\
\hline cis-Chlordane Dieldrin $p, p^{\prime}$-DDD $p, p^{\prime}$-DDE & 40 & 27 \\
\hline Dieldrin $p, p^{\prime}$-DDD $p, p^{\prime}$-DDE trans-Nonachlor & 40 & 34 \\
\hline \multicolumn{3}{|l|}{ 5-compound mixtures } \\
\hline cis-Chlordane $p, p^{\prime}$-DDD $p, p^{\prime}$-DDE trans-Chlordane trans-Nonachlor & 46 & 19 \\
\hline cis-Chlordane $p, p^{\prime}$-DDD $p, p^{\prime}$-DDE $p, p^{\prime}$-DDT trans-Nonachlor & 44 & 9 \\
\hline cis-Chlordane Dieldrin $p, p^{\prime}$-DDE trans-Chlordane trans-Nonachlor & 43 & 24 \\
\hline cis-Chlordane Dieldrin $p, p^{\prime}$-DDD $p, p^{\prime}$-DDE trans-Nonachlor & 40 & 26 \\
\hline cis-Chlordane $c i s$-Nonachlor Dieldrin $p, p^{\prime}$-DDE trans-Nonachlor & 39 & 23 \\
\hline
\end{tabular}




\section{Importance of Mixtures}

The frequent detection of pesticide mixtures in NAWQA samples from streams and ground water indicates that aquatic life, fish-eating wildlife, and potentially humans, are exposed primarily to mixtures of pesticides, rather than to individual compounds. As examined in Chapter 6 , determining the potential effects of mixtures is an increasingly important aspect of risk-assessment procedures for pesticides. These procedures generally rely on indirect estimates of mixture toxicity - made from the toxicities of individual pesticides that occur-primarily because toxicity data are seldom available for specific unique mixtures that occur in the environment. The large number of unique mixtures present in streams, and to a lesser extent in ground water, make it impractical to assess the potential effects of all that are encountered (Lydy and others, 2004). NAWQA results provide an assessment of the unique mixtures that were detected most frequently - such as those summarized in tables 5-1 and 5-2-and make it possible to prioritize specific mixtures for further investigation. In developing a strategy for investigation, however, it must be kept in mind that findings about mixtures, like those regarding individual pesticides, are limited to the pesticides measured, and are influenced by the analytical methods used in this study. Thus, NAWQA data yield a minimum assessment of the occurrence of mixtures because of the limited number of pesticides and degradates that were analyzed.

NAWQA data on mixtures are beginning to be used to prioritize toxicological investigations. For example, the ATSDR is in the process of evaluating the toxicity of the mixture of atrazine, deethylatrazine, diazinon, nitrate, and simazine (ATSDR, 2004a) because of the frequency of its occurrence in public-supply and domestic wells that were sampled by NAWQA (Squillace and others, 2002). The importance to aquatic life, wildlife, and humans of mixtures that occur in streams and ground water is difficult to determine, and will require multiple approaches over an extended period of time.

\section{Pesticide Degradates}

Once released into the environment, pesticides are transformed over time by a variety of chemical, photochemical, and biologically mediated reactions into other compounds, which are referred to in this report as degradates. With time, degradates may become as prevalent as parent pesticides - or more so-depending on their rate of formation and their relative persistence. For example, deethylatrazine, which is a degradate of atrazine and other triazine herbicides, was one of the few degradates included in routine NAWQA analyses, one of the most frequently detected pesticide compounds in water (fig. 4-2), and one of the most frequent contributors to pesticide mixtures (fig. 5-8). In addition, degradates and by-products of organochlorine pesticides were among the most commonly detected pesticide compounds in fish (fig. 4-4). This and other evidence from many studies in a wide range of settings indicate that a diverse range of pesticide compounds routinely occur along with mixtures of parent pesticides (Boxall and others, 2004).

Degradates, like their parent compounds, have the potential to adversely affect water quality, depending on their toxicity. Degradates may be either more or less toxic than their parent pesticides, although most have toxicities to aquatic life that are similar to, or lower than, those of their parent compounds (Sinclair and Boxall, 2003; see accompanying sidebar, p. 81). For some pesticides that have not been registered or reregistered by USEPA during the last several years, the toxicities of degradates have not been evaluated, but current registration requirements include assessment of the toxicities of major degradates, as described in the accompanying sidebar on USEPA risk assessments (p. 86).

The rates of pesticide transformation and degradate formation vary widely among pesticides and under different environmental conditions, as discussed in Chapter 2. Each transformation reaction requires specific physical, chemical, and biological conditions. For example, most oxidation reactions require the presence of dissolved oxygen, whereas reduction reactions require its absence. Photochemical reactions require the presence of sunlight that has sufficient energy to break specific chemical bonds. Many transformations-such as the conversion of atrazine to deethylatrazine, or the formation of alachlor ethanesulfonic acid (ESA) from alachlor in soil-will not occur without the assistance of microbes or other organisms (Barbash, 2004). Selected transformations of atrazine are dis- 


\section{Potential Risks of Pesticide Degradates to Aquatic Life}

Alistair B. A. Boxall, University of York, United Kingdom

Chris J. Sinclair, Central Science Laboratory, York, United Kingdom

Dana W. Kolpin, U.S. Geological Survey

Recent advances in analytical methodology and greater access to analytical standards have led to the detection of degradates from a wide variety of pesticides and other compounds in surface water, ground water, precipitation, air, and sediment (Boxall and others, 2004). Many of these degradates are more persistent in the environment than their parent compounds, and many are more mobile, as well.

In most cases, degradates have similar or lower toxicity to aquatic life than their parents, but some are more toxic. In a recent review of available ecotoxicity data for degradates of pesticides and other compounds, Sinclair and Boxall (2003) reported that 41 percent of degradates were less toxic than their parent compounds and 39 percent had a toxicity similar to their parents; however, 20 percent were more than 3 times more toxic than their parent compound and 9 percent were more than 10 times more toxic. In general, the greatest increases in toxicity from parent to degradate were observed for parent compounds that had a low toxicity. Similar patterns are apparent for degradates of 8 pesticides frequently detected by NAWOA (fig. 5-11), with 28 percent of the degradates being more toxic to fish than their parent compounds and 21 percent being more toxic to daphnids.

Because pesticides and their degradates are more commonly detected in environmental media as mixtures than as isolated compounds, assessments of their potential biological effects should account for the combined effects of multiple substances. As discussed in further detail in Chapter 6 of this report, the influence of a given compound $A$ on the toxicity of a second compound $B$ may be antagonistic (overall toxicity less than that of $A$ and $B$ combined),

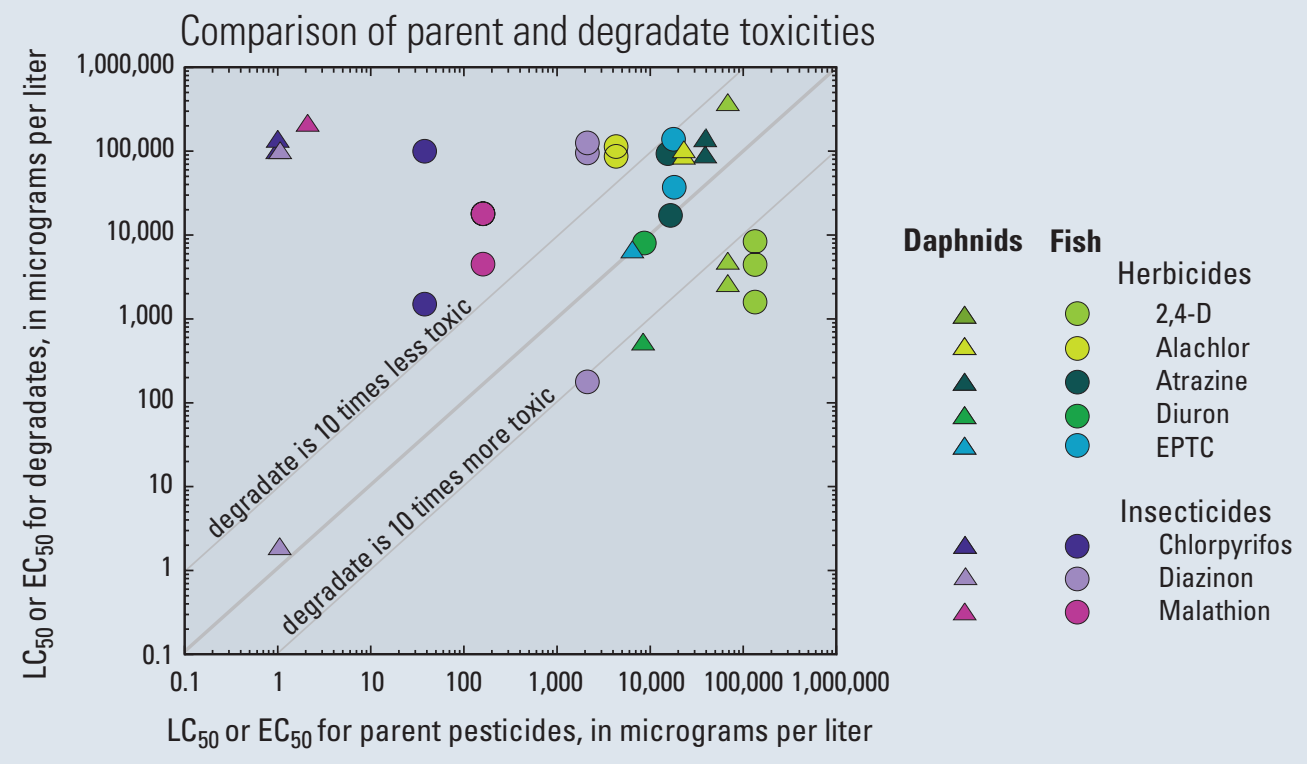

additive (overall toxicity is roughly equal to that of $A$ and $B$ combined) or synergistic (overall toxicity exceeds the added effects of the two compounds). The "mixture risk quotient" can be used to assess the combined risk of multiple compounds (parent compounds and/or degradates) simultaneously, based on the assumption that the toxic effects of different compounds are additive. This approach was recently applied by Fenner and others (2002) to assess the potential toxicities of predicted concentrations of nonylphenol ethoxylate (NPEO, a widely used nonionic surfactant) and its degradates to aquatic biota in Switzerland.

Although a variety of methods have been used to estimate mixture risk quotients, Fenner and others (2002) computed this parameter by summing the ratios of the concentrations predicted in Swiss rivers to the no-effect levels (for acute health effects in aquatic organisms) predicted for individual compounds in hypothetical mixtures of NPEO and its degradates. Risk quotients for NPEO alone and for each of the individual NPEO degradates were all below 1 for water and sediment, indicating relatively low risk to aquatic ecosystems with respect to acute (but not necessarily chronic) effects. The risk quotient calculated for the mixture of NPEO plus all of its transformation products, however, was 2.2, indicating a high risk of acute health effects for aquatic organisms if the toxicities are additive. This and other studies indicate that, in some instances, degradates from pesticides and other anthropogenic compounds may be of concern in the environment. An improved understanding is therefore needed of the environmental distributions, patterns of co-occurrence, and toxicities of these compounds in the hydrologic system-both in isolation and in mixtures.

Figure 5-11. Comparison of acute toxicity values ( $\mathrm{LC}_{50}$ or $^{\mathrm{E} C} \mathrm{C}_{50}$; see glossary) for parent compounds and degradates for 8 pesticides frequently detected by NAWOA in water samples from streams shows that 28 percent were more toxic to fish and 21 percent of the degradates were more toxic to daphnids than the parent pesticides. Multiples of the same symbol are different degradates of the same parent pesticide. 
played in figure 5-12, to show three of the multiple pathways that these reactions may involve, and to provide a sense of the complexity involved with tracking the formation, transport and fate of degradates for all of the pesticides in use. This example also illustrates the varying effects of different reactions on toxicity, discussed earlier. The first two reactions produce degradates with mammalian toxicities similar to that of the parent compound (atrazine). By contrast, the third reaction generates a compound (hydroxyatrazine) with substantially lower mammalian toxicity, owing to the removal of chlorine (Jordan and others, 1970; Rodriguez and Harkin, 1997).

As noted earlier, degradates are often more prevalent than their parent pesticides in streams and ground water, particularly when conditions favor transformation to degradates that are chemically persistent. In parts of some hydrologic systems, the concentrations of degradates may exceed those of the parent pesticides throughout much of the year. In surface waters, degradates often predominate when much of the streamflow is either from ground water, or from surface runoff occurring long enough after pesticide applications for the parent pesticide to have substantially transformed. For example, the summed concentrations of atrazine, cyanazine, acetochlor, alachlor, and metolachlor in the Iowa River in the Eastern Iowa Basins changed rapidly in response to the timing of their applications, but the summed concentrations of their degradates were higher and relatively constant throughout most of the year (fig. 5-13). Similarly, in the Mermentau River in the Acadian-Pontchartrain Drainages, the concentration of the insecticide fipronil reached its maximum value immediately following the spring application season, and then declined, to be exceeded by concentrations of fipronil degradates from June to February. This cycle repeated itself with the springtime applications the following year (fig. 5-14). Information on the concentrations and fluxes of degradatesespecially in relation to those of their parent

\section{Atrazine transformation}<smiles>CCNC1NC(Cl)NC(NC(C)CBr)N1</smiles>

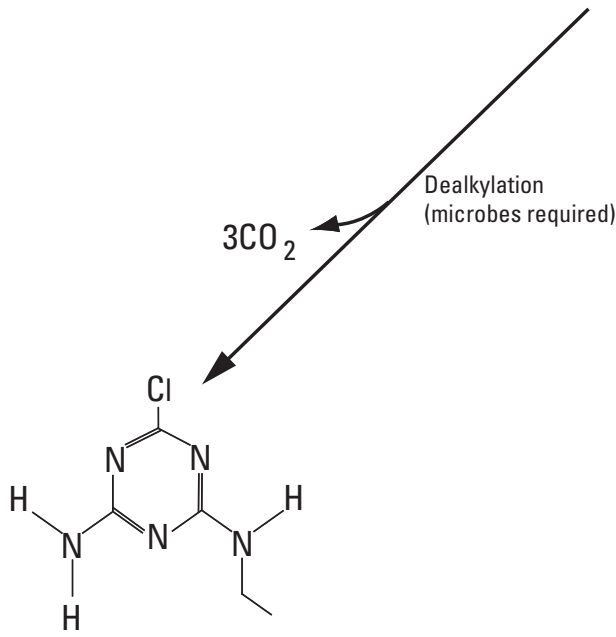

deisopropyl atrazine

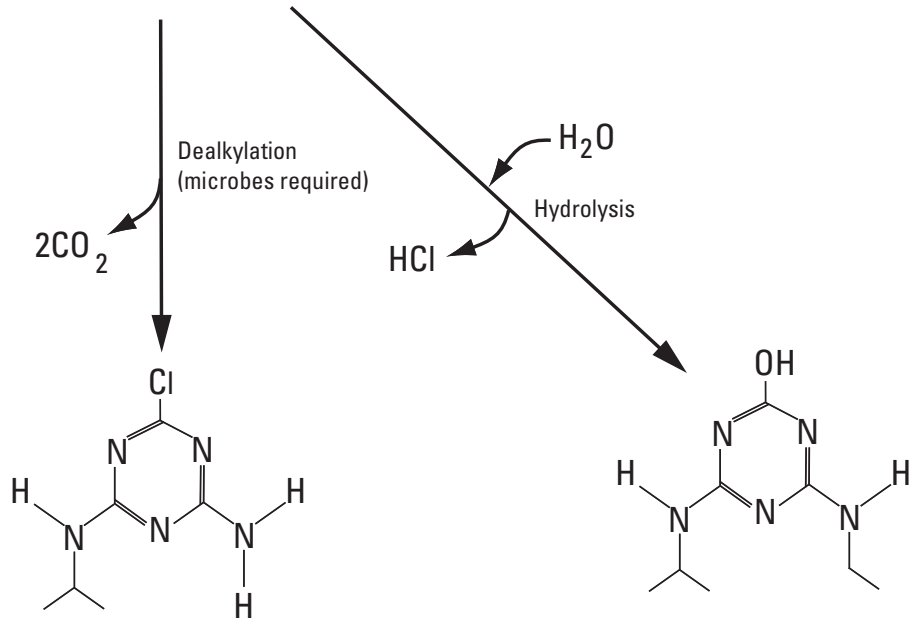

deethylatrazine hydroxyatrazine

Figure 5-12. Atrazine transforms to three primary degradates (although there are others as well), one of whichdeethylatrazine-was routinely measured by NAWQA. Two of these transformation reactions require microbes, resulting in the formation of deethylatrazine and deisopropyl atrazine. The third is hydrolysis, an abiotic reaction with water that produces the degradate hydroxyatrazine. 


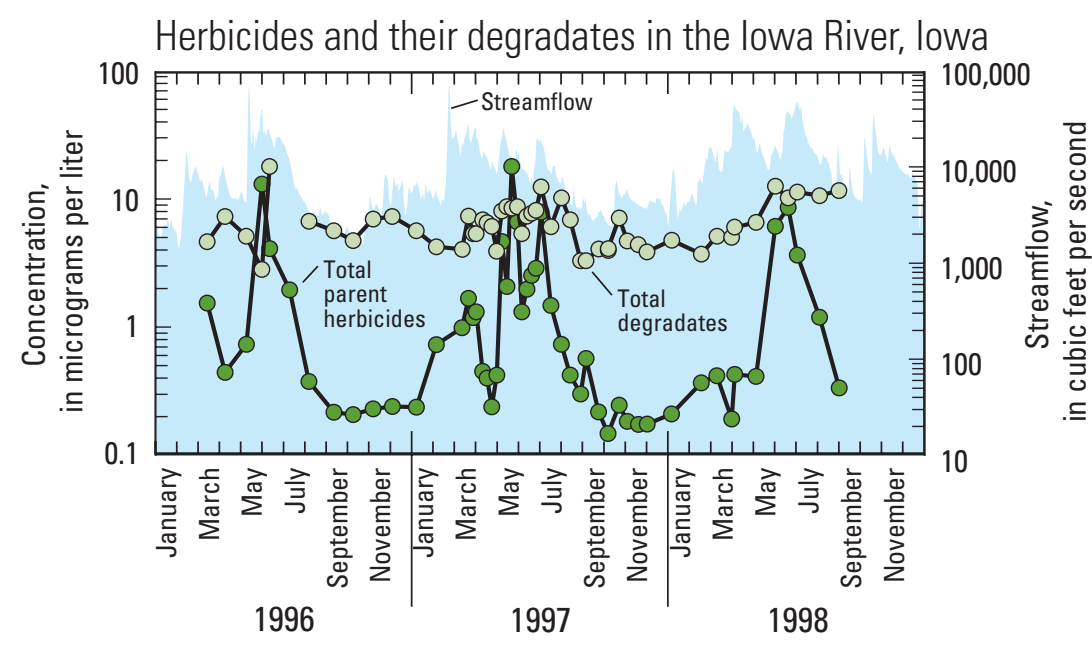

Figure 5-13. The summed concentrations of the parent herbicides atrazine, cyanazine, acetochlor, alachlor, and metolachlor in the lowa River (Eastern lowa Basins) rose and fell in response to spring applications, whereas the summed concentrations of their degradates remained relatively steady and at higher levels throughout most of the year (Schnoebelen and others, 2003).

Fipronil and its degradates in the Mermentau River, Louisiana

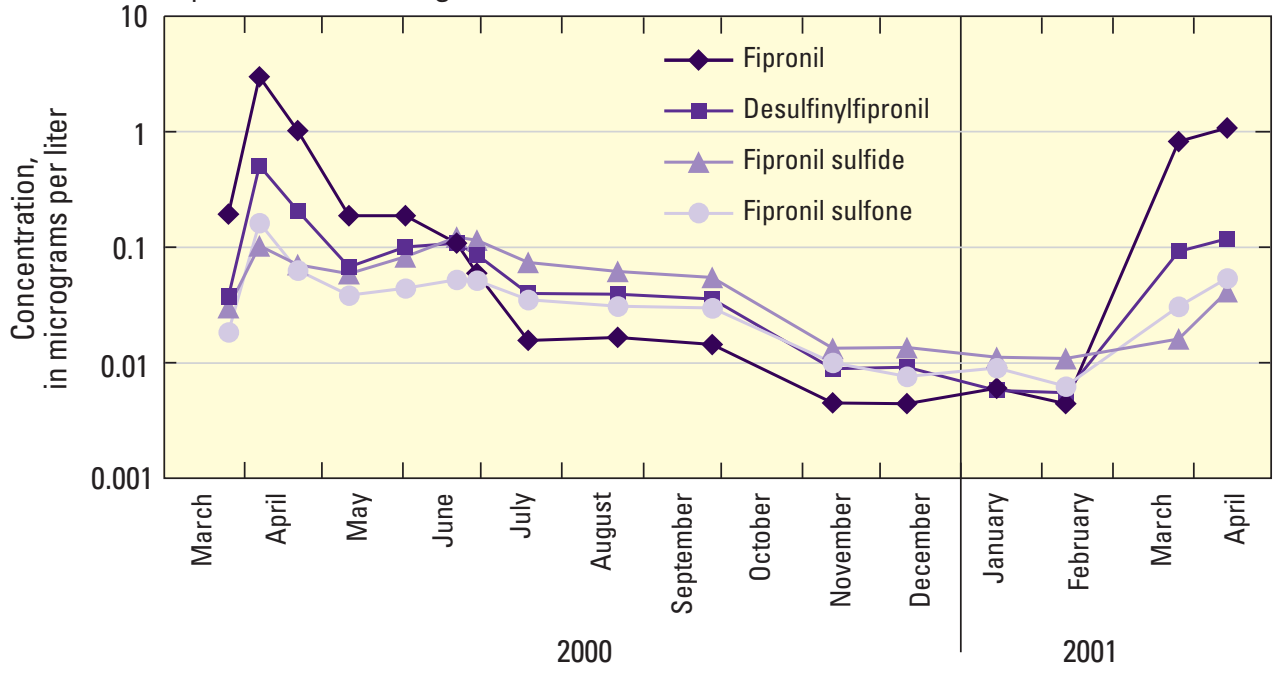

Figure 5-14. Concentrations of the insecticide fipronil and its degradates in the Mermentau River (Acadian-Pontchartrain Drainages) peaked in March or April, following applications. Although fipronil dominated the total concentration of fipronil compounds during the high-use period, concentrations of its degradates were greater during the rest of the year (Demcheck and others, 2004). 
pesticides - contributes to our understanding of the environmental fate of pesticides as they move and transform within the hydrologic system.

In ground water, degradates were often detected more frequently, or at higher concentrations, than their parent pesticides. For example, in ground water of the Upper Illinois River Basin, degradates of acetochlor, alachlor, metolachlor, and atrazine accounted for substantially more detections than the parent compounds (fig. 5-15). Two of the principal factors likely to be responsible for this general observation are that (1) ground water recharges through soil where microbial populations - and thus transformation rates-are relatively high, and (2) residence times in ground water are usually long prior to sample collection, allowing more time for transformations to occur than is usually the case for surface waters.

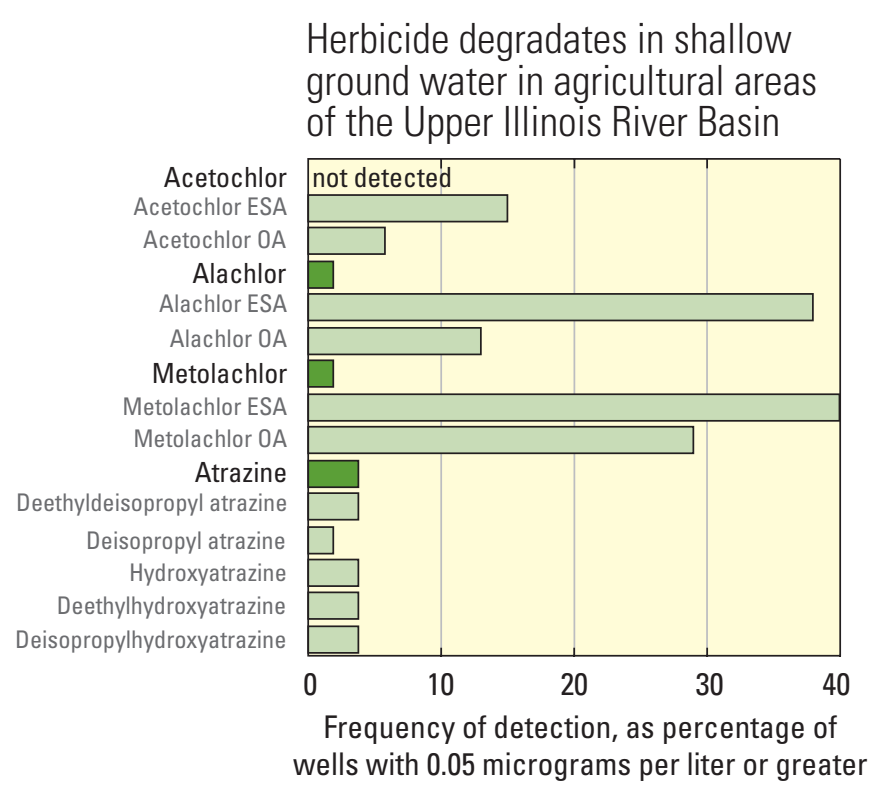

Figure 5-15. In ground water of the Upper Illinois River Basin, degradates (light bars) were generally detected more frequently than parent compounds (dark bars) for the acetanilide herbicides (acetochlor, alachlor, and metolachlor), but at comparable frequencies for atrazine (Groschen and others, 2004).

\section{Deethylatrazine-to-Atrazine Ratios}

As pesticides are transported through the hydrologic system, transformations occur continuously and at various rates, resulting in changes in the proportional relations between parent pesticides and their degradates with time and space. In general, the extent of transformation increases with increasing residence time in the hydrologic system. As a result, degradate-toparent compound concentration ratios-such as the deethylatrazine-to-atrazine ratio (Adams and Thurman, 1991)—have been used as indicators of residence time in the environment. Because the transformation of atrazine to deethylatrazine requires microbial assistance (fig. 5-12) - and microbial populations are generally much higher in the soil than at greater depths beneath the land surface or in surface waters - the deethylatrazine-to-atrazine ratio provides an indication of the amount of time that atrazine has been in contact with soil. In streams, the deethylatrazineto-atrazine ratio increased with the time elapsed between atrazine applications and samplingfrom the lowest values during atrazine applications in the spring, to higher values in autumn, and to the highest values in winter, just before applications (fig. 5-16). Figure 5-17 shows how the ratio changed over time during the year in the White River. Because the analytical recovery (the proportion of the actual total concentration that could be measured) for deethylatrazine was lower than for atrazine, the ratios reported here underestimate the true value, but the focus of this analysis is on the relative magnitudes of the ratios among different media, settings, and times of year, rather than their absolute values.

Deethylatrazine-to-atrazine ratios were generally higher in ground water than in streams throughout the year, reflecting the longer periods of time spent in contact with soil for the atrazine detected in the ground-water system, relative to streams (fig. 5-16). The proportions of deethylatrazine in water collected from major aquifers-which generally represents ground water that is deeper and older than water collected from shallow wells-were typically higher than those measured in the shallow ground water sampled within agricultural areas. 


\section{Importance of Pesticide Degradates}

NAWQA results are consistent with findings from other studies that found that pesticide degradates occur frequently in streams and ground water (Battaglin and others, 2001; Scribner and others, 2003; Kolpin and others, 1998; Kolpin and others, 2004). Assessment of the occurrence, distribution, and toxicities of pesticide degradates in the hydrologic system is important because of the potential effects of these compounds on human health and the environment (Sinclair and Boxall, 2003), as well as their value for under- standing the ultimate fate of pesticides in the hydrologic system (Barbash, 2004). Pesticide degradates should continue to be considered and accounted for in assessments of pesticide exposure and in evaluating the potential effects of pesticides. Improved assessment of pesticide degradates will require expanded coverage of degradates in water-quality monitoring, continued research on pesticide transformations and transport, and continued attention to these compounds in toxicity studies, including as components of pesticide mixtures (see Chapter 6).

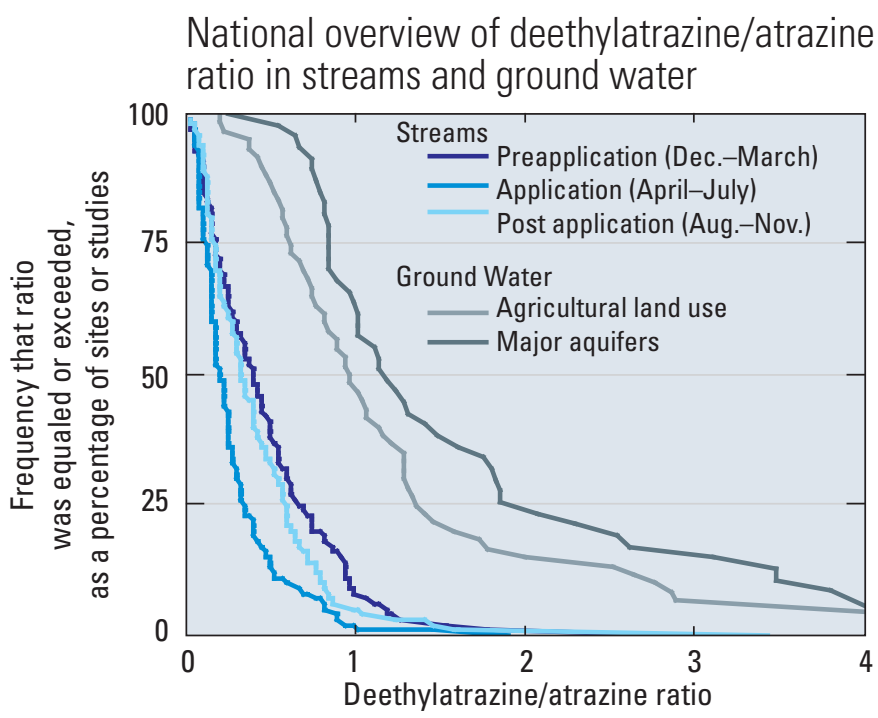

Deethylatrazine/atrazine ratio in the

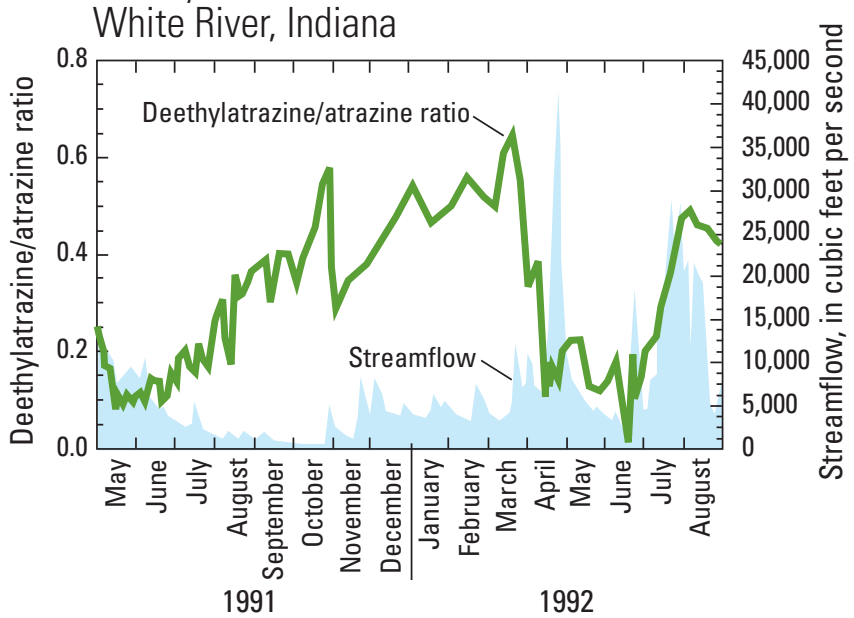

Figure 5-17. The ratios of deethylatrazine to atrazine concentrations in the White River (White River Basin) were lowest in the spring, following widespread atrazine applications. The ratio generally increased through the summer and winter as atrazine transformed to deethylatrazine and ground water made up an increasing proportion of streamflow. (Ratios were computed from $\mu \mathrm{g} / \mathrm{L}$ concentrations; modified from Carter and others, 1995.)
Figure 5-16. The ratios of deethylatrazine to atrazine concentrations-which increase with the transformation of atrazine to deethylatrazineincreased with increasing residence time in the hydrologic system. (Ratios were computed from $\mu \mathrm{g} / \mathrm{L}$ concentrations for all NAWOA stream and ground-water samples in which both compounds were detected.) 


\section{Pesticide Degradates in USEPA Risk Assessments and Regulations}

\section{Federal Insecticide, Fungicide, and Rodenticide Act (FIFRA)}

When USEPA characterizes the risks of a pesticide to humans and the environment to meet the requirements of FIFRA, the agency evaluates both the parent pesticide and its degradates. Before a pesticide is registered, USEPA reviews and evaluates available studies on the pesticide's properties and effects, including its degradates (USEPA, 2005a). The types of data needed vary depending on how and where the pesticide is used (USEPA, 2004a).

Available studies may provide information on the degradation rates, mobility parameters, and toxicity for potentially important degradates. If adequate data are not available for specific degradates, USEPA's risk assessments for drinking-water exposure under FIFRA assume that degradates are highly persistent and mobile. If different toxicities are expected between degradates and the parent pesticide, concentrations are estimated separately. If the same toxicity is expected, concentrations of the parent and degradates are added together. These risk estimates are often conservative (protective) because it is frequently assumed that the degradate and parent have equal toxicities and that they are mobile and persistent. If data are available for a specific degradate, however, then those data are used. In some cases, degradates are known to be more toxic than the parent compound. In situations where degradates occur in substantial amounts or are of toxicological concern, risk assessments include a quantitative or qualitative analysis of the potential implications of an organism's exposure to these degradates, in addition to the parent pesticide.

USEPA environmental fate scientists work with human health and ecotoxicology scientists to identify the degradates of toxicological concern. The formation of degradates is monitored as part of fate studies required for pesticide registration. Methods are used that have detection limits sufficiently low to allow for detailed tracking of the production of degradates. Degradates formed at greater than 10 percent of radioactively labeled parent pesticide are considered major degradates and must be identified (USEPA, 1982). The 10-percent criterion is a general guideline, such that degradates approaching concentrations of 10 percent of the parent are usually identified as well. In addition, degradates of known toxicological or ecotoxicological concern must be quantified and identified even when present at lower levels.

When environmental monitoring data are available for pesticide degradates, the data are characterized and summarized in USEPA's assessments for FIFRA. In evaluating monitoring data, scientists evaluate the analytical methods used, pesticide-use information, and the design of the monitoring studies. Monitoring data on the occurrence of degradates are included in the FIFRA risk assessment, but the assessment of risk also depends on a variety of additional factors, including the mode of toxicity of the degradate-information that is needed to determine if concentrations of the parent pesticide and degradates can reasonably be aggregated to assess risk.

\section{Clean Water Act (CWA)}

Ambient water-quality criteria, developed by USEPA under section 304(a) of the CWA, focus on individual chemicals. If a degradate is toxicologically important, a separate criterion may be developed for the degradate. Human health ambient water-quality criteria exist for DDT, DDE, and DDD; endrin and endrin aldehyde; heptachlor and heptachlor epoxide; and endosulfan and endosulfan sulfate. Wholeeffluent toxicity tests, described in Chapter 6 in relation to assessing potential effects of pesticide mixtures on aquatic life, also provide an approach for assessing degradate toxicity.

\section{Safe Drinking Water Act (SDWA)}

Maximum Contaminant Levels (MCLs) are legally enforceable drinking-water standards developed by USEPA under the SDWA. Although drinking-water standards have typically been developed only for the pesticide parent, the SDWA does not preclude USEPA from developing standards for pesticide degradates. Several unregulated pesticide degradates are listed on USEPA's drinking-water Contaminant Candidate List (CCL) and its Unregulated Contaminant Monitoring Regulation (UCMR) (USEPA, 2005b,c). Once sufficient information and data are available on health risks, occurrence, analytical methods, and treatment technologies, USEPA will determine whether any of the listed pesticide degradates are candidates for future drinking-water standards.

USEPA also develops drinking-water Health Advisories for chemical substances, including some pesticides and pesticide degradates. Health Advisories, which are not legally enforceable, provide technical guidance for Federal, State, Tribal and local officials in the event of an emergency spill or contamination situation. USEPA periodically updates Health Advisories when new information becomes available (USEPA, 2005d). 


\section{Potential for Effects on Human Health, Aquatic Life, and Wildlife}

The occurrence of pesticides in streams and ground water raises the question-Do pesticides occur at concentrations that may affect human health or stream ecosystems? Comparisons of concentrations measured by NAWQA to water-quality benchmarks provide a screening-level assessment of the potential for adverse effects. Concentrations of pesticides detected in streams and wells were usually lower than human-health benchmarks, indicating that the potential for effects on drinking-water sources probably is limited to a small proportion of source waters. More than half of the wells sampled, but none of the stream sites that were sampled, are current sources of drinking water. Concentrations in streams more frequently exceeded benchmarks for aquatic life and fish-eating wildlife. More than half of all agricultural streams sampled and more than three-quarters of all urban streams had concentrations of pesticides in water that exceeded one or more benchmarks for aquatic life. In addition, organochlorine pesticides-most uses of which were discontinued 15-30 years ago-still exceeded benchmarks for aquatic life and fish-eating wildlife in bedsediment or fish-tissue samples from many streams.

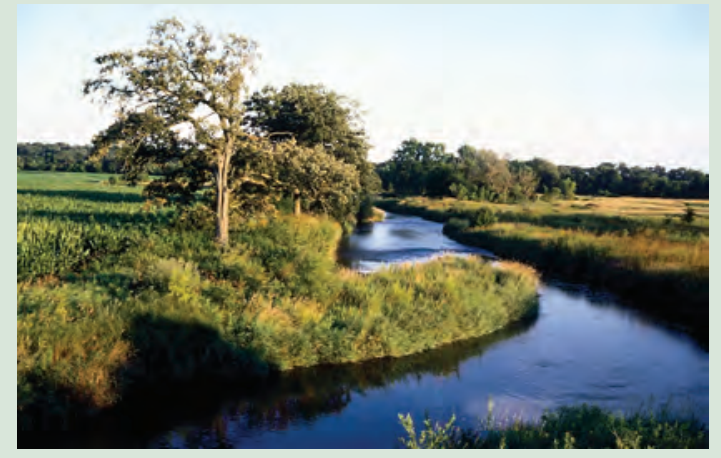

This chapter examines the potential for pesticides to have adverse effects on human health, aquatic life, and fisheating wildlife. The potential is assessed by comparing measured concentrations with water-quality benchmarks The screening-level assessment provides indications of the distribution of potential effects and the pesticides that may cause them, which can be used to prioritize further investigations. 


\section{Screening-Level Assessment of Potential Effects}

The potential for pesticide concentrations measured by NAWQA to adversely affect human health, aquatic life, or fish-eating wildlife was evaluated by screening-level assessments similar in concept to USEPA screening-level assessments (USEPA, 2004d). The NAWQA screening-level assessments compare site-specific estimates of pesticide exposure (concentration statistics or concentrations determined from measurements of pesticides in various media at NAWQA sampling sites) with water-quality benchmarks derived from standards and guidelines established by USEPA, toxicity values from USEPA pesticide risk assessments, and selected guidelines from other sources. The characteristics and limitations of screening-level assessments are summarized in the accompanying sidebar on page 89. The USEPA standards, guidelines, and toxicity values were developed by USEPA as part of the Federal process for assessing and regulating pesticides, as summarized in the sidebar on page 90 .

NAWQA studies were not designed to evaluate specific effects of pesticides on humans, aquatic life, or fish-eating wildlife. The screening-level assessment is not a substitute for either risk assessments, which include many more factors (such as additional avenues of exposure), or site-specific studies of effects. Rather, comparisons of measured concentrations with waterquality benchmarks provide a perspective on the potential for adverse effects, as well as a framework for prioritizing additional investigations that may be warranted. Measured concentrations that exceed a benchmark do not necessarily indicate that adverse effects are occurring-they indicate that adverse effects may occur and that sites where benchmarks are exceeded may merit further investigation.
Screening-level assessments should be considered as a first step toward addressing the question of whether or not pesticides are present at concentrations that may affect human health, aquatic life, or wildlife. They provide a perspective on where effects are most likely to occur and what pesticides or degradates may be responsible. As improved data on toxicity and environmental concentrations are developed, benchmarks and exposure estimates can be updated, and the assessments can be improved and expanded. USGS works closely with USEPA to assist them with incorporating NAWQA findings into their risk assessments.

NAWQA screening-level assessments for pesticides are presented in this chapter for human health (concentrations in water), aquatic life (concentrations in water and bed sediment), and fish-eating wildlife (concentrations in whole fish). The selection of benchmarks for each of these assessments is described below along with results and the specific values and sources for benchmarks used are provided in Appendix 3. Each type of benchmark selected for use in the screening-level assessment applies to a specific sampling medium (such as water or bed sediment) and to a specific use of the water resource (such as for drinking water or to support aquatic life). Priority was given to (1) benchmarks based on USEPA standards, guidelines, or toxicity values; (2) benchmarks that are nationally relevant because of the nature or breadth of toxicity data on which they are based; and (3) systematically derived suites of benchmarks that share a common methodology and are available for a large number of NAWQA analytes. 


\section{Characteristics and Limitations of the Screening-Level Assessment of Potential Effects}

The NAWQA screening-level assessment provides an initial perspective on the potential importance of pesticides to water quality in a national context by comparing measured concentrations with water-quality benchmarks. The screening-level assessment is not a substitute for risk assessment, which includes many more factors, such as additional avenues of exposure. The screening-level results are primarily intended to identify and prioritize needs for further investigation and have the following characteristics and limitations.

- Most benchmarks used in this report are estimates of no-effect levels, such that concentrations below the benchmarks are expected to have a low likelihood of adverse effects and concentrations above a benchmark have a greater likelihood of adverse effects, which generally increases with concentration.

- The presence of pesticides in streams or ground water at concentrations that exceed benchmarks does not indicate that adverse effects are certain to occur. Conversely, concentrations that are below benchmarks do not guarantee that adverse effects will not occur, but indicate that they are expected to be negligible (subject to limitations of measurements and benchmarks described below).

- The potential for adverse effects of pesticides on humans, aquatic life, and fish-eating wildlife can only be partially addressed by NAWOA studies because chemical analyses did not include all pesticides and degradates. In addition, some compounds analyzed by NAWQA do not have benchmarks.

- Most benchmarks used in this report are based on toxicity tests of individual chemicals, whereas NAWQA results indicate that pesticides usually occur as mixtures. Comparisons to single-compound benchmarks may tend to underestimate the potential for adverse effects.

- Water-quality benchmarks for different pesticides and media are not always comparable because they have been derived by a number of different approaches, using a variety of types of toxicity values and test species.

- For some benchmarks, there is substantial uncertainty in underlying estimates of no-effect levels, depending on the methods used to derive them and the quantity and types of toxicity information on which they are based. This is especially true of fish-tissue benchmarks for the protection of fish-eating wildlife, for which there is no consensus on national-scale benchmarks or toxicity values.

- Estimates of pesticide exposure derived from NAWQA concentration measurements are also uncertain-particularly estimates of short-term exposure of aquatic organisms to pesticides in stream water. Generally, short-term average concentrations in stream water, such as 4-day values, are underestimated from NAWOA data.

\section{Screening-Level Assessment for Human Health}

NAWQA studies, as emphasized in Chapter 3, characterized the quality of untreated water from streams and ground water, whether or not that water was used as a source of drinking water during the study period. More than half of the wells sampled for ground-water studies, but none of the stream sites that were sampled, were sources of domestic or public water supplies. In this report, measured concentrations of pesticides in all wells and streams sampled, whether or not they were sources of drinking water during the study period, are compared with human-health benchmarks derived from available USEPA drinking-water standards and guidelines as a starting point for understanding the potential importance of pesticides in a human-health context. The benchmarks are described in the accompanying sidebar on page 91 and values are listed in Appendix 3A.

Comparisons of human-health benchmarks to the concentrations observed in NAWQA studies provide a perspective on the potential importance to human health as use of water resources expands, but they are not appropriate for assessing current compliance with drinking-water regulations. A measured concentration or computed annual mean that is greater than a benchmark indicates the potential need for further investigation if such water either is presently used as a drinking-water source, or may be used as a source in the future. A concentration greater than a Maximum Contaminant Level (MCL), even in water that is now a source of drinking water, does not indicate violation of a standard. For water currently used as a drinking-water source, pesticide concentrations in finished water may be lower than those measured in untreated 


\section{Federal Regulation of Pesticides in Water}

The potential effects of pesticides on humans and the environment are managed under several Federal Acts and regulated through a combination of Federal, State, and Tribal responsibilities. The Federal Insecticide, Fungicide, and Rodenticide Act (FIFRA), the Federal Food, Drug and Cosmetic Act (FFDCA), the Food Quality Protection Act (FOPA), the Safe Drinking Water Act (SDWA), and the Clean Water Act (CWA) - all of which are administered by USEPA and partner agencies-provide the regulatory framework that affects the assessment and control of pesticides and their degradates in water resources.

The FIFRA, first enacted in 1947 and amended most recently by the FQPA in 1996, provides the original framework for the Federal pesticide licensing program administered by USEPA and covers the evaluation and registration of pesticides for specific uses. Before a pesticide may be registered it must be shown, among other things, that it will not generally cause "unreasonable adverse effects" to water, air, land, plants, and man and other animals. The FFDCA authorizes USEPA to set maximum residue levels, or tolerances, for pesticides used in or on foods or animal feed, and mandates strong provisions to protect infants and children. Before a pesticide registration may be granted for use on a food commodity, a tolerance must be set or an exemption from a tolerance granted. The FOPA amended the FIFRA and FFDCA to set more stringent safety standards for new and old pesticides. Among its provisions are that (1) human-health assessments must consider aggregate exposures, including all dietary, drinking-water, and nonoccupational exposure; and (2) assessments leading to tolerance decisions must consider, relative to human health, the cumulative effects and common mode of toxicity among related pesticides, the potential for endocrine-disrupting effects, and appropriate safety factors to further protect infants and children. Through application of the FIFRA, FFDCA, and FOPA, USEPA determines the specific conditions under which a pesticide can be legally sold, distributed, and used in the United States, including where, how, and at what application rates pesticides may be used.
The SDWA was originally passed by Congress in 1974 to protect public health by regulating the Nation's public drinking-water supply. The law was amended in 1986 and 1996 and requires protection of drinking water and its sources, including rivers, lakes, reservoirs, springs, and wells (the SDWA does not regulate private wells that serve fewer than 25 individuals). The SDWA authorizes the USEPA to set national health-based standards for drinking water to protect against both naturally occurring and manmade contaminants that may be found in drinking water. The USEPA works with States and water utilities to make sure that these standards are met.

The CWA (originally the Federal Water Pollution Control Act Amendments of 1972, and subsequently amended several times) provides for protection against releases of toxic chemicals. Section 101(a)(3) of the CWA states that "it is national policy that the discharge of toxic pollutants in toxic amounts be prohibited." Section 303(c) of the CWA requires States to develop water-quality standards to protect the public health or welfare, enhance the quality of water, and serve the purposes of the CWA. The control of the discharge of toxic substances is a key objective of the National Pollutant Discharge Elimination System (NPDES) and water-quality standards programs. Section 304(a) of the CWA requires USEPA to develop and publish and, from time to time, revise ambient water-quality criteria for the protection of both human health and aquatic life. When final, these criteria provide USEPA's recommendations to States and authorized Tribes as they develop their own water-quality standards. USEPA-recommended criteria are not regulations, and they do not impose legally binding requirements on USEPA, States, authorized Tribes, or the regulated community. However, USEPA-recommended criteria may form the basis for State or Tribal water-quality standards and become enforceable through NPDES permits or other environmental programs. USEPA's role in this process, in addition to providing criteria recommendations, is to review and approve the water-quality standards developed by States and Tribes. 
water (depending on whether and how the water is treated), because some drinking-water treatment processes reduce pesticide concentrations. In addition, NAWQA sampling methods were not designed to meet the specific sampling and analytical requirements for determining compliance with an MCL.

\section{Streams}

Annual mean concentrations of pesticides in the 186 streams sampled by NAWQA were seldom greater than human-health benchmarks during 1992-2001, and most exceedances were in streams draining agricultural and urban watersheds (fig. 6-1). Specifically, pesticide concentrations exceeded one or more human-health benchmarks in about 10 percent of agricultural streams, 7 percent of urban streams, and in 1 of the 65 mixed-land-use streams sampled by NAWQA. No benchmarks were exceeded in the eight undeveloped streams that were sampled.

The streams sampled by NAWQA that had concentrations of a pesticide greater than a human-health benchmark were clustered in a few regions. Specifically, 6 agricultural streams and 1 mixed-land-use stream with concentrations greater than one or more benchmarks ( 5 of 7 streams for atrazine and 4 of 7 for cyanazine) were in the Corn Belt or southern Mississippi River Basin, where atrazine and cyanazine use was high during the study period (fig. 6-2). Two agricultural streams, 1 in California and 1 in Washington, had concentrations of dieldrin that were greater than its benchmark. The 2 urban streams in which benchmarks were exceeded are in Texas (diazinon) and Hawaii (dieldrin).

A new analysis of atrazine's potential risks has been developed by USEPA as part of the reregistration process (USEPA, 2003a). The analysis is based on the concentrations of atrazine and three of its chlorinated degradates, referred to, collectively, as "total atrazine." The human-health benchmarks from this new analysis are $37.5 \mu \mathrm{g} / \mathrm{L}$ for the 90-day moving average if the monitoring frequency is at least weekly and $12.5 \mu \mathrm{g} / \mathrm{L}$ if monitoring is less frequent. Comparison of these benchmark values to 90-day moving averages determined from NAWQA data for the sum of atrazine and deethylatrazine (NAWQA did not measure the 2 other chlorinated degradates) indicates that 4 of the 5 sites that exceeded the MCL-based benchmark also had 90-day averages that exceeded the $12.5 \mu \mathrm{g} / \mathrm{L}$ level. Of these 4 sites, however, 3 had at least weekly sampling frequencies during the high-concentration period of the year and concentrations would thus be compared with the $37.5 \mu \mathrm{g} / \mathrm{L}$ benchmark. Of the 3 sites with at least weekly sampling, 1 exceeded the $37.5 \mu \mathrm{g} / \mathrm{L}$ benchmark. Use of benchmarks from the new risk analysis would, therefore, result in screening-level exceedances for 2 sites instead of 5 sites, although inclusion of the other chlorinated degradates could increase the number of sites with exceedances. Further analysis of the distribution of atrazine concentrations in streams nationwide is presented in Chapter 7.

\section{Human-Health Benchmarks for Pesticides in Water}

Benchmarks for assessing the potential for pesticides in water to affect human health were derived from three types of USEPA drinking-water standards and guidelines developed by USEPA's Office of Water (USEPA, $2004 c, 2005 e)$. One or more drinking-water standards or guidelines are available for 47 of the 83 pesticides and degradates analyzed by NAWOA (Appendix 3A).

Maximum Contaminant Level (MCL)-The maximum permissible concentration of a contaminant in water that is delivered to any user of a public water system. This is an enforceable standard issued by USEPA under the Safe Drinking Water Act and established on the basis of health effects and other factors (analytical and treatment technologies, and cost).

Lifetime Health Advisory (HA-L) - The concentration of a chemical in drinking water that is not expected to cause any adverse, noncarcinogenic effects over a lifetime exposure. A health advisory is not a legally enforceable Federal standard, but serves as technical guidance to assist Federal, State, Tribal and local officials. The HA-L is based on toxicity (dose-response) information for the chemical. It assumes lifetime consumption of 2 liters $(L)$ of water per day by a 70 -kilogram $(\mathrm{kg})$ adult, and that 20 percent of total exposure to the contaminant comes from drinking water ( 80 percent is assumed to come from other sources).

$10^{-6}$ Cancer Risk Concentration-The concentration of a chemical in drinking water corresponding to an excess estimated lifetime cancer risk of 1 in 1 million $\left(10^{-6}\right)$. These values are calculated from the estimated cancer potency, which is derived using a conservative (protective) model of carcinogenesis, so that the cancer risk is an upper-limit estimate. The definition of "acceptable" level of cancer risk is a policy issue, not a scientific one. USEPA reviews individual State and Tribal policies on cancer risk levels as part of its oversight of water-quality standards under the Clean Water Act. USEPA's policy is to accept measures adopted by States to limit cancer risk to the range of $10^{-6}$ to $10^{-4}$ (USEPA, 1992a). The concentration corresponding to a cancer risk of $10^{-6}$ was used as the benchmark for the NAWQA screening-level assessment, consistent with the conservative (protective) nature of such assessments.

\section{Application of Human-Health Benchmarks for Water}

If available, the MCL was used as the human-health benchmark for a given pesticide. For pesticides with no MCL, the lower of the HA-L and the $10^{-6} \mathrm{can}$ cer risk concentration was used. Human-health benchmarks were compared with time-weighted annual mean concentrations of pesticides in streams, as well as with concentrations measured in individual wells for ground water. 
Concentrations greater than human-health benchmarks

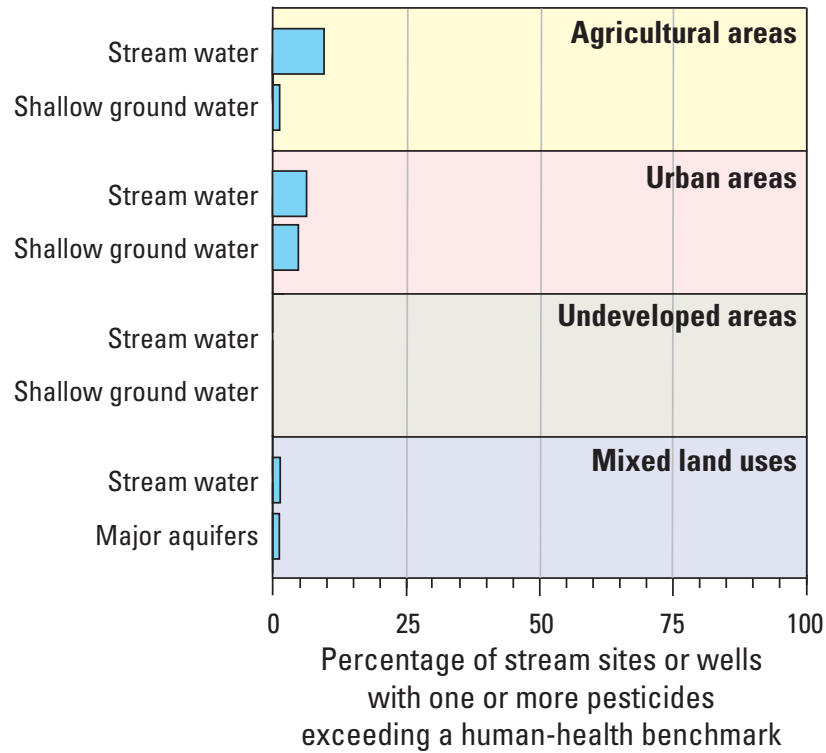

Figure 6-1. Annual mean concentrations of one or more pesticides were greater than a humanhealth benchmark in about 10 percent of agricultural streams and about 7 percent of urban streams that were sampled. No streams draining undeveloped watersheds, and only 1 stream with mixed land uses in its watershed, had concentrations greater than a benchmark. About 1 percent of all domestic and public-supply wells sampled had concentrations greater than a benchmark. More than half of the wells sampled for ground-water studies, but none of the stream sites sampled, were sources of domestic or public water supplies during the study period.

Sites or studies with concentrations greater than a human-health benchmark
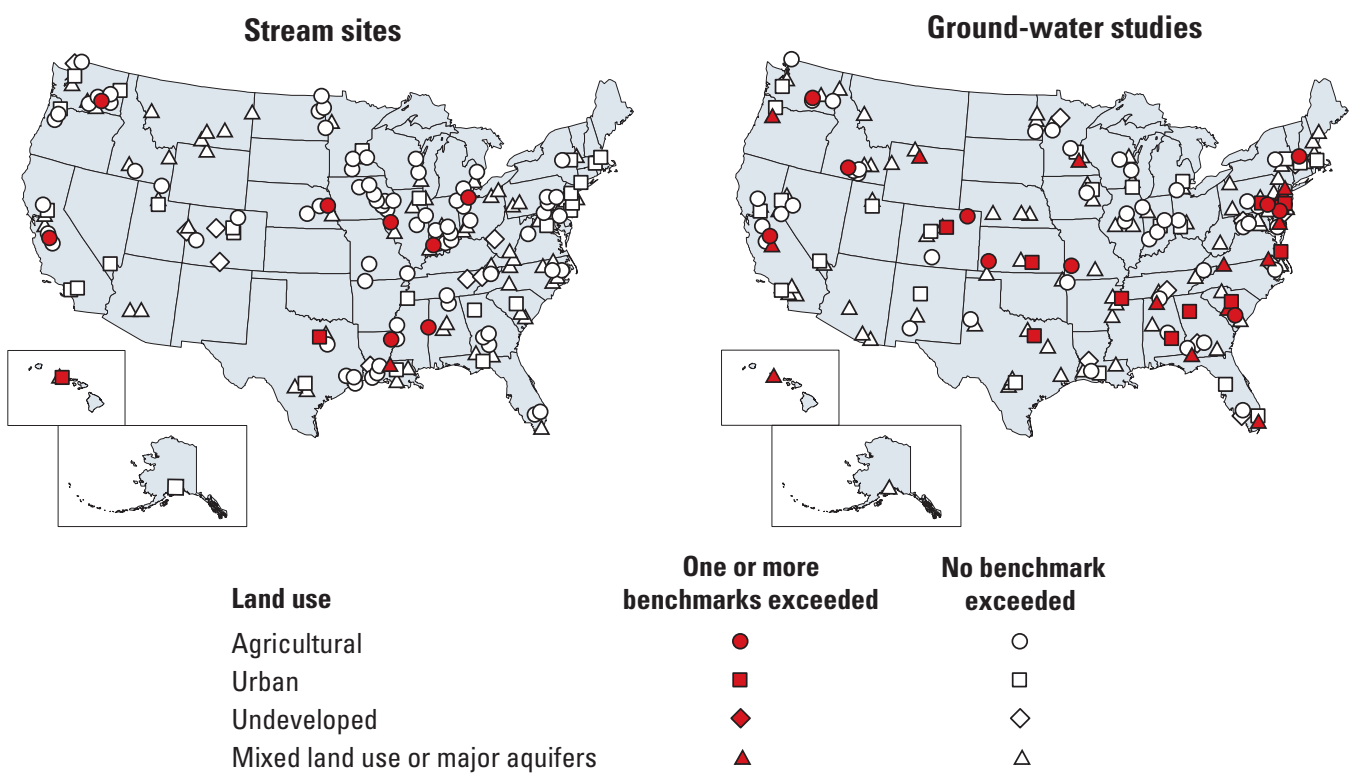

Figure 6-2. Most streams sampled by NAWQA that had concentrations of a pesticide greater than a human-health benchmark were agricultural streams in the Corn Belt and lower Mississippi River Basin, where atrazine and cyanazine accounted for the exceedances. Two urban streams in Texas and Hawaii had concentrations greater than benchmarks for diazinon and dieldrin, respectively. Wells with concentrations greater than benchmarks were widely scattered among 36 of the 187 ground-water study areas, with the highest proportion in urban areas. Dieldrin accounted for most benchmark exceedances in ground water. Streams are indicated if the annual mean concentration of one or more pesticides was greater than a benchmark, and ground-water studies are indicated if one or more wells had a concentration greater than a benchmark. 
Although NAWQA findings for streams are not directly applicable to drinking-water supplies because no NAWQA stream sites were located at water-supply intakes, a perspective on potential significance to human health is provided by comparing streams sampled by NAWQA with streams that serve as sources of drinking water and that have similar land uses in their watersheds. The Nation's 1,679 public water-supply intakes on streams were classified using NAWQA's land-use definitions (table 3-1 and fig. 3-1). The stream sites where intakes are located are composed of 12 percent agricultural streams (194 intakes); 1 percent urban streams (22 intakes); 55 percent undeveloped streams (926 intakes); and 32 percent streams that drain watersheds with mixed land use (537 intakes). As a group, however, agricultural streams with drinking-water intakes have proportionally less agricultural land in their watersheds than do the agricultural streams sampled by NAWQA (see Chapter 3). Thus, the finding that 10 percent of agricultural streams sampled by NAWQA had concentrations of pesticides greater than one or more benchmarks indicates that probably fewer than 10 percent of the 194 drinking-water intakes on agricultural streams used source waters with concentrations greater than human-health benchmarks during the study period. In addition, source water may be treated or mixed with other water sources to reduce pesticide concentrations prior to consumption.

Overall, the human-health screening-level assessment for streams sampled by NAWQA during the study period indicates that few of the drinking-water intakes that currently withdraw water from streams are likely to be located on streams with pesticide concentrations greater than a benchmark. This broad finding is derived from combined data from multiple sites sampled in different sampling periods from 1993 to 2000. In addition, there are sufficient NAWQA stream sites with primary sampling years distributed throughout the study period to assess changes over time in benchmark exceedances for agricultural streams in the corn-and-soybeans crop setting (fig. 4-6) and for urban streams. Although there were too few exceedances of humanhealth benchmarks at urban sites for meaningful assessment of trends, agricultural streams in the corn-and-soybeans crop setting had the highest frequencies of benchmark exceedances by atrazine and cyanazine. In this agricultural setting, the changes in percentages of stream sites that had concentrations that exceeded a benchmark were different for the two herbicides (fig. 6-3).
Observations about changes shown in figure 6-3, however, are preliminary because they are based on different groups of sites for each sampling period and site-to-site variability in conditions may distort actual trends. There was no clear pattern of change through the study period for atrazine, but the highest proportion of sites with exceedances by atrazine occurred near the end of the study period, during 1998-2000. In contrast, there was a consistent decrease in exceedances for cyanazine during the study period, with none during 1998-2000. Data on the agricultural use of these two pesticides in the Corn Belt show that these changes in frequencies of benchmark exceedances are consistent with their use (fig. 6-3).

Trends in use and benchmark exceedances for agricultural streams in the corn-and-soybeans crop setting
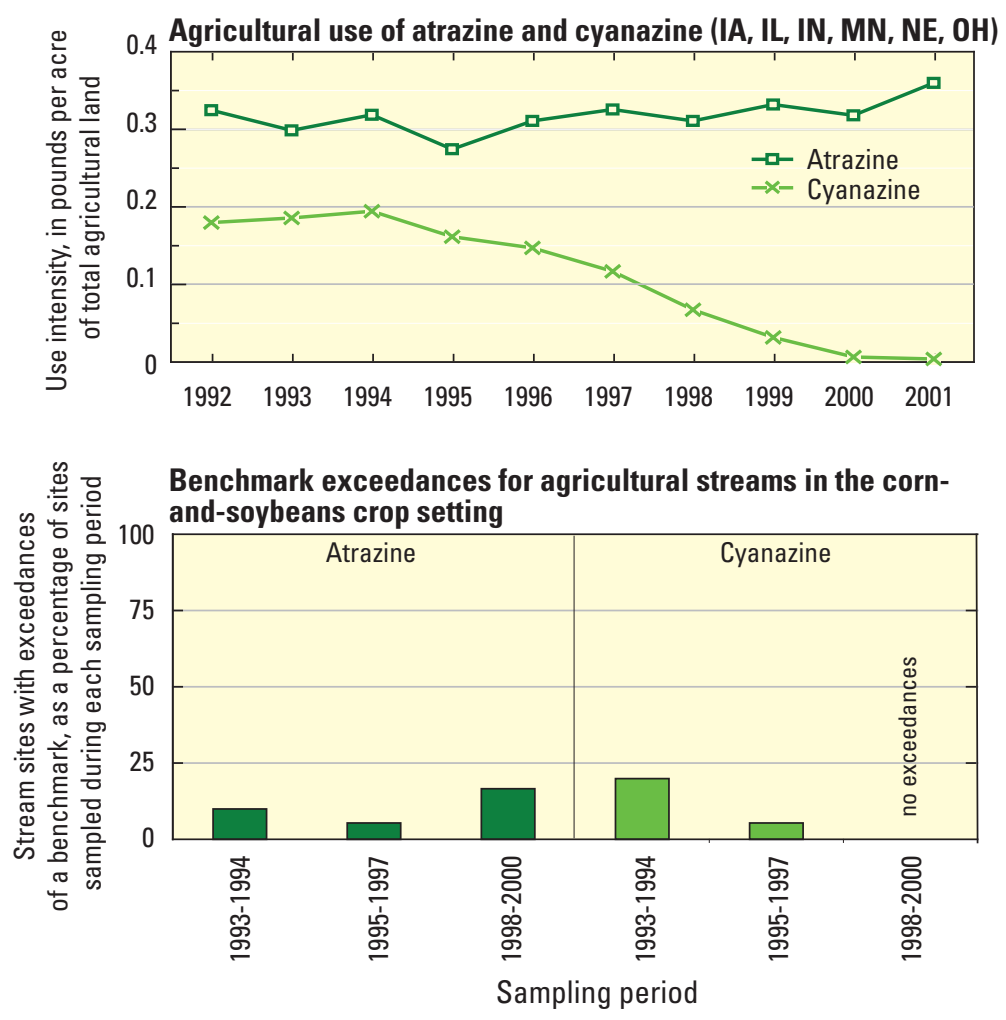

Figure 6-3. Changes over time in the percentage of agricultural stream sites in the corn-and-soybeans crop setting that had exceedances of human-health benchmarks for atrazine and cyanazine generally followed trends in use. Sites were grouped according to the year of sampling. The 1993-1994 sampling period included 10 sites, the 1995-1997 period included 19 sites, and the 1998-2000 period included 6 sites. 


\section{Potential Effects of Fish Consumption on Human Health}

In addition to drinking water, humans also can be exposed to pesticides through consumption of contaminated fish. When persistent, hydrophobic compounds, such as organochlorine pesticides, enter a stream, they tend to bioaccumulate in fish and other aquatic organisms. Because USEPA sets tolerances only for currently registered pesticides, there are no tolerances for the cancelled organochlorine pesticides in fish. However, 48 States, the District of Columbia, American Samoa, and three Tribes have issued active fish-consumption advisories and safe-eating guidelines to inform people about the recommended level of consumption for fish caught in local waters. Fish advisories are advice to limit or avoid eating certain fish. USEPA has published guidance to States, Territories, Tribes, and local governments to use in establishing fish-consumption advisories (USEPA, 2000a). As of 2004, there were a total of 79 active fish-consumption advisories for chlordane, 67 advisories for DDT and its degradation products DDE and DDD, and 22 for dieldrin (USEPA, 2005f,g). Although some advisories for organochlorine pesticides have been rescinded in recent years, as residues of these pesticides continue to degrade slowly in the environment (see chapter 8), new advisories were issued in 2004 for DDT, toxaphene, mirex, and chlorinated pesticides (USEPA, 2005f).

USEPA guidelines include recommended screening values, which are "concentrations of target analytes in fish or shellfish tissue that are of potential public health concern and that are used as threshold values against which levels of contamination in similar tissue collected from the ambient environment can be compared" (USEPA, 2000a). Screening values were derived separately for carcinogenic and noncarcinogenic effects, and USEPA recommends that the lower of the two screening values be used for pesticides that have both types of effects. USEPA screening values are intended to protect the majority of the United States population and are based on average fish and shellfish consumption rates by recreational fishers. For potential carcinogens, the recommended screening value is based on a maximum acceptable cancer risk of $10^{-5}(1$ in 100,000). USEPA screening values are available for 9 of the 12 organochlorine pesticides and pesticide groups (such as total chlordane) measured by NAWQA in whole fish.

Comparisons of concentrations of organochlorine pesticide compounds measured in NAWQA fish samples with USEPA screening values are limited in two ways. First, NAWQA analyzes contaminants in whole fish, whereas USEPA screening values apply to edible fish tissue. Organochlorine compounds have high affinities for the lipid (fat) in fish and other biota. Whole fish generally have higher lipid content and, therefore, may have higher organochlorine concentrations than the part of the fish that is consumed (fillets). Thus, comparisons of NAWQA measurements with USEPA screening values are probably, in this sense, worst-case assessments. Second, most fish sampled by NAWQA are bottom-feeding species, such as carp and white sucker, which are not consumed as frequently as game fish. Depending on the compound, however, the difference between game-fish fillets and the whole bodies of bottom-feeders may not be significant. For example, in a national study of bioaccumulative chemicals in fish, the USEPA (1992b) found that some organochlorine compounds (including dieldrin, oxychlordane, and DDE) were roughly similar in average concentrations in game-fish fillets and whole-fish samples of bottomfeeders, whereas other compounds (including chlordane, nonachlor, and heptachlor epoxide) had higher average concentrations in wholefish samples of bottom feeders than in game-fish fillets.

NAWQA results for whole fish, with these caveats considered, may be useful for screening-level assessment of streams for which there are no data specifically on edible tissue of fish commonly consumed in that area. If pesticide concentrations measured in a wholefish sample are less than a screening value for edible tissue, then residues in the edible portion of the fish are likely to be less than the screening value, suggesting low human-health concern. On the other hand, if a concentration in whole fish exceeds the screening value, the level in edible tissue may not exceed the value, but additional sampling and analysis of fillets for species that are commonly consumed may be warranted to determine whether or not the concentration in edible fish tissue exceeds the screening value.

The NAWQA analysis provides the following general perspective:

- Organochlorine concentrations measured by NAWQA in whole fish exceeded USEPA screening values most often in agricultural and urban streams (67 percent of sites), followed by streams draining areas of mixed land use ( 55 percent).

- Concentrations greater than screening values in agricultural streams were dominated by dieldrin, total DDT, and heptachlor epoxide, whereas these same compounds plus total chlordane accounted for most concentrations greater than screening values in urban streams.

- If people commonly consume fish from a stream where screening values were exceeded by NAWOA-measured concentrations in whole fish, and no prior monitoring of the commonly consumed fish has been done, then further investigation of organochlorine pesticide compounds in edible fish tissue may be warranted. 


\section{Ground Water}

Concentrations of one or more pesticides were greater than human-health benchmarks in about 1 percent of sampled wells that are used for drinking water-including 17 of 2,356 domestic wells and 8 of 364 public-supply wells (table 6-1). Many public-supply wells have some level of water treatment, which may or may not affect pesticide concentrations, whereas domestic wells generally have no treatment, so that samples usually represent the actual quality of water consumed. Shallow ground water in urban areas had the greatest proportion of sampled wells with concentrations of pesticides that were greater than one or more benchmarks, including 1 of 9 public-supply wells, 3 of 17 domestic wells, and 37 of 835 observation wells, for a total of about 5 percent. About 1 percent of wells sampled in agricultural areas and about 1 percent of wells sampled in major aquifers had concentrations greater than one or more benchmarks. Wells with concentrations greater than benchmarks were widely scattered among 36 of the 187 groundwater studies across the Nation, including 11 of 33 urban land-use studies, 10 of 53 agricultural land-use studies, and 15 of 92 major aquifer studies (fig. 6-2). Most of these studies with one or more benchmark exceedances had only 1 or 2 wells with exceedances. All concentrations greater than benchmarks were accounted for by dieldrin ( 72 wells) and four other pesticides: dinoseb (4 wells), atrazine (4), lindane (2), and diazinon (1).

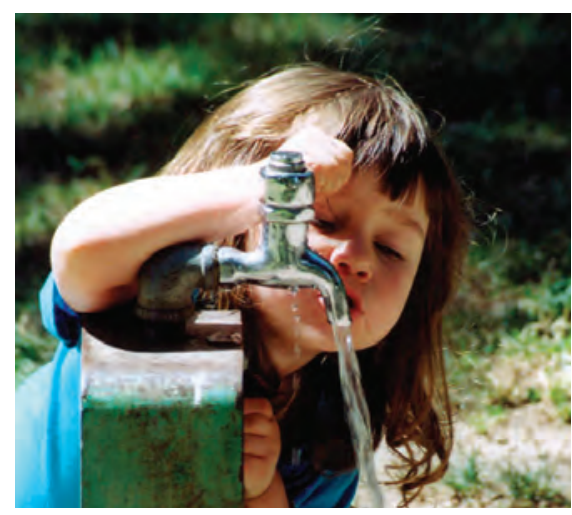

Human-health benchmarks were seldom exceeded in domestic and public-supply wells.

Of the pesticides analyzed by NAWQA, dieldrin is the primary pesticide identified by the screening-level assessment for further consideration regarding ground water. Of the 72 wells with dieldrin concentrations greater than its screening-level benchmark, 39 were shallow wells in urban areas (including 3 domestic wells and 1 public-supply well), 12 were shallow wells in agricultural areas (including 5 domestic wells), and 21 were wells in major aquifers (including 7 domestic and 6 public-supply wells). Although aldrin (which transforms to dieldrin) and dieldrin are no longer used in the United States, the screening-level assessment indicates that some wells may still be affected by dieldrin from historical uses.

Table 6-1. Most wells sampled for agricultural and urban land-use studies were shallow observation wells that are not used for drinking water, but about 29 percent of wells sampled in agricultural areas were domestic wells. Most wells sampled for the major aquifer studies are used for drinking water; about 13 percent were public-supply wells, and 71 percent were domestic wells. Overall, about 1 percent of all domestic and public-supply wells had concentrations of a pesticide greater than a human-health benchmark.

\begin{tabular}{lcccccc}
\hline & \multicolumn{2}{c}{ Public-supply wells } & \multicolumn{2}{c}{ Domestic wells } & \multicolumn{2}{c}{ Observation wells } \\
\cline { 2 - 6 } Type of ground-water study & $\begin{array}{c}\text { Number } \\
\text { sampled }\end{array}$ & $\begin{array}{c}\text { Percentage of } \\
\text { samples exceeding } \\
\text { a benchmark }\end{array}$ & $\begin{array}{c}\text { Number } \\
\text { sampled }\end{array}$ & $\begin{array}{c}\text { Percentage of } \\
\text { samples exceeding } \\
\text { a benchmark }\end{array}$ & $\begin{array}{c}\text { Number } \\
\text { sampled }\end{array}$ & $\begin{array}{c}\text { Percentage of } \\
\text { samples exceeding } \\
\text { a benchmark }\end{array}$ \\
\hline Agricultural land use & 1 & 0.0 & 406 & 1.2 & 1,005 & 1.1 \\
Urban land use & 9 & 11 & 17 & 18 & 835 & 4.4 \\
Major aquifers & 354 & 2.0 & 1,933 & 0.5 & 453 & 2.0 \\
\hline
\end{tabular}




\section{Screening-Level Assessment for Aquatic Life in Streams}

The potential for pesticides to adversely affect aquatic life in streams was evaluated by comparing measured concentrations in water and bed sediment with their respective water-quality benchmarks. The benchmarks are described in the accompanying sidebars (p. 97 and 105) and benchmark values are listed in Appendix 3.

\section{Water}

NAWQA findings indicate that pesticides detected in stream water, most of which were in use during the study period, had the potential to adversely affect aquatic life in many of the streams sampled. Of 186 stream sites sampled nationwide, 57 percent of 83 agricultural streams, 83 percent of 30 urban streams, and 42 percent

Concentrations greater than aquatic-life benchmarks

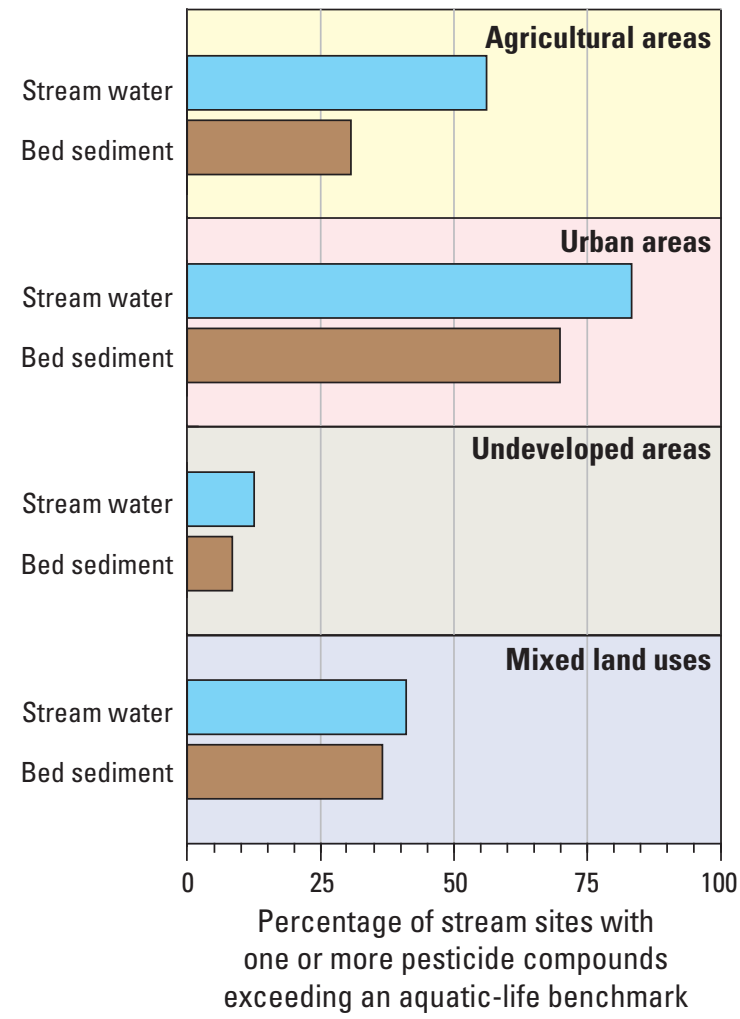

Figure 6-4. Pesticides have the potential to adversely affect aquatic life in many streams, particularly in urban areas, as indicated by the relatively high proportions of sites with measured concentrations greater than aquatic-life benchmarks for both water and bed sediment. of 65 streams with mixed-land-use watersheds had concentrations of at least one pesticide that exceeded one or more aquatic-life benchmarks during the selected year of sampling (fig. 6-4). One of 8 undeveloped streams that were sampled for pesticides in water had concentrations that were greater than an aquatic-life benchmark. Concentrations greater than benchmarks occurred throughout the study period. Agricultural streams had benchmark exceedances at 68 percent of sites sampled during 1993-1994, 43 percent during 1995-1997, and 50 percent during 1998-2000. Urban streams had benchmark exceedances at 90 percent of sites sampled during 1993-1994, 100 percent during 1995-1997, and 64 percent during 1998-2000. Streams with mixed land uses in their watersheds had benchmark exceedances at 38 percent of sites sampled during 1993-1994, 40 percent during 1995-1997, and 46 percent during 1998-2000.

Streams in which one or more pesticides exceeded an aquatic-life benchmark for water are distributed throughout the country in agricultural, urban, and mixed-land-use settings (fig. 6-5). Most concentrations that exceeded benchmarks, particularly by the greatest amounts, occurred during seasonal periods of high concentrations, as illustrated by results for diazinon in Arcade Creek, an urban stream in the Sacramento River Basin (fig. 6-6). The number, type, and degree of benchmark exceedances vary widely among sites indicated in figure 6-5 and meaningful generalizations are difficult. Some streams, such as Arcade Creek (fig. 6-6), exceeded one or more benchmarks by substantial margins for a sustained period during the year. Other sites briefly exceeded a benchmark for one pesticide. Of the 100 sites with one or more benchmark exceedances, 46 sites exeeded 1 benchmark to varying degrees and frequencies, and 30 sites exceeded 3 or more different benchmarks to varying degrees and frequencies. Because of this variability and the complexity of translating exceedances of screening-level benchmarks into specific potential for effects, the screening-level results, as noted earlier should be used as the starting point for further site-specific investigation. Streams in which concentrations did not exceed a benchmark included most undeveloped streams, plus streams in agricultural and mixedland-use settings in regions where pesticide use was low, such as the Yellowstone River Basin and the Ozark Plateaus. 


\section{Aquatic-Life Benchmarks for Pesticides in Water}

Benchmarks for assessing the potential for pesticides in stream water to adversely affect aquatic life were of two general types: (1) ambient water-quality criteria for the protection of aquatic life (AWOC$A L)$, which were developed by USEPA's Office of Water (OW), and (2) benchmarks derived from toxicity values obtained from registration and risk-assessment documents developed by USEPA's Office of Pesticide Programs (OPP). Toxicity data from OPP documents were used to supplement $\mathrm{OW}$ criteria to expand the coverage of pesticides and to incorporate the most recent toxicity information used by USEPA. AWOC-AL are available for 7 of the 83 pesticides and degradates analyzed by NAWQA. One or more toxicity values from OPP documents are available for 60 of the 83 NAWOA analytes, including 5 of the 7 that have AWOC-AL. A total of 62 of the pesticide compounds analyzed in water by NAWOA have one or more aquatic-life benchmarks (Appendix 3A).

\section{Ambient Water-Quality Criteria for Aquatic Organisms}

USEPA's OW derives both acute and chronic criteria, each of which specifies a threshold concentration for unacceptable potential for effects, an averaging period, and an acceptable frequency of exceedances.

Acute AWOC-AL-The highest concentration of a chemical to which an aquatic community can be exposed briefly without resulting in an unacceptable effect. Except where a locally important species is very sensitive, aquatic organisms should not be unacceptably affected if the 1-hour average concentration does not exceed the acute criterion more than once every 3 years, on average. The intent is to protect 95 percent of a diverse group of organisms (USEPA, 2004d).

Chronic AWOC-AL-The highest concentration of a chemical to which an aquatic community can be exposed indefinitely without resulting in an unacceptable effect. Except where a locally important species is very sensitive, aquatic organisms should not be unacceptably affected if the 4-day average concentration does not exceed the chronic criterion more than once every 3 years, on average. The intent is to protect 95 percent of a diverse group of organisms (USEPA, 2004d).

\section{Toxicity Values from Risk Assessments}

Seven types of aquatic toxicity values were compiled from OPP's registration and risk-assessment documents. The OPP toxicity values are for specific types of organisms. Acute and chronic values were compiled for fish and invertebrates, and acute values for vascular and nonvascular plants. A value for aquatic-community effects was available only for atrazine. The types and amounts of toxicity data available for different pesticides were highly variable. USEPA estimates the toxicity or hazard of a pesticide by selecting the most sensitive endpoints from multiple acute and chronic laboratory and field studies. For many pesticides, USEPA has completed a screening-level ecological risk assessment, which includes acute and chronic assessments for both fish and invertebrates. For some pesticides, acute assessments have also been completed for nontarget aquatic plants. NAWQA derived benchmarks from OPP toxicity values, generally following OPP procedures (USEPA, 2005h).

In recent years, USEPA has developed methods for conducting refined risk assessments, in which probabilistic tools and methods are incorporated to predict the magnitude of the expected impact of pesticide use on nontarget organisms, as well as the uncertainty and variability involved in these estimates. The screening-level benchmarks used in
NAWQA analysis and summarized below were derived from the toxicity values reported in USEPA registration and risk-assessment documents.

In the few cases where refined assessments were available, these were given preference. In deriving a benchmark for a given type of organism (such as fish) and a given exposure duration (acute or chronic), the lowest of the available toxicity values was selected for each benchmark, unless a preferred toxicity value was specified in a refined risk assessment-in which case that preferred toxicity value was used instead. For two of the benchmarks - acute-fish and acute-invertebrates - the selected toxicity values were multiplied by the USEPA level of concern (LOC) of 0.5 , so that the benchmark for NAWOA screening corresponds to the acute risk level defined by USEPA (2005h).

Six benchmarks were based directly on toxicity endpoints used in OPP screening-level assessments (USEPA, 2005i):

Acute fish-The lowest tested 50-percent lethal concentration $\left(\mathrm{LC}_{50}\right)$ for acute (typically 96-hour) toxicity tests with freshwater fish, multiplied by the LOC of 0.5 .

Acute invertebrate-The lowest tested $\mathrm{LC}_{50}$ or 50-percent effect concentration $\left(\mathrm{EC}_{50}\right)$ for acute (typically 48 or 96 -hour) toxicity tests with freshwater invertebrates, multiplied by the LOC of 0.5 .

Acute vascular plant-The lowest tested $\mathrm{EC}_{50}$ for freshwater vascular plants in acute toxicity tests (typically $<10$ days).

Acute nonvascular plant-The lowest tested $\mathrm{EC}_{50}$ for freshwater nonvascular plants (algae) in acute toxicity tests (typically $<10$ days).

Chronic fish-The lowest no-observed-adverse-effects concentration (NOAEC), or the lowest-observed-adverse-effects concentration (LOAEC) if a NOAEC is not available, for freshwater fish in early lifestage or full life-cycle tests.

Chronic invertebrate-The lowest NOAEC, or LOAEC if a NOAEC is not available, for freshwater invertebrates in life-cycle tests.

One additional benchmark, a benchmark for aquatic-community effects, was derived from the refined risk assessment for atrazine. This endpoint for atrazine incorporates community-level effects on aquatic plants and indirect effects on fish and aquatic invertebrates that could result from disturbance of the plant community (USEPA, 2003b).

\section{Application of Aquatic-Life Benchmarks for Water}

Acute AWOC-AL values and all acute benchmarks were compared with each measured concentration for the most complete year of data for each NAWQA stream site. Chronic AWOC-AL values were compared with 4-day moving average concentrations. This approach matches the time periods in the definitions of acute and chronic AWQC-AL, which are 1-hour average and 4-day average concentrations, respectively (Stephan and others, 1985). Chronic benchmarks for invertebrates were compared with 21-day moving averages, and chronic benchmarks for fish and the aquatic-community benchmark for atrazine were compared with 60-day moving averages. These time periods are those used or recommended by USEPA in OPP risk assessments (USEPA, 2003b; USEPA, 2005g). Moving average concentrations for 4-, 21-, and 60-day periods were computed for each day of the year for each stream site from hourly concentration estimates determined by straight-line interpolation between samples. This method was tested using data on pesticide concentrations in Ohio streams studied by Richards and Baker (1993) and Richards and others (1996), using an approach similar to that used by Crawford (2004). Results indicate that all three averages, but particularly the 4-day averages, are consistently underestimated when computed from data collected at frequencies similar to the NAWOA sampling design (indicating a tendency to also underestimate the potential for toxicity to aquatic life in this respect). 
Sites with concentrations greater than an aquatic-life benchmark
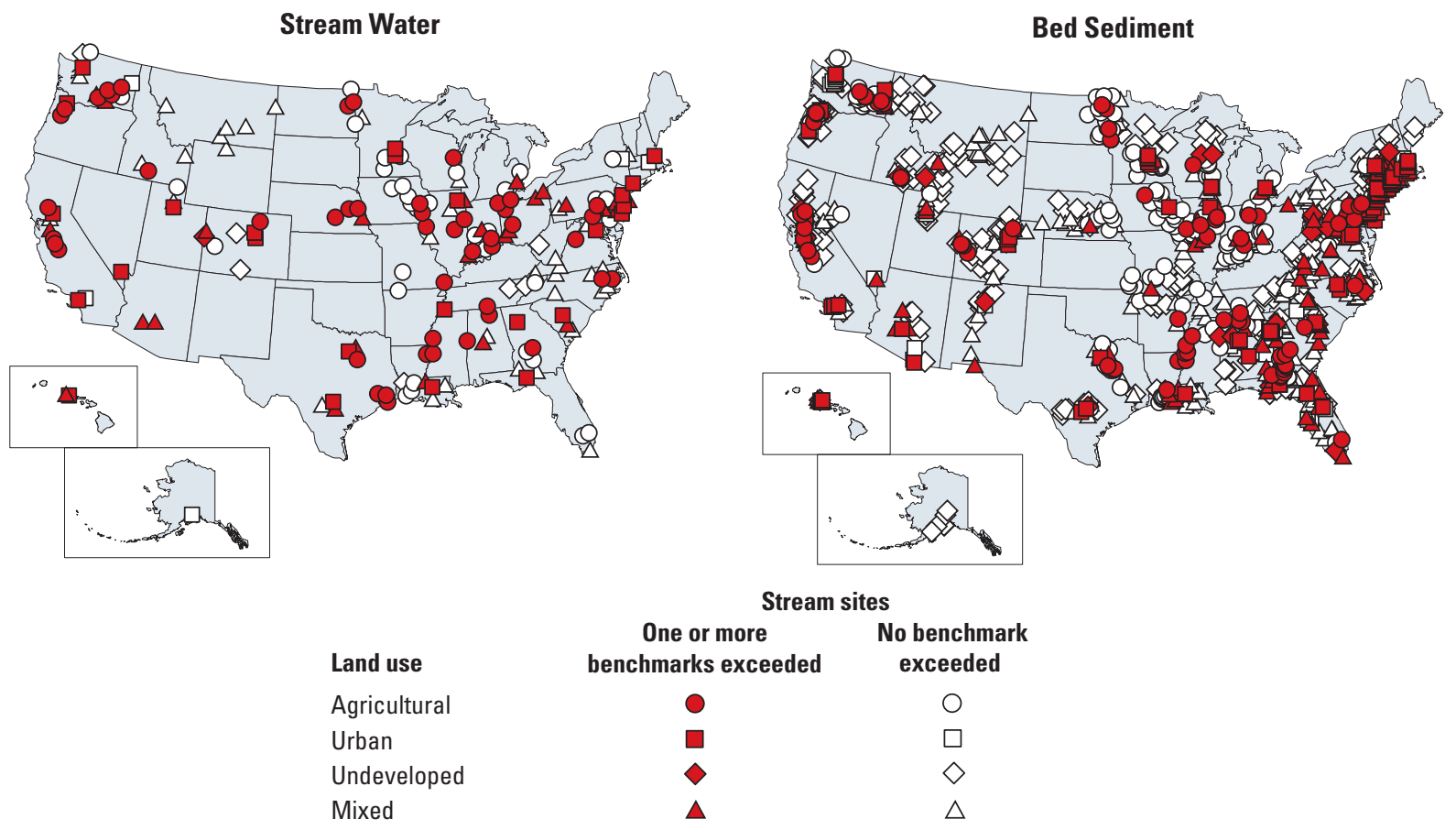

Figure 6-5. Aquatic-life benchmarks for pesticides in water and bed sediment were exceeded by concentrations measured in many agricultural, urban, and mixed-land-use streams throughout the Nation.

Figure 6-6. Concentrations of diazinon in Arcade Creek, an urban creek in Sacramento, California (Sacramento River Basin), exceeded the aquaticlife benchmark for acute effects on invertebrates $(0.10 \mu \mathrm{g} / \mathrm{L})$ by the greatest amounts during seasonal pulses of high concentrations in the winter and spring. (Modified from Domagalski and others, 2000.)

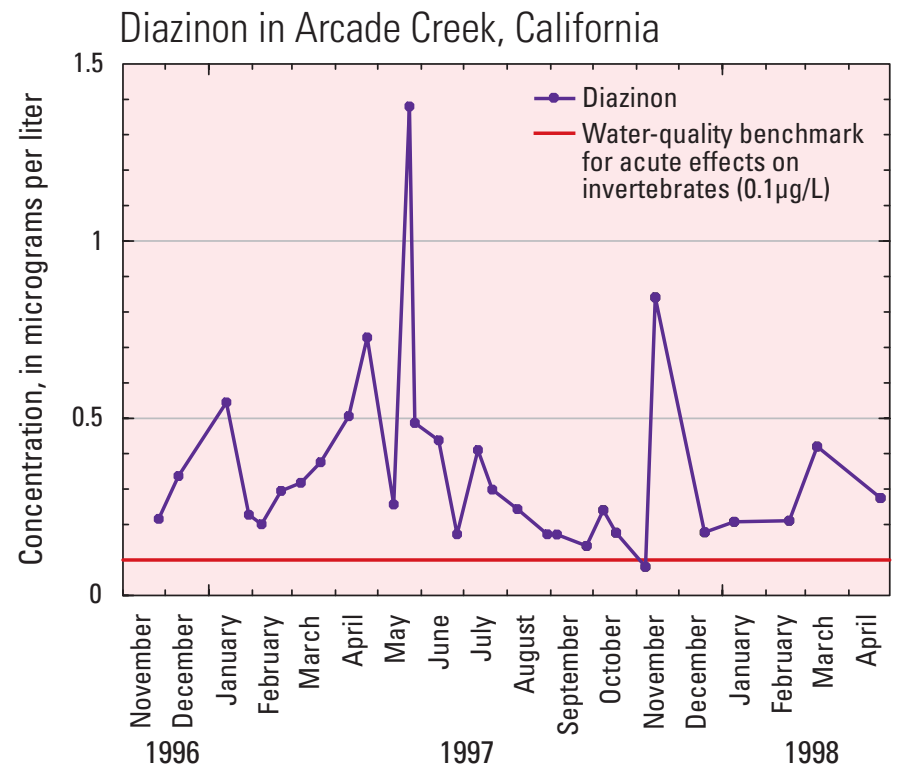


The insecticides diazinon, chlorpyrifos, and malathion accounted for most concentrations that were greater than aquatic-life benchmarks in water from urban streams, whereas chlorpyrifos, azinphos-methyl, atrazine, $p, p^{\prime}$-DDE, and alachlor accounted for most concentrations greater than benchmarks in water from agricultural streams (fig. 6-7). Streams draining watersheds with mixed land uses reflected a combination of urban and agricultural influences. Generally, the types of benchmarks most frequently exceeded by the herbicides atrazine and alachlor were those for acute effects on either vascular or nonvascular plants, whereas the insecticides diazinon, chlorpyrifos, malathion, azinphos-methyl, and carbaryl most frequently exceeded acute or chronic benchmarks for invertebrates or benchmarks based on chronic ambient water-quality criteria.

The geographic distributions of benchmark exceedances for atrazine (fig. 6-8), diazinon (fig. 6-9), and chlorpyrifos (fig. 6-10) illustrate the varying distributions and types of potential effects on aquatic life. Concentrations of atrazine were greater than one or more aquatic-life benchmarks in 18 percent of agricultural streams, but in only one stream with a predominantly nonagricultural watershed. As discussed in Chapter 4, concentrations of atrazine in agricultural streams matched the geographic distribution of corn cultivation, where applications are greatest (fig. 4-9). As noted above, the atrazine benchmarks most frequently exceeded were the acute benchmarks for vascular and nonvascular plants, although the benchmark for aquatic community effects and the chronic benchmark for invertebrates also were exceeded at about 35 and 12 percent, respectively, of the sites where one or more atrazine benchmarks were exceeded (fig. 6-8).

Diazinon concentrations were greater than one or more aquatic-life benchmarks in 73 percent of the urban streams that were sampled, compared with 37 percent for chlorpyrifos (fig. 6-7). The urban stream sites where diazinon exceeded a benchmark were distributed throughout the country (fig. 6-9). Benchmarks for both of these insecticides were exceeded in smaller proportions of agricultural streams, although chlorpyrifos exceeded one or more of its benchmarks in 21 percent of the agricultural streams. The highest concentrations of chlorpyrifos in agricultural streams, as discussed in Chapter 4, were in streams within the corn-growing areas of the central United States; in the lower Mississippi River Basin, where both corn and cotton are grown; and in streams draining agricultural areas in the West, where fruits, nuts, and vegetables are grown.
The diazinon benchmarks most frequently exceeded (fig. 6-9) were the acute and chronic benchmarks for invertebrates reported by USEPA (USEPA, 2004e). As shown in figure 6-10, the chlorpyrifos benchmarks most frequently exceeded were the acute and chronic benchmarks for invertebrates and also the acute and chronic ambient aquatic-life criteria (Appendix 3A). While none currently exists, USEPA is drafting ambient aquatic-life criteria for diazinon. During

\section{Pesticides with concentrations greater than an aquatic-life benchmark}
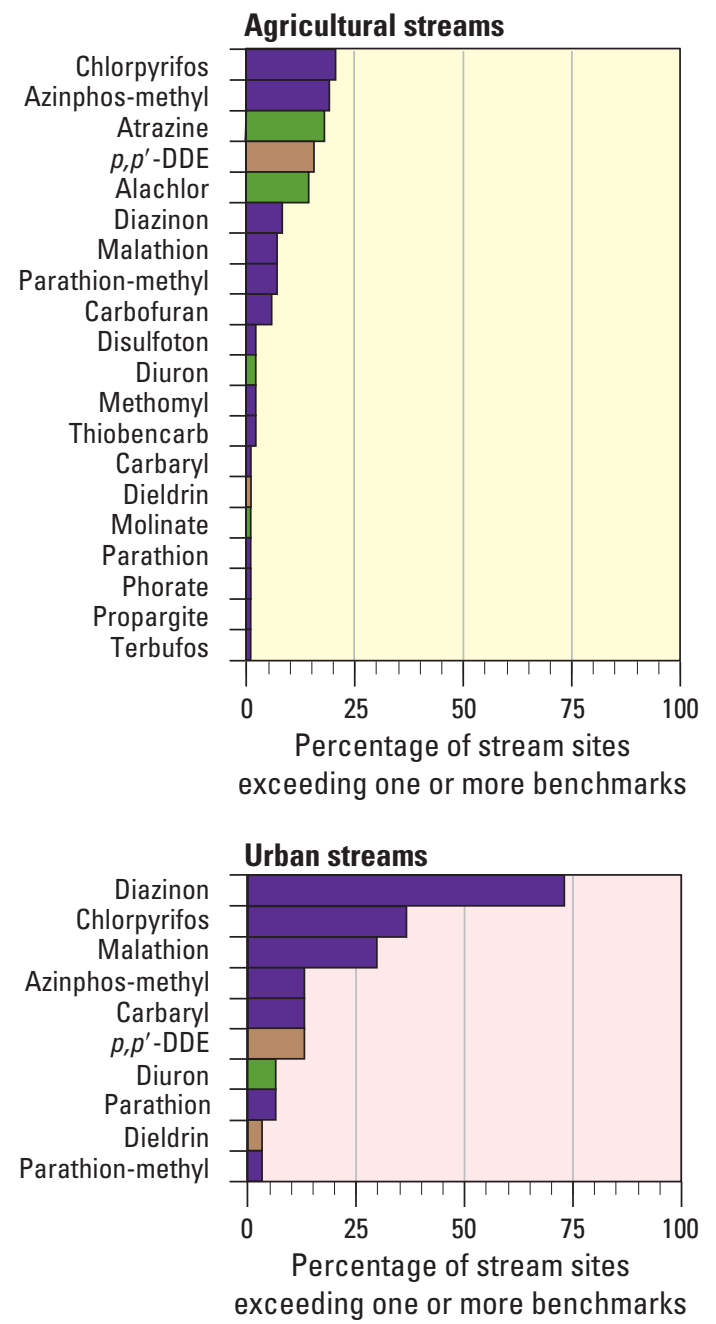

Figure 6-7. Contributions of individual pesticides to exceedances of aquatic-life benchmarks for water show the significance of insecticides in urban streams, particularly diazinon, chlorpyrifos, and malathion during the 1992-2001 study period. In agricultural streams, most exceedances of benchmarks were by chlorpyrifos, azinphos-methyl, atrazine, $p, p^{\prime}$-DDE, and alachlor. Water-quality benchmarks are provided in Appendix $3 \mathrm{~A}$. 
Atrazine concentrations in stream water compared with aquatic-life benchmarks
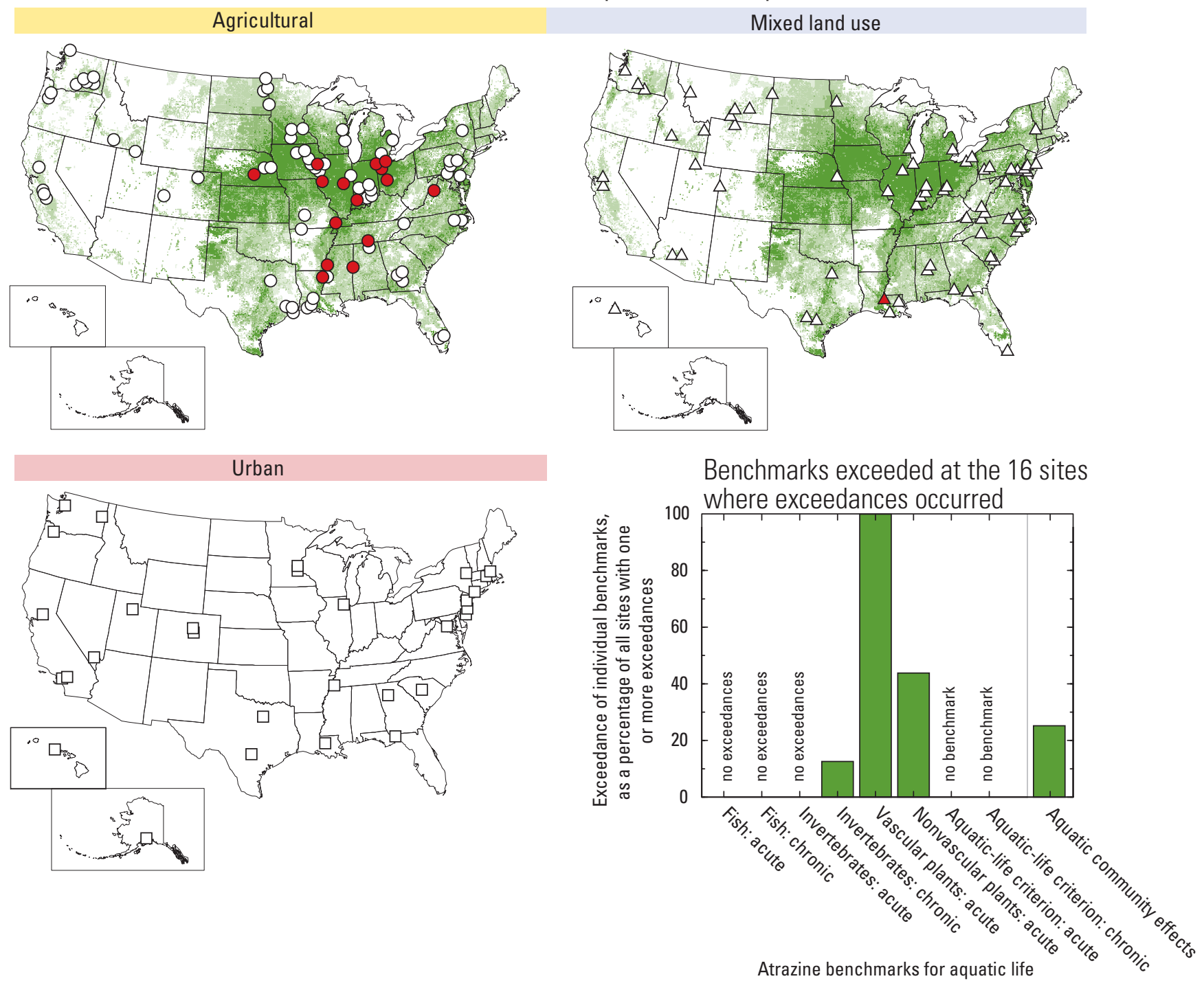

EXPLANATION

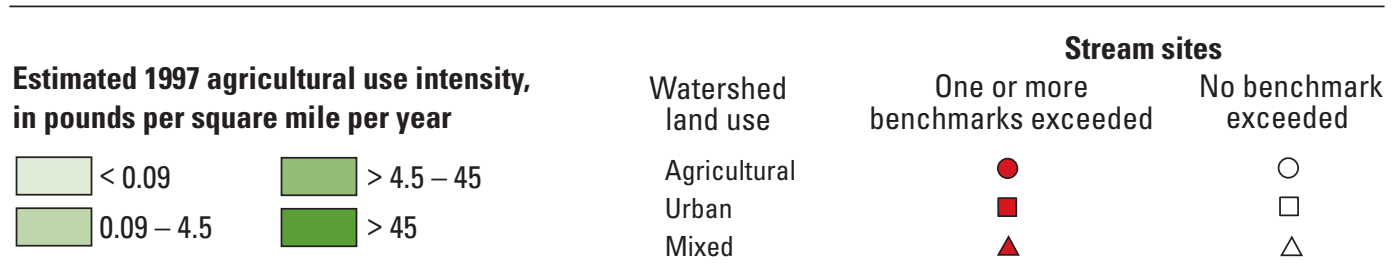

Figure 6-8. Streams in which atrazine concentrations were greater than at least one of its aquatic-life benchmarks were predominantly agricultural streams in areas where applications were greatest. The aquatic-life benchmarks most frequently exceeded by atrazine concentrations were those for vascular and nonvascular plants. Water-quality benchmarks are provided in Appendix 3A. 
Diazinon concentrations in stream water compared with aquatic-life benchmarks
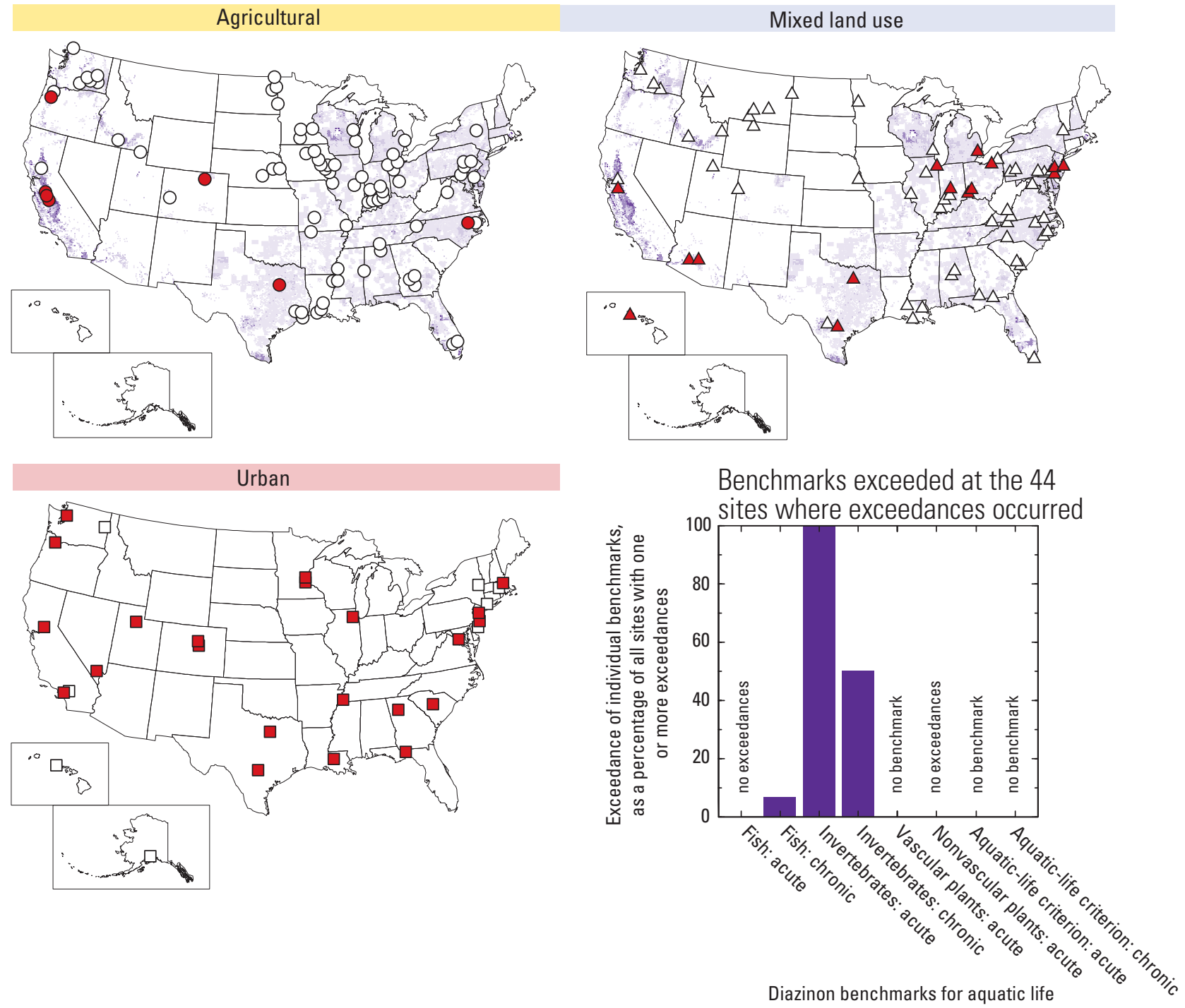

\section{EXPLANATION}

\begin{tabular}{|c|c|c|c|c|}
\hline \multirow{2}{*}{\multicolumn{2}{|c|}{$\begin{array}{l}\text { Estimated } 1997 \text { agricultural use intensity, } \\
\text { in pounds per square mile per year }\end{array}$}} & \multirow{2}{*}{$\begin{array}{l}\text { Watershed } \\
\text { land use }\end{array}$} & \multicolumn{2}{|c|}{ Stream sites } \\
\hline & & & One or more & No benchmark \\
\hline$]<0.09$ & $>4.5-45$ & & benchmarks exceeded & \\
\hline \multirow[t]{2}{*}{$0.09-4.5$} & \multirow[t]{2}{*}{$>45$} & $\begin{array}{l}\text { Agricultural } \\
\text { Urban }\end{array}$ & 0 & $\begin{array}{l}0 \\
\square\end{array}$ \\
\hline & & Mixed & $\Delta$ & $\triangle$ \\
\hline
\end{tabular}

Figure 6-9. Most streams in which diazinon concentrations were greater than at least one aquatic-life benchmark were urban streams, but concentrations in some agricultural streams in areas where applications were greatest also exceeded a benchmark. The aquatic-life benchmarks most frequently exceeded by diazinon were those for invertebrates. Water-quality benchmarks are provided in Appendix 3A. 
Chlorpyrifos concentrations in stream water compared with aquatic-life benchmarks
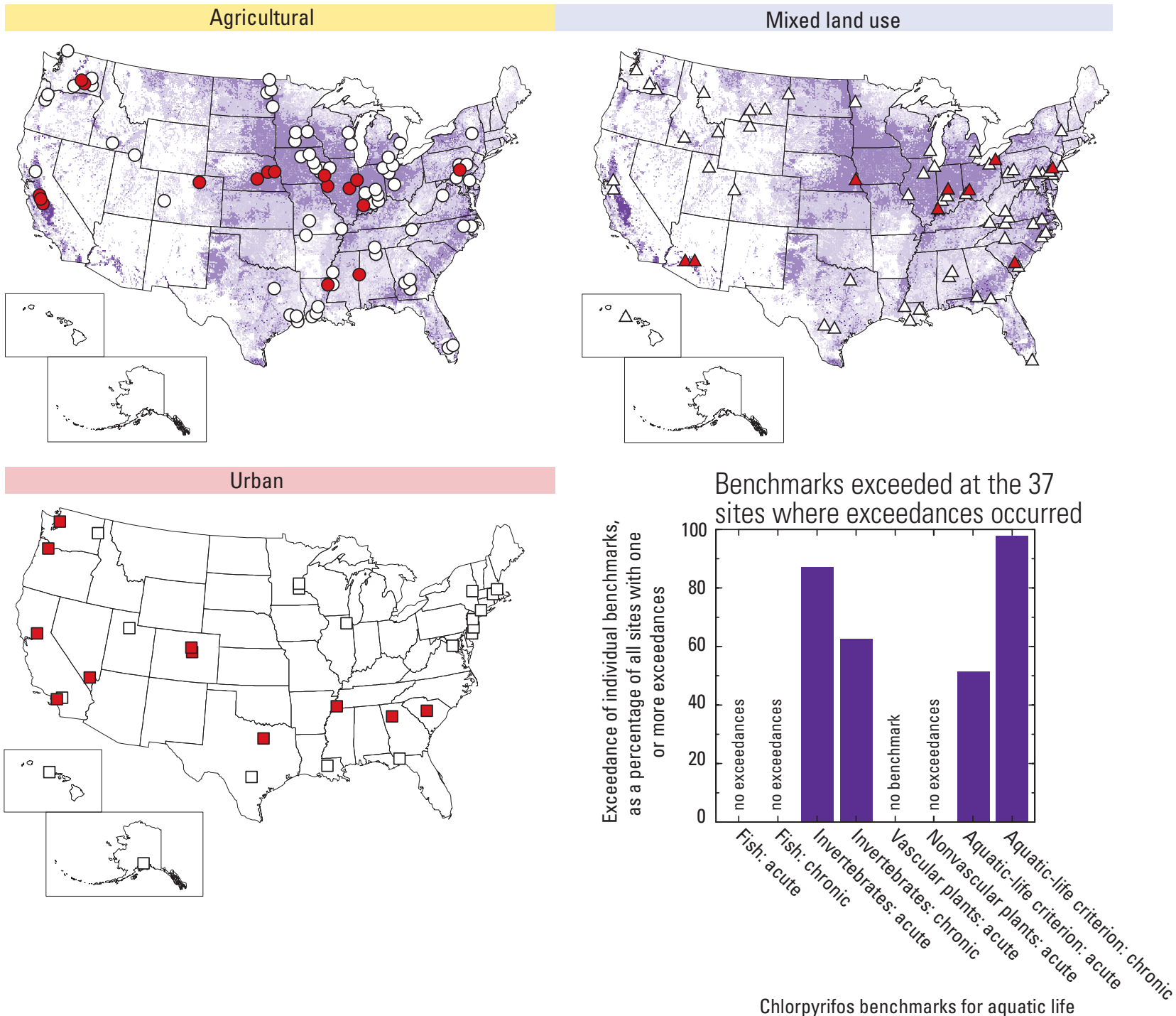

EXPLANATION

Estimated 1997 agricultural use intensity, in pounds per square mile per year

$\begin{array}{rlrl}\square & <0.09 & \square & >4.5-45 \\ \square & 0.09-4.5 & >\end{array}$

Watershed land use

Agricultural Urban

Mixed
Mixed land use 
this development process, and in response to USEPA's diazinon risk assessment, public comment noted an atypical distribution of the acute toxicity data for invertebrates. If data from the second most sensitive study were used (USEPA, 2000b), rather than the most sensitive study, then the calculated acute invertebrate benchmark for diazinon would change from its original $0.1 \mu \mathrm{g} / \mathrm{L}$ to a value of $0.4 \mu \mathrm{g} / \mathrm{L}$. The result of using a benchmark of $0.4 \mu \mathrm{g} / \mathrm{L}$ would be a reduction in the proportions of sites with diazinon exceedances from 73 to 40 percent for urban streams and from 8 to 6 percent for agricultural streams.

Overall, the screening-level assessment for potential effects of pesticides in stream water on aquatic life indicates that 56 percent of the 178 sampled streams that have watersheds dominated by urban, agricultural, or mixed land uses had concentrations of one or more pesticides that exceeded an aquatic-life benchmark during the study period. Pesticide use and occurrence were not constant during 1992-2001, however, and NAWQA data can be used, as for human-health benchmarks, to characterize changes that may have occurred for some pesticides in the land-use settings for which there are adequate data.

As noted for analysis of human-health benchmarks, there are sufficient NAWQA data for limited analysis of changes over time in benchmark exceedances for urban streams and for agricultural streams in the corn-and-soybeans crop setting. When grouped by sampling period, the percentages of urban stream sites that had concentrations of diazinon, chlorpyrifos, or malathion that exceeded a benchmark were lowest for urban sites sampled during the last part of the study (fig. 6-11). Observations about changes shown in figures 6-11 and 6-12, however, are preliminary because they are based on different groups of sites for each sampling period and siteto-site variability in conditions may distort actual trends. Although there are no consistent data available on the trends in the urban use of these pesticides during the study period, these results indicate the possibility that some reductions in urban use may have occurred. As mentioned earlier and discussed in Chapter 8, nonagricultural uses and some agricultural uses of diazinon and chlorpyrifos have declined since 2001 because of use restrictions initiated by USEPA. If concentrations of these insecticides are, in fact, declining in urban streams, the potential for effects on aquatic life in urban streams likely will also decline if their uses are replaced with pesticides that reach streams in less toxic amounts (or with alternative approaches to pest control).

In agricultural streams, most exceedances of aquatic-life benchmarks were by chlorpyrifos, azinphos-methyl, atrazine, $p, p^{\prime}$-DDE, and alachlor (fig. 6-7). The greatest potential for effects on aquatic life was generally in areas where one or more of these pesticides were intensively used, or in the case of $p, p^{\prime}$-DDE, where its parent compounds were intensively used in the past. For the purpose of characterizing changes over time in benchmark exceedances, there were sufficient agricultural stream sites with sampling years distributed throughout the study period only for streams in the corn-and-soybeans crop setting (fig. 4-6). This agricultural setting had the highest use during the study period of chlorpyrifos, atrazine, and alachlor. The changes in the percentages of stream sites in this setting that had concentrations exceeding benchmarks were different for the three pesticides during the study period (fig. 6-12). There was no clear trend for chlorpyrifos, an increasing number of exceedances for atrazine, and a decrease in exceedances for alachlor (with none during 1998-2000). Data on the agricultural use of these three pesticides from 1992 to 2001 in the Corn Belt show that these changes over time in benchmark exceedances are consistent with changes in their use (fig. 6-12).

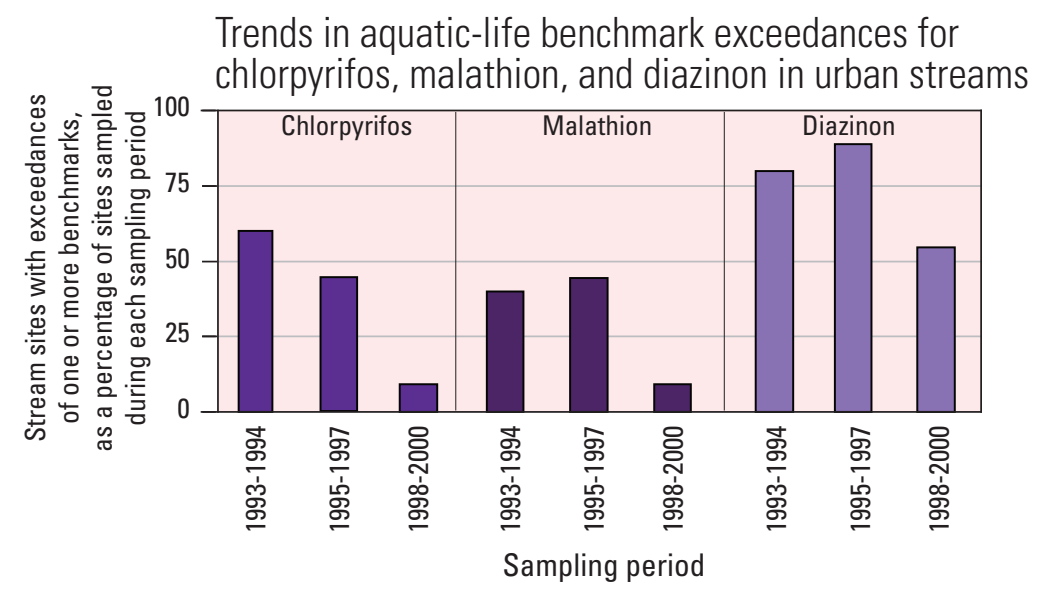

Figure 6-11. The percentages of urban streams that had exceedances of aquatic-life benchmarks for chlorpyrifos, malathion, and diazinon were lowest for each insecticide during the last sampling period. Sites were grouped according to the year of sampling. The 1993-1994 sampling period included 10 sites, the 1995-1997 period included 9 sites, and the 1998-2000 period included 11 sites. 
Trends in use and aquatic-life benchmark exceedances for chlorpyrifos, atrazine, and alachlor
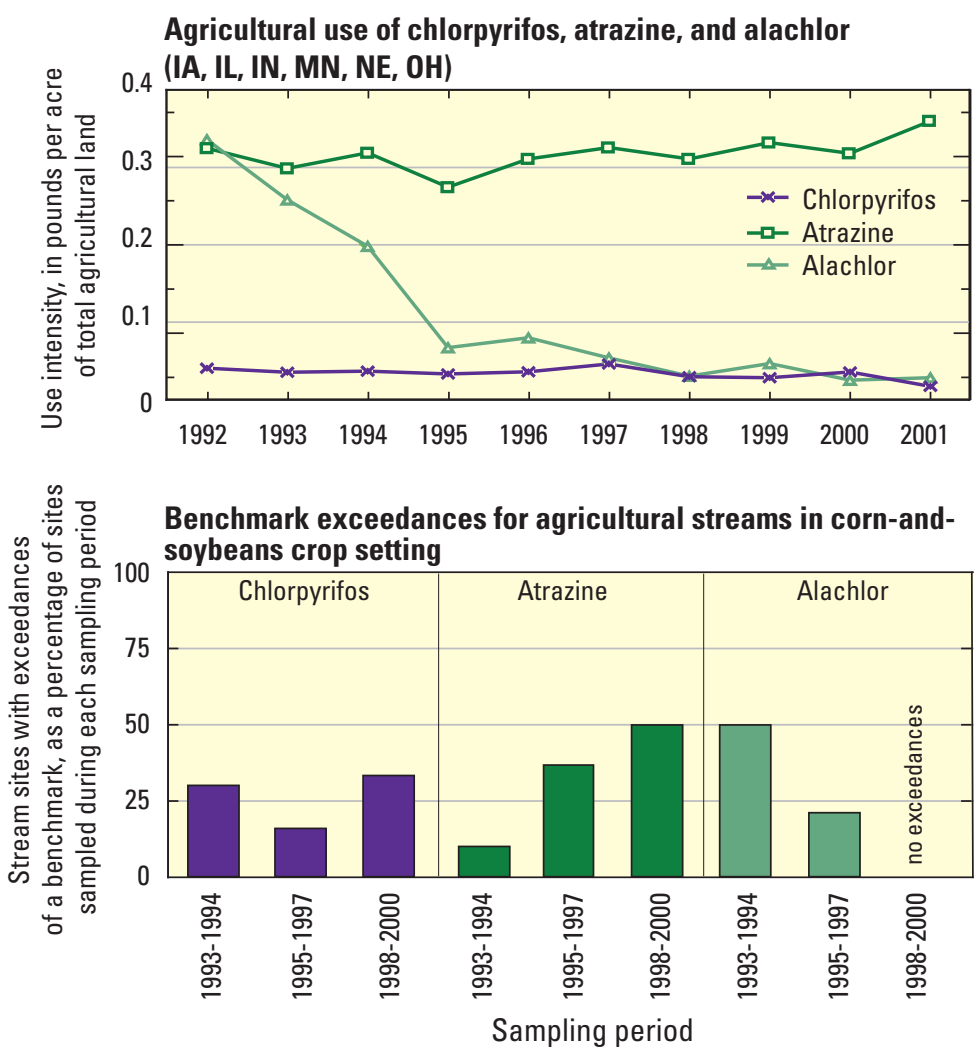

Figure 6-12. Changes over time in the percentage of agricultural stream sites in the corn-and-soybeans crop setting that had exceedances of aquatic-life benchmarks for chlorpyrifos, atrazine, and alachlor generally followed trends in use. Sites were grouped according to the year of sampling. The 1993-1994 sampling period included 10 sites, the 1995-1997 period included 19 sites, and the 1998-2000 period included 6 sites.

\section{Bed Sediment}

Concentrations of organochlorine pesticide compounds measured in bed sediment were greater than one or more aquatic-life benchmarks at 70 percent of urban sites, 31 percent of agricultural sites, 36 percent of mixed-land-use sites and 8 percent of undeveloped sites (fig. 6-4). The geographic distribution of sites where aquatic-life benchmarks for bed sediment were exceeded is similar to findings for water in many respects, including urban streams distributed throughout the country and many agricultural and mixedland-use streams in the Southeast, East, and irrigated areas of the West (fig. 6-5).

In urban streams, concentrations of DDT or one or more of its degradates or by-products were greater than benchmarks at 58 percent of sampled sites, total chlordane at 57 percent of sites, and dieldrin at 26 percent of sites (fig. 6-13). In agricultural streams, compounds in the DDT group exceeded benchmarks at 28 percent of sites and dieldrin at 8 percent of sites.

The geographic distributions of concentrations that were greater than benchmarks are different for DDT compounds (fig. 6-14) compared with dieldrin (fig. 6-15), following their historical use patterns. Concentrations of one or more DDT compounds were greater than benchmarks for aquatic life in 58 percent of urban streams and about 28 percent of agricultural and mixedland-use streams that were sampled. As discussed in Chapter 4, historical use of DDT for agriculture was highest in the Southeast, where cotton, tobacco, and peanuts were grown, and in a number of areas of the Nation where orchard crops, potatoes, vegetables, or specialty crops were grown. Dieldrin concentrations did not exceed its aquatic-life benchmark as frequently as DDT compounds, with 26 percent of urban streams

Organochlorine compounds with concentrations in bed sediment greater than an aquatic-life benchmark

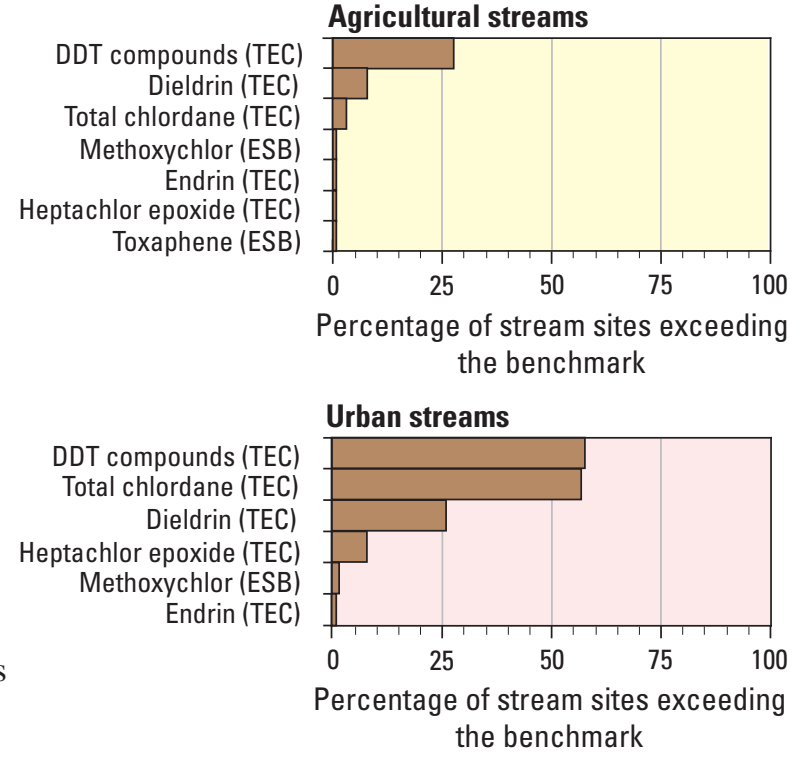

Figure 6-13. Contributions of individual pesticide compounds and groups to exceedances of aquatic-life benchmarks for bed sediment show the importance of historically used insecticides in urban streams, particularly DDT compounds, chlordane, and dieldrin. In agricultural streams, DDT compounds and dieldrin accounted for most exceedances of benchmarks. The type of benchmark is listed after each compound name as ESB for equilibrium partitioning sediment benchmark, or as TEC for threshold effect concentration. Waterquality benchmarks are provided in Appendix 3B. 


\section{Aquatic-Life Benchmarks for Organochlorine Compounds in Bed Sediment}

Benchmarks for assessing the potential for organochlorine pesticides compounds in bed sediment to adversely affect aquatic life were selected from consensus-based sediment-quality guidelines developed for sediment-dwelling aquatic organisms (MacDonald and others, 2000). These benchmarks are available for 6 of the 16 individual organochlorine pesticide compounds and compound groups (such as total chlordane) measured in sediment, including all of the most commonly detected ones. Threshold effect concentrations (TEC), which are concentrations below which harmful effects on sediment-dwelling organisms are not expected, were used as the primary screening-level benchmarks. In NAWQA's analysis, the TEC benchmarks were supplemented by USEPA equilibrium partitioning sediment benchmarks (ESB), which are available for 6 of the 16 organochlorine pesticide compounds and groups measured (USEPA, 2003c,d,e). Although ESBs are not available for some of the most commonly detected pesticides in sediment (DDT and chlordane), the 6 compounds with ESBs include 3 pesticides that do not have TEC benchmarks - toxaphene, methoxychlor, and endosulfan (Appendix 3B). Therefore, sediment benchmarks are available for a total of 9 of the 16 organochlorine pesticides or pesticide groups analyzed by NAWQA.

The two types of sediment benchmarks are quite different from one another. The TECs are empirically derived and are effective predictors of toxicity (or nontoxicity) in field-collected sediment, but they cannot be used to infer cause and effect related to individual contaminants. The TEC was selected as the primary benchmark because it meets the objectives of a screening-level assessment. The ESB is mechanistically based and is not designed to predict toxicity in field-collected sediment that contains multiple contaminants. A concentration greater than an ESB indicates a high likelihood of toxicity resulting from the specific contaminant. ESBs were used to provide some information on potential toxicity for pesticides that do not have TEC benchmarks.

Consensus-based threshold effect concentration (TEC)-The concentration of sediment-associated contaminants below which adverse effects on sediment-dwelling organisms are not expected to occur. The consensus-based TEC benchmarks are empirically based and indicate the likelihood that field-collected samples containing a given pesticide concentration will be toxic or nontoxic, but they do not necessarily indicate cause-and-effect. The particular pesticide upon which the benchmark is based is not necessarily the source of the toxicity because sediment may contain multiple contaminants. Validation data showed that 15-29 percent of sediment samples, depending on the pesticide, had measurable toxicity at organochlorine pesticide concentrations below their respective TECs (MacDonald and others, 2000). The incidence of toxicity above the TEC was consistently higher, with 40 percent of samples for one pesticide (endrin), and 70-100 percent for the rest, showing measurable toxicity above their respective TECs.

Equilibrium partitioning sediment benchmark (ESB)-The concentration of a chemical in sediment that USEPA expects will not adversely affect most benthic organisms. ESBs are mechanistic benchmarks based on the equilibrium partitioning model, which assumes that the toxicity of an organic contaminant in sediment is causally related to bioavailability and that bioavailability is controlled by contaminant sorption to sediment organic carbon. ESBs further assume that the contaminant is in equilibrium with sediment particles and sediment pore water. In the natural environment, including areas with highly erosional or depositional bed sediment, contaminants may not attain equilibrium. Each ESB is designed to predict toxicity caused by a specific contaminant (or group) only, and it is not expected to correctly predict toxicity when other contaminants are present in toxic amounts, such as may occur in field-collected samples containing contaminant mixtures. Thus, when a contaminant concentration exceeds its ESB in field-collected sediment, the sediment is predicted to be toxic because of the presence of that contaminant.

\section{Application of Aquatic-Life Benchmarks for Bed Sediment}

Aquatic-life benchmarks for sediment, both TECs and ESBs, were compared with pesticide concentrations measured by NAWOA in composite bed-sediment samples collected from depositional areas in streams (one sample per site). TECs, which are expressed on a total sediment basis, were compared directly with NAWQA-measured pesticide concentrations in sediment. Because ESBs are in units of micrograms of contaminant per gram of sediment organic carbon, NAWQA-measured pesticide concentrations (micrograms of contaminant per kilogram of total sediment) were first divided by the measured organic carbon content (grams of organic carbon per kilogram of total sediment) of the sediment sample, before comparison with ESBs. and 8 percent of agricultural and mixed-land-use streams having concentrations greater than the benchmark. For dieldrin, a cluster of agricultural sites with concentrations greater than the benchmark is located in the Corn Belt, where use of aldrin and dieldrin on corn was most intensive. In urban areas, these pesticides were used for such purposes as mosquito and termite control.

The screening-level assessment for organochlorine compounds in bed sediment indicates that most urban streams sampled by NAWQA (70 percent), and about one-third of sampled streams with watersheds dominated by agricultural or mixed land uses, had concentrations of organochlorine compounds that exceeded one or more aquatic-life benchmarks during the study period. Although DDT, aldrin, dieldrin, and chlordane are no longer used in the United States, the screening-level assessment indicates that these compounds and their degradates continue to be present at levels in bed sediment that may have adverse effects on aquatic life in some streams. 
Concentrations of DDT compounds in bed sediment compared with aquatic-life benchmarks

Agricultural

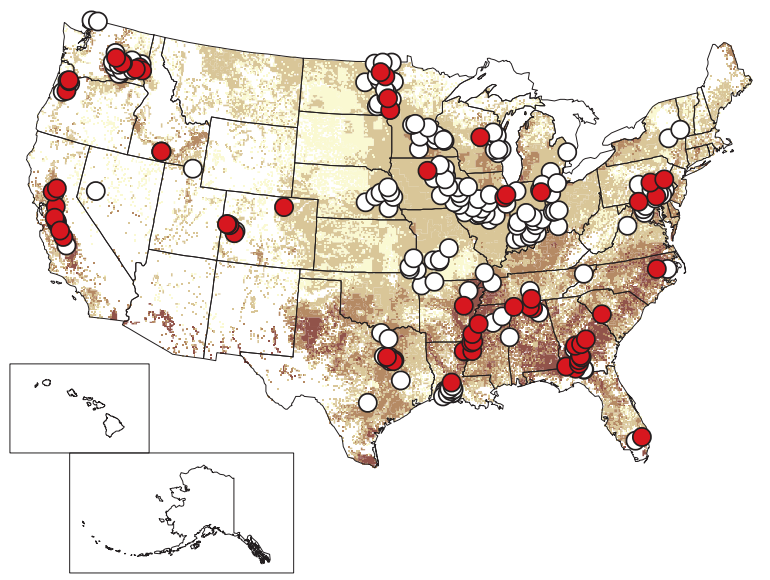

Urban

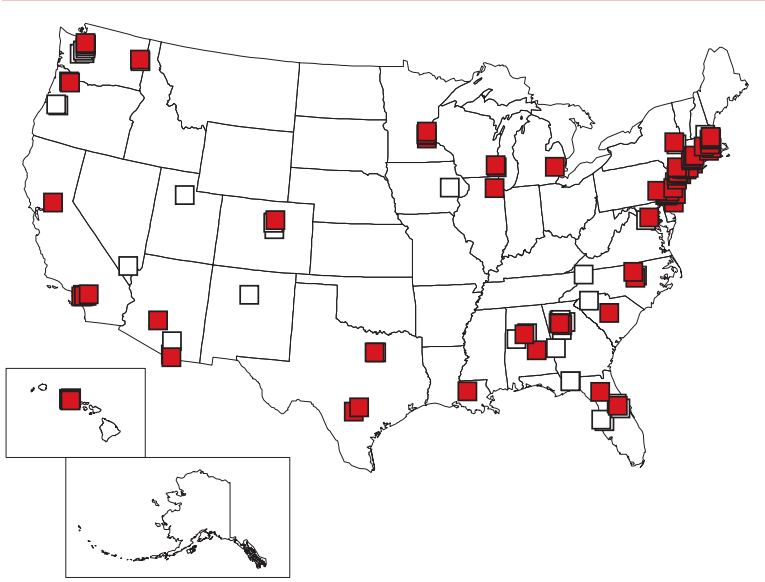

Mixed land use

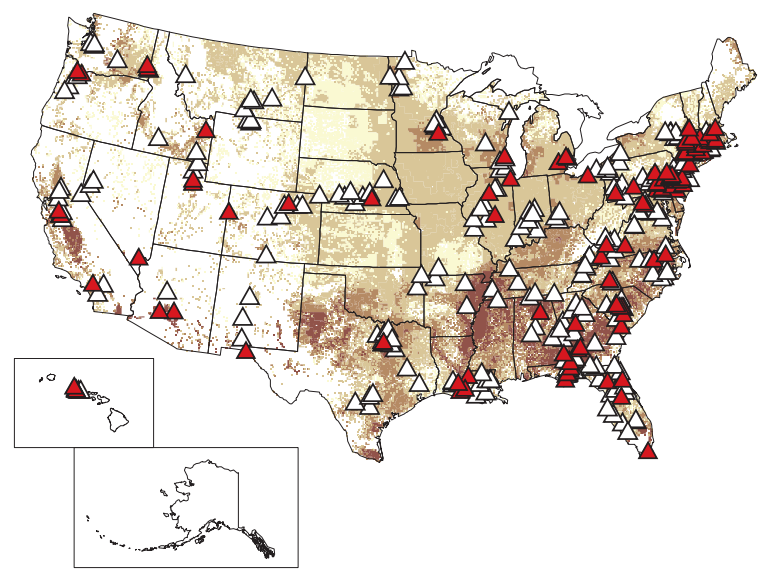

Undeveloped

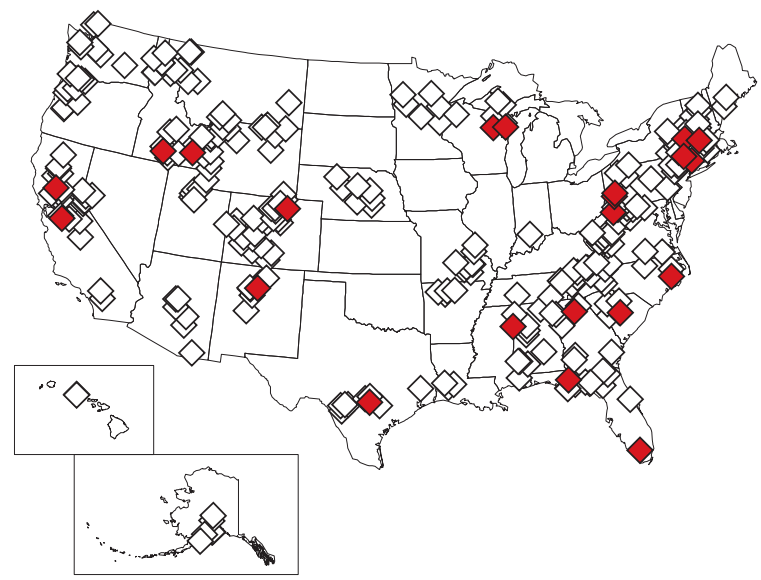

EXPLANATION

Estimated historical agricultural use intensity, in pounds per square mile per year

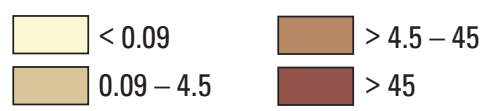

Watershed land use

Agricultural

Urban

Undeveloped

Mixed

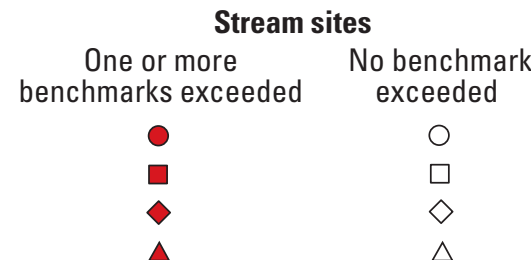

Stream sites

$\triangle$

Figure 6-14. Streams in which concentrations of one or more DDT compounds in bed sediment exceeded an aquatic-life benchmark were predominantly urban streams, or agricultural and mixed-land-use streams in areas where historical use of DDT plus DDD was greatest. Water-quality benchmarks are provided in Appendix 3B. 
Concentrations of dieldrin in bed sediment compared with aquatic-life benchmarks
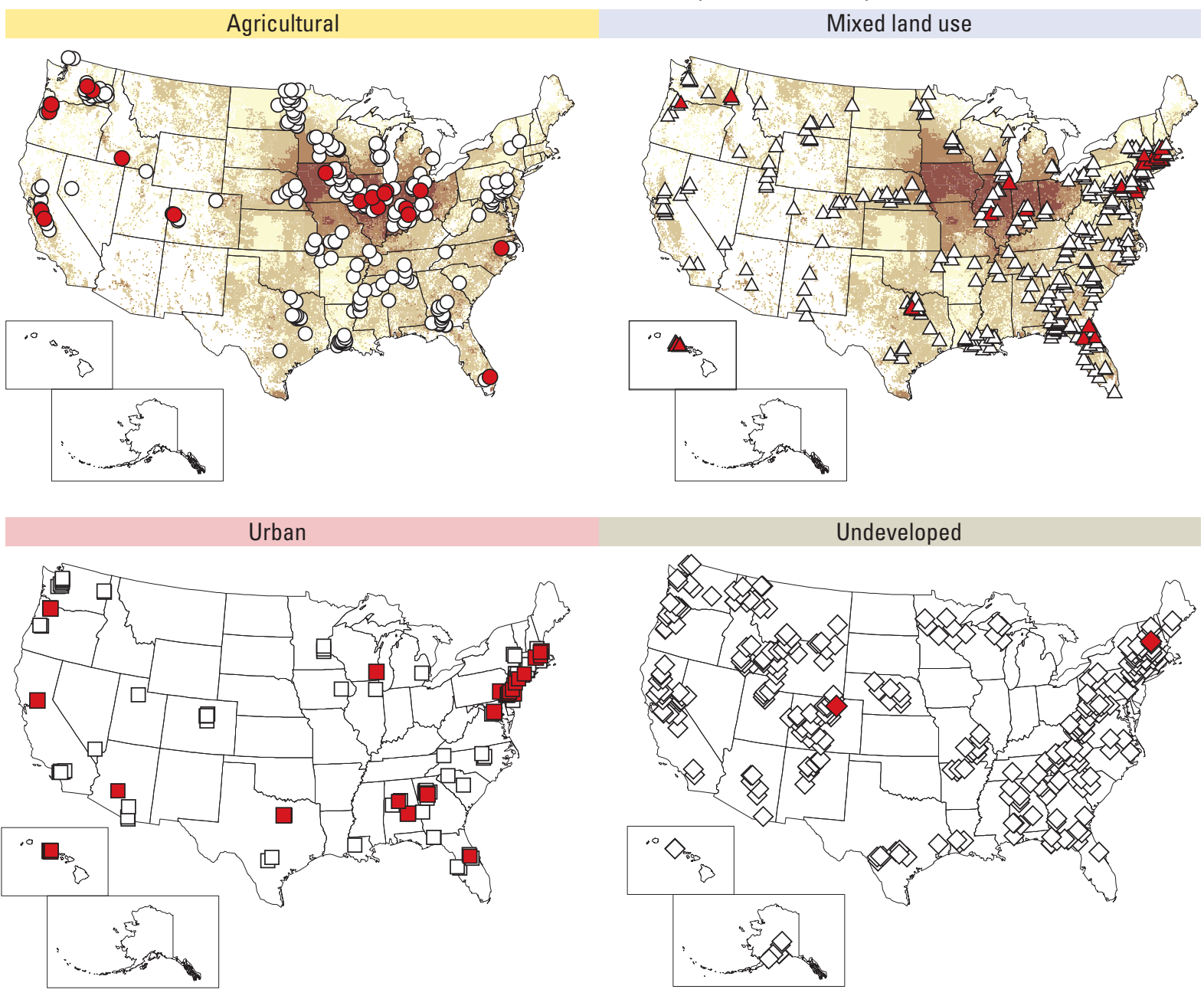

Undeveloped

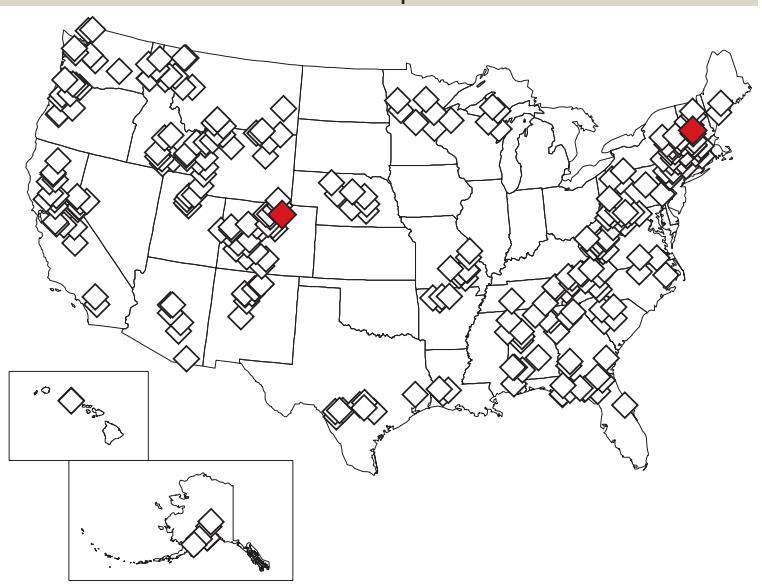

\section{EXPLANATION}

Estimated historical agricultural use intensity, in pounds per square mile per year

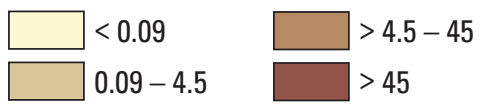

Watershed land use

Agricultural

Urban

Undeveloped

Mixed

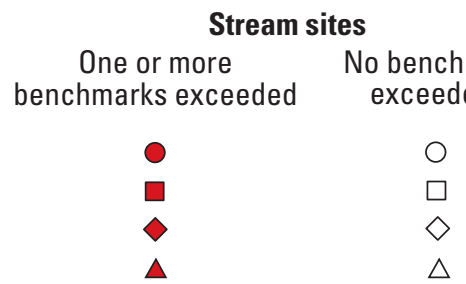

Figure 6-15. Streams in which dieldrin concentrations in bed sediment exceeded its aquatic-life benchmark were predominantly urban streams or agricultural and mixed-land-use streams in areas where historical use of aldrin plus dieldrin was greatest. Water-quality benchmarks are provided in Appendix 3B. 


\section{Screening-Level Assessment for Fish-Eating Wildlife}

NAWQA data on pesticides in whole fish were compared with both the low and high values of the range in available benchmarks, because there is no consensus on a national-scale suite of wildlife benchmarks (see accompanying sidebar, p. 109). Comparisons of measured concentrations of organochlorine pesticide compounds in wholefish tissue with wildlife benchmarks indicate a correspondingly wide range of potential for effects, depending on whether the low or high benchmark values are used (fig. 6-16). The high benchmarks for fish tissue were exceeded most frequently in streams in the populous Northeast; in high-use agricultural areas in the upper and lower Mississippi River Basin; in high-use irrigated agricultural areas of the West, such as eastern Washington and the Central Valley of California; and in urban streams distributed throughout the country (fig. 6-17). Few fish samples were analyzed in the Southeast. The low (more protective) benchmarks generally show an expanded proportion of sites in the same regions and land uses.

Concentrations in whole-fish tissue greater than wild life benchmarks

Figure 6-16. Wildlife benchmarks for concentrations of organochlorine pesticides in fish tissue were often exceeded, but the range of results for high and low benchmark values indicates that there is considerable uncertainty in wildlife benchmark values. Water-quality benchmarks are provided in Appendix 3B.

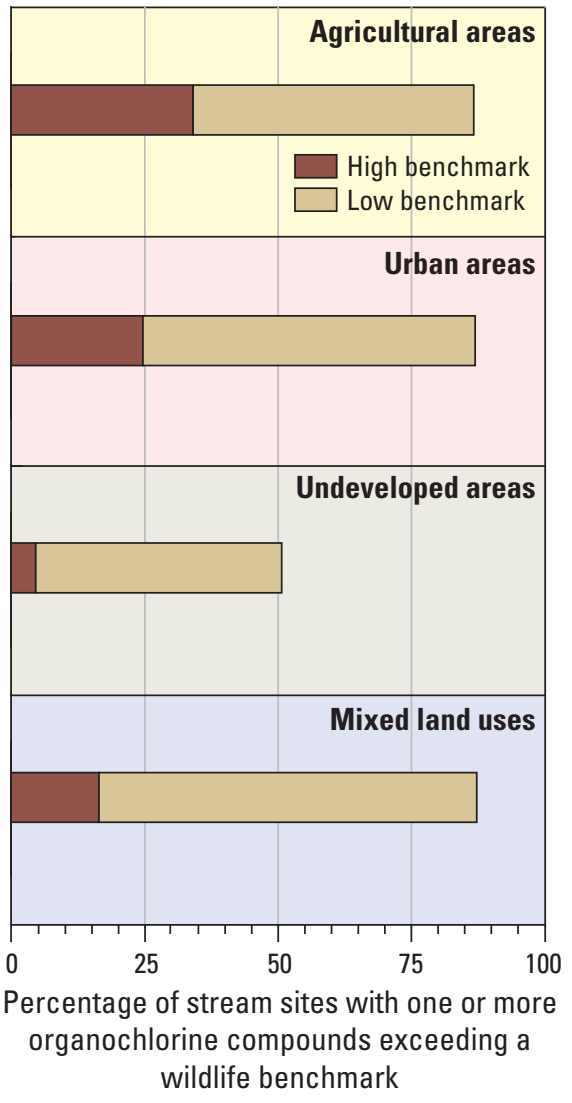

Sites with concentrations greater than a wildlife benchmark

Fish Tissue (high benchmarks for wildlife)

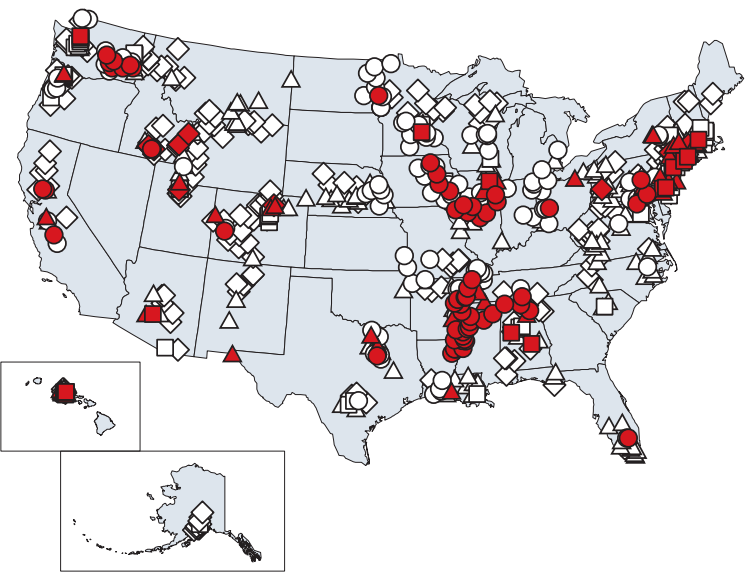

Fish Tissue (low benchmarks for wildlife)

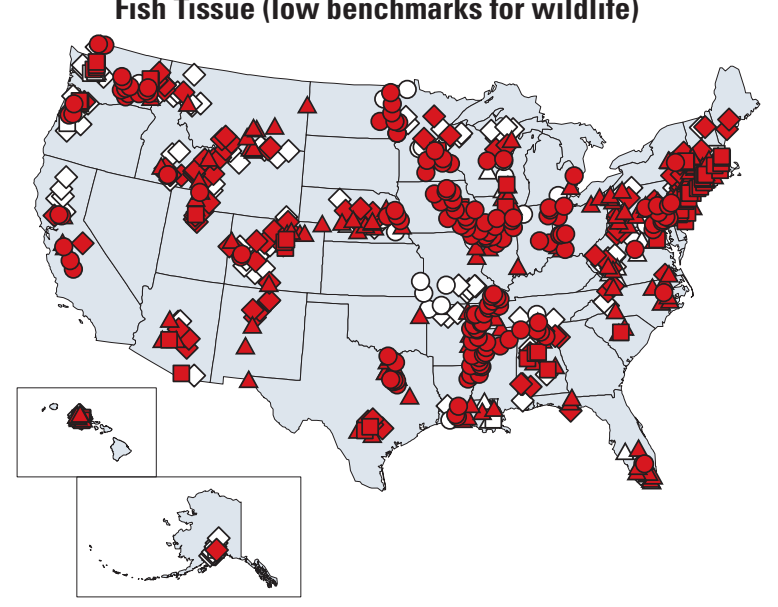

\begin{tabular}{lcc} 
& \multicolumn{2}{c}{ Stream sites } \\
Watershed & $\begin{array}{c}\text { One or more } \\
\text { land use }\end{array}$ & $\begin{array}{c}\text { No benchmark } \\
\text { exceeded }\end{array}$ \\
Agricultural & $\bullet$ & $\bigcirc$ \\
Urban & $\square$ & $\square$ \\
Undeveloped & $\diamond$ & $\diamond$ \\
Mixed & $\Delta$ & $\Delta$
\end{tabular}

Figure 6-17. Wildlife benchmarks were exceeded by organochlorine pesticide compounds in whole fish most frequently in urban and mixed-land-use streams in the populous Northeast, in agricultural streams in areas with high historical use, and in urban streams distributed throughout the country. Water-quality benchmarks are provided in Appendix 3B. 


\section{Wildlife Benchmarks for Pesticides in Whole Fish}

\section{Benchmarks for assessing the potential for organochlorine} pesticide compounds in fish tissue to adversely affect wildlife that consume either fish or other fish-eating wildlife were selected from several sources (Appendix 3B). USEPA is developing tissue-based criteria for bioaccumulative contaminants, but the process is not complete (USEPA, 2005i).

Currently, there is no broad consensus on a single system of national-scale, fish-tissue benchmarks for wildlife. Relatively few tissue-based wildlife benchmarks are available, some of which were developed for State or regional applications. Most available benchmarks have, however, been derived using similar methodologies (based on the same USEPA methodology for using laboratory animal test data to develop human-health benchmarks). First, a noobserved-adverse-effects level (NOAEL) for wildlife is estimated from the NOAEL for the most sensitive test species. Then the concentration of a contaminant in food that would result in a dose equivalent to the NOAEL (assuming no exposure through other environmental media) is calculated from estimates of the food consumption rate and body weight for multiple representative wildlife species. Calculations usually are done for both mammalian and avian species, and the lowest is commonly selected as a screening-level benchmark. Benchmark values from different sources vary considerably for a given compound, despite similar methodologies. The extreme case is total DDT, for which tissue-based wildlife benchmarks range from 6 to $200 \mu \mathrm{g} / \mathrm{kg}$ wet weight. Different values for a particular pesticide may result from the use of different test species in toxicity tests, the use of different uncertainty factors to account for interspecies differences, and differences in the duration of exposure or test endpoints measured. In addition, results may be extrapolated to different representative wildlife species, which typically are selected to reflect the geographic location and objectives of the program or organization setting the benchmarks.

Because of the lack of consensus on tissue-based benchmarks for protection of wildlife, whole-fish concentrations measured by NAWQA were compared with a range of available benchmark values for each compound. First, systematically derived wildlife benchmarks were compiled, resulting in four sets of wildlife benchmarks (described below). Second, the lowest and highest benchmark values for each organochlorine pesticide or group were selected and used in two separate analyses of NAWQA fish data. Each wildlife benchmark used in this report represents the concentration of a pesticide or group in fish, below which adverse effects on fish-eating wildlife are not expected to occur (100 percent of exposure to the pesticide is assumed to be from consumption of fish). One or more fish-eating wildlife benchmarks were available for 10 of the 12 organochlorine pesticides and groups measured by NAWOA in fish tissue.

\section{NOAEL-based toxicological benchmark for fish-eating wildlife-} This benchmark is the NOAEL-equivalent concentration in food derived for the most sensitive fish-eating wildlife species for which data are available. NOAEL-equivalent concentrations in food were derived for a variety of wildlife species by Sample and others (1996) for the Department of Energy, Oak Ridge National Laboratory, for use in ecological risk assessments at waste sites. Endpoints such as reproductive and developmental toxicity and reduced survival were used whenever possible, but for some contaminants, data were limited and other endpoints (such as organ-specific toxic effects) were used. The representative wildlife species used by Sample and others
(1996) represent a wide range of diets and body weights and have wide geographic distributions within the United States. These include several fish-eating species: mink, river otter, belted kingfisher, osprey, and great blue heron. For this report, the lowest value was selected from the available NOAEL-equivalent concentrations in food that were derived for fish-eating species and used as the benchmark for each compound. These benchmarks are available for 8 of the 12 organochlorine pesticides and pesticide groups measured by NAWOA in fish.

Canadian Tissue Residue Guideline (TRG) - This benchmark is designed to protect all life stages of all wildlife during a lifetime exposure to a substance present as a contaminant in aquatic food sources (CCME, 1998). TRGs are calculated from the most sensitive of the available toxicity tests and applied to the Canadian wildlife species with the highest food intake/body weight ratio (CCME, 1998). TRGs are available for two organochlorine pesticides (DDT and toxaphene), which were derived using Wilson's storm petrel and the mink as representative wildlife species (CCME, 1999a,b).

New York fish flesh criteria (FFC) for protection of piscivorous wildlife, noncancer values-These are intended to protect specific wildlife species from adverse effects other than cancer, such as mortality, reproductive impairment, and organ damage (Newell and others, 1987). The New York State Department of Environmental Conservation (NYSDEC) derived these criteria using the same extensive laboratory animal toxicology database that is used to derive criteria for the protection of human health. Instead of extrapolating from laboratory animals to humans, the NYSDEC extrapolated from laboratory animals to wildlife. To represent birds and mammals, the NYSDEC selected a generic bird (with a body weight of $1 \mathrm{~kg}$ and a food consumption rate of $0.2 \mathrm{~kg} /$ day) and the mink. New York FFC are available for 8 of the 12 organochlorine pesticides and pesticide groups measured by NAWOA in fish.

\section{Proposed criteria from the Contaminant Hazard Review series-} Proposed tissue-based criteria for wildlife are included among recommendations for protection of natural resources in the Contaminant Hazard Review series developed by the U.S. Fish and Wildlife Service. Proposed criteria are available from this series for two organochlorine pesticides, toxaphene and chlordane. For chlordane (Eisler, 1990), the criterion is based on birds only-Eisler noted that criteria for protection of mammalian wildlife were lacking, and criteria for birds were incomplete and still required NOAELs from lifetime exposures. Wildlife benchmarks for toxaphene (Eisler and Jacknow, 1985) are based on criteria for human-health protection (ranging in various foods from 0.1 to $7.0 \mathrm{mg} / \mathrm{kg}$ ), which are expected to protect sensitive species of wildlife.

\section{Application of Fish-eating Wildlife Benchmarks for Fish}

Fish-eating wildlife benchmarks for fish tissue were compared with concentrations of organochlorine pesticide compounds or groups measured by NAWOA in composite samples of whole fish (one sample per site). Concentrations measured by NAWQA were compared with both the lowest and the highest benchmark values available for each pesticide compound and group. The analysis thus reflects the degree of uncertainty in estimating the potential for adverse effects on wildlife. 
Most of the concentrations that exceeded a benchmark, as well as most of the variance between high and low benchmarks, were due to total DDT. Using the high and low ends of the range of benchmark values available for different pesticides (or pesticide groups), wildlife benchmarks were exceeded at 11 to 88 percent of urban stream sites for total DDT, 15 to 18 percent for dieldrin, and 0 to 10 percent for total chlordane. In agricultural streams, total DDT exceeded wildlife benchmarks at 29 to 87 percent of sites, dieldrin at 7 to 11 percent, and toxaphene at 0 to 9 percent (fig. 6-18).

Organochlorine compounds with concentrations greater than a wildlife benchmark

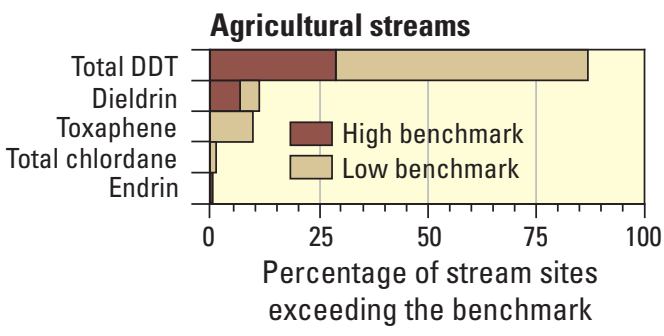

The wildlife screening-level assessment for organochlorine compounds in fish tissue indicates that these compounds still occur at some sites at concentrations that have the potential to adversely affect fish-eating wildlife. Although there is relatively high uncertainty in benchmark values, total DDT and dieldrin accounted for most benchmark exceedances, and there were 34 percent of agricultural sites and 25 percent of urban sites with concentrations that exceeded both low and high benchmark values for one or more pesticide compounds or groups.

Figure 6-18. Contributions of individual organochlorine pesticide compounds or groups to exceedances of whole-fish tissue benchmarks for fish-eating wild life show the potential significance of total DDT and dieldrin. Water-quality benchmarks are provided in Appendix 3B.

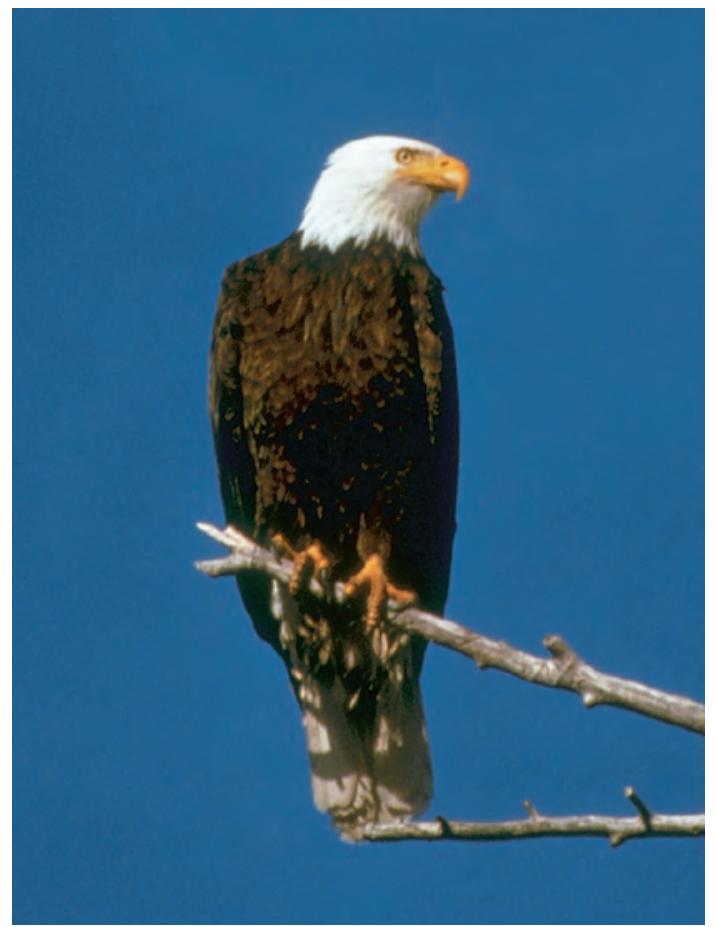




\section{Emerging Issues for Assessment of Pesticide Effects}

Although pesticides are among the most intensively studied of environmental contaminants, and many studies of fate and effects are required to register a pesticide for use, comprehensive assessment of their potential effects continues to present challenges. Two issues receiving particular attention by the scientific and regulatory communities are the potential effects of pesticide mixtures, the occurrence of which was examined in Chapter 5, and the potential effects of pesticides on endocrine systems.

\section{Approaches for Assessing Potential Effects of Pesticide Mixtures on Humans and Aquatic Life}

Understanding the potential effects of chemical mixtures on humans and the environment is one of the most complex problems facing scientists and regulatory agencies. USEPA identified this issue as a priority in its research strategy for 2000 and beyond (USEPA, 2000b). Although guidelines and detailed procedures for evaluating potential effects from exposure to chemical mixtures have been provided by USEPA (USEPA, 1986, 2000b) and other agencies (ATSDR, 2004b), implementation has been difficult because of the complexity of mixtures that occur in the environment and the inadequacy of data on the toxicity of the mixtures. Most toxicological testing is performed on single chemicalsusually at high exposure levels - whereas most human and ecological exposures are to chemical mixtures at relatively low doses (USEPA, 2000b; ATSDR, 2004b).

Humans can be exposed to mixtures of pesticides and their degradates that occur in streams and ground water if such water is used as a source of drinking water and if treatment does not eliminate the pesticide compounds. Aquatic organisms are exposed to mixtures that occur in streams. Pesticide mixtures may be derived from common sources (such as point sources) or from multiple nonpoint sources, and may include several different types of pesticide compounds with different mechanisms of toxicity. Although a review of recent research on the effects of pesticide mixtures is beyond the scope of this report, the present approaches taken by USEPA and other agencies for regulating and assessing pesticide mixtures provide an indication of present knowledge and information gaps.

Evaluation and management of potential risks to humans of pesticide mixtures that may occur in drinking water are primarily addressed at the Federal level by USEPA and the Agency for Toxic Substances and Disease Registry (ATSDR). Much of the attention to potential effects of chemical mixtures on human health has been associated with risk assessments required for hazardous waste sites as part of implementing the Comprehensive Environmental Recovery, Compensation, and Liability Act (CERCLA), but specific assessment of pesticide mixtures is also now occurring to meet requirements of the Food Quality Protection Act (FQPA) of 1996. Under the FQPA, USEPA must assess the cumulative risks of pesticides that share a common mechanism of toxicity, or act the same way in the body. These cumulative assessments consider exposures from food, drinking water, and residential sources. USEPA also incorporates regional exposures from residential and drinking-water sources to account for the considerable variation in potential exposures across the country. To date, USEPA has determined that within each of four different chemical classes (organophosphates, N-methyl carbamates, triazines, and chloroacetanilides), several specific pesticide compounds have a common mechanism of toxicity and require cumulative risk assessments to better define the potential effects of exposure of humans to multiple pesticides within each class.

The potential effects of chemical mixtures on aquatic life have not received as much attention as for human health, although USEPA's Office of Research and Development, National Center for Environmental Assessment, has completed ecological risk-assessment guidelines that support the cumulative risk-assessment approach (USEPA, 2003f). The pesticide registration and reregistration processes require ecological risk assessment, which includes evaluation by USEPA of the likelihood that exposure to more than one pesticide and its degradates may cause harmful ecological effects.

Potential effects of pesticide mixtures on aquatic life also may be considered as part of assessments for National Pollutant Discharge Elimination System (NPDES) permits or hazardous waste sites. Procedures developed by USEPA for conducting assessments for NPDES permits involve a battery of tests, referred to as "whole effluent toxicity" (WET) tests, for both effluents and receiving waters. The WET tests are toxic- 
ity tests applied to actual or simulated effluent and receiving water and, therefore, assess the combined toxicity to aquatic life of all contaminants present in water (USEPA, 2004f). Although the WET test procedures provide a methodology for directly testing ambient waters that contain mixtures, they have not yet been applied more broadly to assess mixtures of pesticides from nonpoint sources that do not involve NPDES permits. Similarly, the risk-assessment methods developed for mixtures that occur at hazardous waste sites (USEPA, 2003f) provide a systematic approach to assessing potential effects of pesticide mixtures on aquatic life, but they are generally not applied to ambient water-quality conditions.

In addition to these various approaches to addressing mixtures as part of the regulatory process, researchers are studying the effects of specific mixtures of pesticides and degradates and relating the occurrence of mixtures to their potential effects on aquatic ecosystems. The accompanying sidebar by Lydy and Belden (p. 114) provides a perspective on current understanding and the status of research regarding the potential effects of pesticide mixtures on aquatic life. NAWQA has begun to examine relations between biological measures of stream quality and the range of stresses introduced by agricultural and urban activities, including exposure to pesticides. The accompanying sidebar on the Pesticide Toxicity Index (p. 116) summarizes how the index is used by NAWQA as a relative indication of the potential toxicity of a mixture to aquatic life and illustrates its applications with examples from NAWQA studies.

Although an array of approaches has been developed for assessing the potential effects of mixtures using the best available data on exposure and effects, progress toward understanding the potential effects of pesticide mixtures on humans and aquatic life has been hampered, in part, by sparse data on the composition and concentrations of mixtures that actually occur in streams and ground water. As examined in Chapter 5, pesticide degradates are potentially important components of pesticide mixtures that need to be considered when evaluating potential effects. Improved data on the occurrence and composition of mixtures from NAWQA and other studies can help to characterize the potential exposure of humans, aquatic life, and wildlife to mixtures and provide a basis for systematically prioritizing mixtures that may occur in streams and ground water.

\section{Endocrine Disruption and Pesticides}

Endocrine systems are present in mammals, birds, fish, and other organisms. They are comprised of glands that produce hormones, which act as chemical messengers, and receptors in various organs and tissues that recognize and respond to the hormones. The endocrine system regulates all body functions from conception through adulthood, including the development of the brain and nervous system, the growth and function of the reproductive system, and metabolism and blood-sugar levels. Disruption of the endocrine system by a contaminant can occur in a number of ways, such as by mimicking a natural hormone, blocking the effects of a hormone, or causing overproduction or underproduction of hormones (Gross and others, 2003).

More than 50 synthetic chemical compounds, including a number of pesticides, have been identified as potential endocrine disruptors in various studies over the past several years (National Academy of Sciences, 1999). The studies include bioassays demonstrating estrogenic or anti-estrogenic activity and field studies correlating contaminants with hormone-related effects. Examples of such field studies include feminization of gull embryos linked to elevated DDT (Fry and Toone, 1981), population declines of alligators in some Florida Lakes with elevated concentrations of organochlorine pesticides (including DDT) (Guillette and others, 1994), and feminization of fish in water bodies receiving municipal discharges or industrial effluents (Purdom and others, 1994).

In 1994, the NAWQA Program investigated the potential influence of contaminants on sex steroid hormones and other biomarkers in common carp (Goodbred and others, 1997). Abnormal ratios of sex steroid hormones in both male and female carp were found at some sites, and the ratio of estrogen to testosterone, an indicator of potential abnormalities in the endocrine system, was significantly lower at sites where some of the highest pesticide concentrations were detected (fig. 6-19). Further investigation is needed to determine whether (1) reduced hormone ratios are caused by pesticides, and (2) the reduced hormone ratios are associated with significant effects on fish populations.

The 1996 Food Quality Protection Act requires USEPA to screen and assess pesticides and other environmental contaminants for potential effects on human endocrine systems, an assessment which USEPA is extending to wild- 
life as well. A review of NAWQA pesticide data compared with a list of potential endocrine disrupting compounds (Keith, 1997) indicates that 17 pesticides measured by NAWQA in water are possible endocrine disruptors (USEPA has not yet designated pesticides that it considers to be potential endocrine disruptors). Eleven of these pesticides were among those most frequently found in NAWQA stream samples (fig. 6-20).

Research on the effects of chemicals on endocrine systems is in its relatively early stages. Several important aspects are still unclear, including the degree to which such effects occur in the environment; whether effects on individual organisms translate to effects on populations and communities; and at what concentrations effects on populations become significant. There is considerable scientific uncertainty about the causes of reported effects (Kavlock and others, 1996). A major effort is underway by USEPA and other agencies to systematically identify and better understand endocrine disruptors (USEPA, 1998).

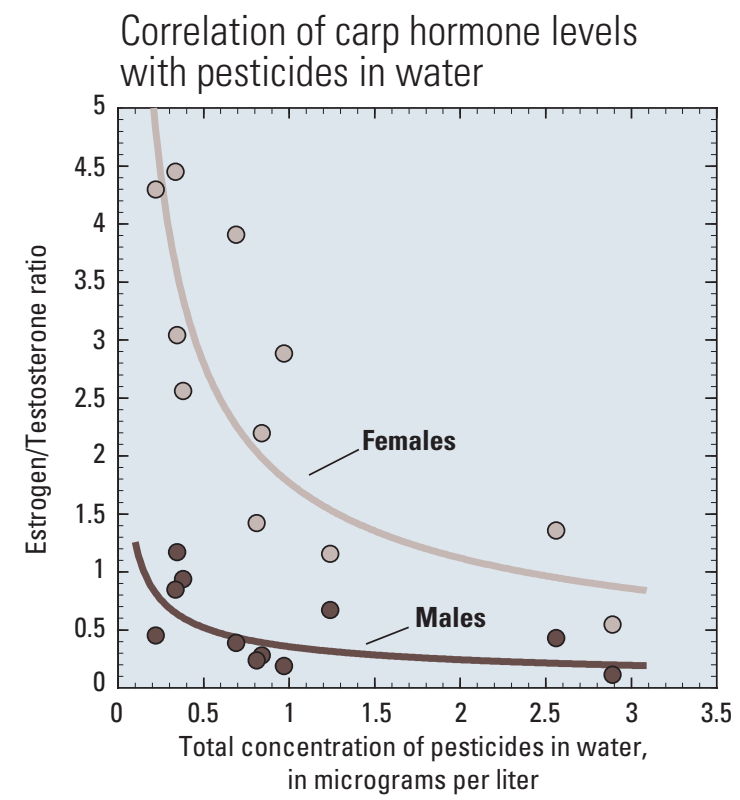

Figure 6-19. Ratios of estrogen-to-testosterone in carp from 11 streams sampled by NAWQA in 1994 were inversely correlated with pesticide concentrations. Low ratios indicate potential abnormalities in carp endocrine systems (Goodbred and others, 1997).

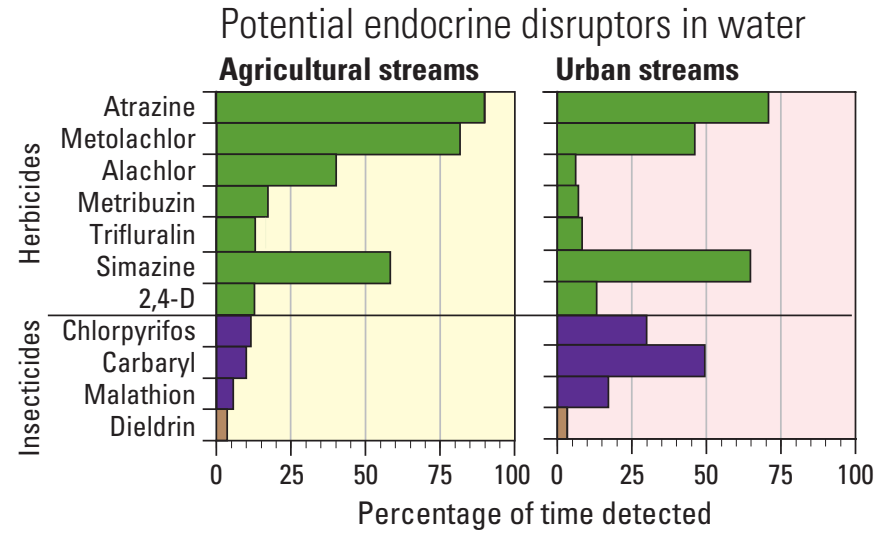

Figure 6-20. Eleven pesticides that have been identified as potential endocrine disruptors (Keith, 1997) were among the pesticides most frequently detected in NAWQA water samples from agricultural and urban streams. 


\section{Assessing Potential Effects of Pesticide Mixtures}

Michael J. Lydy and Jason B. Belden

Fisheries and Illinois Aquaculture Center and Department of Zoology

Southern Illinois University

NAWQA studies show that the most common form of pesticide exposure for aquatic organisms is simultaneous exposure to multiple pesticides. More than 50 percent of all stream samples contained five or more pesticides. Yet, most pesticide research, historically and currently, has evaluated the effects of individual pesticides as if they occurred alone. Scientists and risk assessors are only in the beginning stages of developing the knowledge base and procedures for evaluating the potential environmental effects of pesticide mixtures in aquatic ecosystems.

\section{Conceptual Models of Mixture Effects}

Research on mixtures indicates that a wide array of possible interactions among pesticides may occur, but they all fall into one of four categories:

Independent-Co-occurring pesticides act independently of one another, with each causing the degree of effects on a population as would be expected from its individual concentration. This might occur for pesticides with different target organs and modes of action.

Additive-Co-occurring pesticides act in an additive manner, with effects on a population as would be expected by summing the toxicity-normalized concentrations of multiple individual pesticides that are present. This might be expected for pesticides with similar chemical structures and a common mode of action.

Antagonistic-Co-occurring pesticides have a combined toxicity that is less than that predicted from the additive model.

Synergistic-Co-occurring pesticides have a combined toxicity that is greater than that predicted from the additive model.

The additive model, also called the Concentration Addition Model, is the most common baseline used for assessing effects of pesticide mixtures, although not all mixtures strictly follow it. In a 2-compound mixture, the concentration of chemical $A$ and the concentration of chemical B would be normalized (weighted) by toxicity as follows: the concentration of each chemical present in the sample is divided by its toxicity value (usually the concentration needed to cause a 50-percent effect in a population) and the toxicity-weighted concentrations are then added together. The effect expected would then be based on this normalized total concentration. For example, if two pesticides that have the same toxicity are each present in a stream at $10 \mu \mathrm{g} / \mathrm{L}$, then the expected effect would be the same as the effect of $20 \mu \mathrm{g} / \mathrm{L}$ of either one of the compounds alone.

Experimentally, additive toxicity has been observed for several groups of mixtures, including 2-compound mixtures of the s-triazine herbicides atrazine and cyanazine in reproductive tests with the green alga Chlorella fusca (Faust and others, 1993) and 2-compound mixtures of several organophosphate insecticides, including chlorpyrifos, diazinon, and azinphos methyl, in tests with midges (Lydy and Austin, 2004). In addition, the organophosphate insecticides chlorpyrifos and diazinon were strictly additive in their toxicity to the cladoceran, Ceriodaphnia dubia, in toxicity studies performed in natural, storm, and laboratory waters (Bailey and others, 1996, 1997, 2000).

Several studies have shown that pesticide interaction can result in less (antagonistic) or more (synergistic) toxicity than predicted by the Concentration Addition Model. For example, researchers have demonstrated that simultaneous exposure to esfenvalerate (a pyrethroid insecticide) and diazinon (an organophosphate insecticide) resulted in greater than additive toxicity to fathead minnows (Denton and others, 2003). The likely reason for this synergism is that diazinon inhibits the esterase enzymes, thus reducing the organism's capability to detoxify pyrethroids. Other studies have shown that the herbicide atrazine, when present at concentrations above $40 \mu \mathrm{g} / \mathrm{L}$, increases the toxicity of the organophosphate insecticides chlorpyrifos (fig. 6-21) and diazinon to aquatic invertebrates (Belden and Lydy, 2000; Anderson and Lydy, 2002). Note that atrazine itself is not acutely toxic to these invertebrates, even at high concentrations in water. In this case, the reason for the increased toxicity is that atrazine induces (increases production of) specific oxidative enzymes, resulting in a higher transformation rate of chlorpyrifos into a more toxic metabolic product (Belden and Lydy, 2000). In both of these examples, one contaminant changed the organism's capacity to metabolize the other contaminant, thus increasing or decreasing the amount of pesticide or pesticide breakdown products within the organism, and leading to large changes in the degree of toxicity.

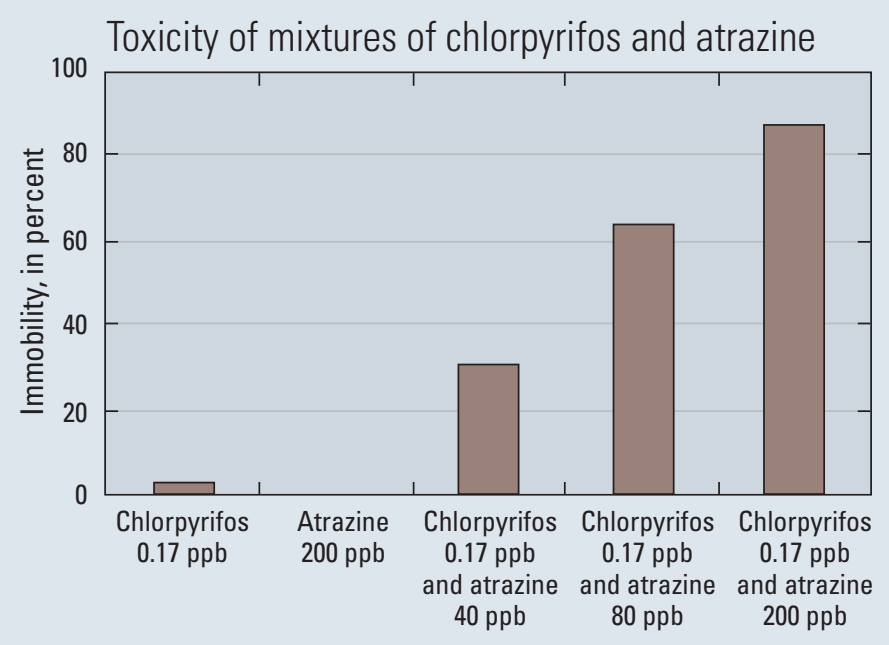

Figure 6-21. Although atrazine itself was not acutely toxic to the aquatic invertebrates tested in this study (chironomids), an increase in atrazine concentration caused an increase in the toxicity observed for chlorpyrifos (a synergistic interaction), as indicated by increased immobility (Belden and Lydy, 2000). (Concentrations are shown in ppb [parts per billion] as in the original report, which is equivalent to micrograms per liter.) 
Studies of the toxicity of pesticide mixtures have resulted in the full spectrum of additive, synergistic, and antagonistic responses. Generally, pesticides within the same pesticide class and that have similar structures and a common mode of action (for example, organophosphate insecticides) are more likely to follow the additive model, while pesticides from different classes (for example, herbicides and insecticides) have more varied effects. Table 6-2 summarizes the results from selected studies of mixtures containing the organophosphate insecticide diazinon. Because of the complexity of the modes of action and chemical transformations that occur for each pesticide, the toxicity of most pesticide mixtures will deviate from the simple additive model. It is not known how likely such deviations from additivity are, nor is there consensus on how large a deviation from the model is significant. In many cases, this deviation may be smaller than that obtained from testing the organisms under slightly different conditions (intraspecies toxicity testing), indicating that other sources of uncertainty may be more significant than errors in mixture models. However, until a more thorough understanding of pesticide interactions is achieved, the possibility of pesticide combinations resulting in greater toxicity than predicted by the additive model needs to be considered.

\section{Implications}

In most situations, a mixture of pesticides presents a greater risk to aquatic organisms than do any of the individual components of the mixture. The ecological effects caused by mixtures of pesticides, however, are highly uncertain and are in the relatively early stages of investigation. Further research must be conducted before the possible impacts that pesticide mixtures may have on the environment can be determined. The large numbers of chemicals and varying exposure routes that occur in the environment make testing every possible exposure scenario impossible. For example, in a mixture of $20 \mathrm{com}-$ pounds, there are 190 pairs of compounds, and more than a million possible combinations (pairs, triples, and so on). Thus, it makes sense for researchers assessing mixture effects to prioritize and test those combinations with a high probability of environmental occurrence and those that are useful in developing refined models to predict the toxicity of similar pesticide mixtures.

Ultimately, aquatic toxicologists need to understand the dynamic world that organisms encounter. Besides pesticides, organisms are exposed to other types of chemical contaminants (such as metals and industrial contaminants) and also biological and physical stressors (such as changes in flow rate, temperature, habitat, food availability, and predation) simultaneously. It is likely that these stressors interact. However, until we better understand the biology of aquatic systems, from the molecular to the ecosystem level, we will continue to struggle in predicting the existence and significance of chemical interactions.

Table 6-2. Selected studies of pesticide mixtures containing diazinon illustrate the spectrum of possible responses for such mixtures. The types of compounds included are two organophosphate insecticides (OP), a pyrethroid insecticide (P), a triazine herbicide (T), and a nutrient.

\begin{tabular}{|c|c|c|c|c|c|}
\hline Mixture & $\begin{array}{l}\text { Type of } \\
\text { compound }\end{array}$ & Species tested & Result & $\begin{array}{l}\text { Deviation from } \\
\text { concentration } \\
\text { addition }\end{array}$ & Reference \\
\hline Diazinon and chlorpyrifos & $\begin{array}{l}\text { OP } \\
\text { OP }\end{array}$ & $\begin{array}{l}\text { Midges } \\
\text { (aquatic invertebrate) }\end{array}$ & Additive & None & Lydy and Austin (2004) \\
\hline Diazinon and chlorpyrifos & $\begin{array}{l}\text { OP } \\
\text { OP }\end{array}$ & $\begin{array}{l}\text { Ceriodaphnia dubia } \\
\quad \text { (aquatic invertebrate) }\end{array}$ & Additive & None & Bailey and others $(1996,1997)$ \\
\hline Diazinon and atrazine & $\begin{array}{c}\mathrm{OP} \\
\mathrm{T}\end{array}$ & $\begin{array}{l}\text { Midges, amphipods } \\
\text { (aquatic inverte- } \\
\text { brates) }\end{array}$ & Synergistic & $\begin{array}{l}\text { Up to } 400 \text { percent } \\
\text { greater toxicity }\end{array}$ & $\begin{array}{l}\text { Anderson and Lydy (2002); } \\
\text { Belden and Lydy (2000) }\end{array}$ \\
\hline Diazinon and ammonia & $\begin{array}{c}\text { OP } \\
\text { Nutrient }\end{array}$ & $\begin{array}{l}\text { Ceriodaphnia dubia } \\
\quad \text { (aquatic invertebrate) }\end{array}$ & Antagonistic & $\begin{array}{l}27 \text { to } 32 \text { percent } \\
\text { less toxic }\end{array}$ & Bailey and others (2001) \\
\hline
\end{tabular}




\section{Pesticide Toxicity Index}

To expand the assessment of potential effects of pesticides in stream water on aquatic life, NAWOA developed a Pesticide Toxicity Index (Munn and Gilliom, 2001). The Pesticide Toxicity Index (PTI) accounts for multiple pesticides in a sample, including pesticides without established benchmarks for aquatic life. The PTI combines information on exposure of aquatic biota to pesticides (measured concentrations of pesticides in stream water) with toxicity estimates (results from laboratory toxicity studies) to produce a relative index value for a sample or stream. The PTI value is computed for each sample of stream water by summing the toxicity quotients for all pesticides detected in the sample. The toxicity quotient is the measured concentration of a pesticide divided by its toxicity concentration from bioassays (such as an $\mathrm{LC}_{50}$ or $\mathrm{EC}_{50}$ ). For each sample, separate PTI values are computed for fish and benthic invertebrates. This approach follows the Concentration Addition Model of toxicity described by Lydy and Belden (accompanying sidebar, p 114). Although simple additivity is unlikely to strictly apply for complex mixtures of pesticides from different classes and with different effects and modes of action, the PTI is still useful as a relative index. Deneer $(2000)$ reported that "for more than 90 percent of 202 mixtures in 26 studies, concentration addition was found to predict effect concentrations correctly within a factor of two." While the PTI does not indicate whether water in a sample is toxic, its value can be used to rank or compare the relative potential toxicity of different samples or different streams.

The PTI provides a means to rank different stream sites compared with each other and is a tool for investigating relationships between pesticide levels and the quality of aquatic ecosystems. For example, pesticides were commonly detected in agricultural streams and drains throughout the Yakima River Basin, often at concentrations exceeding one or more aquatic-life benchmarks for individual pesticides (Fuhrer and others, 2004). Data for 24 stream sites in the Yakima River Basin showed that the number of pollution-tolerant
Pesticide Toxicity Index applied to agricultural streams

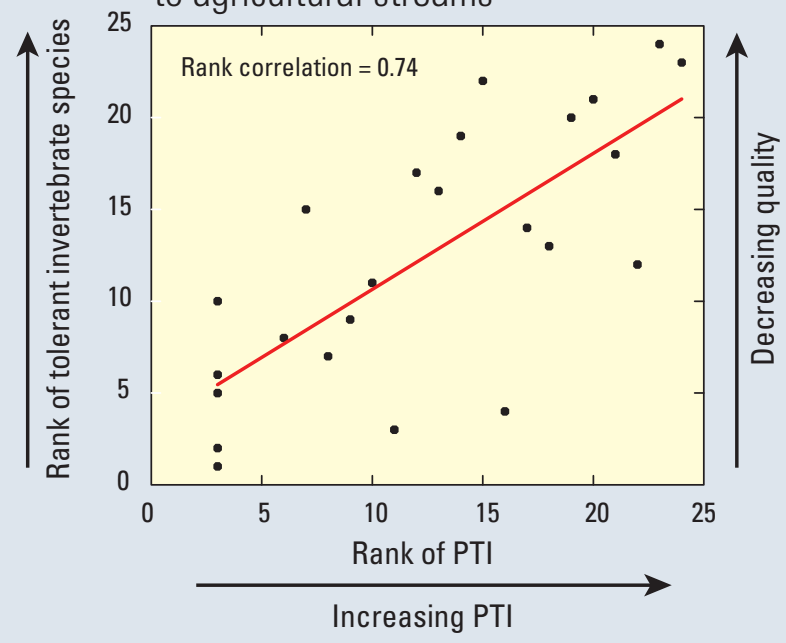

Figure 6-22. Streams and drains in the Yakima River Basin with the highest PTI values tended to have the highest numbers of pollution-tolerant benthic invertebrates, indicating lower water quality. The ranks were significantly correlated at a 95-percent confidence level. (Modified from Fuhrer and others, 2004.)
Pesticide Toxicity Index applied to urban streams

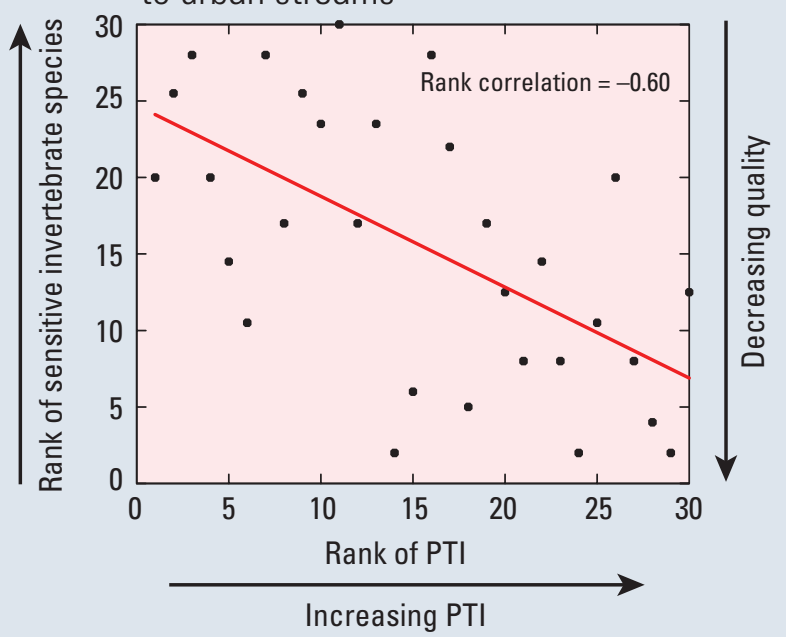

Figure 6-23. Streams in the Dayton and Cincinnati, Ohio areas with the highest PTI values tended to have the lowest numbers of sensitive invertebrate species, indicating lower water quality. The ranks were significantly inversely correlated at a 95percent confidence level. (Modified from Rowe and others, 2004.) 
benthic invertebrates (higher numbers indicate a stressed ecosystem) significantly increased with the rank of PTI values (fig. 6-22). Pesticides, however, are only one of many factors that may affect aquatic communities - other factors include physical habitat quality, food availability, and the presence of other contaminants. Detailed studies are required to distinguish the relative roles of different chemical and physical factors.

Another example is for streams in the Dayton and Cincinnati, Ohio, urban areas, which were studied in the Great and Little Miami River Basins (Rowe and others, 2004). Results for 30 streams with varying degrees of urban land use in their watersheds indicated that the number of sensitive invertebrates (lower numbers indicate a stressed ecosystem) significantly decreased with increasing PTI values (fig. 6-23). As with the Yakima River Basin example, this correlation does not demonstrate a cause-and-effect relationship between pesticides and the benthic invertebrate community. The PTI was one of several factors found to correlate with degree of urbanization-which also included chloride levels in water and synthetic chemicals in bed sediment-that may affect benthic invertebrates (Rowe and others, 2004).

For a national-level perspective, the PTI was used to rank NAWQA stream sites by the potential toxicity of measured pesticide concentrations to fish and benthic invertebrates. Invertebrate PTI values generally were more than 10 times higher than those for fish, as shown by frequency distributions of the 95th percentile PTI values for streams in all land-use settings (fig. 6-24). The higher toxicity values for invertebrates reflect greater sensitivity of invertebrates compared with fish, particularly to insecticides. A large proportion of benthic invertebrates are insects, which explains the high relative toxicity of insecticides to this taxonomic group. PTI values for both fish and invertebrates are highest for samples collected from agricultural and urban streams, lowest for undeveloped streams, and intermediate for mixed-land-use streams. These results are consistent with the results of the screening-level assessment (using aquatic-life benchmarks) of the potential effects of pesticides in water on aquatic life.

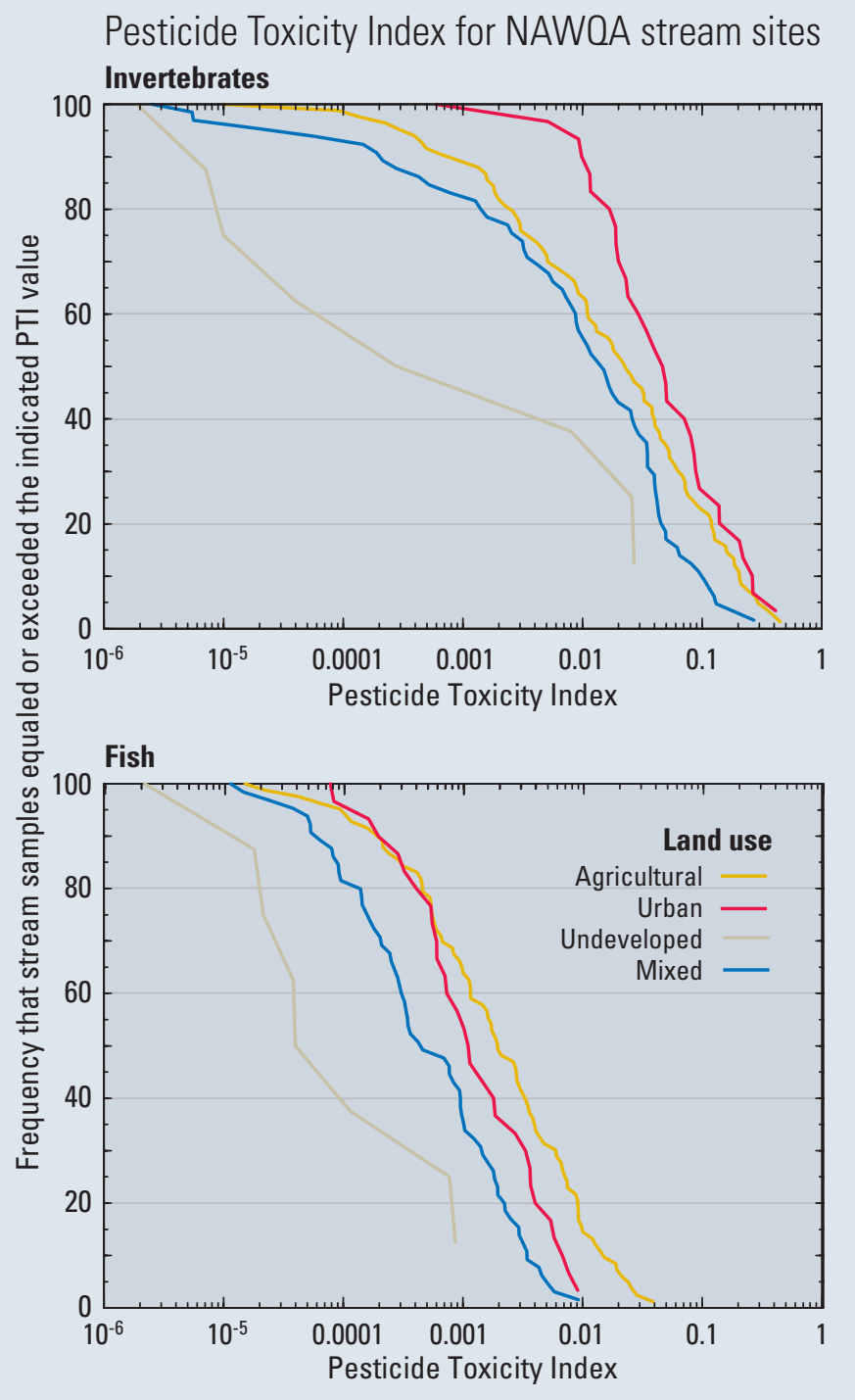

Figure 6-24. Invertebrate PTI values for all land-use categories were more than 10 times higher than fish PTI values. Urban and agricultural streams had the highest PTI values. This analysis is based on the 95th percentile PTI value for each site, which is an estimate of the PTI value that was exceeded by 5 percent of samples at the site. 



\section{Prediction Where Data are Inadequate}

$\mathrm{S}_{\text {trategies for managing pesticides require far more informa- }}$ tion than we can afford to directly measure for all the places, times, and pesticides of interest. In addition, many strategic decisions—-such as setting monitoring priorities, approving a pesticide registration, and determining how much to spend on a management strategy—inherently depend on predicting the potential effects of pesticides on water quality for locations that have never been directly assessed. In these situations, statistical models and other types of models can be useful for predicting water-quality conditions at unmonitored locations under a range of possible circumstances. Such tools are essential for efficient water-quality management.

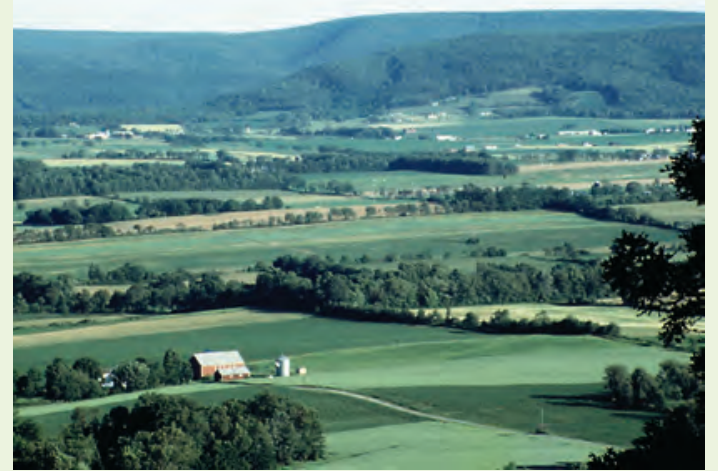

In this chapter, three examples

illustrate the development

of statistical models from

NAWOA data and some of

the ways in which the models

can be applied to national-

scale analysis of water-quality 


\section{Approach to Prediction}

NAWQA pesticide data collected from 1992 to 2001 support the development and testing of a wide range of models, particularly statistical models. Statistical models have been developed by NAWQA to predict pesticide levels in streams and ground water for locations where pesticide concentrations have not been measured. This expansion of water-quality assessment from individual monitoring sites to unstudied locations by use of models for prediction, or spatial extrapolation, is fundamental to extending the targeted local and regional studies of NAWQA to a comprehensive national assessment (Alaska and Hawaii have not been included in these models because there are no suitable pesticide-use data for these States).

The NAWQA statistical models for pesticides use linear regression methods to establish quantitative linkages between pesticide concentrations measured at NAWQA sampling sites and a variety of anthropogenic (human-related) and natural factors that affect pesticides. Such factors include pesticide use, soil characteristics, hydrology, and climate-collectively referred to as explanatory variables. Model-development data consist of measured pesticide concentrations or detection frequencies, together with the associated values of the explanatory variables for the sampling sites. The models are built using the explanatory variables that best correlate with, or explain, the concentrations or frequencies of occurrence of pesticides observed in streams and ground water. Although explanatory variables included in the models are significantly correlated with pesticide concentrations or detection frequencies, the specific cause-and-effect relations responsible for the observed correlations are not always clear, and inferences regarding causes should be considered as hypotheses.

In developing the pesticide models, all potential explanatory variables were required to have values available from existing data sources for all locations in the conterminous United States, so that national extrapolation would be possible (the only exception, as explained below, was fish lipid content for the dieldrin model). Overall, 30 to 60 possible variables were considered, depending on the specific model; these were reduced to the 4 to 6 explanatory variables that were most significant and yielded optimal model formulations. Each model incorporates an uncertainty analysis, which allows assessment of the reliability of the model predictions and also the expression of model predictions as prob- abilities that concentrations will exceed a specific value, such as a water-quality benchmark, at a particular location.

The three NAWQA models and nationally extrapolated results presented in this chapter are those developed for (1) concentrations of atrazine in stream water; (2) concentrations of dieldrin in whole fish; and (3) detection frequencies for atrazine in shallow ground water underlying agricultural settings. The extrapolations for atrazine concentrations in stream water and dieldrin concentrations in fish tissue are for streams included in the USEPA River Reach file (Nolan and others, 2003), which includes more than 600,000 miles of streams and more than 60,000 individual stream reaches with watersheds. The extrapolations of detection frequencies for atrazine in shallow ground water were made for all areas of the Nation where at least 50 percent of the land is in agricultural use. More detailed information on model development methods and supporting data, as well as uncertainty analyses, are provided by Larson and others (2004), Nowell and others (2006), and Stackelberg and others (2006). Additional work is currently underway on (1) a multi-pesticide model for stream water that incorporates selected chemical and physical properties of each compound, (2) expanding the models for fish tissue to include additional organochlorine compounds, and (3) site-specific, concentrationbased models for atrazine in ground water.

\section{Atrazine Concentrations in Streams}

Model predictions of atrazine levels in streams across the Nation show the highest annual mean concentrations throughout the highuse areas of the Corn Belt and the Mississippi Valley and Delta regions, and in some areas of Texas, Pennsylvania, and Maryland. Figure 7-1 shows measured concentrations used to develop the model and figure 7-2 shows predicted concentrations. As noted along with other model details in the accompanying sidebar (p. 121), the model is based on the time-weighted annual mean for each model-development site. Annual means for a few streams in the Ohio and Mississippi Valleys and in southern Louisiana are predicted to exceed $3 \mu \mathrm{g} / \mathrm{L}$, the human-health benchmark used for atrazine (Chapter 6 and Appendix 3A). The benchmark for atrazine is the USEPA MCL for drinking water. As a drinking-water standard, the MCL applies to finished water in public water supplies, whereas the predictions shown in figure 7-2 are for untreated 
stream water. Comparisons of model predictions with human-health benchmarks, however, serve as screening-level assessments of the suitability of potential drinking-water sources, as discussed in Chapter 6.

For more than half of the streams with a predicted annual mean atrazine concentration exceeding $0.3 \mu \mathrm{g} / \mathrm{L}$ (fig. 7-2), there is at least a 5-percent chance that the actual annual mean concentrations will exceed the humanhealth benchmark of $3 \mu \mathrm{g} / \mathrm{L}$ (fig. 7-2). Model estimates of probabilities shown in figure 7-2 indicate that at least 1 out of 20 (5 percent) of the streams shown in yellow, orange, or red would be expected to have annual mean atrazine concentrations greater than $3 \mu \mathrm{g} / \mathrm{L}$. These streams may not be suitable as sources of drinking water without treatment or other management strategies to reduce atrazine concentrations. The streams with a greater than 5-percent probability of exceeding the benchmark represent about 7 percent of the Nation's stream miles (45,704 of 649,935 mi). Approximately 192 stream miles (less than 1/10th of 1 percent of the Nation's stream miles) are predicted to have more than a 50-percent probability of exceeding $3 \mu \mathrm{g} / \mathrm{L}$.

The model indicates that atrazine use intensity is the most important factor explaining atrazine concentrations in streams - the more intensive the use of atrazine in a watershed, the higher the atrazine concentration in the stream. Specifically, estimated atrazine use intensity within each watershed explains 64 percent of the variance in annual mean atrazine concentrations in streams across the Nation. Four additional variables explain another 13 percent of the variability, most of which is accounted for by rainfall erosivity and soil erodibility-factors used in the revised Universal Soil Loss Equation (Renard and others, 1997). Rainfall erosivity and soil erodibility quantify, respectively, the energy of storms in a specific area (averaged over several years), and the susceptibility of soils to erosion by runoff. As these two factors increase, atrazine concentrations also increase, indicating that transport of atrazine is highest in areas of high-energy rain storms and in areas where soils are most susceptible to erosion. Alternatively, soil erodibility may indicate high surface runoff, rather than actual transport of atrazine with soil particles. Overall, the complete model explains a total of 77 percent of the variance in observed annual mean atrazine concentrations.

\section{Development and Application of the Atrazine Model for Stream Water}

As described by Larson and others (2004), the model for estimating atrazine concentrations in streams is based on time-weighted annual mean concentrations measured by NAWQA from 1992 to 2001 at 112 sites (fig. 7-1). The single most complete year of data was used to calculate the annual mean concentration for each site. The predicted values in figure 7-2 are median estimates of the annual mean, such that 50 percent of the actual annual means are expected to be greater than, and 50 percent less than, the predicted value. Nonagricultural uses of atrazine are not included and, as a result, predictions may represent underestimates for watersheds with substantial nonagricultural use. To illustrate a practical example of how such models can be applied to water-quality assessment, model estimates are compared with the human-health benchmark for atrazine, USEPA's Maximum Contaminant Level (MCL) for drinking water (Chapter 6 and Appendix 3). The model also was used to estimate the probability, after accounting for model uncertainty, that any particular stream site may have an annual mean atrazine concentration greater than $3 \mu \mathrm{g} / \mathrm{L}$ (fig.7-2).

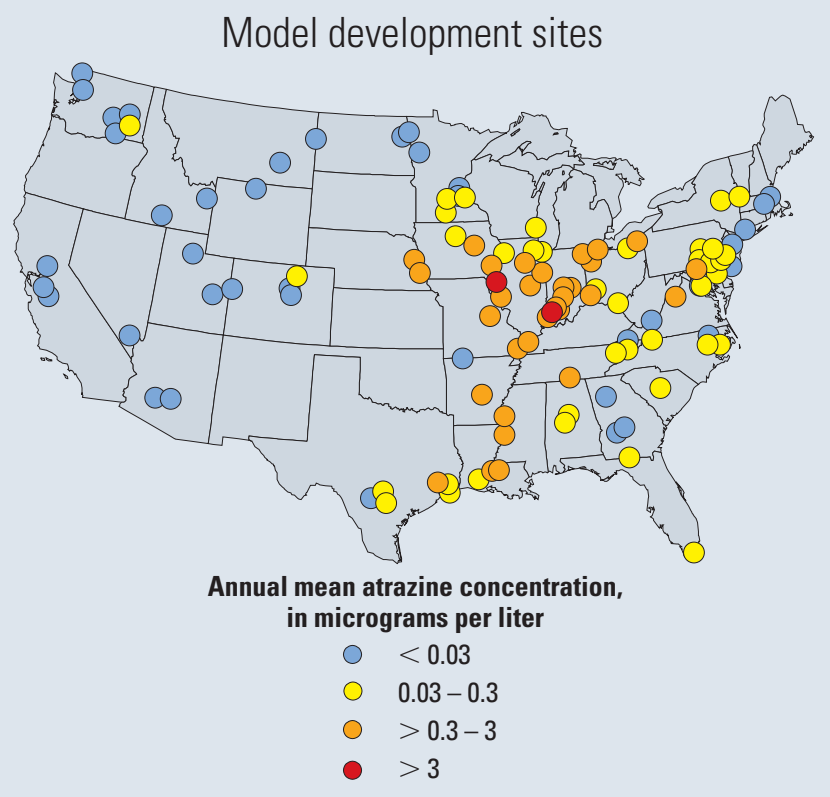

Figure 7-1. The model for annual mean concentrations of atrazine in streams was developed from data for 112 sites distributed across the country, which represent a wide range of hydrologic settings and atrazine concentrations. 


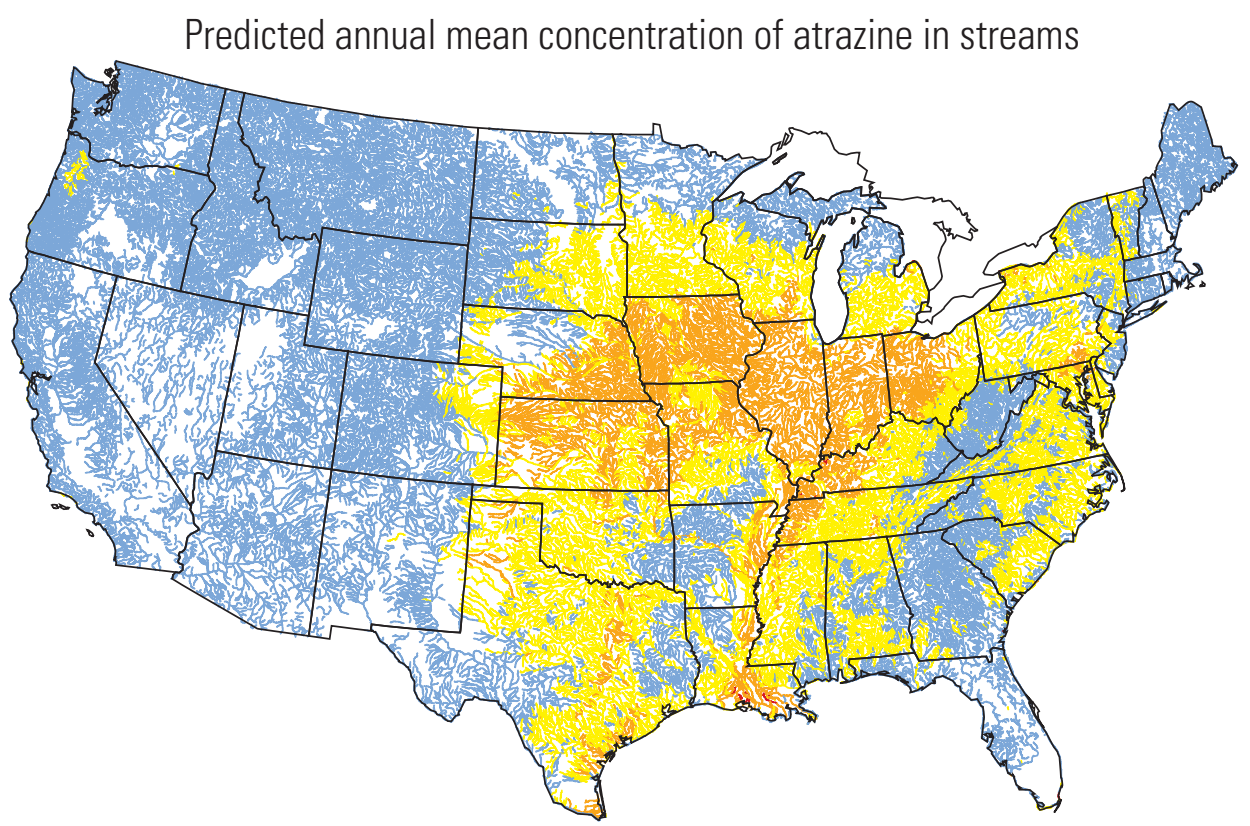

Predicted annual mean concentration of atrazine, in micrograms per liter

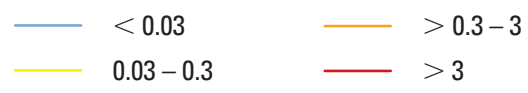

Probability of exceeding the human-health benchmark for atrazine

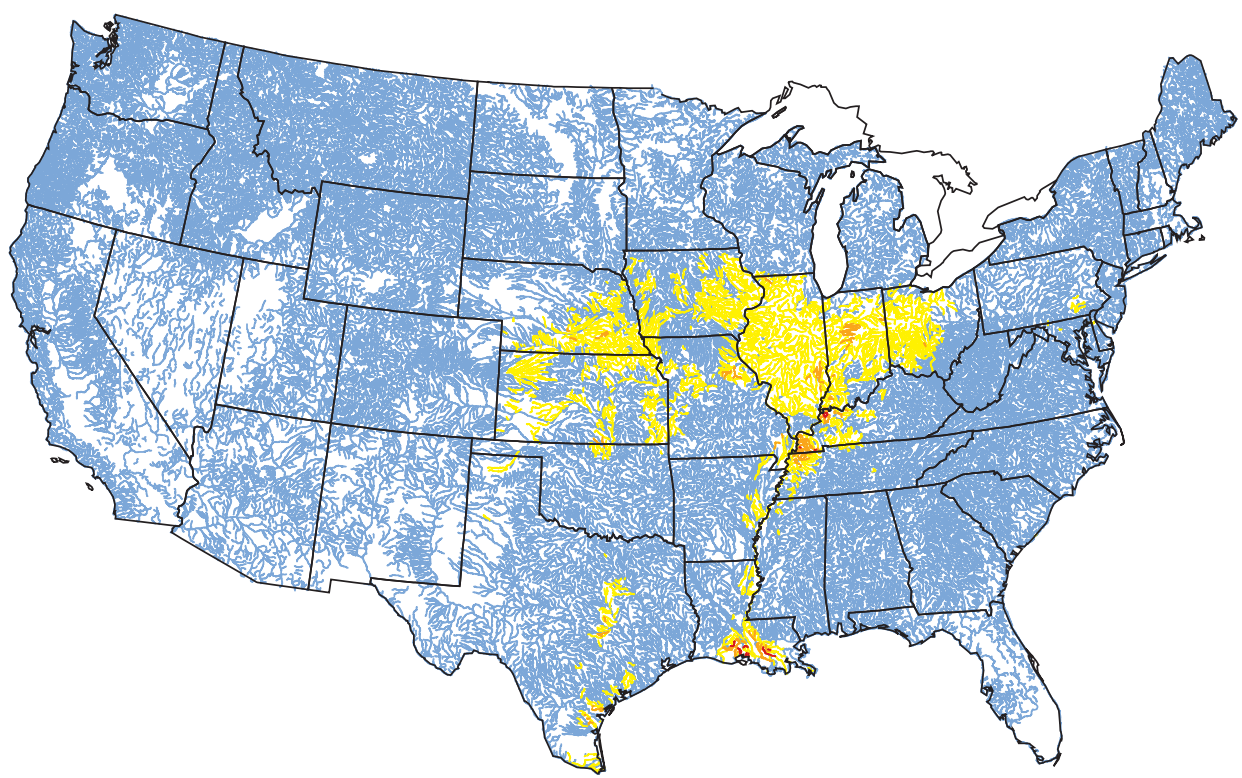

Probability of exceeding 3 micrograms per liter

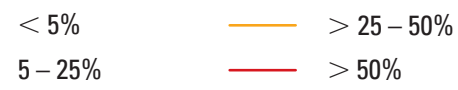

Figure 7-2. Model predictions of annual mean atrazine concentrations in streams across the Nation show the highest concentrations (orange and red streams) throughout the high-use areas of the Corn Belt and the Mississippi Valley, and in some areas of Texas, Pennsylvania, and Maryland. Model predictions of the probability that atrazine concentrations are greater than the humanhealth benchmark of $3 \mu \mathrm{g} / \mathrm{L}$ for drinking water indicate that many streams in the Corn Belt and Mississippi Valley and Delta regions have greater than a 5-percent probability of having annual mean concentrations greater than the benchmark. 


\section{Dieldrin Concentrations in Fish}

Model predictions of dieldrin concentrations in whole fish show the highest concentrations in the Corn Belt-especially in Illinois-where aldrin was heavily used on cropland. Figure 7-3 shows measured concentrations used to develop the model and figure 7-4 shows predicted concentrations. Dieldrin is an organochlorine compound that was used as an insecticide until its agricultural use was discontinued in the early 1970s, and it is also a degradate of aldrin, another insecticide that was used for agricultural purposes through the early 1970s. As noted along with other model details in the accompanying sidebar, model predictions are for fish with a 6.2 percent lipid content, the national average lipid content for all whole fish sampled. Most streams that are predicted to have a dieldrin concentration greater than $25 \mu \mathrm{g} / \mathrm{kg}$ (micrograms per kilogram of fish tissue, wet weight) also have a 5 percent or greater chance (more than 1 in 20) of exceeding $120 \mu \mathrm{g} / \mathrm{kg}$ (fig. 7-4), which is a wildlife benchmark for dieldrin in fish tissue $(120 \mu \mathrm{g} / \mathrm{kg}$ is the highest of the dieldrin benchmarks compiled for this report; see Chapter 6 and Appendix 3B). These streams represent about 6 percent of the Nation's stream miles $(40,222$ out of 649,935 mi). Approximately 627 stream miles (about 1/10th of 1 percent of the Nation's stream miles) are predicted to have a 50-percent or greater probability of exceeding the dieldrin wildlife benchmark of $120 \mu \mathrm{g} / \mathrm{kg}$.

The dieldrin model indicates that the amount of forested land in a watershed is the most important factor explaining the concentrations of dieldrin observed in fish-the greater the proportion of forested land (where historical use would have been least), the lower the dieldrin in fish tissue.

Fish lipid content was also an important variable, which is consistent with the fact that organochlorine pesticides are hydrophobic compounds, which have a strong affinity for lipids, and thus tend to accumulate in high-lipid tissues. Two additional factors in the dieldrin model that, like forested land, are related to past use of dieldrin and aldrin represent (1) the estimated historical use of the compounds in agriculture and (2) their use for termite control. Dieldrin concentrations decrease with increasing amounts of forested land and increase with increasing historical use in agriculture or for termite control. Together, these three use-related factors and lipid content explain 58 percent of the variability in dieldrin concentrations measured in whole fish in streams across the Nation. With the addition of two other less influential variables, the complete model explains 64 percent of this variability.

\section{Development and Application of the Dieldrin Model for Whole Fish}

As described by Nowell and others (2006), the model for estimating dieldrin concentrations in fish is based on concentrations measured in whole fish sampled by NAWQA from 1992 to 2001 at 648 sites across the country. The 514 sites shown in figure 7-3 are limited to the subset of model development sites with whole-fish samples having 2.3-10.4 percent lipid content (the lowest and highest 10 percent of lipid levels were excluded from the map, but not model development). One composite sample (each composed of 5-10 fish of a single species) was collected at each site. The national data include 59 different species of fish, most frequently common carp ( 29 percent of samples) and white sucker (26 percent). One effect of compositing is to reduce variability in contaminant concentrations caused by differences in age and size among individual fish. An important explanatory variable in the dieldrin model is fish lipid content, which is not nationally available for all streams because it is a characteristic of the fish, rather than the stream or watershed. The inclusion of fish lipid content in the model accounts - to some extent-for differences among fish in age, size, and species because lipid content generally varies among species and increases (within a species) with increasing fish age and size (Nowell and others, 1999).

Model predictions were made using the national average lipid content for whole fish, which was 6.2 percent for samples collected by NAWOA and the U.S. Fish and Wildlife Service (Schmitt and Bunck, 1995). Predicted concentrations of dieldrin in fish, shown in figure 7-4, are median estimates for fish with 6.2 percent lipid content. Consequently, actual concentrations are expected to be lower than the predicted value at 50 percent of sites and higher at 50 percent of sites. Also, fish with lipid content greater than 6.2 percent would likely have higher dieldrin concentrations, and fish with lower lipid content would likely have lower dieldrin concentrations, than those shown in figure 7-4. As examples, lipid content values typical of common fish species in the United States are lake trout, 15 percent; channel catfish, 7.5 percent; common carp, 6.5 percent; white sucker, 5.8 percent; largemouth bass, 4.2 percent; and bluegill, 3.1 percent. See Nowell and others (2006) for further discussion of uncertainty in model predictions.

To illustrate a practical example of how such models can be applied to waterquality assessment, model estimates are compared with the New York guideline for the protection of fish-eating wildlife, which was the highest wildlife benchmark compiled for dieldrin in fish tissue (Chapter 6 and Appendix 3B). The model also was used to estimate the probability, after accounting for model uncertainty, that any particular stream site may have a dieldrin concentration greater than $120 \mu \mathrm{g} / \mathrm{kg}$ in whole fish with a 6.2 percent lipid content (fig. 7-4).

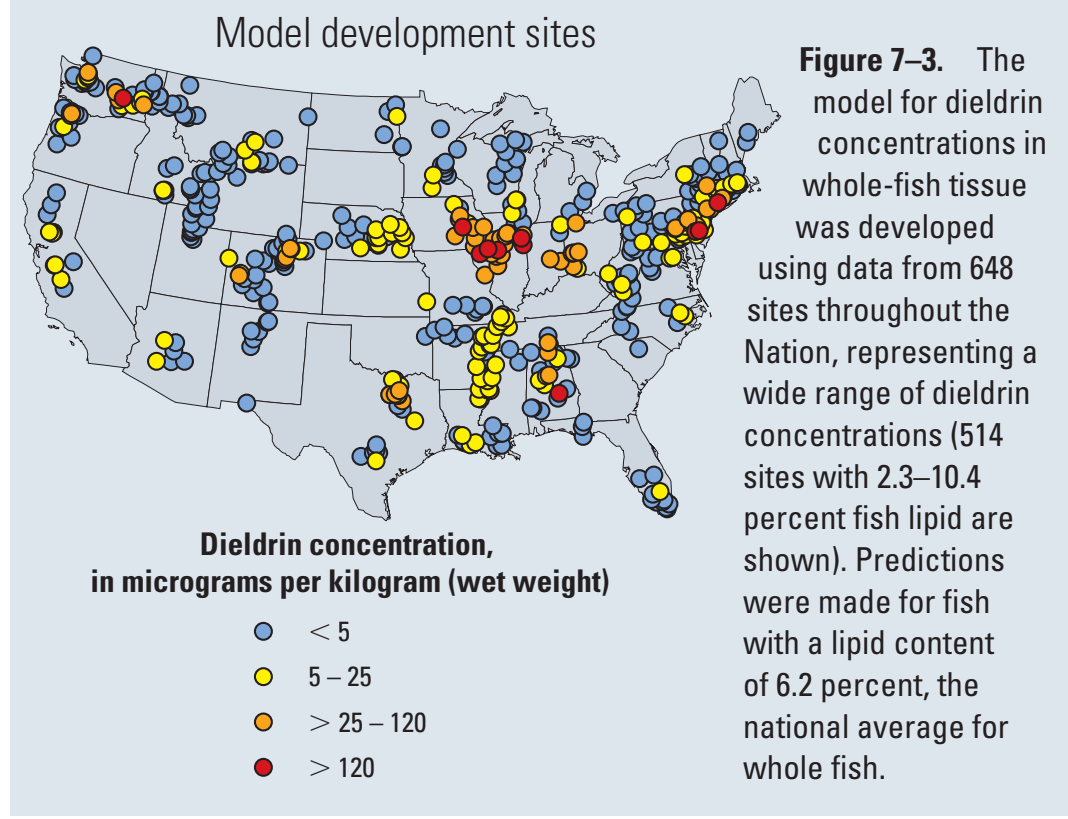




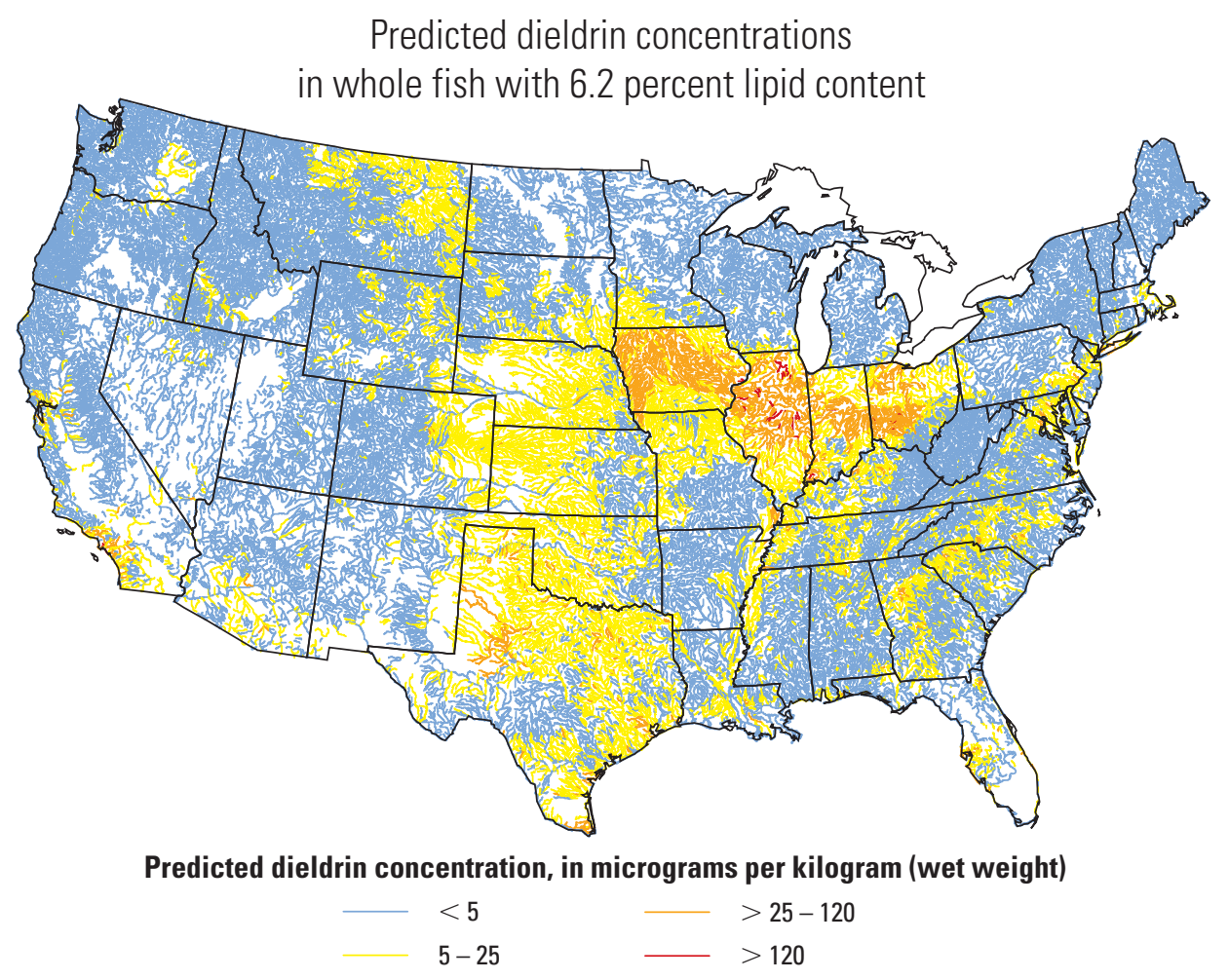

Probability of exceeding the wildlife benchmark for dieldrin in whole fish with 6.2 percent lipid content

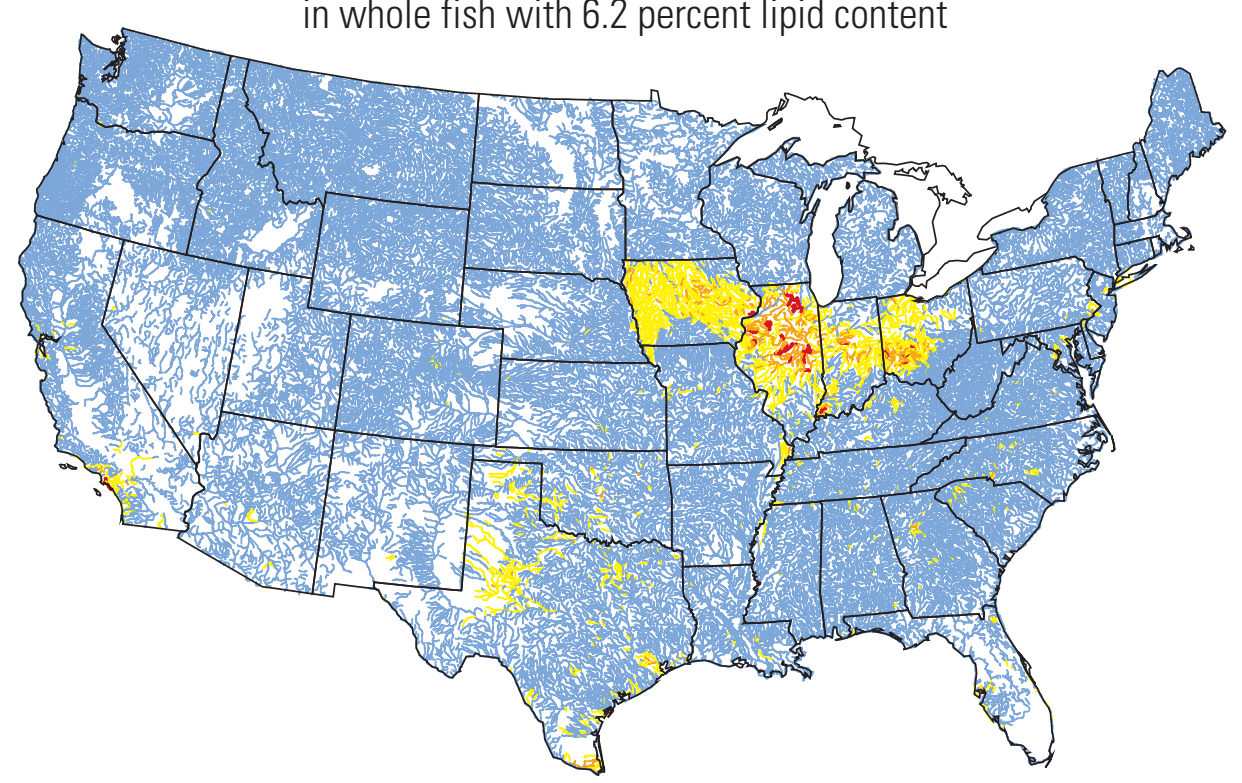

Probability of exceeding 120 micrograms per kilogram
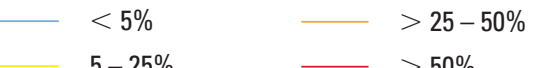

$5-25 \%$

$>50 \%$

Figure 7-4. Model predictions of dieldrin concentrations in whole fish in streams across the Nation show the highest concentrations in the Corn Belt, particularly Illinois, where aldrin (which degrades to dieldrin) was heavily used on cropland. Model predictions of the probability that dieldrin concentrations exceed the wildlife benchmark of $120 \mu \mathrm{g} / \mathrm{kg}$ indicate that there is greater than a 5-percent probability in many Corn-Belt streams that whole fish (with 6.2 percent lipid) contain dieldrin concentrations that exceed the benchmark. 


\section{Atrazine Detection Frequencies in Shallow Ground Water}

Model predictions show that the highest frequencies of atrazine detection in shallow ground water beneath agricultural areas are expected in parts of the western Corn Belt, eastern Great Plains, Pacific Northwest (eastern Washington), and Mid-Atlantic regions (especially southeastern Pennsylvania). Figure 7-5 shows measured detection frequencies used to develop the model and figure 7-6 shows predicted detection frequencies for each square kilometer of land with 50 percent or more agricultural land. The areas with the highest frequencies of detection are those with relatively high atrazine use in hydrologic settings that also favor the transport of pesticides to ground water.

In contrast to the model for atrazine concentrations in stream water, atrazine use is not the most important factor for predicting atrazine occurrence in ground water. This finding is consistent with results from an earlier study of relations between atrazine in ground water and various land-use factors by Kolpin (1997), in which atrazine use was not found to be significantly correlated with atrazine occurrence in ground water. In the model presented herein, atrazine use explains only about 7 percent of the overall variability in the frequency of its detection in ground water. The two most important factors were found to be the proportion of land with subsurface tile drain systems and other artificial drainage, and the average vertical permeability of soil, which together explain 48 percent of the variability in atrazine detection frequencies. As the amount of artificial drainage increases, predicted detection frequencies decrease - a finding consistent with the fact that artificial drainage systems divert water and pesticides away from the ground-water system. Conversely, as the average vertical permeability of soils increases, predicted detection frequencies also increase because water and pesticides at the land surface are more likely to move vertically to ground water in areas with high-permeability soils. The influential role of these factors is particularly evident in Indiana and Ohio, where atrazine use is intense, but NAWQA studies, like several other previous studies (Barbash and Resek, 1996), found relatively low atrazine detection frequencies in ground water.
Soils in these areas tend to be poorly drained and require artificial drainage to dewater the agricultural fields, thus reducing atrazine transport to ground water. With the addition of two other less influential variables, the complete model explains 58 percent of the variability in atrazine detection frequencies observed in shallow ground water beneath the agricultural areas studied.

\section{Development and Application of the Atrazine Model for Ground Water}

As described by Stackelberg and others (2006), the model for predicting atrazine occurrence in shallow ground water within agricultural areas is based on the frequencies of detection measured by NAWQA from 1992 to 2001 in 52 studies, each of which sampled about 20 to 30 shallow wells in agricultural areas (fig. 7-5). The model was used to predict the frequency of atrazine occurrence in shallow ground water in agricultural areas of the United States (fig. 7-6). Predictions were made for each 1 square kilometer area with 50 percent or more agricultural land use. Nonagricultural use of atrazine was not included in use estimates, and thus, predictions may underestimate occurrence in areas where nonagricultural use is substantial.

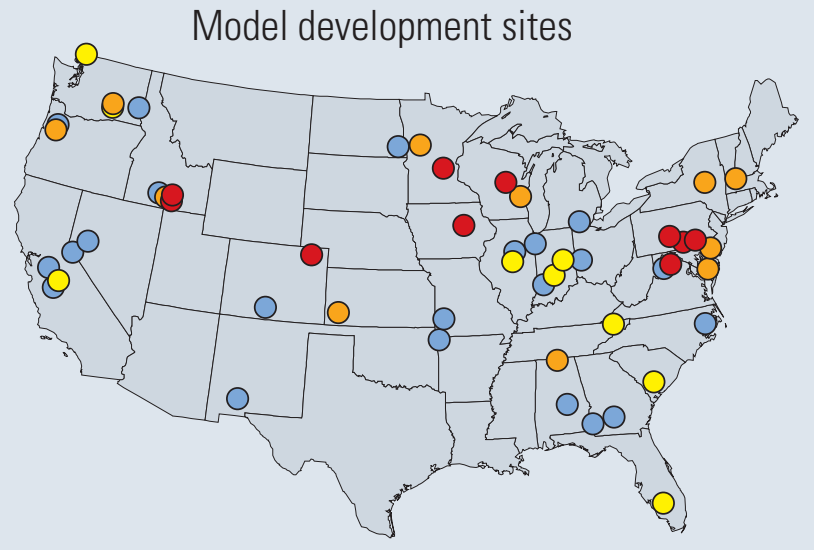
Detection frequency, as a percentage of wells sampled in each study
$0<25$
$>50-75$
○ $25-50$
$>75$

Figure 7-5. The model for atrazine occurrence in shallow ground water within agricultural areas was developed from frequencies of detection in wells sampled for studies of shallow ground water in 52 agricultural areas across the country. The ground-water studies represent a wide range of agricultural and hydrologic settings, as well as atrazine detection frequencies. 


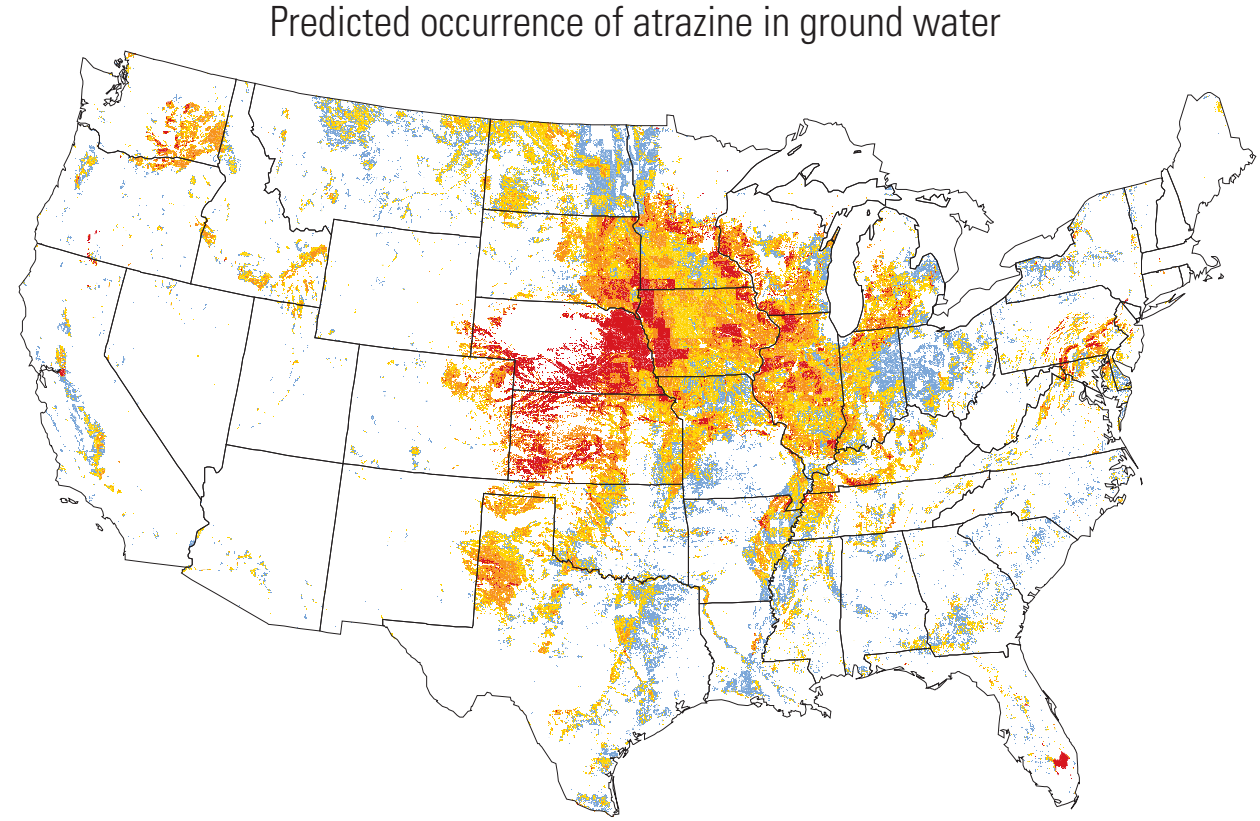

Figure 7-6. Model predictions show that the highest frequencies of atrazine detection in shallow ground water beneath agricultural areas are expected in parts of the western Corn Belt, eastern Great Plains, Pacific Northwest (eastern Washington), and Mid-Atlantic regions (especially southeastern Pennsylvania). These areas represent relatively high atrazine use in hydrologic settings that favor the transport of pesticides to ground water.

Predicted frequency of detections, as a percentage of shallow wells

$<25$
$25-50$
$\begin{aligned} & \text { No prediction }- \text { areas have less than } \\ & 50 \text { percent agricultural land use }\end{aligned}$




\title{
Long-Term Trends
}

\author{
Long-term trends and changes in pesticide concentrations \\ in streams and ground water are controlled largely by shifts \\ in pesticide use, but the rates and geographic distributions of \\ changes are also influenced by the chemical and physical prop- \\ erties of the pesticides and characteristics of the hydrologic \\ settings. The first decade of NAWQA assessments focused \\ primarily on establishing baseline conditions for comparison \\ with future measurements as part of a long-term approach to \\ tracking trends. Many trends, particularly those on a national \\ scale, cannot yet be evaluated because not enough time has \\ elapsed. Trends and changes are already evident, however, for \\ some pesticides in selected localities and regions.
}

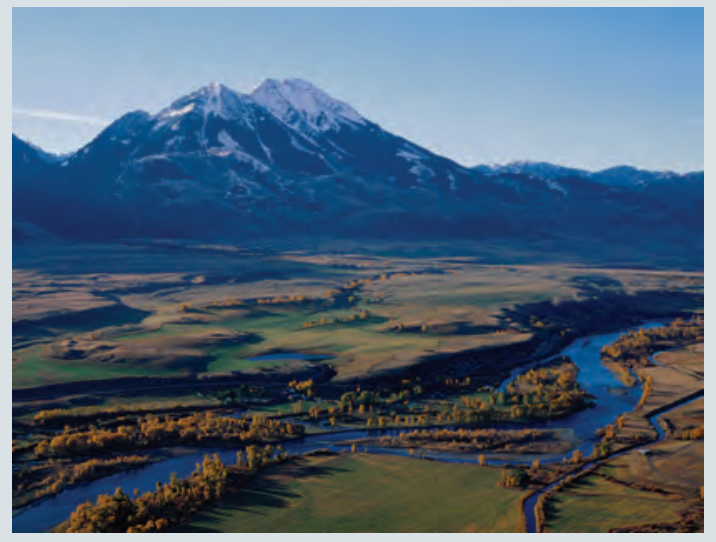

This chapter provides selected examples of trends and illustrates the range of different factors that govern trends for various pesticides in fish tissue, bed sediment, stream water, and ground water. 


\section{Organochlorine Pesticide Compounds in Fish}

One of the most striking trends evident from historical data and more recent NAWQA findings is a national reduction in concentrations of organochlorine insecticides in fish tissue, as illustrated by concentrations of total DDT, total chlordane, and dieldrin measured by NAWQA and the U.S. Fish and Wildlife Service. NAWQA data from 1992 to 2001 for whole fish in streams draining watersheds with mixed land use were combined with 1969-1986 data from the U.S. Fish and Wildlife Service's National Contaminant Biomonitoring Program (NCBP), which sampled mainly large streams in watersheds with mixed land use.

The median and 90th-percentile concentrations of total DDT in whole fish declined markedly from 1969 to about the mid-1970s, with less dramatic declines through the 1990s (fig. 8-1). Concentrations of total chlordane in fish, for which consistent data were not available until 1978, declined similarly during the 1980s and appeared to level off during the 1990s. For dieldrin, the median and particularly the 90th percentile concentrations varied substantially during the early 1970s, but concentrations during the late 1970s were lower than in 1969, and then continued to decline slowly through the early 1990s. Variability in trends in organochlorine pesticides during the 1990s, which is evident in figure 8-1, probably represents differences among groups of NAWQA sites rather than actual trends.

The observed trends reflect the regulatory history of these three insecticides in the United States. Agricultural uses of all three were cancelled during the early 1970s, whereas use of aldrin, dieldrin, and chlordane was permitted for termite control through the late 1980s. The declines shown in figure 8-1 are consistent with an exponential rate of decline in which concentrations decrease by half within a constant interval of time (half-life), following the elimination of use. Nationally, the half-lives in whole fish, as estimated either from the NCBP data alone or from the combined NCBP and NAWQA data, are about 7 years for total DDT, 11-13 years for total chlordane, and about 30 years for dieldrin. The declines in concentrations of total DDT, total chlordane, and dieldrin in whole-fish tissue over the past three decades reflect past regulatory actions to discontinue their use, yet also illustrate that changes can take a long time to occur for pesticides with long half-lives.

\section{Data Used to Evaluate Trends in Organochlorine Concentrations in Fish Tissue}

Although few sites were sampled by both the NCBP and the NAWQA Programs, the sites used in this comparison had similar land uses, and the fishsampling and compositing strategies of the two programs were comparable. Of the 117 NCBP sites, most were sampled every 1-3 years during 1969-1986 (Schmitt and Bunck, 1995). Each of the 228 NAWQA sites was sampled only once during 1992-2001, and sites generally were sampled in three groups corresponding to the rotational investigations of NAWQA Study Units (see Chapter 3). NAWQA sites plotted as 1992 in figure 8-1 actually were sampled during the period 1992-1994 (with most sampled during the first year), sites plotted as 1995 were sampled during 1995-1997, and sites plotted as 1998 were sampled during 1998-2001. Because NAWOA sampled three groups of sites in three different time periods, the variability in NAWOA results includes differences among sites as well as differences over time.

There were also some differences in analytical methods between NAWQA and NCBP. The NCBP measured only concentrations of $p, p^{\prime}$ isomers of DDT, $D D D$, and DDE in whole fish. For consistency, therefore, NAWQA data for the $o, p^{\prime}$ isomers of DDT, DDD, and DDE were not included when computing total DDT for evaluating trends in whole fish (fig. 8-1). On average, the $p, p^{\prime}$ isomers of DDT, DDD, and DDE made up 99 percent of total DDT (the sum of $o, p^{\prime}$ and $p, p^{\prime}$ isomers DDT, DDD, and DDE) in whole fish. 
Trends in organochlorine pesticide compounds in whole-fish tissue
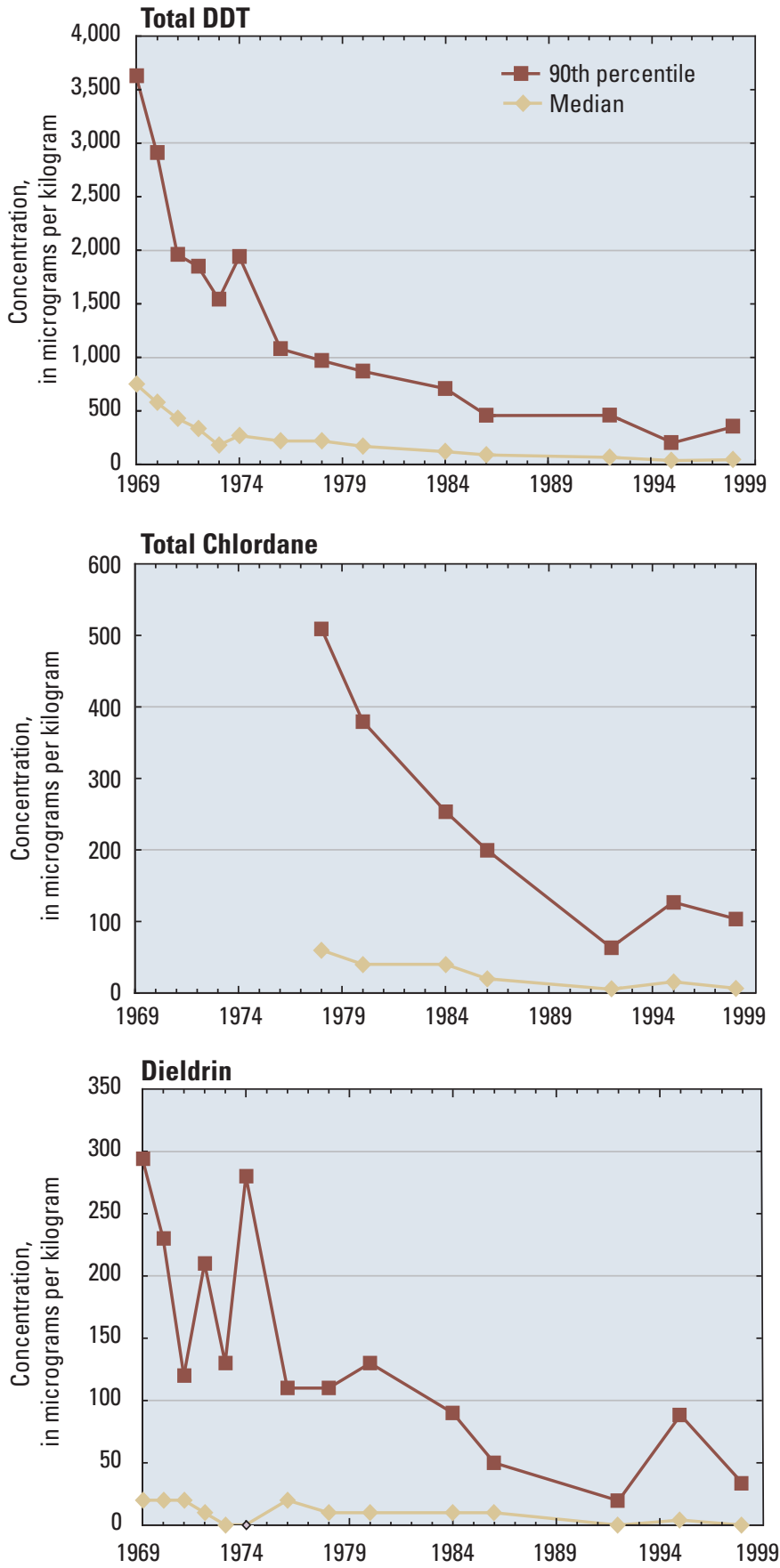

Figure 8-1. Concentrations of total DDT, total chlordane, and dieldrin in whole fish collected from streams draining watersheds with mixed land use throughout the United States have declined over the last 20 to 30 years. The declines followed discontinuation of their uses during the 1970s (agricultural uses of all three) and 1980s (use of aldrin, dieldrin, and chlordane for termite control). Despite the national decline in concentrations, these persistent compounds still are frequently detected in fish. (Data from 1969 to 1986 are from the U.S. Fish and Wildlife Service, Schmitt and Bunck, 1995; and data shown from 1992 to 1998 are from NAWQA. All concentrations are for wet weight of fish tissue.) 


\title{
Trends in Total DDT and Chlordane in Lake Sediments
}

\author{
Peter C. Van Metre, U.S. Geological Survey
}

In addition to the studies of organochlorine pesticides in fish and bed sediment from streams, NAWQA also assessed long-term trends in the concentrations of these compounds through the analysis of sediment cores from lakes and reservoirs, which "record" a history of contaminant concentrations. As soils in a watershed erode, they are deposited as sediment in layers on the bottom of downstream lakes and reservoirs, along with organic particles from aquatic plants and animals. Age-dated sediment cores that penetrate these layered deposits can be used to track trends in total DDT and total chlordane, as well as other sediment-associated contaminants that are relatively stable over time.

Sediment cores from 41 lakes and reservoirs in 16 Statescollectively referred to as lakes for the purposes of this report-were analyzed by Van Metre and Mahler (2005). The study included 31 lakes in urban settings, 7 lakes in undeveloped settings, and 3 additional lakes in watersheds dominated by agriculture. Urban lakes were selected to represent watersheds with primarily residential and com- mercial land uses; only a few of the sites are known to be influenced by significant point-source discharges. The statistical significance of trends (assessed at the 90-percent confidence level) was determined using the Kendall's tau test for trends in concentrations with depth in the core (which is directly related to sediment age). Trends were also evaluated by comparing mean decadal concentrations for 1965-1975 with those for the period from 1990 to approximately 2000 (the top of the core).

Concentrations of total DDT (defined by Van Metre and Mahler (2005) as the sum of the concentrations of $p, p^{\prime}-\mathrm{DDT}, p, p^{\prime}-\mathrm{DDE}$, and $p, p^{\prime}$-DDD) declined significantly since about 1970 in all three of the agricultural lakes, 58 percent of the urban lakes, and 43 percent of the lakes in undeveloped watersheds (fig. 8-2). No lake had a significant upward trend in total DDT. Decadal mean concentrations declined in most lakes from 1965-1975 to 1990-2000, including the lakes without statistically significant trends within the core samples. Overall, the mean total DDT concentration during 1990-2000 was lower than the

\section{Trends in sediment cores at lake sites}
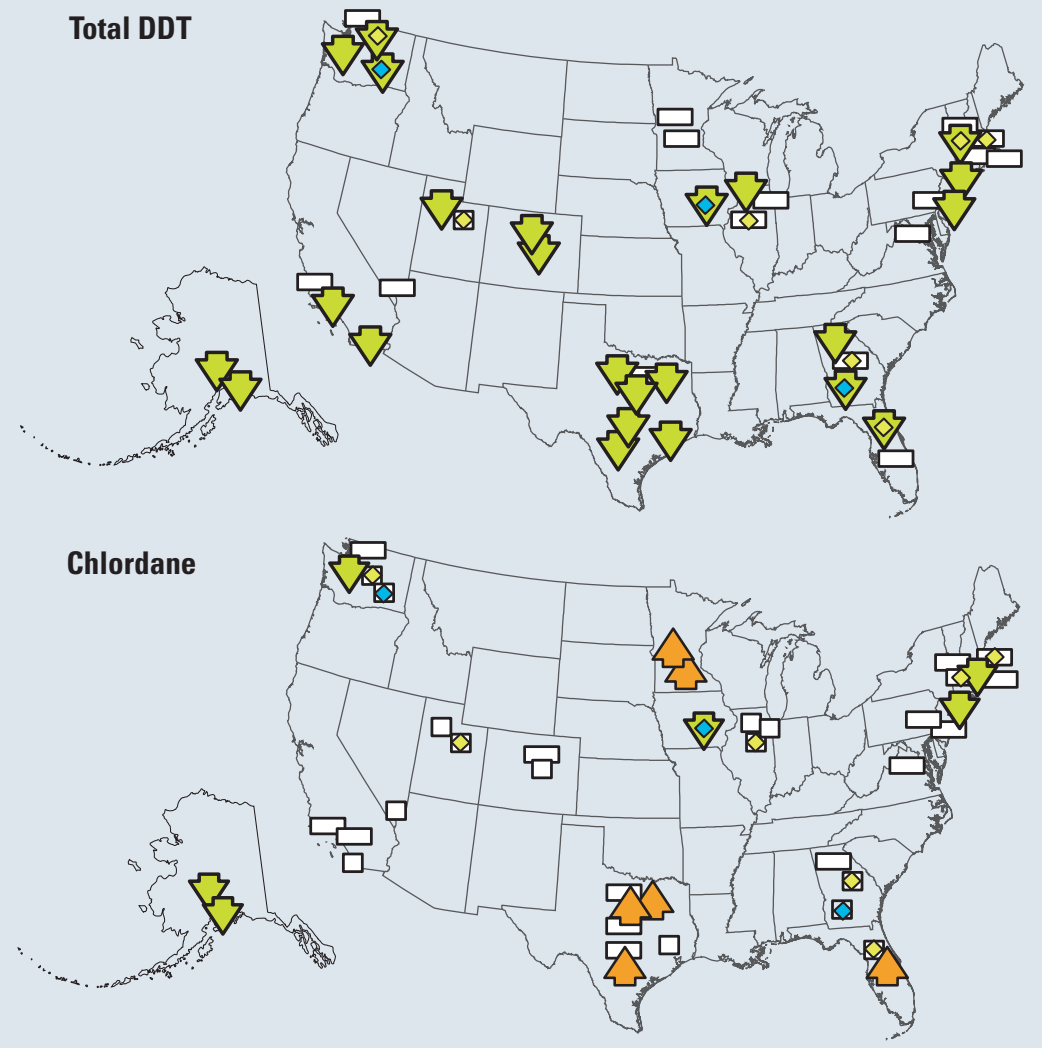

Trend result

$\begin{array}{ll}\square & \text { Increasing trend } \\ \square & \text { No trend } \\ \square & \text { Insufficient detections } \\ \square & \text { Decreasing trend }\end{array}$

\section{Watershed land use}

Urban (only trend result symbol is shown)

$\diamond$ Undeveloped

$\diamond$ Agricultural
Figure 8-2. Concentrations of total DDT declined in most sediment cores collected from 41 lakes in 16 States, most of which were located in urban areas. The sediment cores were analyzed to track historical changes from about 1970 through 2000. The downward trends are consistent with historical changes in DDT use. Upward and downward trends in the concentrations of chlordane, however, were more evenly distributed, reflecting its continued use to control termites until at least 1990.

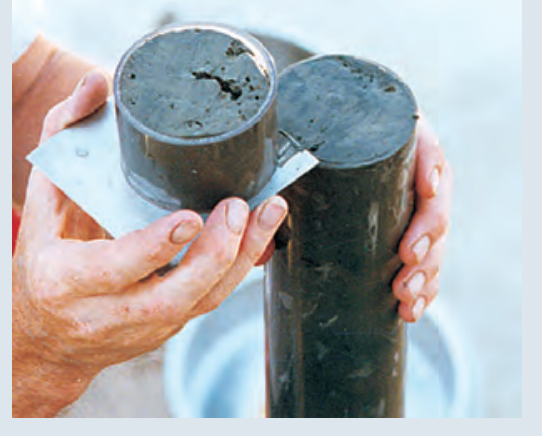

Analyses of sediment cores from lakes were used to reconstruct historical trends in DDT, chlordane, and other contaminants. 


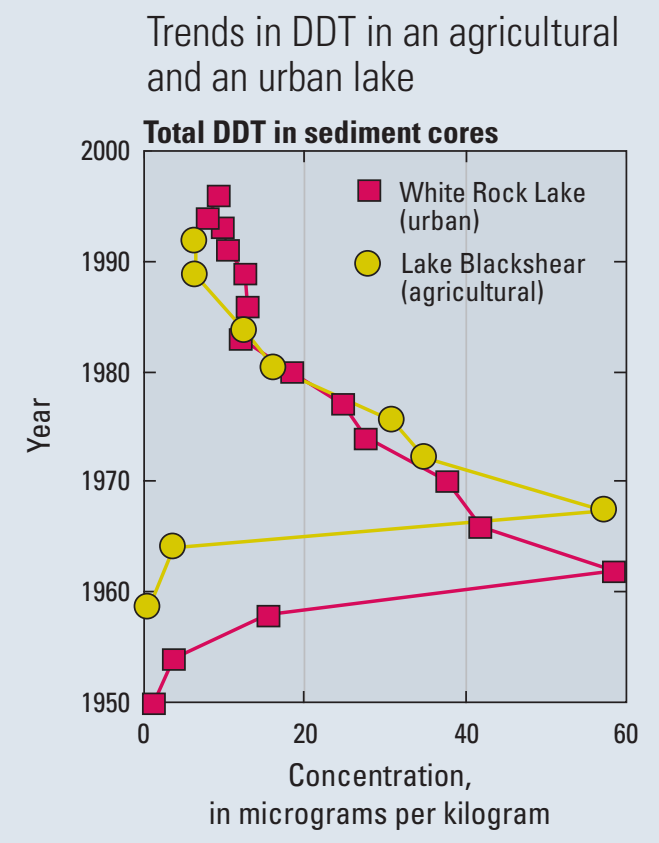

Figure 8-3. Decreases in the concentrations of DDT typically followed an exponential curve after uses began to decline during the 1960s and were cancelled in the early 1970s, as shown in sediment cores collected from White Rock Lake, Texas, and Lake Blackshear, Georgia. The rate of change indicates that an additional 50-percent reduction in concentrations of total DDT is likely to occur by approximately 2015. mean 1965-1975 concentration in 90 percent of the lakes (37 out of 41). The median change in total DDT concentration was a decrease of 68 percent.

These results are consistent with the historical use and regulatory history of DDT, as well as with trends in total DDT concentrations in whole fish (fig. 8-1). As was observed in fish tissue, the decreases in DDT and other persistent hydrophobic contaminants typically followed an exponential curve after use was discontinued (Van Metre and others, 1998), with a steep initial drop followed by a gradual slowing of the change (fig. 8-3). The resulting half-lives for total DDT concentrations in lake sediment range between about 10 and 15 years (Van Metre and others, 1998; Van Metre and Mahler, 2005). Applied in this way, the half-life does not represent a single specific process (for example, chemical degradation), but is a simple measure of the rate of change in lake sediment concentrations over time as a result of a combination of reduced input, chemical transformations, and dilution. The rate of change observed for total DDT provides an indication of what might be expected in the future-an additional 50-percent reduction from present concentrations of these compounds during the next 10 to 15 years.

Trends in total (technical) chlordane (estimated by Van Metre and Mahler [2005] from the concentrations of cis-chlordane, trans-chlordane, and trans-nonachlor) in the sediment cores were more variable than those for total DDT, with upward and downward trends split evenly, and most showing either no significant trend or insufficient data (fig. 8-2). Sixteen percent of urban lakes showed significant downward trends, 19 percent showed upward trends, 42 percent showed no trend, and 22 percent could not be tested for trends because of insufficient detections. Lakes in undeveloped watersheds either showed no trend ( 29 percent), or could not be tested for trends because of insufficient detections (71 percent). Only one of the three agricultural lakes could be tested for a trend and it was significantly downward.

As with total DDT, these results for total chlordane are generally consistent with its historical use and regulation. Chlordane use in agriculture, which was primarily for corn, was discontinued in 1978; however, chlordane use for termite control exceeded its use in agriculture (Andrilenas, 1974; Esworthy, 1987) and continued until 1988 or later (USEPA, 2004g). In addition, use of existing chlordane stocks by homeowners was permitted after 1988 and was common in a 1990 survey (Whitmore and others, 1992). Therefore, it is not surprising that most urban lakes did not show significant downward trends from 1970 to 2000. This result for urban lakes, however, contrasts with the clear decline in total chlordane in fish from watersheds with mixed land uses (fig. 8-1). The difference may be caused by the contrasts in land use - the fish data from large watersheds with mixed land use may be influenced more by agricultural lands, where chlordane use stopped in 1978. Another possible explanation for the apparent upward trends in some of the urban lake cores is that chemical degradation of one or more of the chlordane-derived compounds could be occurring in some of the deeper core samples, thus making it appear that concentrations have increased over time (Van Metre and Mahler, 2005).

The cancellation of DDT and chlordane uses has generally resulted in decreased contaminant levels in samples of sediment and fish tissue from lakes. However, the continuing high levels of chlordane in urban areas, the slow rate of decreasing trends for DDT, and the continuing concern for human exposure from consumption of fish and shellfish (USEPA, 2004h, 2005g) indicate that these organochlorine pesticides will remain a concern for many years to come. 


\section{Herbicides in Agricultural Streams of the Corn Belt}

Concentrations of modern, relatively short-lived pesticides in stream water generally respond rapidly to changes in use. Concentrations of the most heavily used herbicides in streams in the Corn Belt showed both increases and decreases on a regional scale from 1992 to 2001, correlating with changes in use during the same period (see sidebar on p. 133). For example, concentrations of atrazine, alachlor, acetochlor, cyanazine, and metolachlor in the White River - a large stream in Indiana that drains an extensive agricultural area dominated by corn and soybeans-followed regional trends in use (fig. 8-4). Acetochlor concentrations in

Trends in herbicide use and stream concentrations
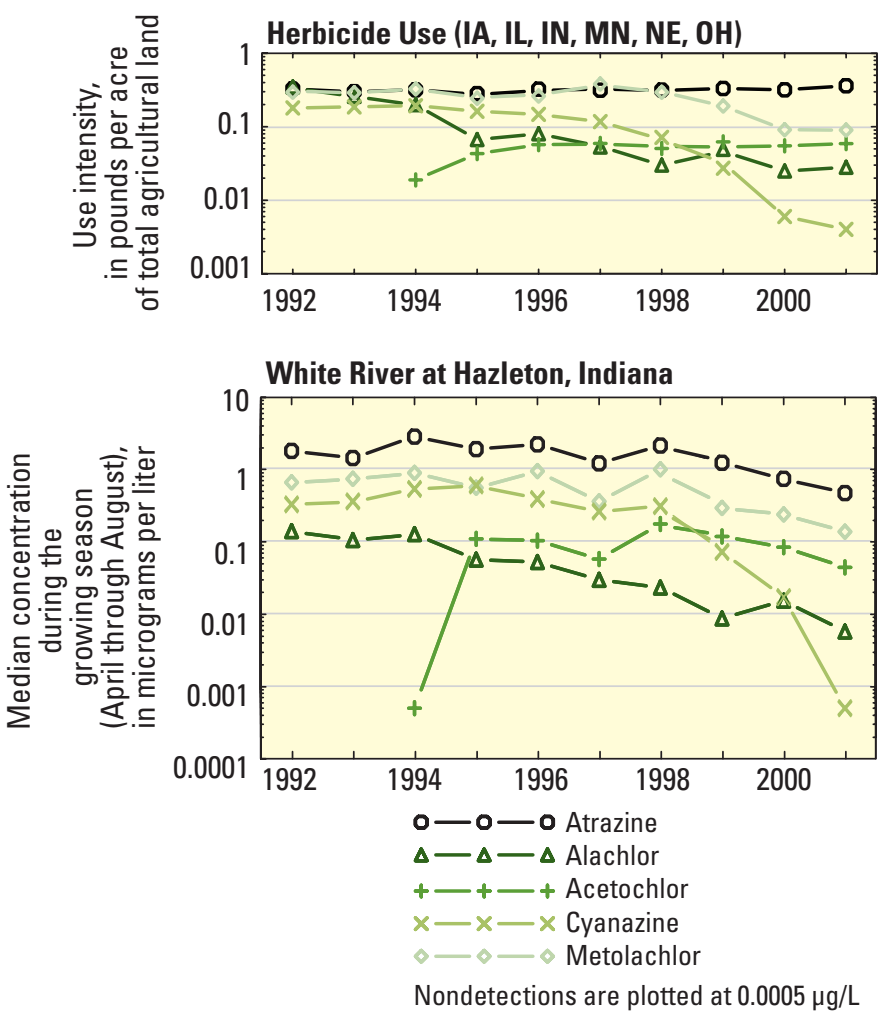

the White River rapidly increased following its introduction in 1994, whereas alachlor concentrations decreased to less than one-tenth of its 1994 concentrations by 2001, as acetochlor replaced part of alachlor use (note the logarithmic scale in figs. 8-4 and 8-5). Among these five herbicides, the concentrations of atrazine changed the least through the decade, consistent with its relatively stable use during this time. Cyanazine concentrations declined most dramatically, following the reductions in its use, which began in the mid1990s. The consistency of these trends in the region is illustrated by cyanazine results from 1996 to 2001 for streams in five different States within the Corn Belt (fig. 8-5).
Figure 8-4. Concentrations of herbicides measured in the White River (White River Basin) during 1992-2001 show the correlation between stream concentrations and the regional trends in use intensity in Corn Belt States. The most dramatic examples are the increase in acetochlor concentrations after its introduction in 1994 and the decreases in alachlor and cyanazine that followed reductions in their use. (Pesticide use data are from the National Agricultural Chemical Use Database, accessed January 25, 2006 at $h t t p: / / w w w$. pestmanagement.info/nass/app_usage.cfm.) 


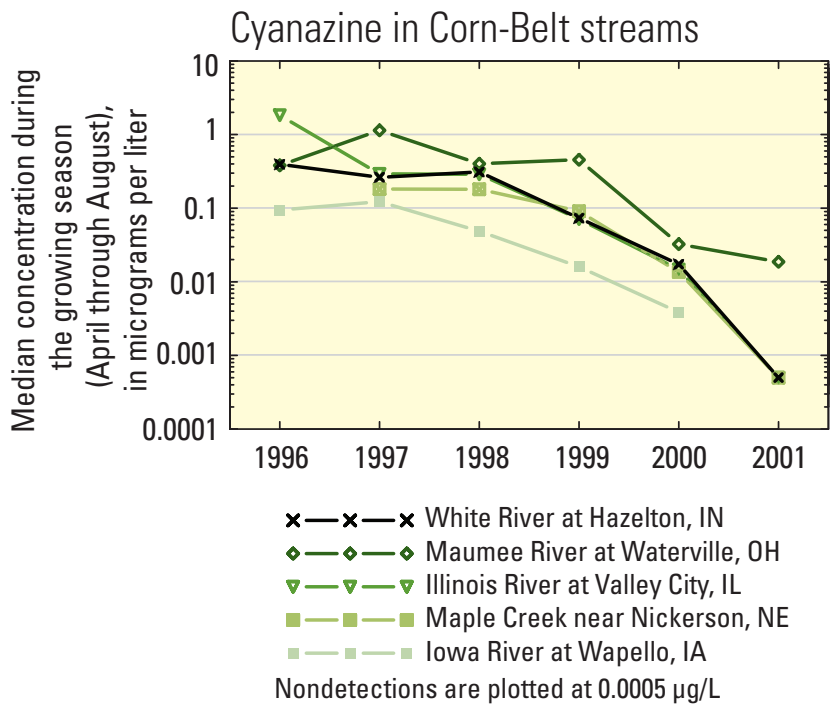

Figure 8-5. The consistency of declines in cyanazine concentrations in streams throughout the Corn Belt is illustrated by results for streams in five different States during 1996-2001. Similar consistency was evident for other major herbicides as well.

\section{Trends in Use of Herbicides in the Corn Belt}

From 1992 to 2001, there were major changes in the primary herbicides used for corn and soybean production in the Corn Belt States of lowa, Illinois, Indiana, Minnesota, Nebraska, and Ohio (see fig. 8-4), even though the total treated crop acreage remained fairly constant. Changes in these herbicides, which combine to account for more than 40 percent of all national herbicide use, exemplify the shifts in use patterns that are typical of pesticides in response to changes in factors such as regulations, monitoring results, effectiveness, and cost.

Throughout the 1990s, atrazine was the herbicide used most widely on corn, and the area treated each year varied little. In the early 1990s, atrazine use decreased slightly because of reduced application rates resulting from regulatory agreements between USEPA and the atrazine manufacturer. This decline, however, was soon offset by increased use of atrazine in tank mixes with other herbicides, and total use remained near the 1990 level in major corn-producing States.

Metolachlor and alachlor were the second and third most heavily used herbicides in 1990, but their use declined substantially by 2001 because of the introduction of new herbicides. In 1994, acetochlor was conditionally registered for use on corn, with the goal of reducing the use of alachlor and other corn herbicides by one-third. By 1997, acetochlor had virtually replaced alachlor use and was rapidly becoming one of the most widely used herbicides (note the logarithmic scale in fig. 8-4). Also in 1997, S-metolachlor was conditionally registered for use. S-metolachlor is the more effective form of two different isomers of metolachlor (both the R- and S-metolachlor isomers were present in metolachlor products). The introduction of S-metolachlor, which has a 30-percent lower application rate, contributed to the decrease in total metolachlor use during the late 1990s. An additional development that probably contributed to the decline in the use of metolachlor and other herbicides was the introduction of bioengineered crops that were genetically modified to be resistant to specific herbicides, such as glyphosate.

The most dramatic decline in herbicide use during the 1990s was for cyanazine. Because of frequent detection of cyanazine in surface and ground water, cyanazine manufacturers began to phase out this product beginning in 1994 . This phase-out, which was completed in 2000 , shifted cyanazine from the fourth most heavily used herbicide in 1992, to only minor use by 2001. 


\section{Recent NAWOA Data Show that Diazinon Concentrations in Some Northeast Streams have Declined Following Recent Reductions in Use}

Patrick J. Phillips, U.S. Geological Survey

Scott W. Ator, U.S. Geological Survey

Elizabeth A. Nystrom, U.S. Geological Survey

Until about 2001, diazinon was one of the most widely used insecticides in the United States for residential lawn and garden pest control (accounting for almost 70 percent of the 11 million $\mathrm{lb}$ of diazinon used for all purposes each year), for residential indoor uses (up to 5 percent of total use), and for agricultural pest control (almost 30 percent of total use). In December 2000, USEPA and diazinon registrants agreed to phase out the sale of diazinon for residential uses (both outdoor and indoor), as well as for many agricultural uses. As part of the agreement, indoor uses of diazinon were terminated and all outdoor nonagricultural uses (principally on residential lawns and gardens) were phased out during 2002-2004. Manufacturing of diazinon for application to gardens, lawns, and other turf stopped in June 2003, and sales and distribution to retailers ended in August 2003. Retail sales ended on December 31, 2004, after which a buy-back program helped to remove from the market the remaining diazinon products. USEPA and the registrants also agreed to reduce the uses of diazinon on agricultural crops by about one-third. By 2005, these combined actions eliminated most of the use of diazinon, compared with use in 2000.

Analysis of data from seven NAWQA stream sites in the Northeast-five classified as urban streams and two as mixed land use- - using Seasonal Kendall tests at the 95-percent confidence level (Schertz and others, 1991), indicate predominantly downward trends in concentrations of diazinon since the reductions in diazinon use began in 2000 (fig. 8-6). Specifically, concentrations of diazinon decreased by 20 to 41 percent since 1998 at the five sites with statistically significant changes. Concentrations at the two sites with no statistically significant change showed decreases of 13 and 22 percent for the same period. Diazinon concentrations observed in one of the five urban streams (Accotink Creek, VA) provide an illustration of how concentrations have recently declined in some streams - in this case by about 39 percent from 1998 to 2004 (fig. 8-7).
Trends in diazinon concentrations at selected stream sites

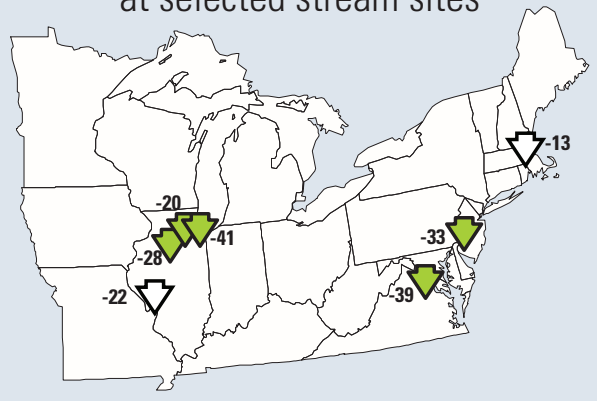

Decreasing trends and percentage change

$-20 \checkmark$ Statistically significant

$-13 \bigvee$ Not statistically significant

Figure 8-6. Diazinon concentrations decreased significantly from 1998 to 2004 in 5 of 7 urban and mixed-land-use streams in the northeastern United States. Trends were evaluated using the Seasonal Kendall test at the 95-percent confidence level.

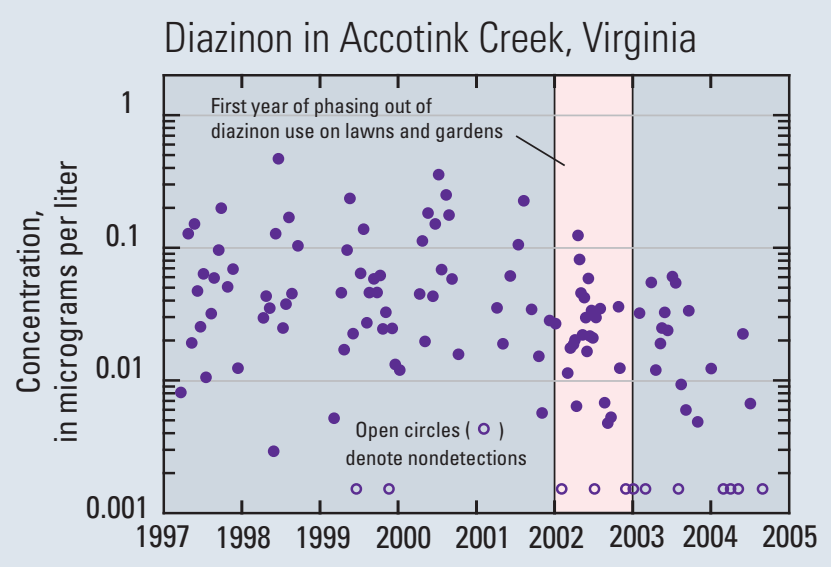

Figure 8-7. From 1997 to 2001, the levels and ranges of diazinon concentrations in Accotink Creek (Potomac River Basin) were relatively similar from year to year, but from 2002 to 2004, diazinon concentrations generally decreased. These decreases correspond to the national reduction in total sales and use of diazinon through this period, although no specific use data were available for the Accotink Creek watershed. 


\section{Ground Water}

Pesticide concentrations in ground water, compared with streams, respond more slowly to changes in pesticide use or land-management practices, often lagging by years or decades, depending on the nature of the flow system and the depth and location of wells sampled. During the long periods of time that it takes for water to move through most ground-water flow systems, the types and amounts of pesticides applied at the land surface often change. This makes it difficult to link the concentrations of pesticides detected in specific wells with the locations where the pesticides were used. Evaluation of trends in ground water is also made more difficult by the complex flow paths along which ground water moves, and the resulting uncertainty about where sampled water originally entered the ground-water flow system.

For these reasons-as well as a general shortage of suitable data - trends in pesticide levels in ground water have not been extensively characterized. As noted by Barbash and Resek (1996), few previous studies have used consistent sampling and analytical methods over long enough periods, or developed a sufficient understanding of the flow system and age of sampled ground water, to reliably evaluate longterm trends in ground-water quality. Although NAWQA ground-water studies use consistent sampling and analytical methods, NAWQA monitoring has not yet covered a long enough period of time in most locations to assess trends. Despite these challenges, examples of ground-water trend assessments from USGS studies, conducted in cooperation with other agencies in Iowa and Florida, illustrate the types of trends that may occur over different time scales and demonstrate some of the approaches to trend assessment.

\section{Herbicides in lowa Ground Water}

Results from the Iowa Ground Water Monitoring Program, a joint study by the Iowa Geological Survey, USEPA, and USGS, show that herbicide concentrations have increased in Iowa ground water with increasing herbicide use since the 1950s (Kolpin and others, 2004). Low levels of tritium (less than 0.8 tritium units [TU]) were used as an indicator of water recharged before 1953, which was prior to the onset of substantial herbicide use. All but 1 of 42 samples with detectable concentrations of herbicides or degradates were samples of water that had recharged after 1953 (fig. 8-8), whereas more than 80 percent of the samples with undetectable herbicides or degradates had recharged prior to 1953. The detection of herbicides in one sample with low tritium probably resulted from the mixing of younger and older waters in samples collected from a municipal supply well. The results from this study demonstrate the value of information on ground-water recharge dates and residence times for the analysis of data for trend assessment. Use of estimated recharge dates provided the most reliable means available for determining that most samples without detections were ground water that had recharged before the beginning of major herbicide use. In addition, because the correlations between estimated recharge date and the occurrence of pesticide
Figure 8-8. The lowa Ground-Water Monitoring Program showed that herbicides or their degradates were detected in 41 of 42 municipal supply wells in lowa that tap ground water recharged after 1953 (as indicated by tritium concentrations greater than 0.8 tritium units). Conversely, more than 80 percent of the samples in which herbicide compounds were not detected were samples of ground water recharged prior to 1953 , before significant use of herbicides began. (Modified from Kolpin and others, 2004.)
Detections of herbicide compounds in ground water recharged before and after 1953

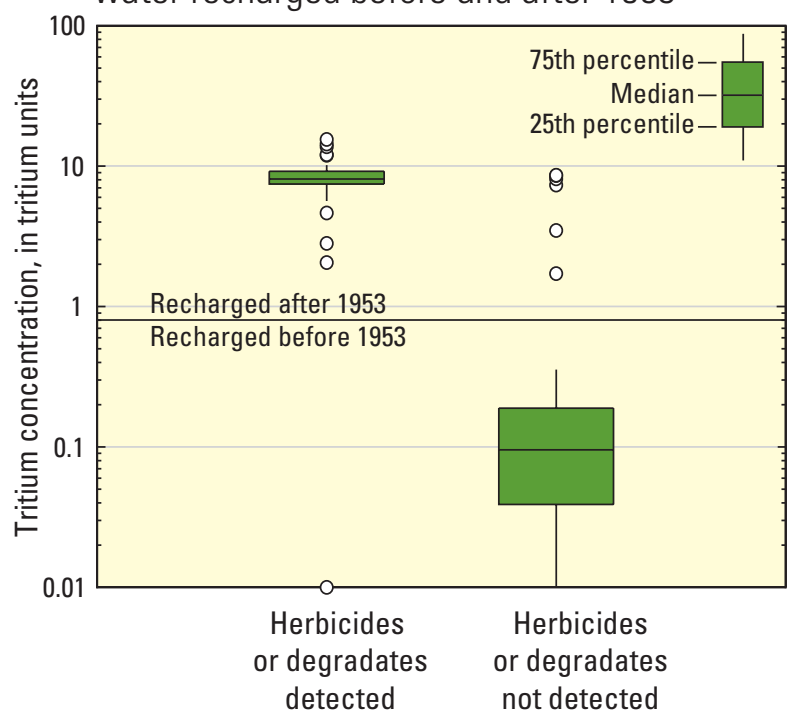




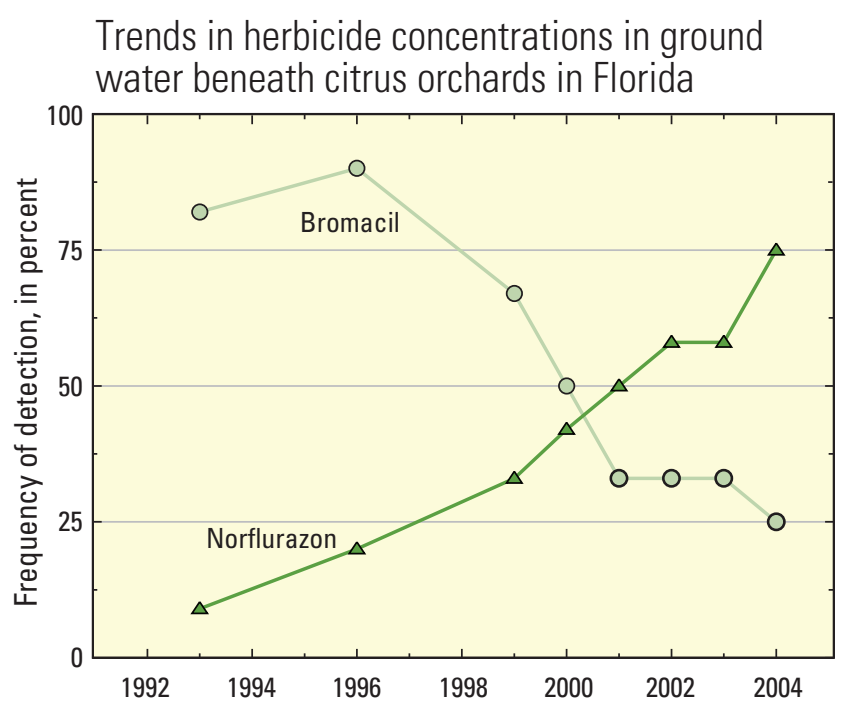

Figure 8-9. In central Florida, applications of bromacil in citrus orchards were discontinued in 1994, yet it was still detected at or above $2 \mu \mathrm{g} / \mathrm{L}$ in 25 percent of the sampled wells 10 years later. The frequency of detecting norflurazon, which began to replace bromacil on citrus in 1994, did not exceed that of bromacil for about 6 years. (Modified from Choquette and others, 2005.)

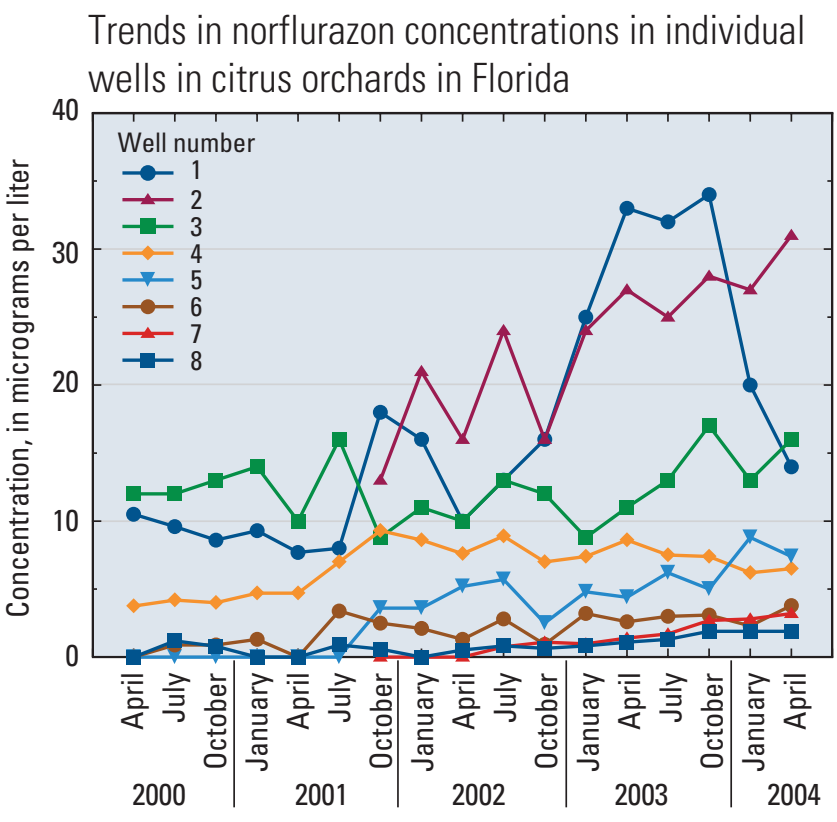

Figure 8-10. Although concentrations of norflurazon increased from 2000 to 2004, there was substantial seasonal and annual variability. Variability among wells was associated with depth to water, depth of the well screen below the water table, the length of the well screen, and the thickness of the aquifer zone sampled. (Modified from Choquette and others, 2005.) compounds in ground water were more evident when degradates were considered, the study by Kolpin and others (2004) demonstrates the value of incorporating data on degradate occurrence for detecting trends.

\section{Herbicides in Florida Ground Water}

A study by the USGS, Florida Department of Agriculture and Consumer Services, and the Southwest Florida Water Management District was undertaken to monitor and assess the quality of shallow ground water in central Florida (Choquette and Sepúlveda, 2000). This region is dominated by citrus production and is characterized by well-drained sandy soils that are conducive to relatively rapid movement of water and pesticides to and within the ground-water flow system (Choquette and others, 2003).

The study found that bromacil, a widely used herbicide, declined but continued to be detected in 25 percent or more of the sampled wells for up to 10 years after its use in the region's citrus orchards was prohibited in 1994 (fig. 8-9). The decline in bromacil detections coincided with an increase in detections of norflurazon, which began to replace bromacil in 1994. The frequency of norflurazon detections, however, did not exceed that of bromacil until the year 2000, about 6 years after the use of bromacil was discontinued (Choquette and others, 2005).

Although figure 8-9 indicates that the overall frequency of norflurazon detection in ground water increased from 1993 to 2004 within the area studied by Choquette and others (2005), concentrations of norflurazon showed considerable seasonal and annual variability in the individual wells sampled, as well as variability among different wells (fig. 8-10). These variations were associated with differences among the wells in the age of the ground water, the depth to water, the depths of the sampled zone below the water table, and the thickness of the aquifer zone sampled. The highest and most variable concentrations (wells 1-3) occurred where depths to the water table were relatively shallow and in wells that sampled water closest to the water table. The lower and less variable concentrations occurred in the deeper wells (wells 4-8) with long screened intervals. These observations are consistent with results from previous studies, indicating that the temporal variability in pesticide concentrations generally tends to diminish with increasing well depth (Barbash and Resek, 1996). 


\section{References Cited}

Adams, C.D. and Thurman, E.M., 1991, Formation and transport of deethylatrazine in the soil and vadose zone: Journal of Environmental Quality, v. 20, p. 540-547.

ATSDR (Agency for Toxic Substances and Disease Registry), 2004a, Interaction profile for atrazine, deethylatrazine, diazinon, nitrate, and simazine, December 2004, accessed November 18, 2005, at http://www.atsdr.cdc. gov/interactionprofiles/iplo.html.

ATSDR (Agency for Toxic Substances and Disease Registry), 2004b, Guidance manual for the assessment of joint toxic action of chemical mixtures, May 2004, http://www.atsdr. cdc.gov/interactionprofiles/ip10.html.

Anderson, T.D., and Lydy, M.J., 2002, Increased toxicity to invertebrates associated with a mixture of atrazine and organophosphate insecticides: Environmental Toxicology and Chemistry, v. 21, no. 7, p. 1507-1514.

Andrews, W.J.; Fong, A.L.; Harrod, Leigh; and Dittes, M.E.; 1998, Water-quality assessment of part of the Upper Mississippi River Basin-Ground-water quality in an urban part of the Twin Cities metropolitan area, Minnesota, 1996: U.S. Geological Survey Water-Resources Investigations Report 97-4248, 54 p.

Andrilenas, P.A., 1974, Farmers' use of pesticides in 1971quantities: U.S. Department of Agriculture, Economic Research Service, Agricultural Economic Report No. 252, $56 \mathrm{p}$.

Anthony, S.S., Hunt, Jr., C.D., Brasher, A.M.D., Miller, L.D., and Tomlinson, M.S., 2004, Water quality on the island of Oahu, Hawaii: U.S. Geological Survey Circular 1239, 31 p.

Aspelin, A.L., and Grube, A.H., 1999, Pesticides industry sales and usage_-1996 and 1997 market estimates: U.S. Environmental Protection Agency, Pesticide Industry Sales and Usage Report 733-R-99-001, 39 p.

Atkins, J.B.; Zappia, Humbert; Robinson, J.L.; McPherson, A.K.; Moreland, R.S.; Harned, D.A.; Johnston, B.F.; and Harvill, J.S.; 2004, Water quality in the Mobile River Basin, Alabama, Georgia, Mississippi, and Tennessee, 1999-2001: U.S. Geological Survey Circular 1231, 35 p.

Bailey, H.C.; DiGiorgio, Carol; Kroll, Kevin; Miller, J.L.; Hinton, D.E.; and Starrett, Gwen; 1996, Development of procedures for identifying pesticide toxicity in ambient waters - carbofuran, diazinon, chlorpyrifos: Environmental Toxicology and Chemistry, v. 15, no. 6, p. 837-845.
Bailey, H.C.; Miller, J.L.; Miller, M.J.; Wiborg, L.C.; Deanovic, Linda; and Shed, Theodore; 1997, Joint acute toxicity of diazinon and chlorpyrifos to Ceriodaphnia dubia: Environmental Toxicology and Chemistry, v. 16, no. 11 , p. 2304-2308.

Bailey, H.C.; Deanovic, Linda; Reyes, Emilie; Kimball, Tom; Larson, Karen; Cortright, Kristi; Connor, Valerie; and Hinton, D.E.; 2000, Diazinon and chlorpyrifos in urban waterways in northern California, USA: Environmental Toxicology and Chemistry, v. 19, no. 1, p. 82-87.

Bailey, H.C., Elphick, J.R., Krassoi, R. and Lovell, Adam, 2001, Joint acute toxicity of diazinon and ammonia to Ceriodaphnia dubia: Environmental Toxicology and Chemistry, v. 20, no.12, p. 2877-2882.

Baker, D.B., Wallrabenstein, L.K., and Richards, R.P., 1994, Well vulnerability and agrichemical contamination-assessments from a voluntary well testing program. in the Fourth National Conference on Pesticides-new directions in pesticide research, development and policy: Blacksburg, Va., Virginia Polytechnic Institute and State University, 25 p.

Barbash, J.E., and Resek, E.A., 1996, Pesticides in ground water-distribution, trends, and governing factors: Chelsea, Mich., Ann Arbor Press, Pesticides in the hydrologic system series, v. 2, 590 p. [available from CRC Press, Boca Raton, Fla.].

Barbash, J.E., Thelin, G.P., Kolpin, D.W., and Gilliom, R.J., 1999, Distribution of major herbicides in ground water of the United States: U.S. Geological Survey Water-Resources Investigations Report 98-4245, 57 p.

Barbash, J.E., 2004, The geochemistry of pesticides, in Lollar, B.S., (ed.), Environmental geochemistry, in Holland, H.D., and Turekian, K.K., (eds.), Treatise on geochemistry: Oxford, UK, Elsevier-Pergamon, v. 9, p. 541-577.

Battaglin, W.A., Furlong, E.T., and Burkhardt, M.R., 2001, Concentration $[\mathrm{sic}]$ of selected sulfonylurea, sulfonamide, and imidazolinone herbicides, other pesticides, and nutrients in 71 streams, 5 reservoir outflows, and 25 wells in the Midwestern United States, 1998: U.S. Geological Survey Water-Resources Investigations Report 00-4225, 123 p.

Battaglin, W.A., Thurman, E.M., Kalkhoff, S.J., and Porter, S.D., 2003, Herbicides and transformation products in surface waters of the Midwestern United States: Journal of the American Water Resources Association, v. 39, no. 4, p. $743-756$.

Belden, J.B., and Lydy, M.J., 2000, Impact of atrazine on organophosphate insecticide toxicity: Environmental Toxicology and Chemistry, v. 19, no. 9, p. 2266-2274. 
Boxall, A.B., Sinclair, C.J., Fenner, K., Kolpin, D., and Maund, S.J., 2004, When synthetic chemicals degrade in the environment: Environmental Science and Technology, v. 38 no. 1 , p. 369a-375a.

Burkart, M.R., and Kolpin, D.W., 1993, Hydrologic and landuse factors associated with herbicides and nitrate in nearsurface aquifers: Journal of Environmental Quality, v. 22, p. 646-656.

CCME (Canadian Council of Ministers of the Environment), 1998, Protocol for the derivation of Canadian tissue residue guidelines for the protection of wildlife that consume aquatic biota: Canadian Council of Ministers of the Environment, 18 p., accessed on December 2, 2005, at http:// www.ec.gc.ca/ceqg-rcqe/English/Pdf/tissue_protocol.pdf.

CCME (Canadian Council of Ministers of the Environment), 1999a, Canadian tissue residue guidelines for the protection of wildlife that consume aquatic biota-DDT (total) in Canadian environmental quality guidelines, 1999, Canadian Council of Ministers of the Environment, Winnipeg.

CCME (Canadian Council of Ministers of the Environment), 1999b, Canadian tissue residue guidelines for the protection of wildlife that consume aquatic biota-Toxaphene, in Canadian environmental quality guidelines, 1999, Canadian Council of Ministers of the Environment, Winnipeg.

Capel, P.D., Ma, Lin, and Wotka, P.J., 1998, Wet atmospheric deposition of pesticides in Minnesota 1989-94: U.S. Geological Survey Water Resources Investigations Report, 97-4026, 43 p.

Capel, P.D., Larson, S.J., and Winterstein, T.A., 2001, The behaviour of 39 pesticides in surface waters as a function of scale: Hydrological Processes, v. 15, no. 7, p. 1251-1269.

Carter, D.S., Lydy, M.J., and Crawford, C.G., 1995, Waterquality assessment of the White River Basin, Indiana-analysis of available information on pesticides, 1972-92: U.S. Geological Survey Water-Resources Investigations Report 94-4024, $60 \mathrm{p}$.

Choquette, A.F., and Sepúlveda, A.A., 2000, Design of a shallow ground-water network to monitor agricultural chemicals, Lake Wales Ridge, Central Florida: U.S. Geological Survey Water-Resources Investigations Report 00-4134, $35 \mathrm{p}$.

Choquette, A.F., Moore, D.K., Dehaven, E.C., Haber, J.D., and Turner, R.M., 2003, A litmus area for transport of agricultural chemicals into ground water and lakes, central Florida in American Water Resources Association, 2003 Spring Specialty Conference-Agricultural Hydrology and Water Quality, May 12-14, 2003, Proceedings: Kansas City, Mo., American Water Resources Association, AWRA Technical Publication Series No. TPS-03-01.
Choquette, A.F., Turner, R.D., Haber, J.D., Lucas, P.A., Daiker, D.H., and DeHaven, E.C., 2005, Temporal variability of agricultural chemicals in ground water and implications for water-quality sampling in The 15th Tennessee Water Resources Symposium, April 13-15, 2005: Burns, Tenn., American Water Resources Association, Proceedings, p. 2B-6-2B-14.

Crawford, C.G., 2004, Sampling strategies for estimating acute and chronic exposures of pesticides in streams: Journal of the American Water Resources Association, v. 40, no. 2 , p. 485-502.

Cromwell, A.E. and Thurman, E.M., 2000, Atmospheric transport, deposition, and fate of triazine herbicides and their metabolites in pristine areas at Isle Royale National Park: Environmental Science and Technology, v. 34, p. 3079-3085.

Demcheck, D.K., Tollett, R.W., Mize, S.V., Skrobialowski, S.C., Fendick Jr., R.B., Swarzenski, C.M., and Porter, Stephen, 2004, Water quality in the Acadian-Ponchartrain drainages; Louisiana and Mississippi, 1999-2001: U.S. Geological Survey Circular 1232, 41 p.

Deneer, J.W., 2000, Toxicity of mixtures of pesticides in aquatic systems: Pest Management Science, v. 56, no. 6, p. 516-520.

Denton, D.L., Wheelock, C.E., Murray, S.A., Deanovic, L.A., Hammock, B.D., and Hinton, D.E., 2003, Joint acute toxicity of esfenvalerate and diazinon to larval fathead minnows (Pimephales promelas): Environmental Toxicology and Chemistry, v. 22, no. 2, p. 336-341.

Domagalski, J.L., Knifong, D.L., Dileanis, P.D., Brown, L.R., May, J.T., Connor, Valerie, and Alpers, C.N., 2000, Water quality in the Sacramento River basin, California, 1994-98: U.S. Geological Survey, Circular 1215, 36 p.

Donaldson, David; Kiely, Timothy; and Grube, Arthur; 2002, Pesticides industry sales and usage-1998 and 1999 market estimates: U.S. Environmental Protection Agency, 33 p.

Eichers, T.R., Andrileanas, P.A., Blake, H., Jenkins, R., and Fox, A., 1970, Quantities of pesticides used by farmers in 1966: U.S. Department of Agriculture, Economic Research Service, Agricultural Economic Report 179, 61 p.

Eisler, Ronald, and Jacknow, Joel, 1985, Toxaphene hazards to fish, wildlife, and invertebrates-a synoptic review: U.S. Department of the Interior, Fish and Wildlife Service Biological Report 85(1.4), Contaminant Hazard Reviews Report 4, $17 \mathrm{p}$.

Eisler, Ronald, 1990, Chlordane hazards to fish, wildlife, and invertebrates - a synoptic review: U.S. Department of the Interior, Fish and Wildlife Service Biological Report 85(1.21), Contaminant Hazard Reviews, Report 21, 49 p. 
Esworthy, R.F., 1987, Incremental benefit analysis-restricted use of all pesticides registered for subterranean termite control: U.S. Environmental Protection Agency, Benefits and Use Division, Economic Analysis Branch.

Faust, M., Altenburger, R., Boedeker, W., and Grimme, L., 1993, Additive effects of herbicide combinations on aquatic non-target organisms: The Science of the Total Environment supplement, p. 941-952.

Fegeas, R.G., Claire, R.W., Guptill, S.C., Anderson, K.E., and Hallam, C.A., 1983, Land use and land cover digital data: U.S. Geological Survey Circular 895-E, 21 p.

Fenner, Kathrin; Kooijman, Cornelis; Cheringer, Martin; and Hungerbuhler, Konrad; 2002, Including transformation products into [sic] the risk assessment for chemicals-the case of nonylphenol ethoxylate usage in Switzerland: Environmental Science and Technology, v. 36, no. 6, p. 1147-1154.

Fry, D.M., and Toone, C.K., 1981, DDT-induced feminization of gull embryos: Science, v. 213, no. 4510, p. 922-924.

Fuhrer, G.J., Morace, J.L., Johnson, H.M., Rinella, J.F., Ebbert, J.C., Embrey, S.S., Waite, I.R., Carpenter, K.D., Wise, D.R., and Hughes, C.A., 2004, Water quality in the Yakima River Basin, Washington, 1999-2000: U.S. Geological Survey Circular 1237, 44 p.

Gianessi, L.P., and Marcelli M.B., 2000, Pesticide use in U.S. crop production —1997 national summary report: Washington, D.C., National Center for Food and Agricultural Policy, variously paged.

Gilliom, R.J., and Thelin, G.P., 1997, Classification and mapping of agricultural land for National Water-Quality Assessment: U.S. Geological Survey Circular 1131, 70 p.

Goodbred, S.L., Gilliom, R.J., Gross, T.S., Denslow, N.P., Bryant, W.B., and Schoeb, T.R., 1997, Reconnaissance of 17ß-estradiol, 11-ketotestosterone, vitellogenin, and gonad histopathology in common carp of United States streamspotential for contaminant-induced endocrine disruption: U.S. Geological Survey Open-File Report 96-627, 47 p.

Goolsby, D.A., Thurman, E.M., Pomes, M.L., Meyer, M.T., and Battaglin, W.A., 1997, Herbicides and their metabolites in rainfall—origin, transport, and deposition patterns across the midwestern and northeastern United States, 1990-1991: Environmental Science and Technology, v. 31, no. 5, p. $1325-1333$.

Groschen, G.E., Arnold, T.L., Harris, M.A., Dupré, D.H., Fitzpatrick, F.A., Scudder, B.C., Morrow Jr., W.S., Terrio, P.J., Warner, K.L., and Murphy, E.A., 2004, Water quality in the upper Illinois River Basin, Illinois, Indiana, and Wisconsin, 1999-2001: U.S. Geological Survey Circular 1230, 32 p.
Gross, T.S., Arnold, B.S., Sepulveda, M.S., and McDonald, K., 2003, Endocrine disrupting chemicals and endocrine active agents, in Hoffmann, D.J., Rattner, B.A., Burton Jr., G.A., and Cairns Jr., J., (eds.), Handbook of Ecotoxicology: Lewis Publishers: New York, NY, p. 1033-1098.

Guillette, L.J., Gross, T.S., Masson, G.R., Matter, M.M., Percival H.F., and Woodward, A.R., 1994, Developmental abnormalities of the gonad and abnormal sex hormone concentrations in juvenile alligators from contaminated and control lakes in Florida: Environmental Health Perspectives, v. 102 , p. $680-688$.

Hallberg, G.R., 1989, Pesticide pollution of groundwater in the humid United States: Agriculture, Ecosystems and Environment, v. 26, p. 299-367.

Hampson, P.S., Treece Jr., M.W., Johnson, G.C., Ahlstedt, S.A., and Connell, J.F., 2000, Water quality in the Upper Tennessee River Basin, Tennessee, North Carolina, Virginia, and Georgia 1994-98: U.S. Geological Survey Circular 1205, 32 p.

Hermanson, M.H., Isaksson, E., Teixeira, C., Muir, D.C.G., Compher, K.M., Li, Y-F., Igarashi, M., and Kamiyama, K., 2005, Current-use and legacy pesticide history in the Austfonna Ice Cap, Svalbard, Norway: Environmental Science and Technology, v. 39, no. 21, p. 8163-8169.

International Agency for Research on Cancer, 2001, Chlordane and heptachlor (Group 2B): IARC Summary and Evaluation, v. 79.

Jordan, L.S., Farmer, W.J., Goodin, J.R., and Day, B.E., 1970, Nonbiological detoxication of the s-triazine herbicides: Residue Reviews, v. 32, p. 267-286.

Kalkhoff, S.J., Kolpin, D.W., Thurman, E.M., Ferrer, I., and Barcelo, D., 1998, Degradation of chloroacetanilide herbicides - the prevalence of sulfonic and oxanilic acid metabolites in Iowa groundwaters and surface waters: Environmental Science and Technology, v. 32, no. 11, p. 1738-1740.

Kavlock, R.J., Daston, G.P., DeRose, C., Fenner-Crisp, P., Gray, L.E., Kaattari, S. Lucier, G., Luster, M., Mac, M.J., Maczka, C., Miller, R., Moore, J., Rolland, R., Scott, G., Sheehan, D.M., Sinks, T., and Tilson, H.A.,1996, Research needs for the risk assessment of health and environmental effects of endocrine disruptors-a report of the U.S. Environmental Protection Agency-sponsored workshop: Environmental Health Perspectives, v. 104, p. 715-740.

Keith, L.H., 1997, Environmental endocrine disruptors-a handbook of property data: New York, NY., John Wiley \& Sons, Inc.,1231 p. 
Kiely, Timothy; Donaldson, David; and Grube, Arthur; 2004, Pesticides industry sales and usage_-2000 and 2001 market estimates: U.S. Environmental Protection Agency, Office of Prevention, Pesticides, and Toxic Substances, EPA-733-R04-001, 33 p.

Kolpin, D.W., Thurman, E.M., Goolsby, D.A., 1996, Occurrence of selected pesticides and their metabolites in nearsurface aquifers of the Midwestern United States: Environmental Science and Technology, v. 30, p. 335-340.

Kolpin, D.W., 1997, Agricultural chemicals in groundwater of the Midwestern United States-relations to land use: Journal of Environmental Quality, v. 26, no. 4, p. 1025-1037.

Kolpin, D.W., Stamer, J.K., and Goolsby, D.A., 1998, Herbicides in ground water of the Midwest-a regional study of shallow aquifers, 1991-94: U.S. Geological Survey Fact Sheet 076-98, 4 p.

Kolpin, D.W., Schnoebelen, D.J., and Thurman, E.M., 2004, Degradates provide insight to spatial and temporal trends of herbicides in ground water: Ground Water, v. 42, no. 4, p. 601-608.

Larson, S.J., Capel, P.D., and Majewski, M.S., 1997, Pesticides in surface waters-distribution, trends, and governing factors: Chelsea, Mich., Ann Arbor Press, Pesticides in the Hydrologic System series, v. 3, 373 p. [available from CRC Press, oca Raton, Fla.]

Larson, S.J., Gilliom, R.J., and Capel, P.D., 1999, Pesticides in streams of the United States-initial results from the National Water-Quality Assessment Program: U.S. Geological Survey Water-Resources Investigations Report 98-4222, $92 \mathrm{p}$.

Larson S.J., Crawford, C.G., and Gilliom, R.J., 2004, Development and application of watershed regressions for pesticides (WARP) for estimating atrazine concentration distributions in streams: U.S. Geological Survey Water-Resources Investigations Report 2003-4047, 68 p.

Leonard, R.A., 1990, Movement of pesticides into surface waters, in Cheng, H.H., (ed.), Pesticides in the Soil Environment: Soil Science Society of America Book Series, no. 2, p. 303-349.

Lydy, M.J., and Austin, K.R., 2004, Toxicity assessment of pesticide mixtures typical of the Sacramento-San Joaquin Delta using Chironomus tentans: Archives of Environmental Contamination and Toxicology, v. 48, no. 1, p. 49-55.

Lydy, Michael; Belden, Jason; Wheelock, Craig; Hammock, Bruce; and Denton, Debra; 2004, Challenges in regulating pesticide mixtures: Ecology and Society, v. 9, no. 6, art. 1, p. $1-15$.
MacDonald, D.D., Ingersoll, C.G., and Berger, T.A., 2000, Development and evaluation of consensus-based sediment quality guidelines for freshwater ecosystems: Archives of Environmental Contamination and Toxicology v. 39, p. 20-31.

Majewski, M.S., and Capel, P.D., 1995, Pesticides in the atmosphere-distribution, trends, and governing factors: Chelsea, Mich., Ann Arbor Press, Pesticides in the hydrologic system series, v. 1, 214 p. [available from CRC Press, Boca Raton, Fla.].

Milne, G.W.A., 1995, CRC handbook of pesticides: Boca Raton, Fla., CRC Press, 402 p.

Munn, M.D., and Gilliom, R.J., 2001, Pesticide toxicity index for freshwater aquatic organisms: U.S. Geological Survey Water-Resources Investigations Report 2001-4077, 55 p.

Nakagaki, Naomi, and Wolock, D.M., 2005, Estimation of agricultural pesticide use in drainage basins using land cover maps and county pesticide data: U.S. Geological Survey Open-File Report 2005-1188, 46 p.

National Academy of Sciences, 1999, Hormonally active agents in the environment: Washington, DC., National Academy Press, 430 p.

Newell, A.J., Johnson, D.W., and Allen, L.K., 1987, Niagara River biota contamination project-fish flesh criteria for piscivorous wildlife: New York State Department of Environmental Conservation, Division of Fish and Wildlife, Bureau of Environmental Protection Technical Report 87-3, $182 \mathrm{p}$.

Nolan, J.V., Brakebill, J.W., Alexander, R.B., and Schwarz, G.E., 2003, Enhanced River Reach File 2.0, Version 2.0, November 10, 2003: U.S. Geological Survey Open-File Report 2002-40, variously paged.

Nowell, L.H., Capel, P.D., and Dileanis, P.D., 1999, Pesticides in stream sediment and aquatic biota-distribution, trends, and governing factors: Boca Raton, Fla., CRC Press, Pesticides in the Hydrologic System series, v. 4, 1001 p.

Nowell, L.H., Crawford, C.G., Nakagaki, N., Thelin, G.P., and Wolock, D.M., 2006, Regression model for explaining and predicting concentrations of dieldrin in whole fish in United States streams: U.S. Geological Survey Scientific Investigations Report, 2006-5020.

Purdom, C.E., Hardiman, P.A., Bye, V.J., Eno, N.C., Tyler, C.R., Sumpter, J.P., 1994, Estrogenic effects of effluents from sewage treatment works: Chemistry and Ecology, v. 8, p. 275-285. 
Renard, K.G., Foster, G.R., Weesies, G.A., McCool, D.K., and Yoder, D.C., 1997, Predicting soil erosion by water-a guide to conservation planning with the Revised Universal Soil Loss Equation (RUSLE): U.S. Department of Agriculture Agricultural Handbook no. 703, 384 p.

Richards, R.P., and Baker, D.B., 1993, Pesticide concentration patterns in agricultural drainage networks in the Lake Erie Basin: Environmental Toxicology and Chemistry, v. 12, p. 13-26.

Richards, R.P., Baker, D.B., Kramer, J.W., and Ewing, E.W., 1996, Annual loads of herbicides in Lake Erie tributaries in Ohio and Michigan: Journal of Great Lakes Research v. 22, p. 414-428.

Rodriguez, C.J., and Harkin, J.M., 1997, Degradation of atrazine in subsoils, and groundwater mixed with aquifer sediments: Bulletin of Environmental Contamination Toxicology, v. 59, p. 728-735.

Rowe Jr., G.L., Reutter, D.C., Runkle, D.L., Hambrook, J.A., Janosy, S.D., and Hwang, L.H., 2004, Water quality in the Great and Little Miami River Basins, Ohio and Indiana, 1999-2001: U.S. Geological Survey Circular 1229, 40 p.

Sample, B.E., Opresko, D.M., Suter II, G.W., 1996, Toxicological benchmarks for wildlife, 1996 revision: Prepared by the Risk Assessment Program, Health Sciences Research Division, Oak Ridge National Laboratory, for the U.S. Department of Energy ES/ER/TM-86/R3, variously paged.

Schertz, T.L., Alexander, R.B., and Ohe, D.J., 1991, The computer program estimate trend (ESTREND), a system for the detection of trends in water-quality data: U.S. Geological Survey Water-Resources Investigations Report 91-4040, $63 \mathrm{p}$.

Schmitt, C.J., and Bunck, C. M., 1995, Persistent environmental contaminants in United States fish and wildlife: U.S. Geological Survey, Biological Resources Division, Columbia Environmental Research Center, accessed December 2, 2005, at http://www.cerc.usgs.gov/data/ncbp/fish.htm.

Schnoebelen, D.J., Kalkhoff, S.J., Becher, K.D., and Thurman, E.M., 2003, Water-quality assessment of the Eastern Iowa basins - selected pesticides and pesticide degradates in streams, 1996-98: U.S. Geological Survey Water-Resources Investigations Report 2003-4075, $61 \mathrm{p}$.

Scribner, E.A., Battaglin, W.A., Dietze, J.E., and Thurman, E.M., 2003, Reconnaissance data for glyphosate, other selected herbicides, their degradation products, and antibiotics in 51 streams in nine midwestern states, 2002: U.S. Geological Survey Open-File Report 2003-217, 101 p.
Seiler, R.L., Skorupa, J., Naftz, D.L., and Nolan, B.T., 2003, Irrigation-induced contamination of water, sediment, and biota in the western United States-synthesis of data from the National Irrigation Water Quality Program: U.S. Geological Survey Professional Paper 1655, 123 p.

Shedlock, R.J., Denver, J.M., Hayes, M.A., Hamilton, P.A., Koterba, M.T., Bachman, L.J., Phillips, P.J., and Banks, W.S.L., 1999, Water-quality assessment of the Delmarva Peninsula, Delaware, Maryland, and Virginia—results of investigations, 1987-91: U.S. Geological Survey WaterSupply Paper 2355-A, 41 p.

Sinclair, C.J., and Boxall, A.B.A., 2003, Assessing the ecotoxicity of pesticide transformation products: Environmental Science and Technology, v. 37, no. 20, p. 4617-4625.

Squillace, P.J., Thurman, E.M., and Furlong, E.T., 1993, Groundwater as a nonpoint source of atrazine and deethylatrazine in a river during base flow conditions: Water Resources Research, v. 29, no. 6, p. 1719-1729.

Squillace, P.J., Scott, J.C., Moran, M.J., Nolan, B.T., and Kolpin, D.W., 2002, VOCs, pesticides, nitrate, and their mixtures in groundwater used for drinking water in the United States: Environmental Science and Technology, v. 36, no. 9, p. 1923-1930.

Stackelberg, P.E., Gilliom, R.J., Wolock, D.M., and Hitt, K.J., 2006, Development and application of a regression equation for estimating the occurrence of atrazine in shallow ground water beneath agricultural areas of the United States: U.S. Geological Survey Scientific Investigations Report 20055287, p 27.

Stephan, C.E., Mount, D.I., Hansen, D.J., Gentile, J.H., Chapman, G.A., and Brungs, W.A., 1985, Guidelines for deriving numerical national water quality criteria for the protection of aquatic organisms and their uses: U.S. Environmental Protection Agency, PB 85-227049, 98 p., accessed June 9, 2005, at http://www.epa.gov/waterscience/criteria/ 85guidelines.pdf.

Thelin, G.P., and Gianessi, L.P., 2000, Method for estimating pesticide use for county areas of the United States: U.S. Geological Survey Open-File Report 2000-25, 62 p.

Thurman, E.M., Goolsby, D.A., Meyer, M.T., and Kolpin, D.W., 1991, Herbicides in surface waters of the midwestern United States - the effect of spring flush: Environmental Science and Technology, v. 25, no. 10, p. 1794-1796.

U.S. Department of Agriculture, 1999, 1997 Census of Agriculture, Geographic Area Series Volume1, 1A, 1B, 1C, CD-ROM Set [3 CD set]. 
U.S. Department of Agriculture, 2005, National Agricultural Statistics Service (NASS), Agricultural chemical use database, accessed December 1, 2005, at http://www. pestmanagement.info/nass/.

U.S. Department of Health and Human Services, 2005, Report on carcinogens, eleventh edition. U.S. Department of Health and Human Services, Public Health Service, accessed January 30, 2006 at http://ntp.niehs.nih.gov/ntp/roc/eleventh/ profiles/s064ddt.pdf.

USEPA (U.S. Environmental Protection Agency), 1982, Pesticide assessment guidelines, Subdivision N, Chemistry: Environmental Fate; U.S. Environmental Protection Agency Office of Pesticide Programs EPA-540/9-82-021.

USEPA (U.S. Environmental Protection Agency), 1986, Guidelines for the health risk assessment of chemical mixtures; September 1986: U.S. Environmental Protection Agency, National Center for Environmental Assessment, Office of Research and Development, EPA/630/R-98/002. 51 FR 34014, accessed August 26, 2005, at http://www.epa. gov/ncea/raf/pdfs/chem_mix/chemmix_1986.pdf.

USEPA (U.S. Environmental Protection Agency), 1992a, Water quality standards: establishment of numeric criteria for priority toxic pollutants; States' compliance; Final rule (12/22/92) (“Toxics Rule”): Federal Register, v. 57, no. 246, p. 60848-60923.

USEPA (U.S. Environmental Protection Agency), 1992b, National study of chemical residues in fish: U.S. Environmental Protection Agency, Office of Science and Technology: EPA-823-R-92-008a, v. 1166 p., 2 appendices.

USEPA (U.S. Environmental Protection Agency), 1997, Ecological risk assessment guidance for Superfund-process for designing and conducting ecological risk assessments, Interim final: U.S. Environmental Protection Agency EPA 540-R-97-006, Solid Waste and Emergency Response OSWER9285.7-25, Publication PB97-963211, 77 p.

USEPA (U.S. Environmental Protection Agency), 1998, Endocrine disruptor screening and testing advisory committee (EDSTAC), final report, August 1998, U.S. Environmental Protection Agency, accessed December 1, 2005, at http:// www.epa.gov/scipoly/oscpendo/edspoverview/finalrpt.htm.

USEPA (U.S. Environmental Protection Agency), 2000a, Guidance for assessing chemical contaminant data for use in fish advisories, vol. 1, fish sampling and analysis, (3rd ed): U.S. Environmental Protection Agency, Office of Water, EPA 823-B-00-007.
USEPA (U.S. Environmental Protection Agency), 2000b, Environmental risk assessment for diazinon, revised October 2000: U.S. Environmental Protection Agency, accessed September 28, 2005, at http://www.epa.gov/pesticides/op/ diazinon/risk_oct2000.pdf.

USEPA (U.S. Environmental Protection Agency), 2000c, Supplementary guidance for conducting health risk assessment of chemical mixtures: U.S. Environmental Protection Agency Risk Assessment Forum EPA/630/R-00/002, accessed December 1, 2005, at http://www.epa.gov/NCEA/ raf/chem_mix.htm.

USEPA (U.S. Environmental Protection Agency), 2003a, Interim reregistration elegibility decision for atrazine-Case No. 0062: U.S. Environmental Protection Agency, accessed January 9, 2006, at http://www.epa.gov/oppsrrdl/REDs/ atrazine_ired.pdf.

USEPA (U.S. Environmental Protection Agency), 2003b, Atrazine MOA Ecological Subgroup-recommendations for aquatic community level of concern (LOC) and method to apply LOC(s) to monitoring data, final report, October 22, 2003, U.S. Environmental Protection Agency Electronic docket, Public Docket Number OPP-2003-0367-0007, accessed January 24, 2006, at http://www.regulations.gov/ fdmspublic-rel11/component/main.

USEPA (U.S. Environmental Protection Agency), 2003c, Procedures for the derivation of equilibrium partitioning sediment benchmarks (ESBs) for the protection of benthic organisms - dieldrin: U.S. Environmental Protection Agency, Office of Research and Development EPA-600R-02-010, accessed December 1, 2005, at http://www.epa. gov/nheerl/publications/files/dieldrin.pdf.

USEPA (U.S. Environmental Protection Agency), 2003d, Procedures for the derivation of equilibrium partitioning sediment benchmarks (ESBs) for the protection of benthic organisms - endrin: U.S. Environmental Protection Agency, Office of Research and Development EPA-600-R-02-009, accessed December 1, 2005, at http://www.epa.gov/nheerl/ publications/files/endrin.pdf.

USEPA (U.S. Environmental Protection Agency), 2003e, Procedures for the derivation of equilibrium partitioning sediment benchmarks (ESBs) for the protection of benthic organisms-nonionics compendium, Draft: U.S. Environmental Protection Agency, Office of Research and Development EPA-822-R-02-016.

USEPA (U.S. Environmental Protection Agency), 2003f, Framework for cumulative risk assessment: U.S. Environmental Protection Agency Risk Assessment Forum EPA/630/P-02/001F, 129 p.

USEPA (U.S. Environmental Protection Agency), 2004a, 40 CFR Part 158 Data Requirement Tables: U.S. Environmental Protection Agency. 
USEPA (U.S. Environmental Protection Agency), 2004b, An examination of EPA risk assessment principles and practices-staff paper prepared for the U.S. Environmental Protection Agency by members of the Risk Assessment Task Force: U.S. Environmental Protection Agency, Office of the Science Advisor EPA/100/B-04/001, 193 p.

USEPA (U.S. Environmental Protection Agency), 2004c, 2004 Edition of the drinking water standards and health advisories: U.S. Environmental Protection Agency, Office of Water EPA-822-R-04-005, accessed December 1, 2005, at $h t t p: / / w w w . e p a . g o v / w a t e r s c i e n c e / d r i n k i n g / s t a n d a r d s /$ dwstandards.pdf.

USEPA (U.S. Environmental Protection Agency), 2004d, National recommended water quality criteria: U.S. Environmental Protection Agency, Office of Water and Office of Science and Technology, 23 p., accessed December 1, 2005, at $h t t p: / / w w w . e p a . g o v / w a t e r s c i e n c e / c r i t e r i a / n r w q c-2004$. $p d f$.

USEPA (U.S. Environmental Protection Agency), 2004e, Interim reregistration eligibility decision diazinon: U.S. Environmental Protection Agency, Prevention, Pesticides and Toxic Substances, EPA 738-R-04-006 (May 2004), accessed September 21, 2005, at http://cfpub.epa.gov/ oppref/rereg/status.cfm?show=rereg.

USEPA (U.S. Environmental Protection Agency), 2004f, National whole effluent toxicity (WET) implementation guidance under the NPDES program (draft): U.S. Environmental Protection Agency, Office of Wastewater Management EPA 832-B-04-003, accessed December 1, 2005, at http://www.epa.gov/npdes/pubs/wet_draft_guidance.pdf.

USEPA (U.S. Environmental Protection Agency), 2004g, Persistent bioaccumulative and toxic chemical program-priority PBT profiles: U.S. Environmental Protection Agency, accessed January 10, 2006, at http://www.epa.gov/pbt/pubs/ cheminfo.htm.

USEPA (U.S. Environmental Protection Agency), 2004h, The incidence and severity of sediment contamination in surface waters of the United States, national sediment quality survey (2nd ed.): U.S. Environmental Protection Agency, Office of Science and Technology EPA 823-R-04-007, $280 \mathrm{p}$.

USEPA (U.S. Environmental Protection Agency), 2005a, Technical overview of ecological risk assessment: U.S. Environmental Protection Agency, accessed January 27, 2006 at $h t t p: / / w w w . e p a . g o v / o p p e f e d 1 / e c o r i s k \_d e r s /$.

USEPA (U.S. Environmental Protection Agency), 2005b, Drinking water contaminant candidate list 2-final notice: Federal Register, v. 70, no. 36, p. 9071-9077, February 24, 2005; accessed December 1, 2005, at http://www.epa.gov/ fedrgstr/EPA-WATER/2005/February/Day-24/w3527.htm.
USEPA (U.S. Environmental Protection Agency), 2005c, Unregulated contaminant monitoring regulation (UCMR) for Public Water Systems Revisions-proposed rule: Federal Register, v. 70, no. 161, p. 49093-49138, accessed December 1, 2005, at http://www.epa.gov/fedrgstr/EPAWATER/2005/August/Day-22/w16385.htm.

USEPA (U.S. Environmental Protection Agency), 2005d, Drinking water health advisories: U.S. Environmental Protection Agency, accessed November 14, 2005, at http:// www.epa.gov/waterscience/criteria/drinking/.

USEPA (U.S. Environmental Protection Agency), 2005e, Integrated Risk Information System (IRIS) database for risk management: U.S. Environmental Protection Agency, Office of Research and Development, National Center for Environmental Assessment, accessed December 1, 2005, at http://www.epa.gov/iris.

USEPA (U.S. Environmental Protection Agency), 2005f, 2004 National listing of fish advisories: U.S. Environmental Protection Agency, Office of Water, Fact Sheet EPA-823F-05-004, 6 p., accessed December 2, 2005, at http://epa. gov/waterscience/fish/advisories/fs2004.pdf.

USEPA (U.S. Environmental Protection Agency), 2005g, The national listing of fish advisories database, release of 2004 data: U.S. Environmental Protection Agency, Office of Water, accessed November 9, 2005, at http://epa.gov/ waterscience/fish/advisories/.

USEPA (U.S. Environmental Protection Agency), 2005h, Technical overview of ecological risk assessment, risk characterization: U.S. Environmental Protection Agency, accessed November 16, 2005, at http://www.epa.gov/ oppefedl/ecorisk_ders/toera_risk.htm.

USEPA (U.S. Environmental Protection Agency), 2005i, Technical overview of ecological risk assessment, analysis phase- ecological effects characterization: U.S. Environmental Protection Agency, accessed January 9, 2006, at http://www.epa.gov/oppefedl/ecorisk_ders/toera_analysis_ eco.htm.

USEPA (U.S. Environmental Protection Agency), 2005j, Proposed revisions to the aquatic life criteria guidelinescharge to the panel: U.S. Environmental Protection Agency, accessed November 17, 2005, at http://www.epa.gov/ sciencel/pdf/aquatic_life_criteria_guidelines_consultative _ panel_charge.pdf.

U.S. Geological Survey, 1999, The quality of our Nation's waters-nutrients and pesticides: U.S. Geological Survey Circular 1225, $82 \mathrm{p}$. 
Van Metre, P.C., Wilson, J.T., Callender, Edward, and Fuller, C.C., 1998, Similar rates of decrease of persistent, hydrophobic and particle-reactive contaminants in riverine systems: Environmental Science and Technology, v. 32, no. 21, p. 3312-3317.

Van Metre, P.C., and Mahler, B.J., 2005, Trends in hydrophobic organic contaminants in urban and reference lake sediments across the United States, 1970-2001: Environmental Science and Technology, v. 39, no. 15, p. 5567-5574.

Vogelmann, J.E., Howard, S.M., Yang, L., Larson, C.R., Wylie, B.K., and VanDriel, Nick, 2001, Completion of the 1990's national land cover dataset for the conterminous United States from Landsat Thematic Mapper data and ancillary data sources: Photogrammetric Engineering and Remote Sensing, v. 67, p. 650-662.

Whitmore, R.W., Kelly, J.E., and Reading, P.L., 1992, Executive summary, results, and recommendations, Volume 1 of National home and garden pesticide use survey, final report: U.S. Environmental Protection Agency, Research Triangle Institute RTI/5100/17-01F, $140 \mathrm{p}$. 


\section{Glossary}

(Terms in definitions that are defined elsewhere in the Glossary are shown in boldface within the definition. Most definitions are described as they apply to pesticides.)

\section{A}

$\mathbf{1 0}^{-6}$ cancer risk concentration (CRC) The concentration of a chemical in drinking water that corresponds to an excess estimated lifetime cancer risk (in addition to cancer risk from other causes) of 1 in 1,000,000.

Acetanilide herbicides A class of pesticides derived from $\mathrm{N}$-acetylaniline and used primarily for weed control in corn, soybeans, and sorghum.

Active ingredient The chemical component of a pesticide product that kills or otherwise controls the target organism(s).

Acute effects Rapid physiological response of an organism (such as death or immobility) resulting from relatively short-term exposure to elevated concentrations of one or more chemicals or other changes in biological, chemical, or physical conditions in the environment.

Adjuvants Chemicals included in a pesticide product to facilitate the application of the product or to enhance the effectiveness of the active ingredient. Adjuvants are often referred to as "inert ingredients."

Agricultural management practices Methods used as part of crop cultivation and livestock husbandry (such as irrigation, fertilization, or integrated pest management) to maximize product yields, control soil erosion, maintain soil quality, and (or) minimize any adverse effects on water quality or ecosystem health.

Agricultural stream A stream draining a watershed with more than 50 percent agricultural land (cropland or pasture) and 5 percent or less of urban land.

Ambient water-quality criteria (AWOC) Guidelines issued by USEPA for pollutants designated as toxic under the Clean Water Act and that may provide the basis for state standards. There are two types of these guidelines - those for the protection of human health and those for the protection of aquatic organisms. Aquatic-life criteria may be acute (established for short-term exposure) or chronic (for long-term exposure).

Aquatic-life benchmark A threshold value above which the concentration of a chemical in water or bed sediment may have adverse effects on aquatic organisms. Benchmarks for water are established to address either acute (short-term) or chronic (long-term) exposures.

Aquifer A geologic formation, group of formations, or part of a formation that contains a sufficient amount of saturated permeable material (for example, soil, sand, gravel and (or) rock) to yield significant quantities of water to wells and springs.
B

Baseflow Hydrologic regime in streams, following extended periods of minimal precipitation, during which streamflow is derived primarily from ground-water discharge.

Bed sediment Sediment particles, including eroded soil and organic matter, deposited at the bottom of a stream or other surface-water body.

Benchmark See water-quality benchmark.

Benthic Living on or close to the bottom of a stream, lake, or sea.

Bioaccumulative The tendency of a chemical compound to be taken up and retained by organisms from all sources in their environment, such as diet, sediment, soil, or water.

Bioassay The quantitative measurement, under standardized conditions, of the biological effects of a substance on an organism or part of an organism.

C

Carbamate insecticides A class of pesticides consisting of various esters of carbamic acid. Like the organophosphate insecticides, they are inhibitors of cholinesterase-the enzyme required for nerve function in the animal body-and are used to kill or control insects in a variety of agricultural and nonagricultural settings.

Chlordane group The set of five compounds whose concentrations are summed to compute the concentration of total chlordane, including the cis and trans isomers of chlordane and nonachlor, and the chlordane degradate, oxychlordane.

Chronic effects Physiological responses of an organism (such as death, impaired reproduction, or changes in organ function) resulting from long-term exposure to one or more chemicals or other changes in biological, chemical, or physical conditions in the environment.

Common detection level A single concentration threshold, used for assessing the presence or absence of each one of a group of compounds within a sample or set of samples on an equal basis. Use of this threshold avoids biases in detection frequencies caused by varying analytical sensitivities to different compounds - it is also sometimes referred to as a "common assessment level."

Confidence level The probability threshold used to decide whether a particular observation or result of a statistical test was likely to have arisen solely by chance.

Conventional pesticides Compounds that are commonly used to kill or control unwanted organisms in either agricultural or nonagricultural settings. Such chemicals include herbicides, insecticides, fumigants, fungicides, and many other types of biocidal compounds, but exclude several other types, such as antifouling agents, disinfectants, and wood preservatives.

Corn Belt The area of the Great Plains and the Midwest where corn and soybeans are the principal crops. It generally 
includes Illinois, Indiana, Iowa, Nebraska, and Ohio, as well as parts of adjoining states.

Crop-group setting A classification of agricultural land that is based on the dominant presence of one, two, or three specific crops (such as "rice," or "corn and soybeans"), as derived from the classification system described by Gilliom and Thelin (1997).

\section{D}

DDT group Six compounds derived from the parent pesticides DDT and DDD whose concentrations are summed to compute the concentration of total DDT, specifically the $p, p^{\prime}$ and $o, p^{\prime}$ isomers of DDT, DDD, and DDE.

Deethylatrazine-to-atrazine ratio The ratio of concentrations of deethylatrazine to atrazine in a particular environmental medium (usually water), used to track the transformation of atrazine to one of its principal degradates over time or distance.

Degradate A compound produced from the transformation of a parent pesticide or another degradate through either abiotic or biotic processes.

Diffusion The movement of chemicals (in either the gas, liquid, or solid phase) from regions of higher concentration to those of lower concentration.

Domestic well A privately owned well that usually serves one home and supplies water for human consumption and other homeowner uses.

\section{E}

$\mathbf{E C}_{\mathbf{5 0}}$ In a toxicity test, the "50 percent effect concentration" - that is, the concentration of a chemical at which a specified effect is observed in half of the test organisms within a specified period of time (typically 48 hours).

Endocrine disruptor A chemical that interferes with the endocrine system in an organism by mimicking a natural hormone, blocking the effects of a hormone on certain receptors, or causing the overproduction or underproduction of hormones.

Endocrine system A biochemical regulatory system in mammals, birds, fish, and other organisms that is comprised of hormones (which act as chemical messengers), glands that produce hormones, and receptors in various organs and tissues that recognize and respond to the hormones. The system regulates a wide variety of physiological processes in the body, including the development of the brain and nervous system, the growth and function of the reproductive system, metabolic activity, and blood sugar levels.

Environmental medium Any natural solid, liquid, or gas in the environment-such as ground water, stream water, bed sediment, or biological tissues.

Explanatory variable A parameter (for example, chemical use, population, or soil permeability) whose value is used in regression and other statistical models to evaluate and estimate the magnitude of another parameter (the response variable).

\section{$\mathbf{F}$}

Fish-consumption advisory A recommendation issued by a public agency that people limit or avoid consumption of certain fish species caught from particular water bodies because of contamination of fish with bacterial or bioaccumulative pollutants.

Flow path The route or pathway followed by water flowing through the hydrologic system. Usually refers to subsurface flow.

Fumigant A compound or mixture of compounds that produces a gas, vapor, fumes, or smoke intended to destroy, repel, or control organisms such as insects, bacteria, or rodents.

Fungicides Pesticides that are used to kill unwanted fungi.

\section{G}

Glacial till Poorly sorted unconsolidated geologic material deposited by glaciers and generally having low permeability, unless fractures or other interconnected openings for flow are present.

Ground-water recharge Water that reaches ground water by infiltration of precipitation or irrigation water through the unsaturated zone or by seepage of water from surface-water bodies, such as streams and lakes.

Guideline A threshold value for the maximum acceptable concentration of a pesticide or other contaminant in a given environmental medium, specified for the protection of humans, aquatic life, or wildlife. Guidelines are issued for advisory purposes and are not legally enforceable.

\section{H}

Half-life The time required for the concentration of a compound in a given environmental medium to be reduced to half of its original value by one or more processes, such as degradation or transport into another environmental medium.

Health advisory An estimate of acceptable drinking-water concentrations for a chemical substance, established by USEPA on the basis of health effects information. Although it is not a legally enforceable federal standard, it provides technical guidance to assist Federal, State, and local officials.

Henry's law constant $\left(\mathbf{K}_{\mathbf{H}}\right)$ A measure of the partitioning of a compound between an aqueous solution and a gas with which it is in contact, quantified as the ratio between the concentrations of the compound in the gas phase and in the aqueous solution at equilibrium.

Herbicides Pesticides that are used to kill unwanted plants.

Human-health benchmark A threshold value above which the concentration of a chemical in water may have adverse effects on humans if the water is used as drinking water without treatment or other measures to lower the concentration. 
Hydraulic conductivity The rate at which a porous medium transmits water.

Hydrogeology The geologic and hydrologic features that control the movement of water, solutes, and small particles through the subsurface.

Hydrologic system The assemblage of pathways by which water travels as it circulates beneath, at, and above the Earth's surface through various processes such as precipitation, runoff, evaporation, infiltration, transpiration, and ground-water discharge.

Hydrophilic The tendency of a compound to favor dissolution in, or association with water, rather than organic matter. Often used to refer to compounds with comparatively low $\mathbf{K}_{\mathbf{o c}}$ values.

Hydrophobic The tendency of a compound to favor sorption to, or association with organic matter, rather than dissolution in water. Often used to refer to compounds with comparatively high $\mathbf{K}_{\mathbf{~ o c}}$ values.

\section{I}

Immobile zones Regions within the subsurface through which water and solutes move relatively slowly, if at all. (Contrast with mobile zones.)

Inert ingredients See adjuvants.

Insecticides Pesticides that are used to kill unwanted insects.

Isomers Compounds with identical chemical composition but with slightly different structures (arrangement of atoms). Examples include $o, p^{\prime}$ - and $p, p^{\prime}$-DDT; and cis- and transchlordane.

\section{K}

$\mathbf{K}_{\mathbf{o c}}$ See soil organic carbon-water partition coefficient.

$\mathbf{K}_{\mathbf{H}}$ See Henry's law constant.

Kendall's tau test A nonparametric statistical test used to determine whether a particular trend in magnitude is significant at a specified confidence level.

\section{$\mathbf{L}$}

$\mathbf{L C}_{50}$ In a toxicity test, the "50 percent lethal concentration"that is, the concentration of a chemical at which 50 percent of test organisms die within a specified period of time (typically 48 or 96 hours).

Lifetime Health Advisory (HA-L) The concentration of a chemical in drinking water that is not expected to cause any adverse noncarcinogenic effects in humans over a lifetime of exposure (70 years). This parameter is not a legally enforceable federal standard, but provides technical guidance to assist Federal, State, Tribal, and local officials.
Linear regression A statistical method for analyzing and estimating the magnitude of a response variable as a function of one or more explanatory variables.

Lipid Any one of a diverse group of hydrophobic organic compounds produced and stored by living organisms and that contain long hydrocarbon chains or rings. Examples include fats, oils, waxes, steroids, and carotenoids.

M

Major aquifer A regionally extensive subsurface geologic formation or group of formations that is used, or has the potential to be used, as a significant ground-water resource.

Major aquifer studies NAWQA investigations involving the sampling of 20 to 30 domestic and (or) public-supply wells that withdraw water from major aquifers.

Manufacturing by-products Compounds used for, or generated during, the production of a particular chemical (such as a pesticide active ingredient) that may be present in the commercial formulation itself, especially those such as technical mixtures that are less highly purified.

Maximum Contaminant Level (MCL) A drinking-water standard that is legally enforceable and that sets the highest permissible concentration of a specific compound in water that is delivered to any user of a public water system. In this report, only values established by the USEPA are used.

Mixed-land-use streams Streams draining watersheds in which no single type of land use (agricultural, urban, or undeveloped) predominates. These include all streams not meeting the specific land-use criteria for agricultural, urban, or undeveloped streams.

Mixture A combination of two or more compounds detected in the same environmental sample.

Mobile zones Regions within the subsurface through which water flows more rapidly than in other locations, often consisting of worm holes, cracks, fractures, and other highly conductive channels. Also referred to as zones of "preferential flow." (Contrast with immobile zones.)

Mobility The speed or ease with which a compound moves through the hydrologic system relative to the rate of water flow- mobility generally increases with decreasing $\mathbf{K}_{\mathbf{o c}}$ values.

$\mathbf{N}$

No-effect level In a toxicity study, the highest concentration or dose that was observed to have a negligible impact on the health of the test organisms.

Nonpoint sources Contaminant releases that are diffuse and widely dispersed, such as agricultural runoff or atmospheric deposition.

Nontarget organisms Organisms other than those that a pesticide active ingredient is applied to control or kill. 
0

Observation well A well designed for measuring water levels and testing ground-water quality, and generally not used as a source for drinking water. Also referred to as a "monitoring well."

Organochlorine pesticide compounds A class of synthetic organic chemicals (mostly insecticides) with hydrocarbon structures containing one or more chlorine substituents, and that includes manufacturing by-products and degradates, in addition to active ingredients.

Organophosphate insecticides A group of pesticides, consisting of various derivatives of phosphoric, phosphorothioic, or phosphorodithioic acids, in some cases with a nitrogen, fluorine, methyl, or cyano group substituting for one or more of the phosphate oxygens. Like the carbamate insecticides, they are inhibitors of cholinesterase-the enzyme required for nerve function in the animal body - and are used to kill or control insects in a variety of agricultural and nonagricultural settings.

\section{$\mathbf{P}$}

Parent pesticide The form of an active ingredient as it is released into the environment.

Partitioning The processes by which a compound becomes distributed among different environmental media. Such processes include sorption, volatilization, dissolution, and biological uptake.

Permeability A measure of the relative ease with which a porous medium can transmit a fluid.

Persistence The tendency of a compound to remain in its original form, rather than undergo transformation, in the environment.

Pesticide A chemical applied to crops, rights-of-way, lawns, residences, golf courses, or other settings to kill or control weeds, insects, fungi, nematodes, rodents, or other unwanted organisms.

Pesticide compounds A term used to refer collectively to parent pesticides, their degradates and, where applicable, their manufacturing by-products.

Point source A specific location at which one or more contaminants are known to be released into the hydrologic system.

Public-supply well A privately or publicly owned well that provides water for public use to: (1) community water systems, (2) transient non-community water systems, such as campgrounds, or (3) non-transient, non-community systems, such as schools.

\section{R}

Rainfall erosivity A parameter in the Universal Soil Loss Equation that quantifies the effects of rainfall on soil loss within a particular area, and accounts for both the energy and intensity of rainstorms, averaged over a specified number of years. Also referred to as the "R factor."

Residence time The amount of time that a solute, particle, organism, or other entity spends within a given environmental medium.

Response variable The dependent parameter (for example, chemical concentration) whose magnitude is estimated from quantitative relations with other, independent parameters (explanatory variables) using statistical relations such as regression models.

Rill irrigation Water management method that employs a series of parallel surface ditches to distribute water to crops.

\section{S}

Saturated zone The region in the subsurface in which all the interstices or voids are filled with water under a pressure exceeding that of the atmosphere.

Seasonal Kendall test A statistical method that corrects for possible seasonal patterns in a given variable to detect temporal trends in the parameter (or lack thereof) over a period of years.

Seasonal pulse Temporary increase in the concentration of one or more compounds in surface water or ground water that commonly occurs at a particular time of the year-for example, the substantial increases in the concentrations of corn herbicides typically observed in streams of the Corn Belt in the spring.

Simulation model A mathematical model used to predict the combined effects and (or) consequences of one or more processes of interest by reproducing these effects using mathematical relations and (or) numerical techniques, typically through the use of computer programs.

\section{Soil erodibility A parameter in the Universal Soil Loss} Equation that quantifies the ease with which a given soil may be carried away by water and which is based on a number of soil characteristics such as soil texture (that is, the percentages of different size fractions such as sand, silt, and clay), organicmatter content, permeability, and structure. Also referred to as the "K factor."

\section{Soil organic carbon-water partition coefficient $\left(\mathrm{K}_{\mathrm{oc}}\right)$ A} measure of the partitioning of a compound that is anticipated to occur between soil and water when the two phases are in contact. This parameter is quantified as the ratio between the concentrations of the compound in the soil (normalized to the organic carbon content of the soil) and in the aqueous solution at equilibrium. The $\mathrm{K}_{\mathrm{oc}}$ provides an indication of the extent of sorption of a compound to natural organic matter in the hydrologic system and, by extension, an inverse measure of the mobility of the compound in water within the subsurface.

Sorption The retention, through binding or association, of a solute ion or molecule by a solid. 
Source water A stream, lake, other surface-water body, or aquifer from which water is drawn for human use.

Spatial extrapolation The use of statistical or other models to predict the value of a parameter (for example, the concentration of a chemical compound) in a location where it has not been measured.

Statistical model A model used to represent the effects of one or more processes of interest by quantitative, probabilistic relations (such as regressions) between one or more explanatory variables and a particular response variable.

Statistical significance The likelihood (commonly expressed as a probability, p) that the result of a statistical test may have occurred solely by chance. Observations associated with $p$ values of 0.05 or less (a "95 percent or greater confidence level") are typically deemed to be "statistically significant," and thus, are unlikely to have occurred solely by chance.

Study Unit A major hydrologic system of the United States, geographically defined by surface- or ground-water features, in which NAWQA sampling studies are focused. The NAWQA studies during the first decade of assessments examined 51 Study Units.

Subsurface The region of earth materials beneath the land surface that encompasses the soil, unsaturated, and saturated zones.

Subsurface tile-drain systems Perforated pipes that are buried in the ground to reduce the water content of poorly drained soils and divert shallow ground water to nearby streams.

Surface runoff The flow of water over the land surface, usually in response to intense rainfall or snowmelt events, irrigation, or rainfall on saturated soils, snow, or impervious surfaces (such as pavement).

\section{$\mathbf{T}$}

Target organism An organism that an active ingredient of a pesticide is designed to control or kill.

Technical DDT A commercial DDT formulation that commonly contained approximately 80 percent $p, p^{\prime}$-DDT, approximately 20 percent $o, p^{\prime}$-DDT, and small amounts of $o, o^{\prime}$-DDT, $m, p^{\prime}$-DDT, $p, p^{\prime}$-DDD, and other manufacturing by-products.

Technical mixture A formulation of a commercial chemical product that usually contains minor amounts of manufacturing by-products or other compounds in addition to the compound of interest (such as the active ingredient in a pesticide product).

Termiticide Pesticides that are used to kill termites, usually in buildings and other structures.

Time-weighted $95^{\text {th }}$ percentile concentration The concentration of a given compound that is exceeded 5 percent of the time, or about 18 days per year (generally not consecutive).

Tolerance level The maximum permissible concentration of a pesticide or pesticide degradate allowed in or on foods or animal feed, for the protection of human health. (Also referred to as a "maximum pesticide residue level.")

Total chlordane concentration The sum of the concentrations of multiple compounds derived from commercial chlordane formulations (including components of the original product and degradates) that might be present in an environmental sample. For NAWQA bed-sediment and fish-tissue analyses, this consisted of the cis and trans isomers of both chlordane and nonachlor, as well as the chlordane degradate oxychlordane. For the chemical analyses of lake sediment cores by Van Metre and Mahler (2005), only cis-chlordane, trans-chlordane and trans-nonachlor were included.

Total DDT concentration The sum of the concentrations of all compounds of interest derived from DDT that might be present in an environmental sample. For NAWQA bed-sediment and fish-tissue analyses, this consisted of the $p, p^{\prime}$ and $o, p^{\prime}$ isomers of DDT, DDD, and DDE. For the chemical analyses of lake sediment cores by Van Metre and Mahler (2005), only the $p, p^{\prime}$ isomers of DDT, DDD, and DDE were included.

Total detection frequency The percentage of samples in which any of the analytes of interest are measured at any concentration without correcting to a common detection level.

Toxicity The degree to which the presence of a chemical substance at a particular concentration in a given environmental medium may be harmful to the health of humans and other organisms that come in contact with that medium.

Toxicity value A quantitative measure of the dose-response relationship observed in a test of the physiological effect of a particular chemical on a specific organism. Examples include $\mathbf{L C}_{\mathbf{5 0}}$ and NOAEC values.

Transformation The conversion of one compound to another through either abiotic or biotic processes.

Transformation product See degradate.

Triazine herbicides A group of pesticides-all sharing a six-membered aromatic ring consisting of three nitrogen atoms and three carbon atoms in an alternating sequence (a "symmetrical triazine ring") — used primarily for weed control on corn, sorghum, cotton, sugarcane, orchards, fallow land, sod, rights-of-way, lawns, golf courses, and Christmas tree farms.

Tritium unit (TU) A measure of the concentration of tritium $\left({ }^{3} \mathrm{H}\right)$, equal to $1{ }^{3} \mathrm{H}$ atom in $10^{18}$ atoms of hydrogen $(\mathrm{H})$, or 3.24 picocuries per liter $(\mathrm{pCi} / \mathrm{L})$.

\section{$\mathbf{U}$}

Undeveloped stream A stream draining a watershed with 25 percent or less of agricultural land and 5 percent or less of urban land.

Unique mixture A combination of two or more specific compounds detected in an environmental sample, regardless of whether other compounds are detected in the same sample.

Universal Soil Loss Equation An empirical equation developed by the U.S. Department of Agriculture to predict the 
average amount of soil lost from a given location per year through wind and water erosion. The equation employs a variety of parameters related to rainfall, soil properties, and topography as explanatory variables.

Unsaturated zone The subsurface region of earth materials above the water table in which the pore spaces may contain a combination of air and water.

Urban stream A stream draining a watershed with more than 5 percent of residential, commercial, transportation, urban recreational areas, and (or) industrial land, and 25 percent or less of agricultural land.

Use intensity The total quantity of a pesticide applied over a specified area, expressed in terms of the amount applied per unit area.

\section{V}

Volatilize To move spontaneously from a liquid or dissolved state to a gaseous state.

\section{W}

Water table The point below the land surface at which ground water is first encountered and below which the earth is saturated.

Water-quality benchmark A threshold value above which the concentration of a specific chemical in a particular environmental medium may have adverse effects on human health, aquatic life, or fish-eating wildlife, and below which there is a low likelihood of such effects (see also aquatic-life benchmark, human-health benchmark, and wildlife benchmark).

Watershed The land area that drains into a particular stream, river, lake, estuary, or coastal zone.

Wildlife benchmark A threshold value above which the concentration of a chemical in water or fish tissue may have adverse effects on fish-eating wildlife. 
Appendixes 1-4 



\section{Appendix 1-Pesticide compounds analyzed in NAWOA samples.}

Table A. Pesticide compounds analyzed in NAWQA water samples.

[Pesticide compounds include pesticides, degradates, and manufacturing by-products. Pesticide compounds are grouped by pesticide class. Common synonyms are listed in parentheses in column 1. The cited references are listed by number at the end of Appendix 1. CAS, Chemical Abstracts Service; GCMS, gas chromatography/mass spectrometry; HPLC, high performance liquid chromatography; Parameter code, the number used to identify a pesticide in the U.S. Geological Survey National Water Information System and the U.S. Environmental Protection Agency Data Storage and Retrieval System; $\mu \mathrm{g} / \mathrm{L}$, micrograms per liter.]

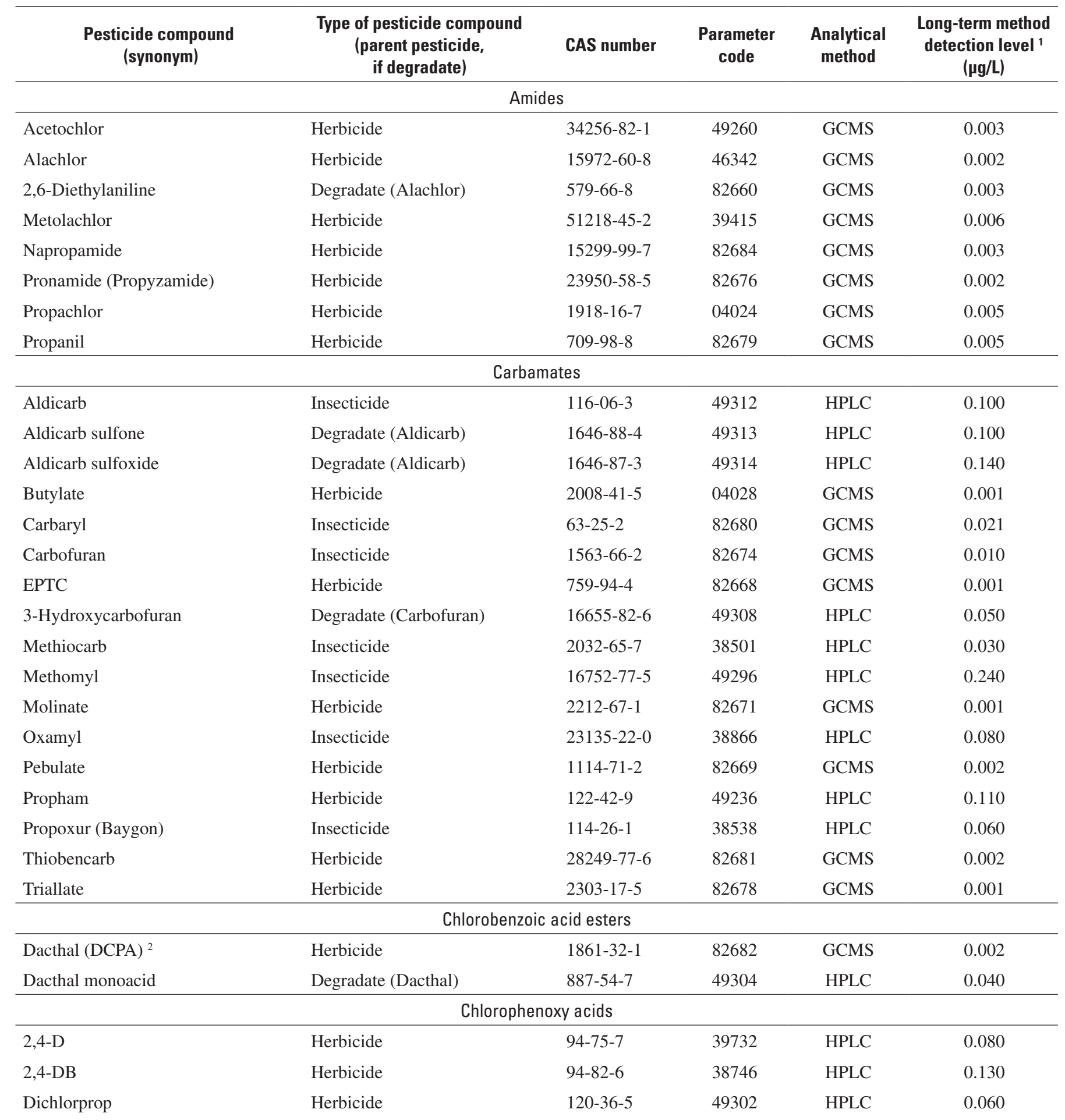


Table A. Pesticide compounds analyzed in NAWQA water samples._- Continued

[Pesticide compounds include pesticides, degradates, and manufacturing by-products. Pesticide compounds are grouped by pesticide class. Common synonyms are listed in parentheses in column 1. The cited references are listed by number at the end of Appendix 1. CAS, Chemical Abstracts Service; GCMS, gas chromatography/mass spectrometry; HPLC, high performance liquid chromatography; Parameter code, the number used to identify a pesticide in the U.S. Geological Survey National Water Information System and the U.S. Environmental Protection Agency Data Storage and Retrieval System; $\mu \mathrm{g} / \mathrm{L}$, micrograms per liter.]

\begin{tabular}{|c|c|c|c|c|c|}
\hline $\begin{array}{l}\text { Pesticide compound } \\
\text { (synonym) }\end{array}$ & $\begin{array}{l}\text { Type of pesticide compound } \\
\text { (parent pesticide, } \\
\text { if degradate) }\end{array}$ & CAS number & $\begin{array}{l}\text { Parameter } \\
\text { code }\end{array}$ & $\begin{array}{l}\text { Analytical } \\
\text { method }\end{array}$ & $\begin{array}{c}\text { Long-term method } \\
\text { detection level }^{1} \\
(\mu \mathrm{g} / \mathrm{L})\end{array}$ \\
\hline MCPA & Herbicide & $94-74-6$ & 38482 & HPLC & 0.100 \\
\hline $\mathrm{MCPB}$ & Herbicide & $94-81-5$ & 38487 & HPLC & 0.130 \\
\hline $2,4,5-\mathrm{T}$ & Herbicide & $93-76-5$ & 39742 & HPLC & 0.040 \\
\hline Benfluralin & Herbicide & $1861-40-1$ & 82673 & GCMS & 0.005 \\
\hline Ethalfluralin & Herbicide & $55283-68-6$ & 82663 & GCMS & 0.005 \\
\hline Oryzalin & Herbicide & $19044-88-3$ & 49292 & HPLC & 0.140 \\
\hline Pendimethalin & Herbicide & $40487-42-1$ & 82683 & GCMS & 0.011 \\
\hline Bentazon & Herbicide & $25057-89-0$ & 38711 & HPLC & 0.030 \\
\hline Norflurazon & Herbicide & 27314-13-2 & 49293 & HPLC & 0.021 \\
\hline \multicolumn{6}{|c|}{ Miscellaneous acids } \\
\hline Acifluorfen & Herbicide & $50594-66-6$ & 49315 & HPLC & 0.040 \\
\hline Chloramben methyl ester & Herbicide & $7286-84-2$ & 61188 & HPLC & 0.110 \\
\hline Clopyralid & Herbicide & $1702-17-6$ & 49305 & HPLC & 0.210 \\
\hline Dicamba & Herbicide & 1918-00-9 & 38442 & HPLC & 0.050 \\
\hline Picloram & Herbicide & $1918-02-1$ & 49291 & HPLC & 0.040 \\
\hline \multicolumn{6}{|c|}{ Nitrophenols } \\
\hline Dichlobenil & Herbicide & $1194-65-6$ & 49303 & HPLC & 0.050 \\
\hline Dieldrin & $\begin{array}{l}\text { Insecticide, Degradate } \\
\quad \text { (Aldrin) }\end{array}$ & $60-57-1$ & 39381 & GCMS & 0.002 \\
\hline alpha-HCH & $\begin{array}{l}\text { Degradate (gamma-HCH), } \\
\text { By-product in technical } \\
\text { lindane }^{3}\end{array}$ & $319-84-6$ & 34253 & GCMS & 0.002 \\
\hline gamma-HCH (Lindane) & Insecticide & $58-89-9$ & 39341 & GCMS & 0.002 \\
\hline Triclopyr & Herbicide & $55335-06-3$ & 49235 & HPLC & 0.040 \\
\hline \multicolumn{6}{|c|}{ Organophosphates } \\
\hline Azinphos-methyl (Guthion) & Insecticide & $86-50-0$ & 82686 & GCMS & 0.020 \\
\hline Chlorpyrifos & Insecticide & $2921-88-2$ & 38933 & GCMS & 0.003 \\
\hline Diazinon & Insecticide & $333-41-5$ & 39572 & GCMS & 0.003 \\
\hline
\end{tabular}


Table A. Pesticide compounds analyzed in NAWQA water samples.-Continued

[Pesticide compounds include pesticides, degradates, and manufacturing by-products. Pesticide compounds are grouped by pesticide class. Common synonyms are listed in parentheses in column 1. The cited references are listed by number at the end of Appendix 1. CAS, Chemical Abstracts Service; GCMS, gas chromatography/mass spectrometry; HPLC, high performance liquid chromatography; Parameter code, the number used to identify a pesticide in the U.S. Geological Survey National Water Information System and the U.S. Environmental Protection Agency Data Storage and Retrieval System; $\mu \mathrm{g} / \mathrm{L}$, micrograms per liter.]

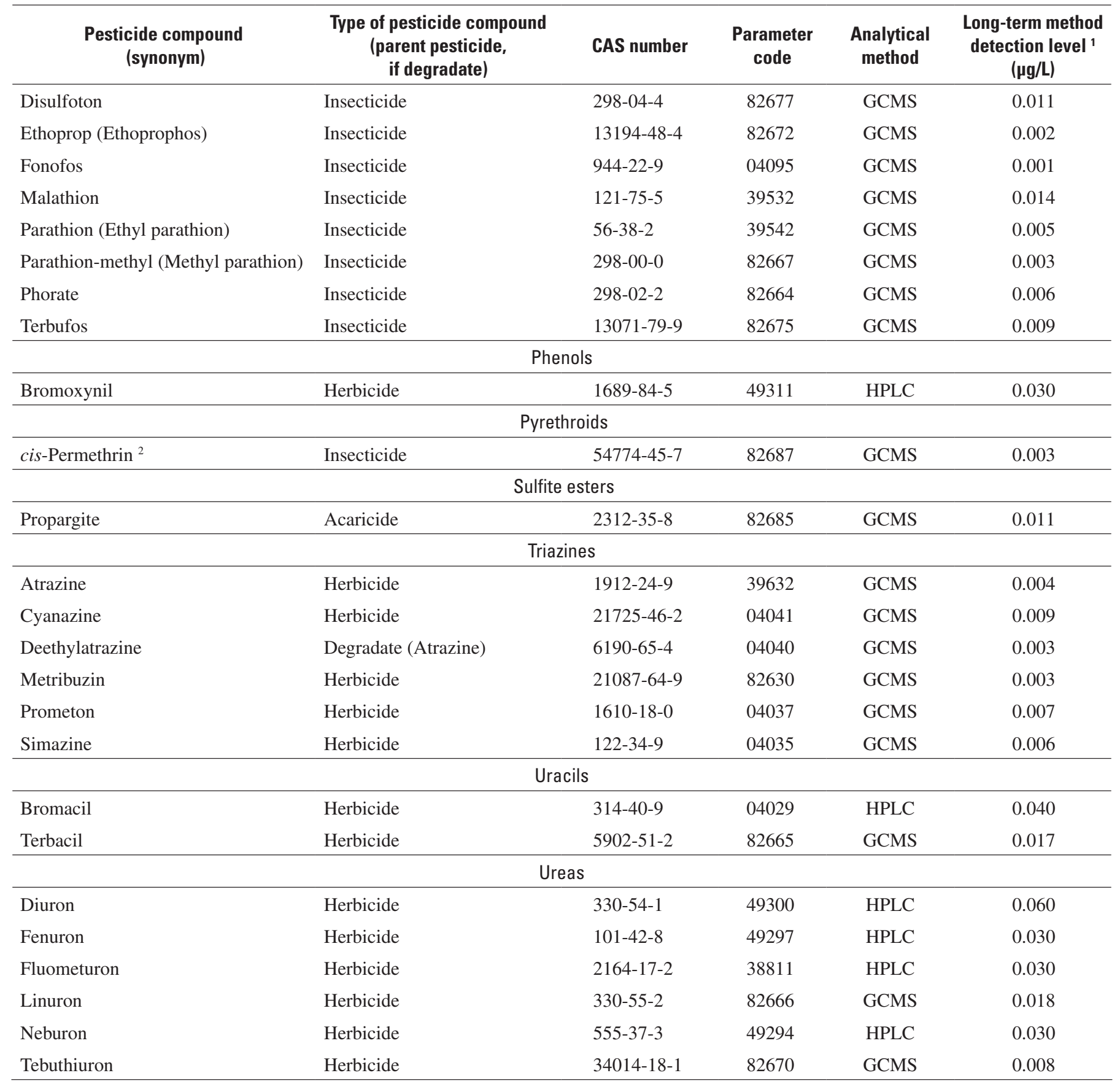

\footnotetext{
${ }^{1}$ The long-term method detection level (reference 1) is calculated annually. The value reported in the table is the maximum long-term method detection level for the period 1992-2001.

${ }^{2}$ This pesticide also can be considered an organochlorine pesticide because it is an organic pesticide with multiple chlorine substituents.

${ }^{3}$ Prior to 1977, alpha-HCH was a manufacturing by-product in technical lindane, which is a mixture of several isomers of hexachlorocyclohexane (reference 2).
} 
Table B. Pesticide compounds analyzed in NAWQA bed-sediment or whole-fish samples.

[Pesticide compounds include pesticides, degradates, and manufacturing by-products. Pesticide compounds are grouped by pesticide class. Common synonyms are listed in parentheses in column 1. The cited references are listed by number at the end of Appendix 1. CAS, Chemical Abstracts Service; Parameter code, the number used to identify a pesticide in the U.S. Geological Survey National Water Information System and the U.S. Environmental Protection Agency Data Storage and Retrieval System; $\mu \mathrm{g} / \mathrm{kg}$ dw, micrograms per kilogram dry weight; $\mu \mathrm{g} / \mathrm{kg}$ ww, micrograms per kilogram wet weight; —, not analyzed.]

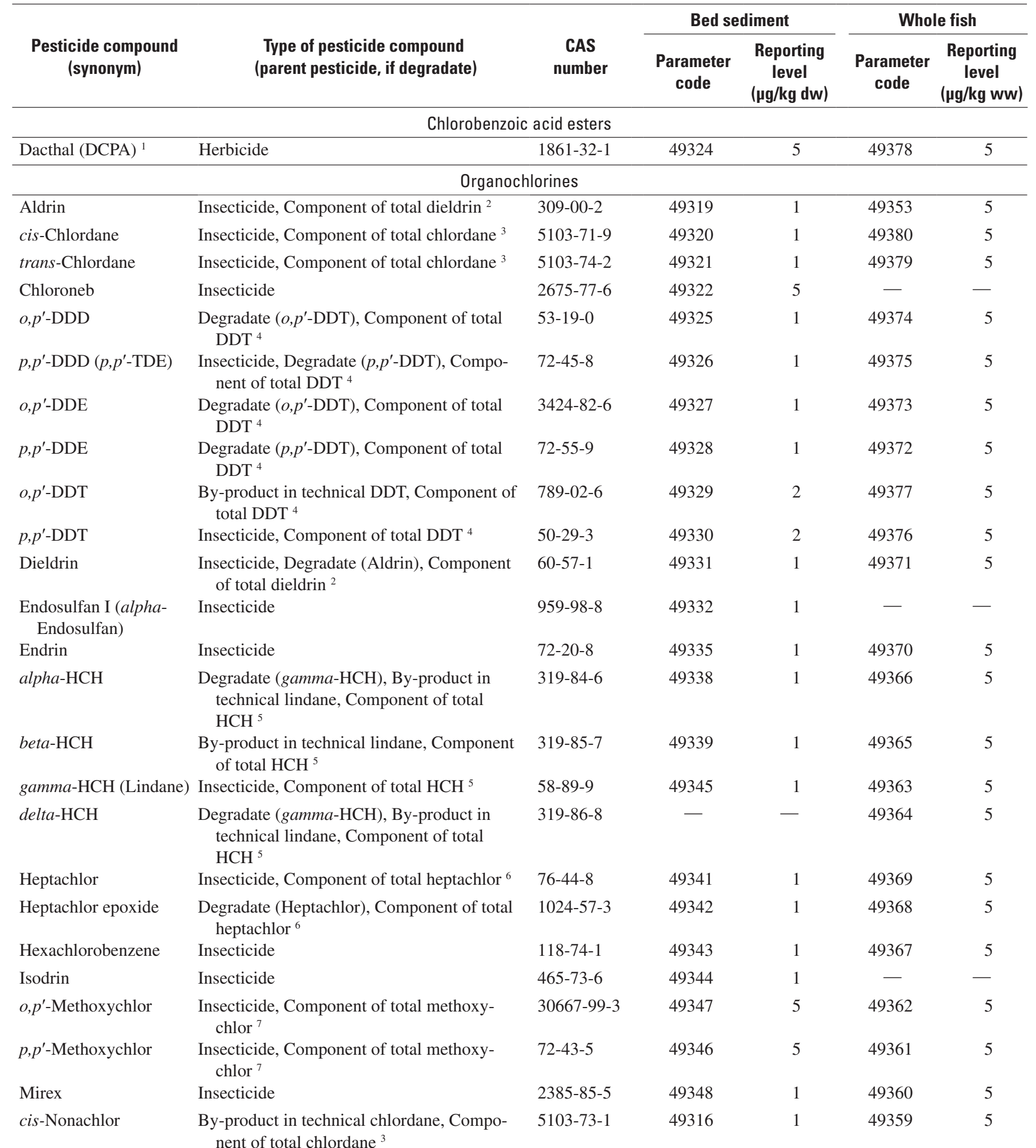


Table B. Pesticide compounds analyzed in NAWQA bed-sediment or whole-fish samples.-Continued

[Pesticide compounds include pesticides, degradates, and manufacturing by-products. Pesticide compounds are grouped by pesticide class. Common synonyms are listed in parentheses in column 1. The cited references are listed by number at the end of Appendix 1. CAS, Chemical Abstracts Service; Parameter code, the number used to identify a pesticide in the U.S. Geological Survey National Water Information System and the U.S. Environmental Protection Agency Data Storage and Retrieval System; $\mu \mathrm{g} / \mathrm{kg}$ dw, micrograms per kilogram dry weight; $\mu \mathrm{g} / \mathrm{kg}$ ww, micrograms per kilogram wet weight; —, not analyzed.]

\begin{tabular}{|c|c|c|c|c|c|c|}
\hline \multirow[b]{2}{*}{$\begin{array}{l}\text { Pesticide compound } \\
\text { (synonym) }\end{array}$} & \multirow[b]{2}{*}{$\begin{array}{l}\text { Type of pesticide compound } \\
\text { (parent pesticide, if degradate) }\end{array}$} & \multirow[b]{2}{*}{$\begin{array}{c}\text { CAS } \\
\text { number }\end{array}$} & \multicolumn{2}{|c|}{ Bed sediment } & \multicolumn{2}{|c|}{ Whole fish } \\
\hline & & & $\begin{array}{l}\text { Parameter } \\
\text { code }\end{array}$ & $\begin{array}{c}\text { Reporting } \\
\text { level } \\
\text { ( } \mu \mathrm{g} / \mathrm{kg} \mathrm{dw} \text { ) }\end{array}$ & $\begin{array}{l}\text { Parameter } \\
\text { code }\end{array}$ & $\begin{array}{c}\text { Reporting } \\
\text { level } \\
\text { ( } \mu \mathrm{g} / \mathrm{kg} \mathrm{ww} \text { ) }\end{array}$ \\
\hline trans-Nonachlor & $\begin{array}{l}\text { By-product in technical chlordane, Compo- } \\
\text { nent of total chlordane }\end{array}$ & $39765-80-5$ & 49317 & 1 & 49358 & 5 \\
\hline Oxychlordane & $\begin{array}{l}\text { Degradate (Chlordane), Component of total } \\
\text { chlordane } \\
3\end{array}$ & $27304-13-8$ & 49318 & 1 & 49357 & 5 \\
\hline Toxaphene & Insecticide, Technical mixture & $8001-35-2$ & 49351 & 200 & 49355 & 200 \\
\hline \multicolumn{7}{|c|}{ Pyrethroids } \\
\hline cis-Permethrin ${ }^{1}$ & Insecticide, Component of total permethrin ${ }^{8}$ & $52774-45-7$ & 49349 & 5 & - & - \\
\hline trans-Permethrin ${ }^{1}$ & Insecticide, Component of total permethrin ${ }^{8}$ & $51877-74-8$ & 49350 & 5 & - & - \\
\hline
\end{tabular}

${ }^{1}$ This pesticide also can be considered an organochlorine pesticide because it is an organic pesticide with multiple chlorine substituents.

${ }^{2}$ The pesticide group "total dieldrin" refers to the summed concentrations of aldrin and dieldrin.

${ }^{3}$ The pesticide group "total chlordane" refers to the summed concentrations of cis-chlordane, trans-chlordane, cis-nonachlor, trans-nonachlor, and oxychlordane. Chlordane was applied as a technical-grade mixture of over 140 compounds, including nonachlor isomers and other manufacturing by-products.

${ }^{4}$ The pesticide group "total DDT" refers to the summed concentrations of $o, p^{\prime}$-DDT, $p, p^{\prime}$-DDT, $o, p^{\prime}$-DDD, $p, p^{\prime}$-DDD, $o, p^{\prime}$-DDE, and $p, p^{\prime}$-DDE. Technical DDT contained $p, p^{\prime}$-DDT (the active ingredient) and $o, p^{\prime}$-DDT (a manufacturing by-product).

${ }^{5}$ The pesticide group "total $\mathrm{HCH}$ " refers to the summed concentrations of alpha-HCH, beta-HCH, gamma-HCH, and delta-HCH. Technical lindane is a mixture of several isomers of hexachlorocyclohexane; gamma-HCH is the active ingredient, and the other isomers are manufacturing by-products. In 1977, USEPA cancelled inclusion of alpha- and beta-HCH in technical-grade lindane (reference 2).

${ }^{6}$ The pesticide group "total heptachlor" refers to the summed concentrations of heptachlor and heptachlor epoxide.

${ }^{7}$ The pesticide group "total methoxychlor" refers to the summed concentrations of $o, p^{\prime}$-methoxychlor and $p, p^{\prime}$-methoxychlor.

${ }^{8}$ The pesticide group "total permethrin" refers to the summed concentrations of cis-permethrin and trans-permethrin.

\section{References-Appendix 1}

1. Oblinger Childress, C.J., Foreman, W.T., Conner, B.F., and Maloney, T.J., 1999, New reporting procedures based on long-term method detection levels and some considerations of interpretations of water-quality data provided by the U.S. Geological Survey National Water Quality Laboratory: U.S. Geological Survey Open-File Report 99-193, 19 p.

2. U.S. Environmental Protection Agency, 1992, National study of chemical residues in fish: U.S. Environmental Protection Agency, Office of Science and Technology, EPA823-R-92-008b, v. 2, variously paged. 



\section{Appendix 2-Properties affecting transport and fate.}

Table A. Properties affecting the transport and fate of selected pesticide compounds.

[Pesticide compounds selected are those detected most frequently in NAWQA samples (see figs. 4-2 and 4-4), as well as several that were detected infrequently, despite extensive use. All values measured at (or estimated for) $25^{\circ} \mathrm{C}$, except for those shown in italics. Unless noted otherwise, (1) values for octanol-water partition coefficient $\left(\mathrm{K}_{\mathrm{ow}}\right.$, dimensionless), soil organic carbon-water partition coefficient $\left(\mathrm{K}_{\mathrm{oc}}\right)$, water solubility $\left(\mathrm{S}_{\mathrm{w}}\right)$ and Henry's law constant $\left(\mathrm{K}_{\mathrm{H}}\right)$ are from Mackay and others (1997); (2) transformation half-lives in soil and water were measured in the laboratory (rather than in the field) at neutral $\mathrm{pH}$ in the dark, and obtained from the U.S. Department of Agriculture (2005); and (3) all are recommended values selected by the compilation authors when more than one value was available from the literature. Compounds are listed in the same order as in figures 4-2 and 4-4. Numbers of significant figures are identical to those given in original sources. mg/L, milligrams per liter; $\mathrm{mL} / \mathrm{g}$, milliliters per gram; NA, data not available from any of the references consulted; Pa $\mathrm{m}^{3} / \mathrm{mol}$, pascal-cubic meters per mole; >, greater than.]

\begin{tabular}{|c|c|c|c|c|c|c|}
\hline \multirow{2}{*}{$\begin{array}{l}\text { Pesticide compound } \\
\text { (synonym) }\end{array}$} & \multirow{2}{*}{$\log K_{o w}$} & \multirow{2}{*}{$\left(\mathrm{K}_{\mathrm{oc}}^{\log \mathrm{mL} / \mathrm{g})}\right.$} & \multirow{2}{*}{$\begin{array}{c}S_{w} \\
(m g / L)\end{array}$} & \multirow{2}{*}{$\begin{array}{c}\log K_{H} \\
\left(K_{H} \text { in } \mathrm{Pa}^{3} \cdot m^{3} /\right. \\
\text { mol })\end{array}$} & \multicolumn{2}{|c|}{$\begin{array}{l}\text { Half-life for transformation } \\
\text { (days) }\end{array}$} \\
\hline & & & & & In aerobic soil & In water \\
\hline \multicolumn{7}{|c|}{ Agricultural herbicides and degradates detected most frequently in water } \\
\hline Atrazine & 2.75 & 2.00 & 30 & -3.54 & 146 & ${ }^{1} 742$ \\
\hline Deethylatrazine & ${ }^{1,2} 1.3$ & $1,21.90$ & ${ }^{1} 2,700$ & $1,2-4.12$ & 1,2170 & NA \\
\hline Metolachlor & 3.13 & 2.26 & 430 & -2.63 & 26 & 1,2410 \\
\hline Cyanazine & 2.22 & 2.3 & 171 & -6.52 & ${ }^{2} 17$ & ${ }^{2}>200$ \\
\hline Alachlor & 2.8 & 2.23 & 240 & -2.7 & $1,220.4$ & ${ }^{1,2} 640$ \\
\hline Acetochlor & ${ }^{1} 3.0$ & $1,22.38$ & ${ }^{1,3} 223$ & $1,3-2.15$ & ${ }^{1,2,3} 14$ & ${ }^{1} 2,300$ \\
\hline Metribuzin & ${ }^{1,3} 1.60$ & 1.72 & ${ }^{1,3} 1,000$ & $1,2-5.31$ & 172 & ${ }^{2}>200$ \\
\hline Bentazon & $1,22.80$ & $1,21.54$ & 1,3500 & $1,2,3-3.7$ & 1,235 & ${ }^{1,2,3}>200$ \\
\hline EPTC & 3.2 & 2.3 & 370 & 0.00988 & 1,37 & ${ }^{2}>200$ \\
\hline Trifluralin & 5.34 & 4.14 & ${ }^{2} 0.5$ & 1.00 & 169 & ${ }^{2}>32$ \\
\hline Molinate & 3.21 & 1.92 & 970 & -0.839 & 1,321 & ${ }^{2}>200$ \\
\hline Norflurazon $^{1}$ & 2.45 & 2.55 & 34 & -4.46 & 130 & ${ }^{2}>200$ \\
\hline \multicolumn{7}{|c|}{ Urban herbicides detected most frequently in water } \\
\hline Simazine & 2.18 & 2.11 & 5 & -3.46 & ${ }^{2} 91$ & ${ }^{1,2}>32$ \\
\hline Prometon & 2.99 & 2.54 & 750 & -4.05 & 932 & ${ }^{2}>200$ \\
\hline Tebuthiuron & $1,21.79$ & ${ }^{1} 2.1$ & $1,22,400$ & ${ }^{1}-4.88$ & ${ }^{1} 1,050$ & ${ }^{2}>2,700$ \\
\hline $2,4-\mathrm{D}$ & 2.81 & ${ }^{1} 1.68$ & 890 & -3.61 & $1,22.3$ & 1,2732 \\
\hline Diuron & 2.78 & 2.6 & 40 & -3.17 & 372 & $>500$ \\
\hline Dacthal (DCPA) & ${ }^{1} 4.28$ & 13.75 & ${ }^{1} 0.5$ & ${ }^{1}-0.66$ & ${ }^{1} 16$ & ${ }^{2}>200$ \\
\hline Bromacil & 2.11 & 1.86 & 815 & -4.89 & 275 & ${ }^{2}>30$ \\
\hline \multicolumn{7}{|c|}{ Insecticides detected most frequently in water } \\
\hline Diazinon & 3.3 & 2.76 & 60 & -1.39 & 39 & 140 \\
\hline Chlorpyrifos & 4.92 & 3.78 & 0.73 & 0.0374 & 30.5 & 29 \\
\hline Carbofuran & 2.32 & 2.02 & 351 & -4.30 & 11 & ${ }^{2} 289$ \\
\hline Carbaryl & 2.36 & 2.36 & 120 & -4.35 & 17 & 11 \\
\hline Malathion & 2.8 & 3.26 & 145 & -2.64 & $<1$ & ${ }^{2} 6.3$ \\
\hline Dieldrin & 5.20 & 4.08 & 0.17 & 0.0492 & NA & 3,830 \\
\hline \multicolumn{7}{|c|}{ Organochlorine pesticide compounds detected most frequently in bed sediment and fish tissue } \\
\hline$p, p^{\prime}-\mathrm{DDE}$ & 5.7 & 5.0 & 0.04 & 0.900 & NA & $1,2,3>44,000$ \\
\hline$p, p^{\prime}-\mathrm{DDD}$ & 5.5 & 5.0 & 0.05 & -0.194 & NA & ${ }^{2} 10,000$ \\
\hline$p, p^{\prime}-\mathrm{DDT}$ & 6.19 & 5.4 & 0.0055 & 0.37 & NA & $1,2,35,000$ \\
\hline
\end{tabular}


Table A. Properties affecting the transport and fate of selected pesticide compounds.-Continued

[Pesticide compounds selected are those detected most frequently in NAWQA samples (see figs. 4-2 and 4-4), as well as several that were detected infrequently, despite extensive use. All values measured at (or estimated for) $25^{\circ} \mathrm{C}$, except for those shown in italics. Unless noted otherwise, (1) values for octanol-water partition coefficient $\left(\mathrm{K}_{\mathrm{ow}}\right.$, dimensionless), soil organic carbon-water partition coefficient $\left(\mathrm{K}_{\mathrm{oc}}\right)$, water solubility $\left(\mathrm{S}_{\mathrm{w}}\right)$ and Henry's law constant $\left(\mathrm{K}_{\mathrm{H}}\right)$ are from Mackay and others (1997); (2) transformation half-lives in soil and water were measured in the laboratory (rather than in the field) at neutral $\mathrm{pH}$ in the dark, and obtained from the U.S. Department of Agriculture (2005); and (3) all are recommended values selected by the compilation authors when more than one value was available from the literature. Compounds are listed in the same order as in figures 4-2 and 4-4. Numbers of significant figures are identical to those given in original sources. mg/L, milligrams per liter; $\mathrm{mL} / \mathrm{g}$, milliliters per gram; NA, data not available from any of the references consulted; Pa $\mathrm{m}^{3} / \mathrm{mol}$, pascal-cubic meters per mole; >, greater than.]

\begin{tabular}{|c|c|c|c|c|c|c|}
\hline \multirow{2}{*}{$\begin{array}{l}\text { Pesticide compound } \\
\text { (synonym) }\end{array}$} & \multirow{2}{*}{$\log K_{o w}$} & \multirow{2}{*}{$\begin{array}{c}\log K_{o c} \\
\left(K_{o c} \text { in } m L / g\right)\end{array}$} & \multirow{2}{*}{$\underset{(\mathrm{mg} / \mathrm{L})}{\mathrm{S}_{\mathrm{w}}}$} & \multirow{2}{*}{$\begin{array}{c}\log K_{H} \\
\left(K_{H} \text { in } P^{\prime} \cdot m^{3} /\right. \\
\text { mol) }\end{array}$} & \multicolumn{2}{|c|}{$\begin{array}{l}\text { Half-life for transformation } \\
\text { (days) }\end{array}$} \\
\hline & & & & & In aerobic soil & In water \\
\hline$o, p^{\prime}-\mathrm{DDE}$ & 5.8 & $1,25.58$ & 0.1 & 0.405 & NA & NA \\
\hline$o, p^{\prime}-\mathrm{DDD}$ & 6.0 & $1,25.36$ & ${ }^{2} 0.10$ & ${ }^{1}-2.7$ & NA & ${ }^{2} \mathrm{NA}$ \\
\hline$o, p^{\prime}$-DDT & ${ }^{2} \mathrm{NA}$ & ${ }^{2} \mathrm{NA}$ & 0.026 & -0.460 & NA & NA \\
\hline cis-Chlordane & 6.0 & 5.5 & 0.056 & -0.466 & NA & ${ }^{1}>7.2 \times 10^{7}$ \\
\hline trans-Chlordane & 6.0 & 5.5 & 0.056 & -0.582 & NA & ${ }^{1,2}>10,000$ \\
\hline Nonachlor ${ }^{1}$ & 5.66 & 4.86 & 0.06 & -1.69 & NA & NA \\
\hline Oxychlordane $^{1}$ & 2.6 & 2.48 & 200 & -1.52 & NA & NA \\
\hline Dieldrin & 5.20 & 4.08 & 0.17 & 0.0492 & NA & 3,830 \\
\hline Heptachlor epoxide & 5.0 & 4.0 & 0.35 & ${ }^{1} 0.51$ & NA & NA \\
\hline Pentachloroanisole ${ }^{1}$ & 5.66 & 4.62 & 0.2 & 2.91 & NA & NA \\
\hline Hexachlorobenzene & ${ }^{15} 5.31$ & ${ }^{1} 4.7$ & ${ }^{1} 0.0062$ & ${ }^{1,2} 1.69$ & NA & ${ }^{1,2}>26,000$ \\
\hline \multicolumn{7}{|c|}{ Heavily used pesticides not detected frequently in water } \\
\hline Chlorothalonil & 2.64 & 3.2 & 0.6 & 1.77 & NA & ${ }^{2}>200$ \\
\hline Dicamba & 2.21 & ${ }^{1} 1.11$ & 4500 & -3.66 & 1,228 & ${ }^{2}>200$ \\
\hline $\begin{array}{l}\text { Parathion-methyl (Methyl para- } \\
\text { thion) }\end{array}$ & 3.0 & 3.7 & 25 & -1.68 & $1,23.3$ & 41 \\
\hline Pendimethalin & 15.2 & ${ }^{1} 4.13$ & ${ }^{1} 0.275$ & ${ }^{1} 0.0899$ & 1300 & ${ }^{2}>200$ \\
\hline Terbufos & 4.48 & 2.70 & 5 & 0.39 & 5 & 1.9 \\
\hline
\end{tabular}

${ }^{1}$ Value(s) obtained from sources other than Mackay and others (1997) for $\mathrm{K}_{\mathrm{ow}}, \mathrm{K}_{\mathrm{oc}}, \mathrm{S}_{\mathrm{w}}$, and $\mathrm{K}_{\mathrm{H}}$; or U.S. Department of Agriculture (2005) for transformation half-lives. See http://ca.water.usgs.gov/pnsp/pubs/circ1291/for data sources.

${ }^{2}$ See $h t t p: / / c a . w a t e r . u s g s . g o v / p n s p / p u b s / c i r c 1291 /$ for details related to computation or selection of parameter value.

${ }^{3}$ See $h t t p: / / c a . w a t e r . u s g s . g o v / p n s p / p u b s / c i r c 1291 /$ for temperature of measurement.

\section{References-Appendix 2}

Mackay, D., Shiu, W-Y., and Ma, K-C, 1997, Illustrated handbook of physical-chemical properties and environmental fate for organic chemicals, Volume V. Pesticide Chemicals: New York, NY, Lewis Publishers, 812 p.

U.S. Department of Agriculture, 2005, Agricultural Research Service (ARS), Pesticide Properties Database, accessed August 22, 2005, at http://www.ars.usda.gov/Services/docs. htm? docid $=6433$. 

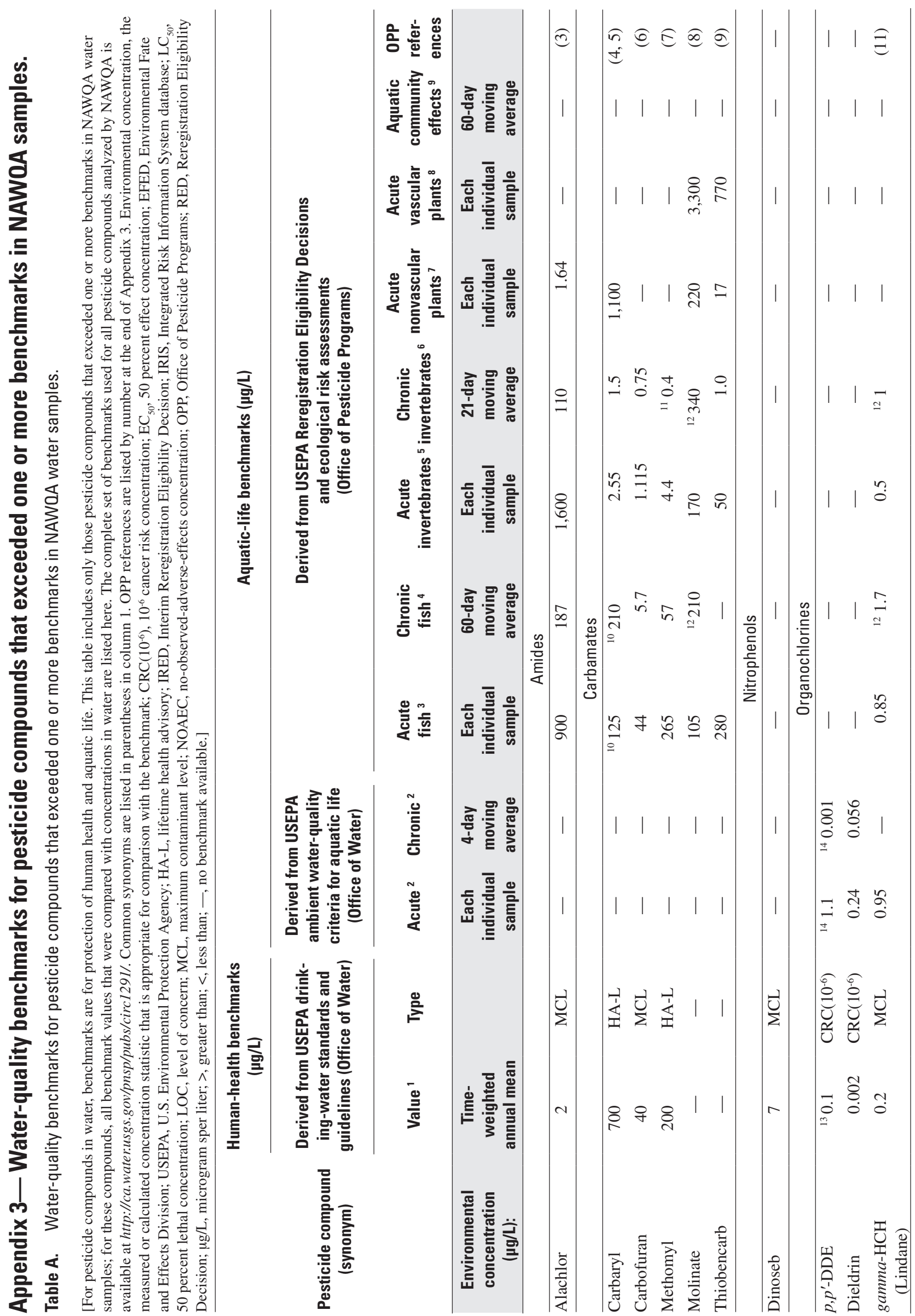

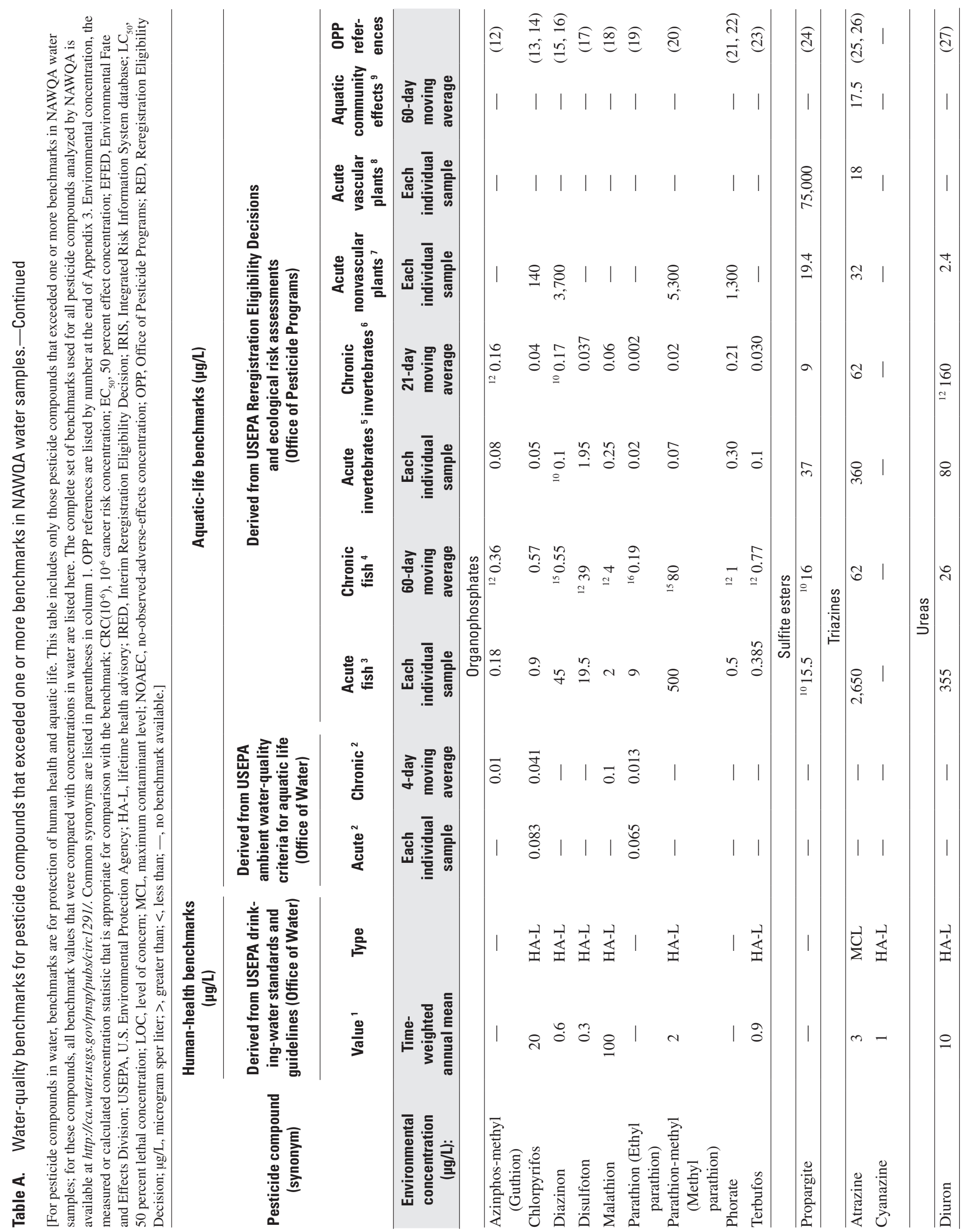


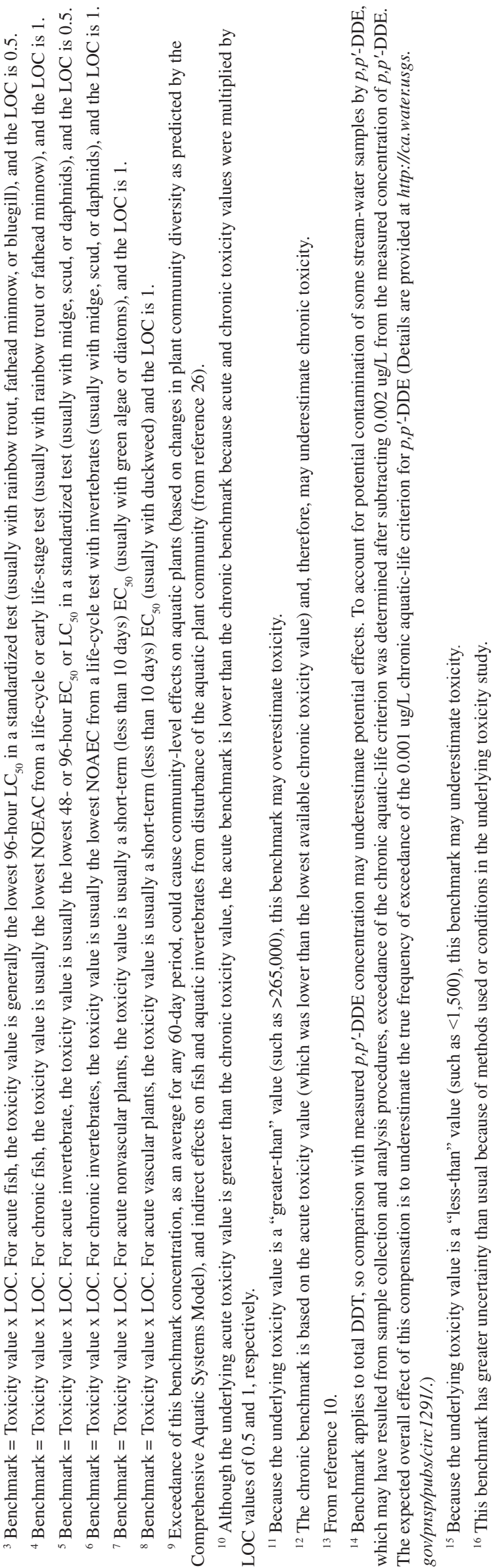




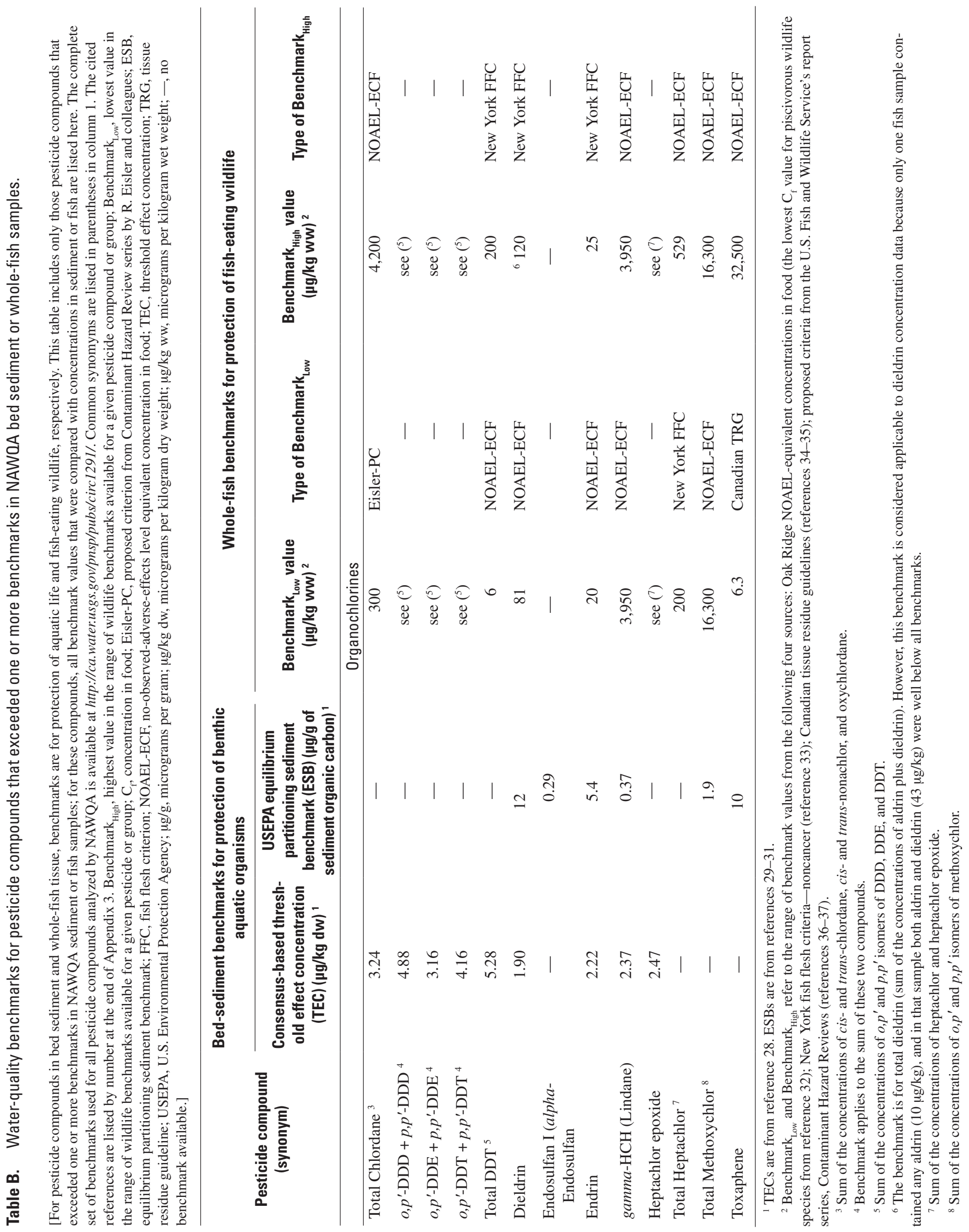




\section{References-Appendix 3}

1. USEPA (U.S. Environmental Protection Agency), 2004, 2004 Edition of the drinking water standards and health advisories: U.S. Environmental Protection Agency, Office of Water, EPA-822-R-04-005, accessed June 9, 2005, at http://www.epa.gov/waterscience/criteria/drinking/ standards/dwstandards.pdf.

2. USEPA (U.S. Environmental Protection Agency), 2004, National recommended water quality criteria: U.S. Environmental Protection Agency, Office of Water, accessed June 9, 2005, at http://www.epa.gov/waterscience/criteria/ nrwqc-2004.pdf.

3. USEPA (U.S. Environmental Protection Agency), 1998, Reregistration eligibility decision (RED) alachlor: U.S. Environmental Protection Agency, Prevention, Pesticides and Toxic Substances, EPA 738-R-98-020, December 1998, accessed September 14, 2005, at http://www.epa. gov/oppsrrd1/REDs/0063.pdf.

4. USEPA (U.S. Environmental Protection Agency), 2003, Environmental fate and ecological risk assessment for the reregistration of carbaryl: U.S. Environmental Protection Agency, Prevention, Pesticides and Toxic Substances, Public Docket Number EPA-HQ-OPP-2003-010-0005, accessed February 1, 2006, at http://www.regulations.gov.

5. USEPA (U.S. Environmental Protection Agency), 2004, Interim reregistration eligibility decision for carbaryl (revised October 22, 2004), list A, case 0080: U.S. Environmental Protection Agency, Office of Pesticide Programs, accessed September 22, 2005, at http://www.epa. gov/oppsrrd1/REDs/carbaryl_ired.pdf.

6. USEPA (U.S. Environmental Protection Agency), 2005, Reregistration eligibility science chapter for carbofuran, environmental fate and effects chapter, June 3, 2005, Appendix 1, Carbofuran deterministic environmental risk assessment: U.S. Environmental Protection Agency, Public Docket Number EPA-HQ-OPP-2005-0162-0006, accessed February 1, 2006, at http://www.regulations.gov.

7. USEPA (U.S. Environmental Protection Agency), 1998, Reregistration eligibility decision (RED) methomyl: U.S. Environmental Protection Agency, Prevention, Pesticides and Toxic Substances, EPA 738-R-98-021 December 1998, accessed October 11, 2005, at http://www.epa.gov/ oppsrrd1/REDs/0028red.pdf.

8. USEPA (U.S. Environmental Protection Agency), 2001a, Revised EFED reregistration eligibility chapter for molinate, Appendix C, ecological toxicity assessment: U.S. Environmental Protection Agency, accessed September 16, 2005, at http:// www.epa.gov/oppsrrd1/reregistration/molinate/AppCecologicaltoxicityasst.pdf.
9. USEPA (U.S. Environmental Protection Agency), 1997, Reregistration eligibility decision (RED) thiobencarb: U.S. Environmental Protection Agency, Prevention, Pesticides and Toxic Substances, EPA 738-R-97-013 December 1997, accessed October 5, 2005, at http://www.epa.gov/ oppsrrd1/REDs/2665red.pdf.

10. USEPA (U.S. Environmental Protection Agency), 2005, Integrated Risk Information System (IRIS) database: U.S. Environmental Protection Agency, Office of Research and Development, National Center for Environmental Assessment, accessed June 9, 2005, at http://www.epa.gov/iris.

11. USEPA (U.S. Environmental Protection Agency), 2001, Lindane RED chapter: environmental fate and ecological risk assessment: seed treatment, Appendix I, Ecological effects data revised December 20, 2001: U.S. Environmental Protection Agency, Office of Pesticide Programs, Environmental Fate and Effects Division, accessed October 10, 2005, at http://www.epa.gov/oppsrrdl/reregistration/ lindanelefed_ra_revised.pdf.

12. USEPA (U.S. Environmental Protection Agency), 2005, Azinphos methyl insecticide: ecological risk assessment for the use of azinphos methyl on caneberries, cranberries, peaches, potatoes, and southern pine seeds (group 2 uses): U.S. Environmental Protection Agency, Office of Prevention, Pesticides and Toxic Substances, Public Docket Number EPA-HQ-OPP-2005-0061-0027, accessed February 1, 2006, at http://www.epa.gov/oppsrrdl/op/azm.htm.

13. USEPA (U.S. Environmental Protection Agency), 2000, EFED risk assessment for reregistration eligibility science chapter for chlorpyrifos, fate and environmental risk assessment chapter: U.S. Environmental Protection Agency June 2000, accessed September 21, 2005, at http:// www.epa.gov/oppsrrdl/op/chlorpyrifos/efedrral.pdf.

14. USEPA (U.S. Environmental Protection Agency), 2002, Interim reregistration eligibility decision for chlorpyrifos: U.S. Environmental Protection Agency, Prevention, Pesticides and Toxic Substances, EPA 738-R-01-007 February 2002, accessed September 21, 2005, at http://www.epa. gov/oppsrrd1/REDs/chlorpyrifos_ired.pdf.

15. USEPA (U.S. Environmental Protection Agency), 2000, Environmental risk assessment for diazinon: U.S Environmental Protection Agency, accessed September 28, 2005, at http://www.epa.gov/pesticides/op/diazinon/risk_ oct2000.pdf.

16. USEPA (U.S. Environmental Protection Agency), 2004, Interim reregistration eligibility decision diazinon: U.S. Environmental Protection Agency, Prevention, Pesticides and Toxic Substances, EPA 738-R-04-006 May 2004, accessed September 21, 2005, at http://www.epa.gov/ oppsrrd1/REDs/diazinon_ired.pdf. 
17. USEPA (U.S. Environmental Protection Agency), 2000, Second revised environmental fate and effects assessment [disulfoton]: U.S. Environmental Protection Agency, Environmental Fate and Effects Division August 26, 2000, accessed October 7, 2005, at http://www.epa.gov/oppsrrdl/ op/disulfoton/EFED\%20Chapter\%208_26_00.pdf.

18. USEPA (U.S. Environmental Protection Agency), 2000, Malathion reregistration eligibility document, environmental fate and effects chapter, revised November 9 , 2000: U.S. Environmental Protection Agency, accessed September 22, 2005, at http://www.epa.gov/oppsrrdl/op/ malathion/efedrra.pdf.

19. USEPA (U.S. Environmental Protection Agency), 1999, EFED RED chapter for ethyl parathion (revised September 13, 1999): U.S. Environmental Protection Agency, accessed October 11, 2005, at http://www.epa.gov/ oppsrrd1/op/ethyl-parathion/efedrra.pdf.

20. USEPA (U.S. Environmental Protection Agency), 2003, Interim reregistration eligibility decision for methyl parathion: U.S. Environmental Protection Agency, Prevention, Pesticides and Toxic Substances, EPA 738-R-01-007 February 2002, accessed October 12, 2005, at http://www. epa.gov/oppsrrdl/REDs/methylparathion_ired.pdf.

21. USEPA (U.S. Environmental Protection Agency), 1998, Preliminary environmental fate and effects assessment, EFED science chapter for phorate RED August 7, 1998: U.S. Environmental Protection Agency, Environmental Fate and Effects Division, accessed October 20, 2005, at http://www.epa.gov/oppsrrd1/op/phorate/phorefed.pdf.

22. USEPA (U.S. Environmental Protection Agency), 1999, Revised environmental fate and effects assessment, outline of section C, Environmental assessment [phorate] September 14, 1999: U.S. Environmental Protection Agency, http://www.epa.gov/oppsrrd1/op/phorate/ phorateefedrevrisk2of6.pdf.

23. USEPA (U.S. Environmental Protection Agency), 1999, Revised environmental fate and effects assessment [terbufos], section 4, Ecological toxicity data, September 14, 1999: U.S. Environmental Protection Agency, accessed October 4, 2005, at http://www.epa.gov/pesticides/op/ terbufos/efed_toxdata.pdf.

24. USEPA (U.S. Environmental Protection Agency), 2000, Environmental Fate and Effects Division science chapter for reregistration eligibility decision for propargite, Appendix 2, June 7, 2000: U.S. Environmental Protection Agency, Office of Pesticide Programs, Environmental Fate and Effects Division, accessed October 20, 2005, at http:// www.epa.gov/oppsrrdl/reregistration/propargitelefedrisk. $p d f$.
25. USEPA (U.S. Environmental Protection Agency), 2003, Interim reregistration eligibility decision for atrazine, case no. 0062: U.S. Environmental Protection Agency, Office of Prevention, Pesticides and Toxic Substances, Office of Pesticide Programs, Special Review and Reregistration Division, accessed September 8, 2005, at http://www.epa. gov/oppsrrd1/REDs/atrazine_ired.pdf.

26. USEPA (U.S. Environmental Protection Agency), 2003, Atrazine MOA Ecological Subgroup - recommendations for aquatic community level of concern (LOC) and method to apply LOC(s) to monitoring data, final report, October 22, 2003: U.S. Environmental Protection Agency, Public Docket Number EPA-HQ-OPP-2003-0367-0007, accessed January 24, 2006, at http://www.regulations.gov.

27. USEPA (U.S. Environmental Protection Agency), 2003, Reregistration eligibility decision for diuron, list A, case 0046: U.S. Environmental Protection Agency, Office of Prevention, Pesticides and Toxic Substances, Special Review and Reregistration Division, accessed September 21, 2005, at http://www.epa.gov/oppsrrdl/REDs/diuron_ RED.pdf.

28. MacDonald, D.D., Ingersoll, C.G., and Berger, T.A., 2000, Development and evaluation of consensus-based sediment quality guidelines for freshwater ecosystems: Archives of Environmental Contamination and Toxicology, v. 39, p. 20-31.

29. USEPA (U.S. Environmental Protection Agency), 2003, Procedures for the derivation of equilibrium partitioning sediment benchmarks (ESBs) for the protection of benthic organisms-dieldrin. U.S. Environmental Protection Agency, Office of Research and Development, EPA-600R-02-010, August 2003, accessed June 9, 2005, at http:// www.epa.gov/nheerl/publications/files/dieldrin.pdf.

30. USEPA (U.S. Environmental Protection Agency), 2003, Procedures for the derivation of equilibrium partitioning sediment benchmarks (ESBs) for the protection of benthic organisms-endrin: U.S. Environmental Protection Agency, Office of Research and Development, EPA-600R-02-009, August 2003, accessed June 9, 2005, at $w$.

31. USEPA (U.S. Environmental Protection Agency), 2003, Procedures for the derivation of equilibrium partitioning sediment benchmarks (ESBs) for the protection of benthic organisms-nonionics compendium: U.S. Environmental Protection Agency, Office of Research and Development, EPA-822-R-02-016 (Draft).

32. Sample, B.E., Opresko, D.M., and Suter II, G.W., 1996, Toxicological benchmarks for wildlife, 1996 revision: prepared by the Risk Assessment Program, Health Sciences Research Division, Oak Ridge National Laboratory, for the U.S. Department of Energy, ES/ER/TM-86/R3, variously paged. 
33. Newell, A.J., Johnson, D.W., and Allen, L.K., 1987, Niagara River Biota Contamination Project-fish flesh criteria for piscivorous wildlife: New York State Department of Environmental Conservation, Division of Fish and Wildlife, Bureau of Environmental Protection, Technical Report 87-3, 182 p.

34. CCME (Canadian Council of Ministers of the Environment), 1999, Canadian tissue residue guidelines for the protection of wildlife that consume aquatic biota-DDT (total), in Canadian environmental quality guidelines, 1999: Winnipeg, Canadian Council of Ministers of the Environment.

35. CCME (Canadian Council of Ministers of the Environment), 1999, Canadian tissue residue guidelines for the protection of wildlife that consume aquatic biota-toxaphene, in Canadian environmental quality guidelines, 1999: Winnipeg, Canadian Council of Ministers of the Environment.

36. Eisler, Ronald, and Jacknow, Joel, 1985, Toxaphene hazards to fish, wildlife, and invertebrates - a synoptic review: U.S. Department of the Interior, Fish and Wildlife Service Biological Report 85(1.4), Contaminant Hazard Reviews, Report 4, 17 p.

37. Eisler, Ronald, 1990, Chlordane hazards to fish, wildlife, and invertebrates-a synoptic review: U.S. Department of the Interior, Fish and Wildlife Service Biological Report 85(1.21), Contaminant Hazard Reviews, Report 21, 49 p. 


\section{Water: Human-Health Benchmarks}

\section{Pesticide compounds without human-health benchmarks:}

The following pesticide compounds measured by NAWQA in stream water and ground water had no human-health benchmarks (names in parentheses are synonyms):

\section{Acetochlor}

Azinphos-methyl (Guthion)

Benfluralin

Bromoxynil

Chloramben methyl ester

Clopyralid

Dacthal mono-acid

2,4-DB

Deethylatrazine

Dichlobenil

Dichlorprop

2,6-Diethylaniline

DNOC

EPTC

Ethalfluralin

Ethoprop (Ethoprophos)

Fenuron

3-Hydroxycarbofuran

Linuron

$\mathrm{MCPB}$

Methiocarb

Molinate

Napropamide

Neburon

Norflurazon

Oryzalin

Parathion (Ethyl parathion)

Pebulate

Pendimethalin

cis-Permethrin

Phorate

Propanil

Propargite

Thiobencarb

Triallate

Triclopyr

\section{Pesticide compounds with human-health benchmarks, but no exceedances:}

The following pesticide compounds measured in water had human-health benchmarks available, but these benchmarks were never exceeded (names in parentheses are synonyms):

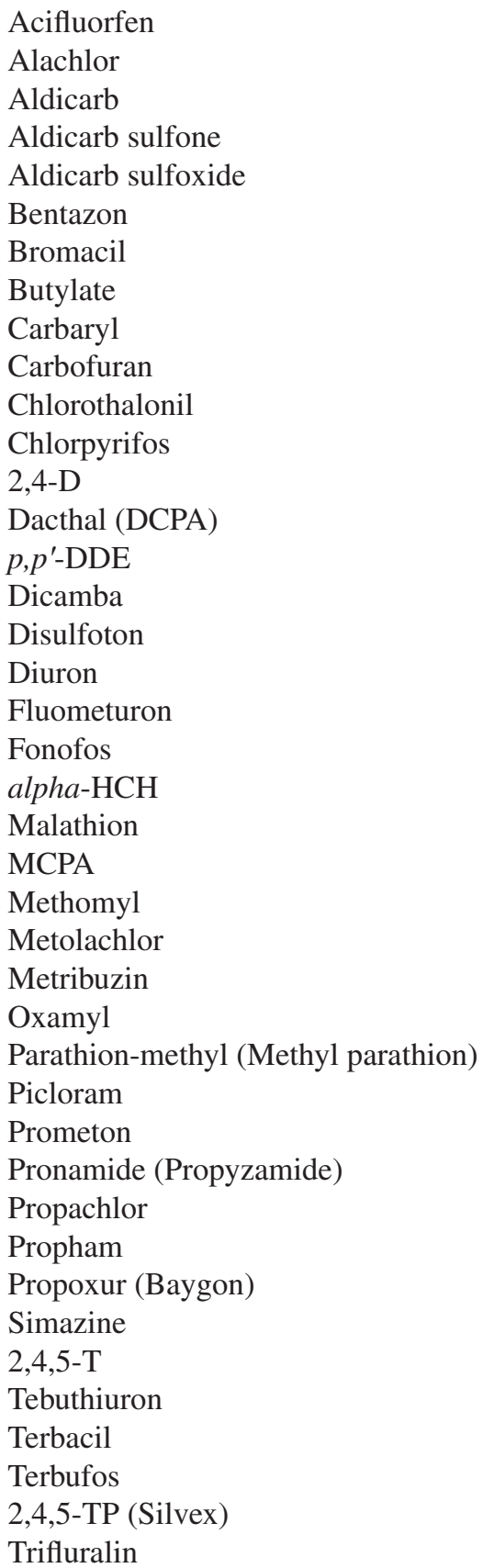




\section{Water: Aquatic-Life Benchmarks}

\section{Pesticide compounds without aquatic-life benchmarks:}

The following pesticide compounds measured by NAWQA in stream water had no aquatic-life benchmarks (names in parentheses are synonyms):

Acetochlor
Chloramben methyl ester
Clopyralid
Cyanazine
Dacthal mono-acid
Deethylatrazine
Dicamba
Dichlorprop
2,6-Diethylaniline
Dinoseb
DNOC
Fenuron
Fonofos
alpha-HCH
3-Hydroxycarbofuran
MCPB
Neburon
Prometon
Propham
2,4,5-T
2,4,5-TP (Silvex)

\section{Pesticide compounds with aquatic-life benchmarks, but no exceedances:}

The following pesticide compounds measured in stream water had aquatic-life benchmarks available, but these benchmarks were never exceeded (names in parentheses are synonyms):

\author{
Acifluorfen \\ Aldicarb \\ Aldicarb sulfone \\ Aldicarb sulfoxide \\ Benfluralin \\ Bentazon \\ Bromacil \\ Bromoxynil \\ Butylate \\ Chlorothalonil \\ 2,4-D \\ Dacthal (DCPA) \\ 2,4-DB \\ Dichlobenil \\ EPTC \\ Ethalfluralin \\ Ethoprop (Ethoprophos) \\ Fluometuron \\ gamma-HCH (Lindane) \\ Linuron \\ MCPA \\ Methiocarb \\ Metolachlor \\ Metribuzin \\ Napropamide \\ Norflurazon \\ Oryzalin \\ Oxamyl \\ Pebulate \\ Pendimethalin \\ cis-Permethrin \\ Picloram \\ Pronamide (Propyzamide) \\ Propachlor \\ Propanil \\ Propoxur (Baygon) \\ Simazine \\ Tebuthiuron \\ Terbacil \\ Triallate \\ Trifluralin \\ Triclopyr
}




\section{Bed Sediment: Aquatic-Life Benchmarks}

\section{Pesticide compounds without aquatic-life benchmarks:}

The following pesticide compounds measured by NAWQA in bed sediment had no aquatic-life benchmarks:

\author{
Aldrin \\ Chloroneb \\ Dacthal (DCPA) \\ alpha- $\mathrm{HCH}$ \\ beta- $\mathrm{HCH}$ \\ Heptachlor \\ Hexachlorobenzene \\ Isodrin \\ Mirex \\ Pentachloroanisole \\ cis-Permethrin \\ trans-Permethrin
}

Note: Several additional compounds measured, such as cischlordane and $p, p^{\prime}$-DDE, did not have benchmarks themselves, but were part of pesticide groups (total chlordane and total DDT, respectively) that did have sediment benchmarks.

\section{Pesticide compounds with aquatic-life benchmarks, but no exceedances:}

All pesticide compounds or groups with benchmarks in sediment exceeded those benchmarks in one or more samples.

\section{Whole Fish Tissue: Wildlife Benchmarks}

\section{Pesticide compounds without wildlife benchmarks:}

The following pesticide compounds measured by NAWQA in whole fish had no benchmarks for fish-eating wildlife:

\author{
Dacthal (DCPA) \\ Pentachloroanisole
}

Note: Several additional compounds measured, such as cischlordane and $p, p^{\prime}$-DDE, did not have benchmarks themselves, but were part of pesticide groups (total chlordane and total DDT, respectively) that did have wildlife benchmarks.

\section{Pesticide compounds with wildlife benchmarks, but no exceedances:}

The following pesticide compounds or groups measured in whole fish had wildlife benchmarks available, but these benchmarks were never exceeded (names in parentheses are synonyms):

\section{beta- $\mathrm{HCH}$}

gamma-HCH (Lindane)

Total $\mathrm{HCH}$

Heptachlor

Hexachlorobenzene

Total Methoxychlor

Mirex 


\section{Appendix 4- List of abbreviations, acronyms, and units of measurement}

Note: Clarification or additional information is provided in parentheses.

ATSDR Agency for Toxic Substances and Disease Registry

AWOC-AL ambient water-quality criterion for the protection of aquatic life (USEPA)

CAS Chemical Abstract Service

CCME Canadian Council of Ministers of the Environment

CERCLA Comprehensive Environmental Recovery, Compensation, and Liability Act

CWA Clean Water Act

DDD 1,1-dichloro-2,2-bis(chlorophenyl)ethane (DDT degradate)

DDE 1,1-dichloro-2,2-bis(chlorophenyl)ethylene (DDT degradate)

DDT 1,1,1-trichloro-2,2-bis(chlorophenyl)ethane

ESA ethanesulfonic acid

ESB equilibrium partitioning sediment benchmark (USEPA)

FFC fish flesh criterion for protection of fish-eating wildlife, noncancer values (NYSDEC)

FFDCA Federal Food, Drug, and Cosmetic Act

FIFRA Federal Insecticide, Fungicide, and Rodenticide Act

FQPA Food Quality Protection Act

$\mathrm{ft}$ foot (feet)

g gram

GCMS gas chromatography with mass spectrometric detection

HA-L lifetime health advisory (USEPA)

HPLC high performance liquid chromatography

IARC International Agency for Research on Cancer

$\mathrm{kg} \quad$ kilogram

$\mathrm{K}_{\mathrm{H}} \quad$ Henry's law constant

$\mathrm{K}_{o c} \quad$ soil organic carbon-water partition coefficient

L liter

Ib pound

LOAEC lowest-observed-adverse-effects concentration

LOC level of concern (USEPA)

MCL Maximum Contaminant Level (USEPA)

mg milligram

mi mile

$\mathrm{mL} \quad$ milliliter

$\mathrm{mm} \quad$ millimeter

NAWQA National Water-Quality Assessment Program (USGS)

NCBP National Contaminant Biomonitoring Program (U.S. Fish and Wildlife Service)

NLCD National Land Cover Data

NOAEC no-observed-adverse-effects concentration

NOAEL no-observed-adverse-effects level

NPDES National Pollutant Discharge Elimination System (USEPA) 


\section{Appendix 4- List of abbreviations, acronyms, and units of measurement}

Note: Clarification or additional information is provided in parentheses.

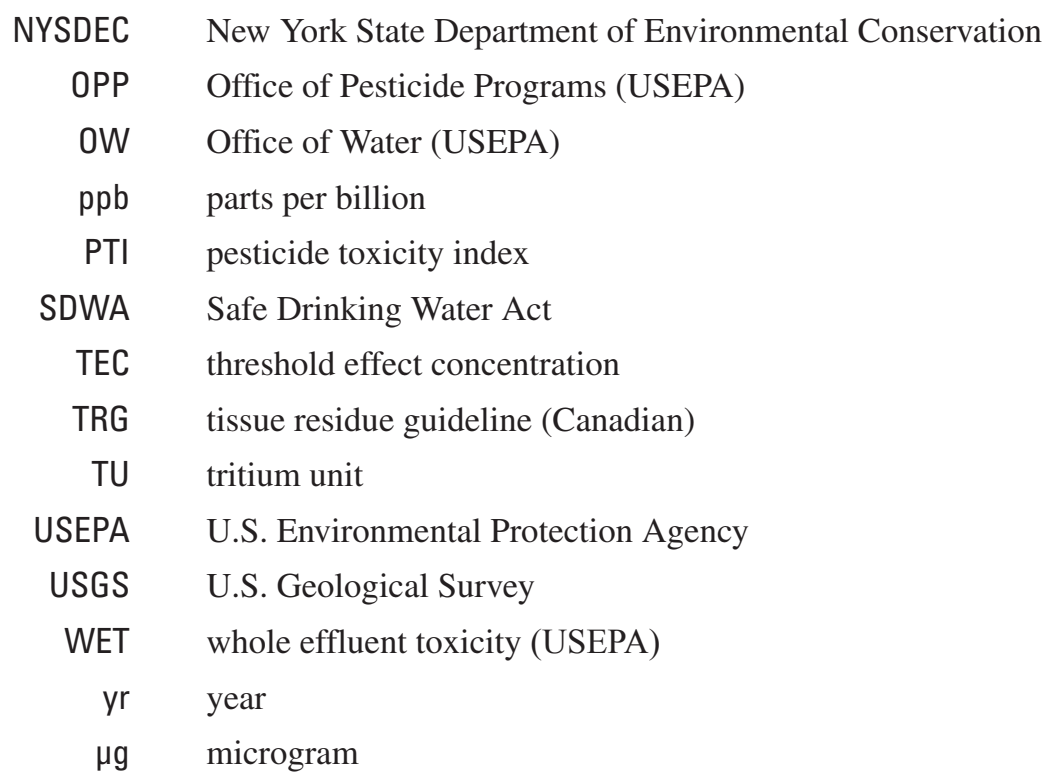




\section{Acknowledgments}

Special thanks to the following individuals and organizations for their contributions:

NAWQA personnel in Study Units across the Nation for their contributions of data, research results, and reviews of findings

NAWQA's many partners in the governmental and nongovernmental sectors who have helped guide scientific efforts and ensure that NAWQA information meets the needs of local, State, Tribal, regional, and national stakeholders

U.S. Environmental Protection Agency's Office of Pesticide Programs and Office of Water for contributions of background information and data regarding current regulatory procedures and risk-assessment results

Reviewers:

Erica Michaels Brown, Association of Metropolitan Water Agencies

Judy Campbell-Bird, Environmental Policy and Communications Consulting

Claudia Copeland, Congressional Research Service

Rebeckah Freeman and Don Parrish, American Farm Bureau Federation

Jane Houlihan, Environmental Working Group

Debra Knopman, RAND Corporation

Timothy Kubiak and George Noguchi, U.S. Fish and Wildlife Service

Jane Nogaki and Paul Schwartz, Clean Water Action

Robin O'Malley, H. John Heinz III Center for Science, Economics and the Environment

Christine Reimer, National Ground Water Association

Marc Ribaudo, U.S. Department of Agriculture

Gary Rowe, U.S. Geological Survey

George Sabbagh, Bayer CropScience

Mark Sandstrom, U.S. Geological Survey

William Wilber, U.S. Geological Survey

Office of Pesticide Programs, U.S. Environmental Protection Agency

Office of Water, U.S. Environmental Protection Agency

Technical editors:

Sandra Cooper, U.S. Geological Survey

Chester Zenone, Editorial Consultant

Graphic design and layout:

Yvonne Roque and Phillip Redman, U.S. Geological Survey

All photos by USGS personnel unless otherwise noted 
